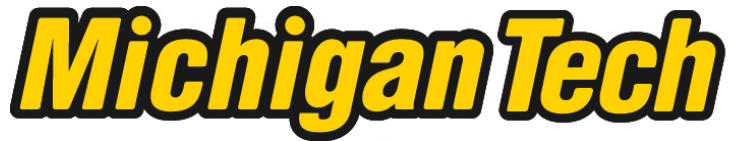 \\ Michigan Technological University Create the Future Digital Commons @ Michigan Tech
}

2012

\section{Probabilistic-based hurricane risk assessment and mitigation considering the potential impacts of climate change}

Sigridur Osk Bjarnadottir

Michigan Technological University

Follow this and additional works at: https://digitalcommons.mtu.edu/etds

Part of the Civil and Environmental Engineering Commons

Copyright 2012 Sigridur Osk Bjarnadottir

\section{Recommended Citation}

Bjarnadottir, Sigridur Osk, "Probabilistic-based hurricane risk assessment and mitigation considering the potential impacts of climate change ", Dissertation, Michigan Technological University, 2012.

https://doi.org/10.37099/mtu.dc.etds/222

Follow this and additional works at: https://digitalcommons.mtu.edu/etds

3 Part of the Civil and Environmental Engineering Commons 
PROBABILISTIC-BASED HURRICANE RISK ASSESSMENT AND MITIGATION CONSIDERING THE POTENTIAL IMPACTS OF CLIMATE CHANGE

\title{
By
}

Sigridur Osk Bjarnadottir

\begin{abstract}
A DISSERTATION
Submitted in partial fulfillment of the requirements for the degree of DOCTOR OF PHILOSOPHY

(Civil Engineering)

MICHIGAN TECHNOLOGICAL UNIVERSITY
\end{abstract}

2012

Copyright (C) Sigridur Osk Bjarnadottir 2012 
This dissertation, "Probabilistic-Based Hurricane Risk Assessment and Mitigation Considering the Potential Impacts of Climate Change," is hereby approved in partial fulfillment of the requirements for the Degree of DOCTOR OF PHILOSOPHY IN CIVIL ENGINEERING.

Department of Civil and Environmental Engineering

Signatures:

Dissertation Co-Advisor

Dr. Yue Li

Dissertation Co-Advisor

Dr. Mark G. Stewart

Department Chair

Dr. David Hand

Date 


\section{Table of Contents}

TABLE OF CONTENTS .......................................................................................................ii

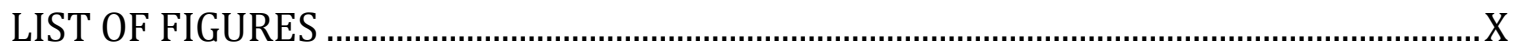

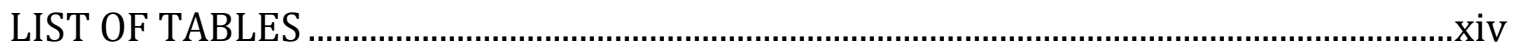

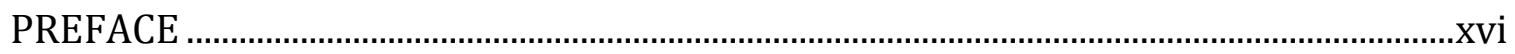

ACKNOWLEDGEMENTS ........................................................................................... xvii

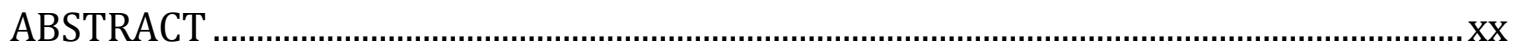

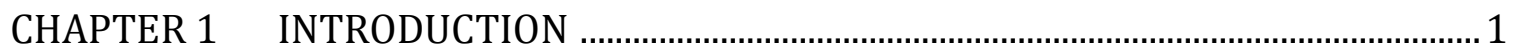

$1.1 \quad$ Literature Review and Critical Appraisal ..........................................................................................

1.1.1 Climatic Change and its Impact of Natural Hazard Patterns.......................................................

1.1.2 Uncertainty, Risk, and Probabilistic Analysis........................................................................

1.1.3 Hurricane Risk for Residential Construction .......................................................................

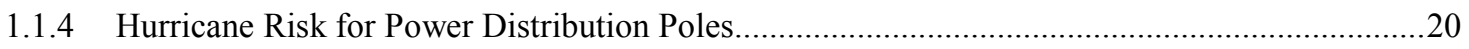

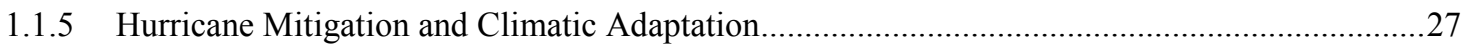

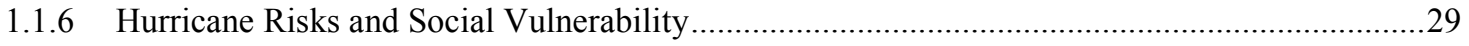

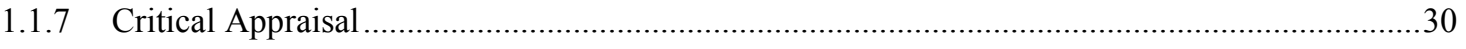

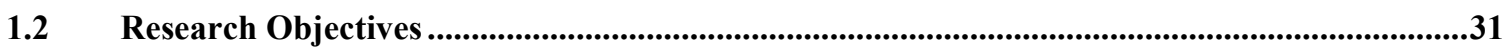

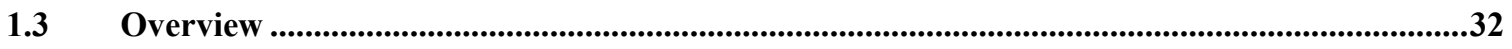

$1.4 \quad$ References .................................................................................................................................35

CHAPTER 2 A PROBABILISTIC-BASED FRAMEWORK FOR IMPACT AND

ADAPTATION ASSESSMENT OF CLIMATE CHANGE ON HURRICANE DAMAGE RISKS

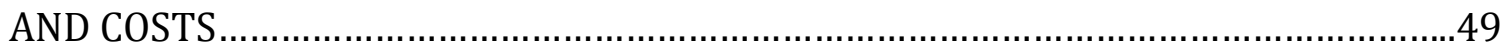

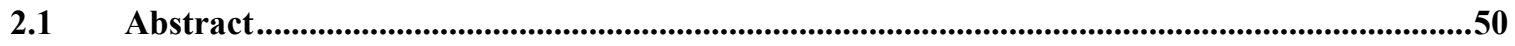




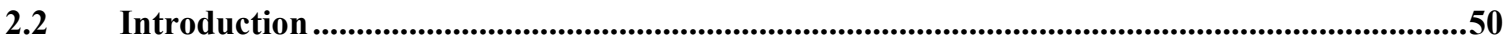

2.3 Hurricane Wind and Vulnerability Models ............................................................................50

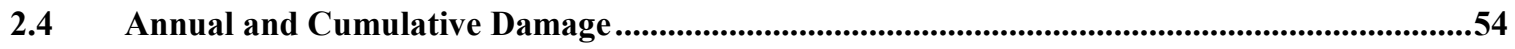

2.5 Impact Assessment Considering Regional hurricane risk ...................................................57

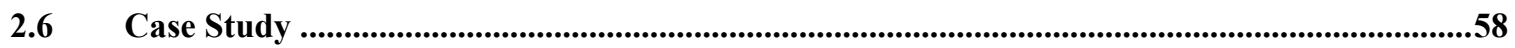

\subsection{Comparison with HAZUS-MH Hurricane and Florida Public Hurricane Loss Model}

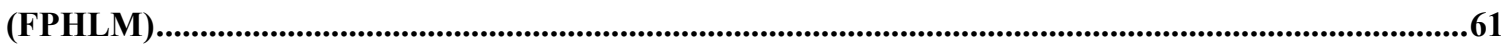

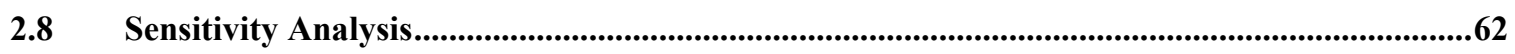

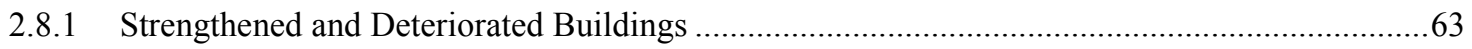

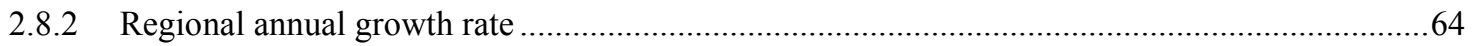

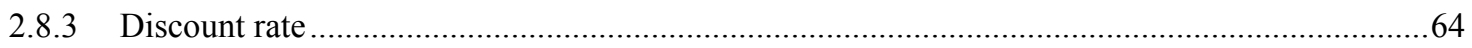

2.8.4 Inventory of houses in different exposure sites...............................................................64

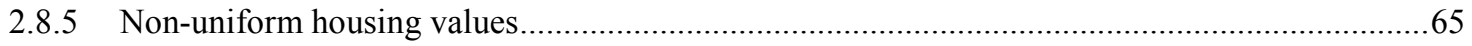

2.9 Cost Effectiveness of Adaptation Strategies..........................................................................66

2.9.1 Adaptation Strategy 1: Strengthening construction built before 1970 at foreshore locations ......68

2.9.2 Adaptation Strategy 2: Strengthening construction built before 1970 within the whole region ..69

2.9.3 Adaptation Strategy 3: Strengthening construction built before 1986 at foreshore locations ......70

2.9.4 Adaptation Strategy 4: Strengthening construction built before 1986 within the whole region ..71

2.9.5 Adaptation Strategy 5: Enhancing new construction at foreshore locations ...........................72

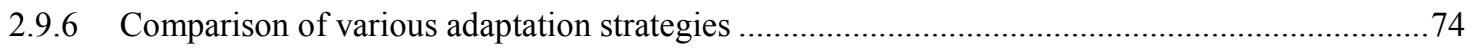

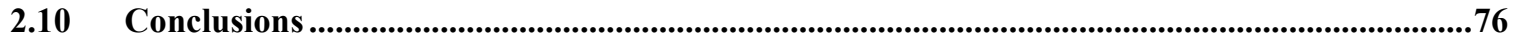

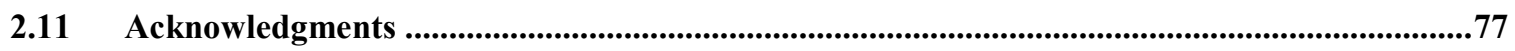

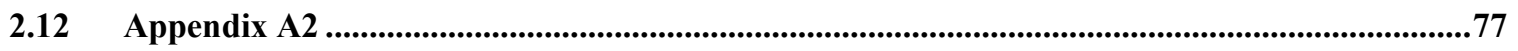

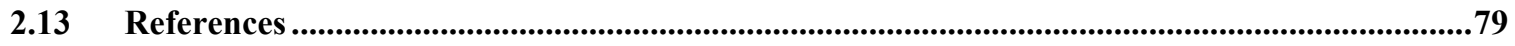




\section{CHAPTER 3 REGIONAL LOSS ESTIMATION DUE TO HURRICANE WIND AND}

HURRICANE-INDUCED SURGE CONSIDERING CLIMATE VARIABILITY ....................... 84

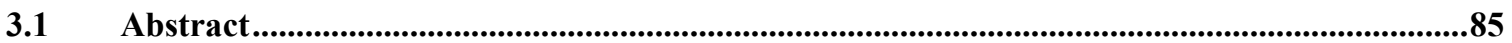

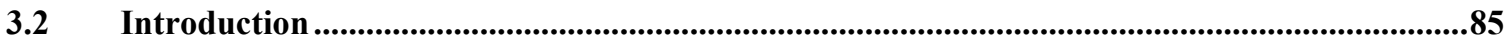

$3.3 \quad$ Hurricane Hazard ...........................................................................................................................8

3.3.1 Hurricane Wind and Frequency Considering Climate Variability ...............................................8

3.3.2 Hurricane-Induced Storm Surge Considering Climate Variability .............................................89

3.4 Vulnerability of Residential Buildings...........................................................................................91

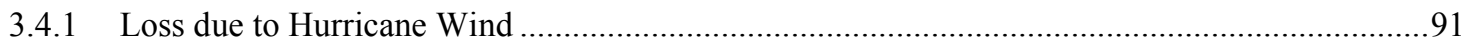

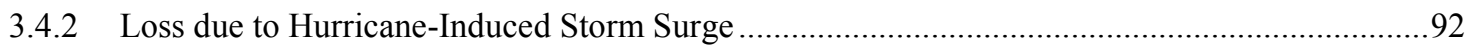

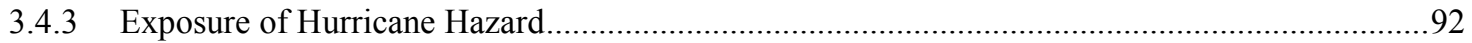

3.5 Regional Loss Estimation Considering Climate Variability .............................................................93

3.5.1 Annual Regional Loss Estimation due to Hurricane Wind ........................................................93

3.5.2 Event-Based Regional Loss Estimation due to Hurricane Wind and Surge ...............................94

3.6 Illustrated Case Studies ..................................................................................................................95

3.6.1 Annual Regional Loss Estimation Considering Climate Variability .........................................97

3.6.2 Event-Based Regional Loss Estimation Considering Climate Variability .................................105

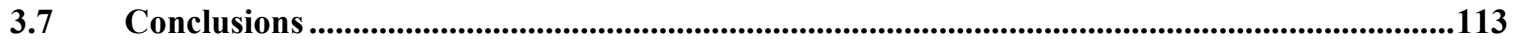

$3.8 \quad$ Acknowledgements............................................................................................................................114

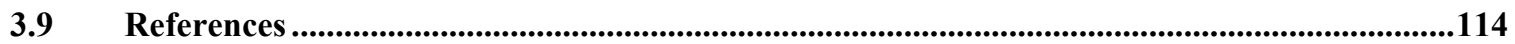

CHAPTER 4 HURRICANE RISK ASSESSMENT OF POWER DISTRIBUTION POLES

CONSIDERING IMPACTS OF A CHANGING CLIMATE ...................................................123

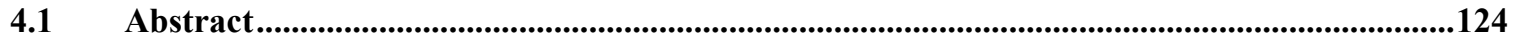

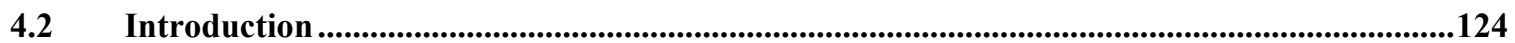




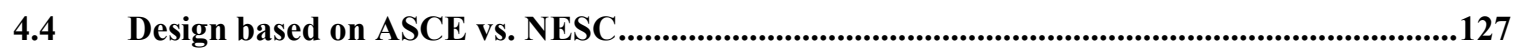

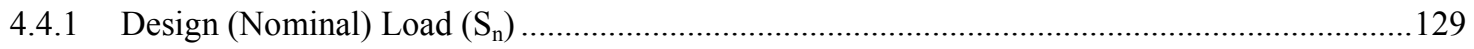

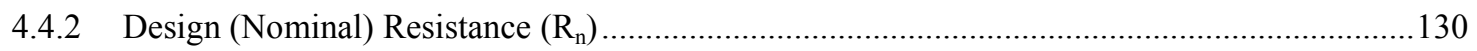

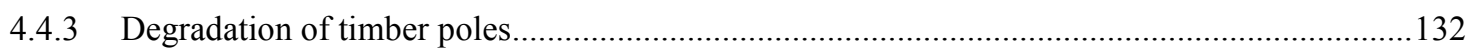

4.5 Risk Assessment .........................................................................................................................136

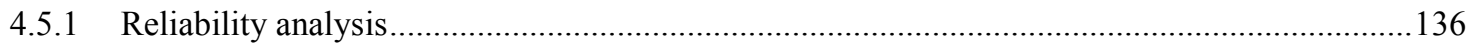

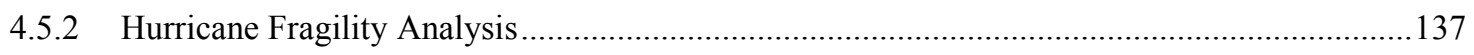

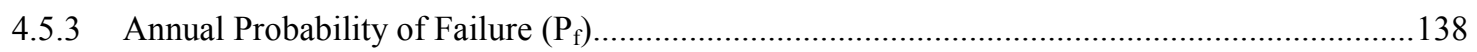

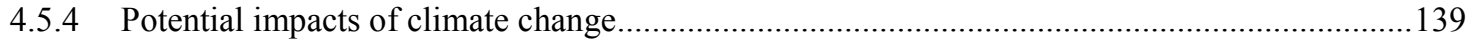

4.6 Illustrative Example ........................................................................................................................139

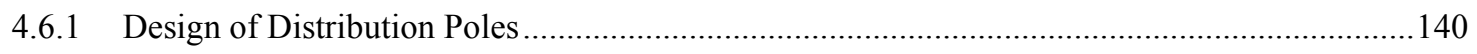

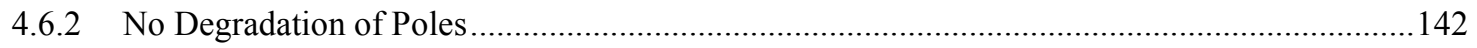

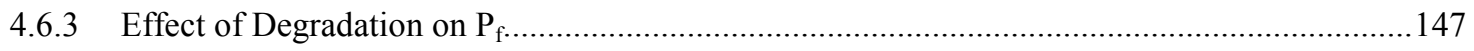

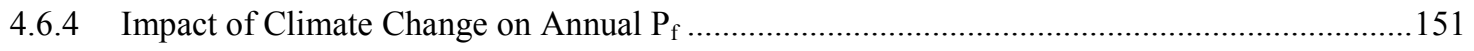

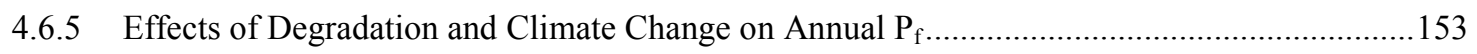

4.6.6 Effects of Degradation and Climate Change on Service Proven Distribution Poles...................156

$4.7 \quad$ Conclusions ....................................................................................................................................159

4.8 Acknowledgements................................................................................................................................160

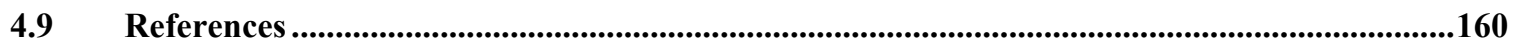

CHAPTER 5 RISK-BASED ECONOMIC ASSESSMENT OF MITIGATION STRATEGIES FOR POWER DISTRIBUTION POLES SUBJECTED TO HURRICANES..............................167

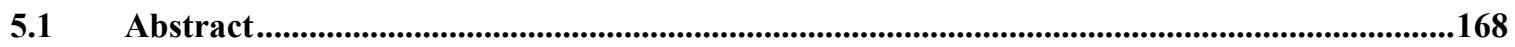

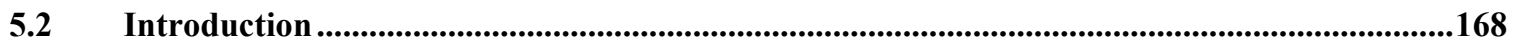

$5.3 \quad$ Design and risk assessment of distribution poles.............................................................................169 
5.4 Mitigation Strategies and Their Cost-effectiveness .......................................................................175

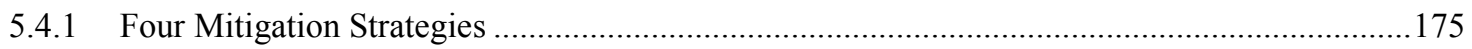

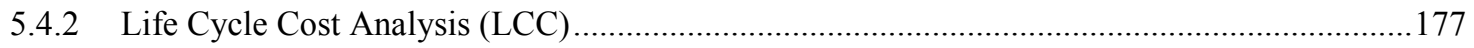

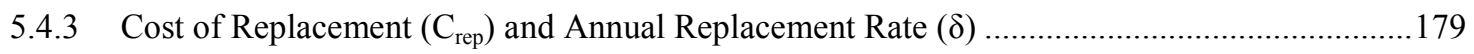

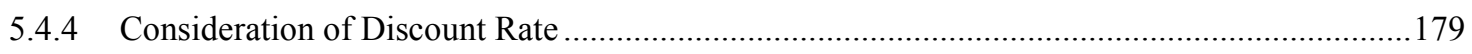

$5.5 \quad$ Illustrative Example .......................................................................................................................181

5.5.1 Annual $\mathrm{p}_{\mathrm{f}}$ Considering Effects of Deterioration................................................................. 185

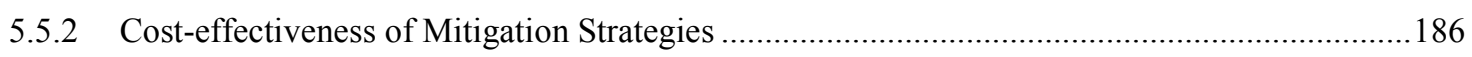

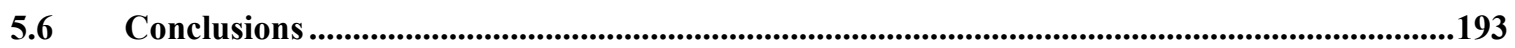

$5.7 \quad$ Acknowledgements..........................................................................................................................194

$5.8 \quad$ References ............................................................................................................................................

CHAPTER 6 SOCIAL VULNERABILITY INDEX FOR COASTAL COMMUNITIES AT

RISK TO HURRICANE HAZARD AND A CHANGING CLIMATE ........................................200

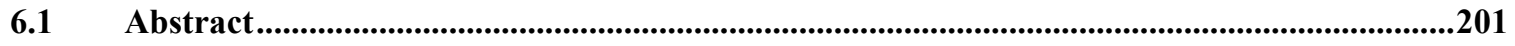

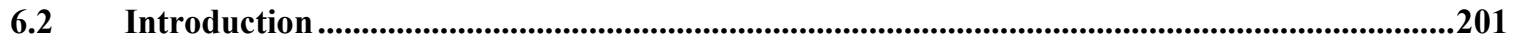

6.3 Development of the Coastal Community Social Vulnerability Index ........................................204

6.3.1 Hurricane Wind Models and Hurricane-Induced Surge Models ...............................................206

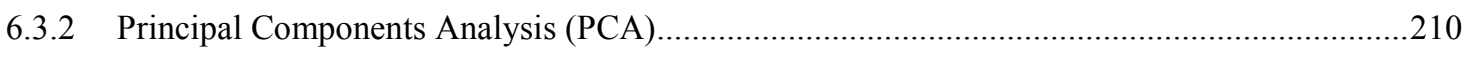

6.3.3 Coastal Community Social Vulnerability Index (CCSVI) ..................................................211

6.4 Illustrative Example .......................................................................................................................214

6.4.1 Hurricane Wind Intensity and Hurricane-Induced Surge .......................................................214

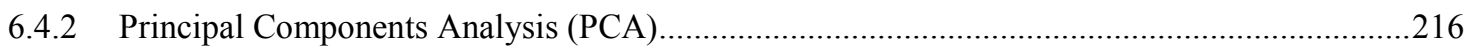

6.4.3 The Coastal Community Social Vulnerability Index (CCSVI) ..............................................217

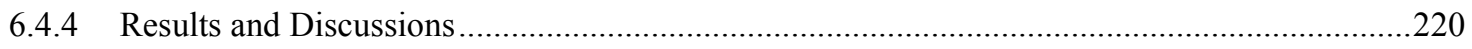

6.5 Uncertainty in CCSVI..............................................................................................................225 
6.6 Conclusions and Future Work ......................................................................................................228

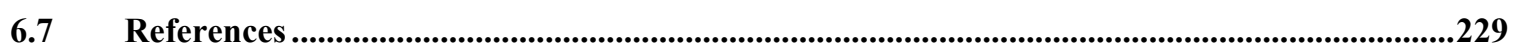

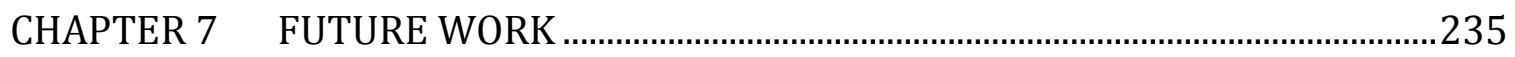

7.1 Hurricane Risk Assessment of Residential Construction Considering Climate Change ........235

7.2 Hurricane Risk Assessment of Timber Poles Considering Climate Change...............................237

7.3 Adaptation/Mitigation for Reduced Hurricane Damage Costs ....................................................240

7.4 Social Vulnerability of Hurricane-Prone Regions Considering Climate Change.....................241

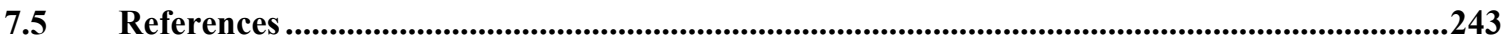

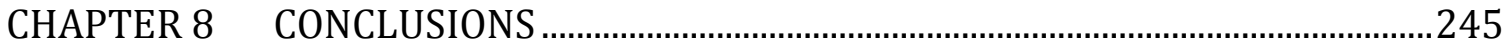

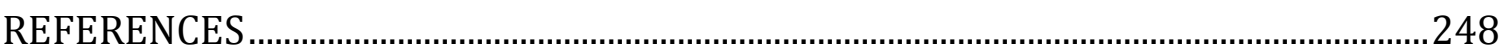

APPENDIX I SUPPLEMENT TO 'A PROBABILISTIC-BASED FRAMEWORK FOR IMPACT AND ADAPTATION ASSESSMENT OF CLIMATE CHANGE ON HURRICANE

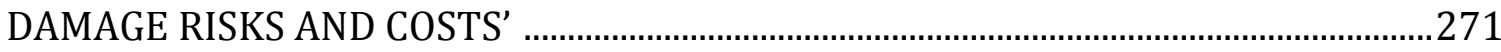

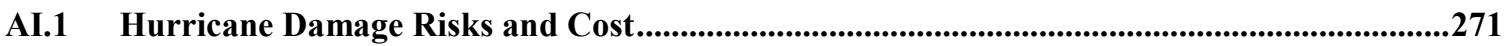

AI.2 Cost-Benefit Analysis of Adaptation Strategies...........................................................................275

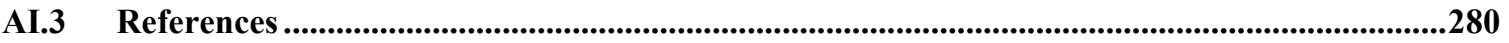

APPENDIX II SUPPLEMENT TO 'RISK-BASED ECONOMIC ASSESSMENT OF MITIGATION STRATEGIES FOR POWER DISTRIBUTION POLES SUBJECTED TO HURRICANES'

AII.1 Mitigation of Timber Distribution Poles considering a Scenario-Based Analysis................281

AII.2 Results. .282

AII.3 References .284

APPENDIX III SUPPLEMENT TO 'SOCIAL VULNERABILITY INDEX FOR COASTAL COMMUNITIES AT RISK TO HURRICANE HAZARD AND A CHANGING CLIMATE' 285

viii 
AIII.1 The Impacts of Social Dynamics in Hurricane Damage Costs.................................................285

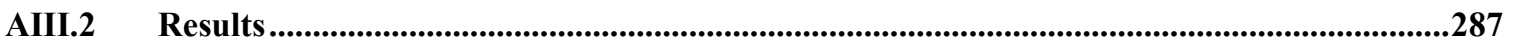

AIII.3 References......................................................................................................................................28

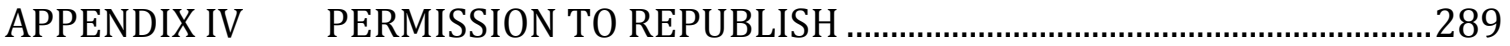




\section{List of Figures}

Figure 1.1:Simulation histogram of annual damage losses in year $50 \ldots \ldots \ldots \ldots \ldots \ldots \ldots \ldots \ldots \ldots . . .8$

Figure 1.2: Generalized Schematic of Power System...................................................... 21

Figure 2.1: Expected annual damage at each location, assuming changes in wind speed of

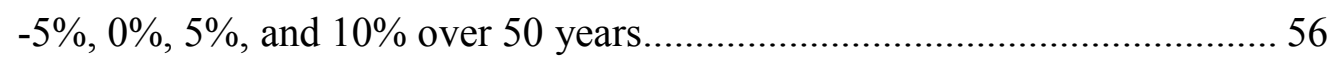

Figure 2.2: Expected cumulative damage at each location, assuming changes of $-5 \%, 0 \%$, $5 \%$ and $10 \%$ in wind speed over 50 years ................................................... 57

Figure 2.3: Percentage change at each exposure site in cumulative damage cost in 50 years from the case of no change in wind speed to changes in wind speed ($5 \%$ to $10 \%)$ 59

Figure 2.4: Cumulative damage cost to single-family units in Miami-Dade County under

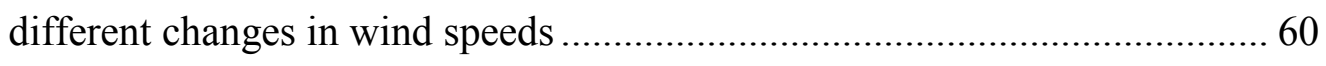

Figure 2.5: Simulation histogram of annual damage losses in year 50 ............................. 61

Figure 2.6: Net benefit for adaptation strategy 1 over 50 years....................................... 69

Figure 2.7: Net benefit for adaptation strategy 2 over 50 years $(5 \%$ increase in wind

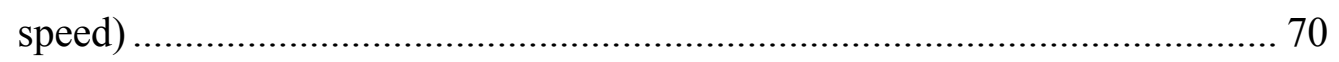

Figure 2.8: Net benefit for adaptation strategy 3 over 50 years....................................... 71

Figure 2.9: Net benefit for adaptation strategy 4 over 50 years $(5 \%$ increase in wind

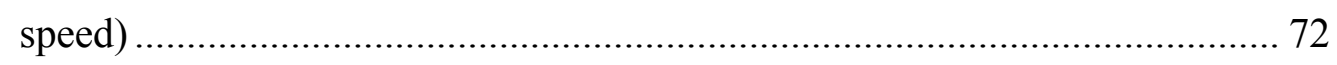

Figure 2.10: Net benefit for adaptation strategy 5 over 50 years $(5 \%$ increase in wind

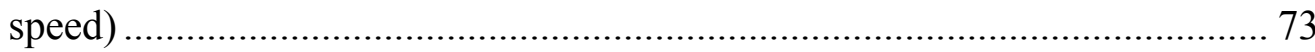

Figure 2.11: Net benefit for adaptation strategy 5 over 50 years $(0 \%$ increase in wind

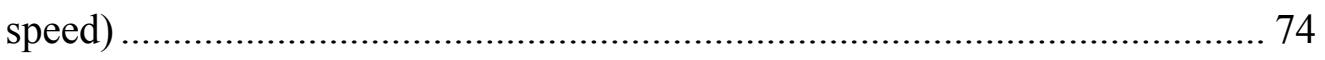

Figure 2.12: Combinations of $\mathrm{C}_{\mathrm{st}}$ and $\mathrm{n}$ in which the net benefit is zero over 50 years for each of the adaptation strategies assuming ( $5 \%$ increase in wind speed)....... 75 
Figure 2.13: Combinations of $\mathrm{C}_{\mathrm{st}}$ and $\mathrm{n}$ in which the net benefit is zero over 50 years for each of the adaptation strategies $(0 \%$ increase in wind speed). 76

Figure 3.1: Map of United States with case study locations (C) 2009 National Atlas of the United States ${ }^{\circledR}$.................................................... 96

Figure 3.2: Percentage Change in Annual Damage Risk at year 50 Considering Scenarios of Climate Change for all three counties (Foreshore)................................... 101

Figure 3.3: Cumulative Damage Costs for the Climate Change Scenarios (\$ billion)... 103

Figure 3.4: Increase in Cumulative Damage Costs from the No Climate Change Scenario (\$ billion) 104

Figure 3.5: Cumulative Damage Cost per 100,000 Residents to Single-Family Units under Various Climate Change Scenarios (\$ million) 105

Figure 3.6: Percentage Change in Damage Costs from the No Climate Change Scenario 111

Figure 3.7: Damage Cost per 100,000 Residents to Single-Family Units under Various Climate Change Scenarios (\$ million) ........................................................ 112

Figure 4.1: Typical Distribution Pole System........................................................... 127

Figure 4.2: Flowchart of the Design Process of the Distribution Pole ............................ 131

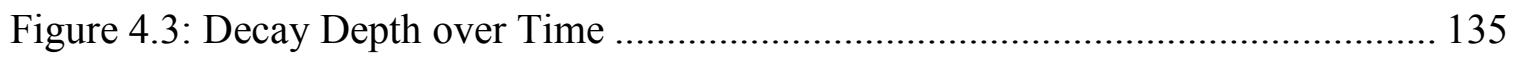

Figure 4.4: Bending Strength over Time …………….................................................. 135

Figure 4.5: Flowchart of the Development of Fragility Curves..................................... 138

Figure 4.6: Fragility Curve (ASCE vs. NESC) ........................................................ 145

Figure 4.7: Effects of Degradation on the Probability of Failure ASCE Design Case 1149 Figure 4.8: Effects of Degradation on the Probability of Failure NESC Design Case 2150 Figure 4.9: Effects of Degradation on the Probability of Failure NESC Design Case 3150 
Figure 4.10: Effects of Degradation on the Probability of Failure NESC Design Case 4 151

Figure 4.11: Effects of Degradation on Annual Pf for Various Scenarios of Climate Change after 100 years for ASCE Design Case 1 154

Figure 4.12: Effects of Degradation on Annual Pf for Various Scenarios of Climate Change after 100 years for NESC Design Case 2 154

Figure 4.13: Effects of Degradation on Annual Pf for Various Scenarios of Climate Change after 100 years for NESC Design Case 3. 155

Figure 4.14: Effects of Degradation on Annual Pf for Various Scenarios of Climate Change after 100 years NESC Design Case 4 155

Figure 4.15: Updated Annual $P f$ for no change in wind speed................................... 157

Figure 4.16: Updated Annual $P f$ for 10\% increase in wind speed in 100 years 157

Figure 5.1: Typical Power Distribution Pole System (Bjarnadottir et al. 2012)..... 171

Figure 5.2: Fragility Curves for Class 5 Distribution Pole of Varying Age 185

Figure 5.3: Updated Annual $\mathrm{p}_{\mathrm{f}}($ Bjarnadottir et al. 2012) 186

Figure 5.4: Cumulative LCC of the "Do Nothing" Case and the Mitigation Strategies at Year 2060 , for $\alpha=5 \%$ per year 190

Figure 5.5: $10^{\text {th }}, 50^{\text {th }}$, and $90^{\text {th }}$ Percentile Values of the Cumulative LCC for the "Do Nothing” Case and Mitigation Strategies at Year 2060 191

Figure 5.6: 10th, 50th, and $90^{\text {th }}$ Percentile Values of the Net Benefit for the Mitigation Strategies at Year 2060 192

Figure 5.7: Probability of Exceedance for Distirbution Poles for: a) the "Do Nothing" Case and b) Mitigation Strategy 2 193

Figure 6.1: Histogram of Wind Speeds.................................................................. 207

Figure 6.2: Histogram of Surge Heights Assuming a Slope of 1:250 ........................ 209 
Figure 6.3: Distributions of CCSVI(50) for various scenarios of climate change. (a) No increase in wind speed and surge height (b) $5 \%$ increase in wind speed and surge height (c) 10\% increase in wind speed and surge height (d) $15 \%$ increase in wind speed and surge height..................................................... 227 


\section{List of Tables}

Table 2.1: Percentage change in cumulative damage for the different inventory assumptions under various changes in wind speed.................................. 65

Table 3.1: Parameters for Surge Model .................................................................... 90

Table 3.2: Demographic Information for Each County used to Estimate the Hurricane

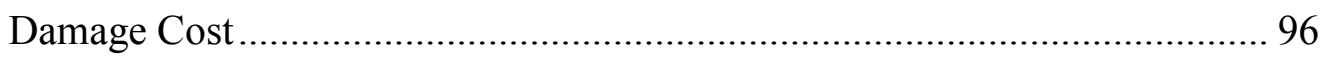

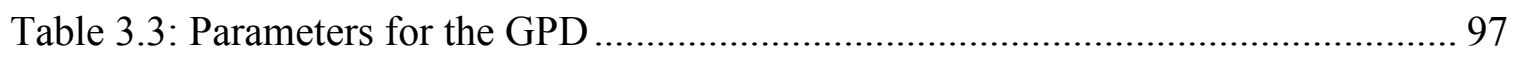

Table 3.4: Annual damage risk (No Climate Change) .............................................. 98

Table 3.5: Annual Damage Risk at year 50 considering Scenarios of Climate Change for all Three Counties (Foreshore Exposure) ............................................... 100

Table 3.6: Parameters for the Event-Based Analysis................................................ 106

Table 3.7: Expected Increase in Sea Level (cm) by 2050....................................... 107

Table 3.8: Combined Hurricane Damage Risk for Foreshore Locations........................ 109

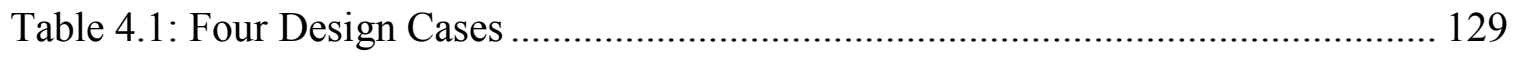

Table 4.2: Design Variables and Values........................................................... 141

Table 4.3: Required Circumference at Ground Line and Pole Class for Design Cases.. 142

Table 4.4: Actual Resistance for Design Cases ...................................................... 142

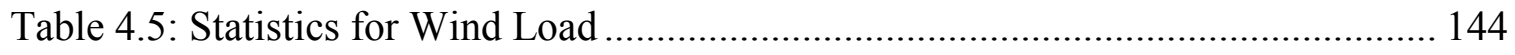

Table 4.6: Lognormal Parameters for Hurricane Fragility ....................................... 146

Table 4.7: Mean and $C O V$ of Resistance $R(t)$ for Various Ages ................................ 148

Table 4.8: Annual $P_{f}$ for Design Cases (New Poles) ................................................. 153

Table 5.1: Design Parameters for Distribution Pole ................................................ 181

Table 5.2: Statistics for Wind Load ........................................................................... 183 
Table 5.3: Mean and COV of Resistance R(t) for Various Ages................................ 184

Table 5.4: Cost of the "Do Nothing" Case at Year 2060 ............................................ 188

Table 5.5: Average Number of Poles Replaced ........................................................ 189

Table 6.1: Wind speed and surge height at year 50 for various scenarios of climate

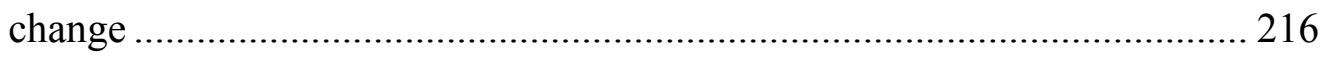

Table 6.2: Results of PCA, including the Social Factors, Eigenvalues, percentage of explained variance, and percentage of cumulative explained variance ........ 217

Table 6.3: Social Indicators for the CCSVI .......................................................... 219

Table 6.4: CCSVI(1) for the three ratios of weight of $\mathrm{H}_{\text {wind }}$ and $\mathrm{H}_{\text {surge }} \ldots \ldots \ldots \ldots \ldots \ldots \ldots \ldots . . . . . . . . . .221$

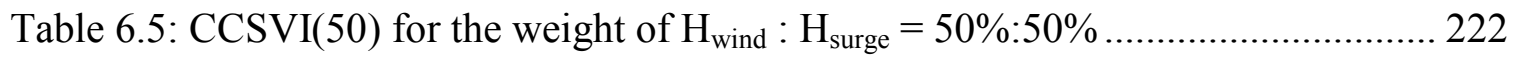

Table 6.6: The percentage change in CCSVI in year 50 from year 1 for weight of $\mathrm{H}_{\text {wind: }}$ :

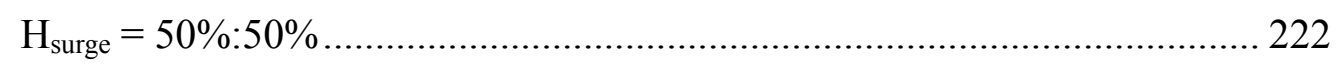

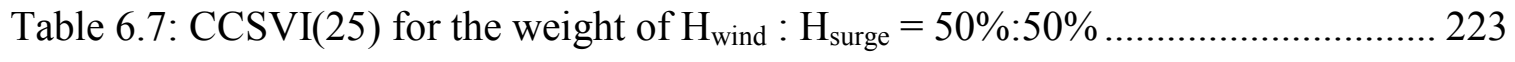

Table 6.8: The percentage change in CCSVI in year 25 from year 1 for weight of $\mathrm{H}_{\text {wind: }}$ :

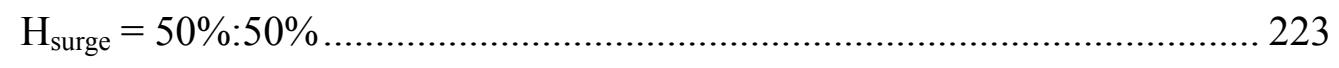

Table 6.9: The mean, the $5^{\text {th }}$ and $95^{\text {th }}$ percentiles of the CCSVI(50).......................... 227 


\section{Preface}

The research presented in this dissertation has been part of research work carried out at Michigan Technological University in the period of 2008-2012. This dissertation contains material that has been previously published (Chapter 2, 4, and 6), accepted for

publication (Chapter 5), and submitted for publication (Chapter 3). Each paper is written according to the style required from the journal which it was published. The author performed the research and wrote the papers, with guidance and editing provided by Dr. Yue Li and Dr. Mark Stewart.

Chapter 2 contains the journal paper "A Probabilistic-based Framework for Impact and Adaptation Assessment of Climate Change on Hurricane Damage Risks and Costs" which has been published in the journal Structural Safety.

- Bjarnadottir, S., Li, Y. and Stewart, M.G. (2011) A Probabilistic-based Framework for Impact and Adaptation Assessment of Climate Change on Hurricane Damage Risks and Costs, Structural Safety, 33(3), 173-185.

Chapter 4 contains the journal paper "Hurricane Risk Assessment of Power Distribution Poles Considering Impacts of a Changing Climate" which has been published in the journal Journal of Infrastructure Systems, ASCE.

- Bjarnadottir, S., Li, Y. and Stewart, M.G. (2012) Hurricane Risk Assessment of Power Distribution Poles Considering Impacts of A Changing Climate, Journal of Infrastructure Systems, ASCE (In press).

Chapter 6 contains the journal paper "Social Vulnerability Index for Coastal Communities at Risk to Hurricane Hazard and a Changing Climate" which has been published in the journal Natural Hazards.

- $\quad$ Bjarnadottir, S., Li, Y. and Stewart, M.G. (2011) Social Vulnerability Index for Coastal Communities at Risk to Hurricane Hazard and a Changing Climate, Natural Hazards 59(2), 1055-1575. 
Chapter 5 contains the journal paper "Risk-Based Economic Assessment of Mitigation Strategies for Power Distribution Poles Subjected to Hurricanes" which has been accepted to the journal Structure and Infrastructure Engineering.

Chapter 3 contains the journal paper "Regional Loss Estimation Due to Hurricane wind and Hurricane-Induced Surge Considering Climate Variability which has been submitted to the journal Structure and Infrastructure Engineering. 


\section{Acknowledgements}

I would like to start by expressing my sincerest gratitude to my advisor, Dr. Yue Li. We have worked together for the past four years. His knowledge and guidance have been an invaluable resource for me throughout the process of writing this dissertation. His open door policy has led to many interesting exchanges of ideas that have, in many cases, found their way onto the pages of this dissertation. Over the years, Dr. Li has developed a knack for knowing exactly what I needed in the form of an advisor, whether it is to provide me with encouragement, patience, praise, or a little push to keep going, and for that I thank him.

I would also like to thank my co-advisor, Dr. Mark Stewart, Professor and Director of the Center for Infrastructure Performance and Reliability at The University of Newcastle in Australia, for his guidance. His instance on asking tough questions has pushed me to go beyond what I initially thought was enough, to make this dissertation a piece of work that I am truly proud of.

I would like to extend my appreciation to Dr. Veronica Griffis and Dr. Qiuying Sha, who served as my graduate advisory committee members, for their assistance and time throughout this process.

I would like to send a special thanks to all the assistance my Graphics Department has given me. The assistance has gone above and beyond.

My parents, Bjarni and Dóra, have stood by me throughout my life. We have had our share of ups and downs, but their support has never faltered. At times when I have been questioning my ability as a researcher or teacher, they have given me the encouragement I have needed to keep going and they have pushed me to be better than I believe possible. My father has always expected me to give my all, which has helped me develop a work ethic that has resulted in this dissertation. My mother has always been there, taking on the various roles I have needed to complete this dissertation, such as cheerleader, confidant, and friend. I would also like to thank my siblings, Stína, Stefán and Valtýr, for 
diverting my attention when it seemed like the process of writing this dissertation would swallow me whole. Sometimes the most awesome (and most needed) thing in the world comes in the form of a link to a video of a clip from Jimmy Kimmel.

Lastly, I would like to thank my husband. I know for a fact that I have not been the easiest person to live with over the last year. So I thank you. 


\section{Abstract}

Studies are suggesting that hurricane hazard patterns (e.g. intensity and frequency) may change as a consequence of the changing global climate. As hurricane patterns change, it can be expected that hurricane damage risks and costs may change as a result. This indicates the necessity to develop hurricane risk assessment models that are capable of accounting for changing hurricane hazard patterns, and develop hurricane mitigation and climatic adaptation strategies. This thesis proposes a comprehensive hurricane risk assessment and mitigation strategies that account for a changing global climate and that has the ability of being adapted to various types of infrastructure including residential buildings and power distribution poles.

The framework includes hurricane wind field models, hurricane surge height models and hurricane vulnerability models to estimate damage risks due to hurricane wind speed, hurricane frequency, and hurricane-induced storm surge and accounts for the timedependant properties of these parameters as a result of climate change. The research then implements median insured house values, discount rates, housing inventory, etc. to estimate hurricane damage costs to residential construction. The framework was also adapted to timber distribution poles to assess the impacts climate change may have on timber distribution pole failure. This research finds that climate change may have a significant impact on the hurricane damage risks and damage costs of residential construction and timber distribution poles.

In an effort to reduce damage costs, this research develops mitigation/adaptation strategies for residential construction and timber distribution poles. The costeffectiveness of these adaptation/mitigation strategies are evaluated through the use of a Life-Cycle Cost (LCC) analysis. In addition, a scenario-based analysis of mitigation strategies for timber distribution poles is included. For both residential construction and timber distribution poles, adaptation/mitigation measures were found to reduce damage costs. 
Finally, the research develops the Coastal Community Social Vulnerability Index (CCSVI) to include the social vulnerability of a region to hurricane hazards within this hurricane risk assessment. This index quantifies the social vulnerability of a region, by combining various social characteristics of a region with time-dependant parameters of hurricanes (i.e. hurricane wind and hurricane-induced storm surge). Climate change was found to have an impact on the CCSVI (i.e. climate change may have an impact on the social vulnerability of hurricane-prone regions). 


\section{Chapter 1}

\section{Introduction}

In recent years, hurricane damage costs in the United States (U.S.) have increased. It is estimated that the 2004-2005 hurricane season caused in excess of $\$ 150$ billion in damages, mainly due to Hurricane Katrina (Pielke et al. 2008). This is a significant increase from the annual average of $\$ 6$ billion, recorded from 1989-1995, and an even more significant increase from the average recorded from 1950-1989 of \$1.6 billion in damages annually (Pielke and Pielke 1997). Furthermore, it is projected that insures in the U.S. have paid more than $\$ 110$ billion in losses due to hurricane events (GAO 2007). Despite these increases in damage costs, the coastal population of the U.S. continues to grow. For example, insured coastal property values in Florida have increased by 55\% from the year 1988 to 1993, from $\$ 566$ billion to $\$ 872$ billion (Stewart et al. 2003). In 2003, approximately 153 million people reside in counties along the U.S. coastline (Crosset et al. 2004). This is an increase in population of 33 million since 1980, and it is estimated that the U.S. coastal population will increase by 12 million in 2015 (W\&PE 2003).

The International Panel on Climate Change (IPCC 2007) has stated that rising sea surface temperatures (SST) are a direct result of the changing global climate. Increased hurricane activity has been recorded in the Atlantic Ocean since 1995 (Goldenberg et al. 2001). However, whether this increased activity can be directly tied to the rising SST of the Atlantic Ocean is a matter of debate. Studies (Elsner et al. 2008, Emanuel 2005, Mann and Emanuel 2006, White House 2009) do show that there is an apparent connection between the two increases. On the other hand, studies (Klotzbach 2006, Landsea et al. 2006, Landsea 2007, Pielke et al. 2005) attribute the increased hurricane activity to the natural variability of hurricanes in the Atlantic Ocean. Whether or not climate change is 
the driving factor, it cannot be disputed that hurricane activity has increased significantly in the Atlantic Ocean in recent years.

Hurricane risk assessment models must be able to account for the potential effects of climate change on hurricane damage costs, by incorporating the non-stationary aspects of various hurricane parameters. However, existing models, such as Stewart et al. (2003) and Li and Ellingwood (2006), that estimate hurricane damage costs as a function of wind speed, assume that the wind speed does not change with time. Hurricane damage costs within a region are not solely affected by the intensity of the hurricanes that make landfall. Hurricane frequency and hurricane-induced storm surge can also account for a portion of damage costs. For instance, four hurricanes made landfall in Florida during a six week period in 2004 (Johnson 2005), and it is estimated that hurricane-induced storm surge cause about $60 \%$ of damage costs due to Hurricane Katrina in 2005 (NWS 2006). These facts indicate the necessity of accounting for hurricane frequency and including hurricane-induced storm surge in a comprehensive hurricane risk assessment.

Because climate change has the potential to result in more devastating hurricane events and coastal populations continue to grow, a descriptive index that considers the effects of climate change could be invaluable in the assessment of the social vulnerability of hurricane-prone areas. Social vulnerability is a combination of a region's capacity to respond and recover from a natural hazard, with minimal damage (Cutter et al. 2003). Therefore, it is important to identify the societal factors that have the greatest affect on hurricane vulnerability and combine them to create an index which describes the hurricane risk for the region (Davidson and Lambert 2001).

The purpose of this paper is not to examine whether there is a direct relationship between climate change and changing patterns of hurricane hazard, nor to endorse any specific scenario of climate change (or lack thereof). Instead, a framework is proposed for a comprehensive hurricane risk assessment to account for the potential impact of climate change. 


\subsection{Literature Review and Critical Appraisal}

The following provides a comprehensive literature review on Climate Change, Uncertainty, Risk, and Probabilistic Analysis, Hurricane Wind Field Models, HurricaneInduced Storm Surge Height Models, Hurricane Vulnerability Models, Power Distribution Poles (Design, Damage and Fragility), Climatic Adaptation, and Social Vulnerability Metrics. In addition, a critical appraisal is included to illustrate the present state-of-the-art and to assess what is lacking.

\subsubsection{Climatic Change and its Impact of Natural Hazard Patterns}

Rising sea surface temperatures (SST) are accepted as a direct result of the global climate change as stated in a report by the Intergovernmental Panel on Climate Change (IPCC 2007). Studies have suggested a relationship between the rising sea surface temperatures and hurricane intensity (Webster et al. 2005). Emanuel (2005) concluded that for every increase in SST of $1^{\circ} \mathrm{C}$ the peak wind speed of hurricanes could increase by approximately 5\%. Elsner (2006) confirmed findings that climate change results in higher SST, and higher SST translates to more energy that can be converted to stronger hurricane winds. If SST increase by $2.2^{\circ} \mathrm{C}$, Knutson et al. (1998) and Knutson and Tuleya (1999) estimated that hurricane intensity may increase by $5 \%$ to $10 \%$. Scavia et al. (2002) added that increases in hurricane intensity of this magnitude may result in the increase of the destructive power of hurricanes by approximately $25 \%$. Knutson et al. (2010) estimates that in the 21 st century hurricane wind speeds may increase by $2 \%$ to $11 \%$ around the world. The CCSP (2008) found that the frequency of hurricanes may increase as hurricane wind speeds increase. In contrast, Knutson et al. (2008) and Knutson et al. (2010) estimate that globally the average number of hurricanes will decrease by $-6 \%$ to $-34 \%$ as a result of global climate change, but Knutson et al. (2010) also states that the occurrence of higher intensity hurricanes (Category 4 and 5) may increase. Bender et al. (2010) verifies these findings by stating that due to the changing global climate the frequency of hurricanes in general will decrease, but that the number of very intense hurricanes may increase. 
Climate change might not only affect the wind speeds and frequency associated hurricanes, but also the storm surge produced by hurricanes. The IPCC (2007) estimates that global sea levels have increased by 10 to $20 \mathrm{~cm}$ over the last 100 years, and predicts that in the 21 st century the global average sea level may increase by an additional $40 \mathrm{~cm}$ as a direct result of climate change. For example, it is estimated that the sea level along Florida's Atlantic coast may increase at a rate of $2 \mathrm{~mm}$ per year over the next 100 years. This increase in sea levels translates to hurricane-induced storm surges that are riding on higher sea levels that are capable of travelling farther inland (Scavia et al. 2002). Wu et al. (2002) found that the vulnerability of coastal communities in the U.S. to flooding will increase as a result of higher sea levels due to climate change. The New York City Panel on Climate Change (2009) found that rising sea levels as a result of climate change could lead to significant increases in structural damage.

Climate change is a global problem, and around the world, governments are trying to identify and quantify the effects climate change may have. The UK Climate Impacts Programme 2002 investigated the effects warming global climate may have on construction and what building code changes may be made to minimize them (Sanders and Phillipson 2003). In Australia, the Australian Building Codes Board is tackling a similar problem. Seattle and London found that not taking measures against climate change may be potentially costly (London Climate Change Partnership 2002, Cohen et al. 2005).

In 2006, the Climate Change Advisory Task Force was established in Miami-Dade County (Climate Change Advisory Task Force 2008). The purpose of the Task Force is to identify the potential effects climate change may have and to provide recommendations for adaptation to mitigate these potential changes. The Task Force stated in the 2008 report that an increase in the sea level of 90 to $150 \mathrm{~cm}$ is to be expected during this century in Miami-Dade County. The report also found that increases in severe weather events could be a result of the warming climate of Miami-Dade County (Climate Change Advisory Task Force 2008). Larsen et al. (2007) conducted a study which concluded that between now and 2030, the changing weather climate, could potentially add $\$ 3.6$ to $\$ 6.1$ billion to public infrastructure costs. If a larger time frame is 
assumed, between now and 2080, it could add $\$ 5.6$ to $\$ 7.6$ billion, assuming that government agencies adapt infrastructure to changing conditions.

\subsubsection{Uncertainty, Risk, and Probabilistic Analysis}

There is a great uncertainty in hurricane risk assessment ( $\mathrm{Li}$ and Ellingwood 2006), in particular under the impact of climate change (Stainforth 2005). Despite the uncertainty on the possible change of wind speeds in the U.S., information is available from other locations. Australian Greenhouse Office (AGO) (2007) and Walsh et al (2002) suggest that there will be an increase in wind speed of 5\% to $10 \%$ by 2050 in Queensland, Australia. A recent study by Vickery et al. (2009) indicates that 5\% to $10 \%$ increase in wind speeds in the U.S. may be possible.

Two groups of uncertainty, i.e. aleatoric uncertainty and epistemic uncertainty, can be identified within hurricane risk assessment. Aleatoric uncertainty arises because of the unpredictable, random nature of the physical system under study. On the other hand, epistemic uncertainty is due to the lack of knowledge of the system in respect to quantities and processes within the system. Aleatoric uncertainty cannot be reduced only identified and quantified, while epistemic uncertainty can be reduced through more comprehensive study. Epistemic uncertainties can be quantified through a thorough sensitivity analysis.

Within the research, the aletoric uncertainties include the frequency and intensity of hurricane wind speeds and the magnitude of hurricane-induced surge, because of the inherent randomness within these parameters. The epistemic uncertainties are found where assumptions are made within this research, such as increase in annual maximum wind speed in 50 years, increase in surge heights, the vulnerability functions, annual house growth rate, building inventory within a region, assumed discount rate, and nonuniform housing prices of a region.

There is also uncertainty with regards to the potential changes in storm surge height. As previously stated, the IPCC (2007) indicated that an increase in surge height of $40 \mathrm{~cm}$ is possible by the end of the century. While the Climate Change Advisory Task Force (2008) of Miami-Dade County estimates that surge heights may increase by 90 to $150 \mathrm{~cm}$ 
for Miami-Dade County. For example, in 1992, Hurricane Andrew devastated South Florida causing around $\$ 25.5$ billion in damages (NWS 2009). Hurricane Andrew had a maximum surge height of $5.2 \mathrm{~m}$. Using the predictions made by the Climate Change Advisory Task Force, which state increases of 90 to $150 \mathrm{~cm}$ over 100 years, or 45 to 75 $\mathrm{cm}$ over 50 years, the surge height of Hurricane Andrew would increase by $9 \%$ to $15 \%$. On the other hand, using IPCC predictions (i.e. increase of $20 \mathrm{~cm}$ over 50 years), the surge height of Hurricane Andrew would increase by $4 \%$.

Epistemic uncertainties are not limited to the effects of climate change on various parameters of hurricanes (i.e. wind speed and surge height), but are also present where assumptions are made in modeling residential construction and power systems (Billinton and Huang 2008, Ellingwood and Kinali 2008). These epistemic uncertainties should be identified and addressed within a comprehensive hurricane risk assessment, and ultimately, reduced if possible through a more detailed study or survey. Epistemic uncertainties relating to the modeling of residential construction include the number of single-family units, annual growth rate, the distribution of houses, the median house value, etc. Similarly, epistemic uncertainties are identifiable within the modeling of the power system, and these include the spatial distribution of distribution lines, the median replacement cost of a distribution pole, the number of customers, etc. Epistemic uncertainties can also be identified within the vulnerability models utilized within the framework for both the hurricane intensity and hurricane-induced surge, as these are often simplified models that are based on assumptions of the housing population.

Current hurricane risk assessment models assume that wind speeds are stationary with time, meaning that the past is representative of the future (Stewart et al. 2003, Li and Ellingwood 2006). Climate change effects, by definition, must take into account nonstationary aspects of wind climatology. Some studies have been conducted exploring the effects climate change may have on residential construction in Australia. Li and Stewart (2009) proposed a risk-based framework for assessment of economic damage risks and costs caused by tropical cyclones in Queensland, Australia due to the possible change in wind speeds resulting from climate change. Stewart and Li (2010) evaluated the costeffectiveness of adaptation strategies in Queensland, Australia for cyclone damage risks 
due to climate change. Similar research is needed to investigate the potential effects of climate change on hurricane risk assessments in the U.S.

\subsubsection{Monte Carlo Simulation (MCS)}

A Monte Carlo Simulation (MCS) can be used to estimate the damage risk to incorporate the epistemic uncertainty in change in hurricane wind speed, i.e. the wind increase is a variable. How climate change will affect regional climates and pertinent variables (epistemic uncertainty) is not well known, limiting the ability to predict consequential effects.

Figure 1.1 shows the results of the MCS for the annual damage in Miami-Dade County, Florida, assuming a mean increase in wind speed of $5 \%$ with COV of 0.50 in year 50 . This figure is for illustration purposes only, as significant refinement is required to estimate probability distributions for future mean temperatures or other climatic variables (e.g. the COV for changes in wind speed) when new information is available (IPCC 2007). A presentation like this figure can also be modified to represent the cumulative damage of a region to allow making statements with certain confidence level, such as "I am 95\% confident that the wind damage for this region will be under $\$ 1.0$ billion for an increase in wind speed of $5 \%$ over 50 years". Such statement can be very useful in risk communication for decision making. 


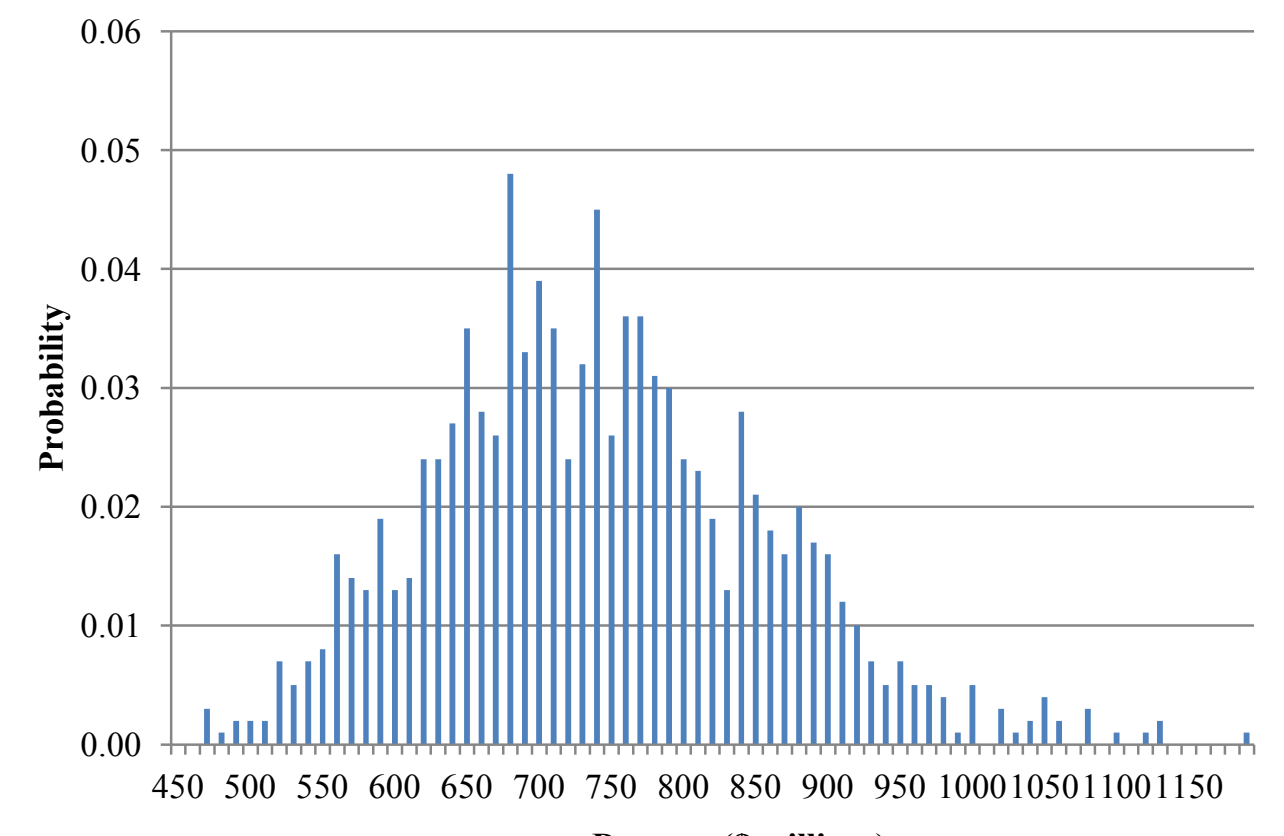

Damage (\$ millions)

Figure 1.1: Simulation histogram of annual damage losses in year 50

\subsubsection{Reliability Analysis including Time-Dependent Reliability}

The reliability of a structural member or structural system is defined as the probability that the structural member or structural system will fulfill the performance criteria (i.e. not fail) ( $\mathrm{Li}$ et al. 2006). As stated previously, climate change may result in increased hurricane activity. Therefore reliability analyses should be capable of accounting for time-dependent changes to resistance $(\mathrm{R})$ and applied load $(\mathrm{S})$. For example, in some cases it can be expected that applied load may increase (e.g. increased hurricane wind speed due to climate change) while the resistance may decrease (e.g. degradation of strength in timber poles due to decay). In general, the time-dependent limit state function of a structural member or structural system is given as:

$$
G(t)=R(t)-S(t)
$$

where $R(t)$ is the actual capacity at time $t$ and $S(t)$ is the actual load at time $t$.

The limit state between failure and not failure is defined as $G(t)=0$. If the variables result in $G>0$, then the system has fulfilled its performance criteria, but if $G<0$, then the system has failed. The $\mathrm{P}(\mathrm{G}>0)$ is defined as the reliability of the system, and the probability of 
failure is defined as $\mathrm{P}(\mathrm{G}<0)$. In order to estimate the probability of failure, a Monte Carlo simulation (MCS) will be utilized. A MCS involves repeated random sampling of R and $\mathrm{S}$, where $\mathrm{R}$ and $\mathrm{S}$ are the resultant of various statistical distributions. The probability of failure can be estimated by counting the number of times $\mathrm{G}<0$.

$p_{f}=\frac{\text { number of times } G<0}{N}$

where $\mathrm{N}$ is the number of times the Monte Carlo simulation was run.

\subsubsection{Hurricane Fragility Analysis}

Hurricane fragility is defined as the conditional $\mathrm{P}_{\mathrm{f}}$ of a structural member or structural system as a function of wind speed ( $\mathrm{Li}$ and Ellingwood 2006). The structural fragility of infrastructure systems is often modeled as a lognormal cumulative distribution function (CDF) (Li and Ellingwood 2006).

$F_{D}(V)=\Phi\left(\left(\ln \left(V / m_{R}\right) / \xi_{\mathrm{R}}\right)\right.$

where $\mathrm{V}$ is the 3 -sec gust wind speed, $\mathrm{m}_{\mathrm{R}}$ is the median capacity or resistance, $\xi_{\mathrm{R}}$ is the logarithmic standard deviation of the capacity or resistance, and $\Phi(\cdot)$ is the standard normal probability integral.

Fragility curves are developed by plotting the conditional failure probability for an increasing wind speed. Reed (2008) investigated the vulnerability of distribution systems to winter storms and strong wind events. The study defined the fragility of distribution systems as the probability of damaged line length given a wind speed, plotting actual damage data from winter storms accompanied with strong winds against a lognormal curve. Because of the lack of data available, the study could not conclude that the fragility curve for distribution systems given wind speed follows a lognormal distribution similar to that of seismic damage (Reed 2008). Reed et al. (2010) plotted damage data due to wind speed from Hurricane Rita in order to assess the fragility of the distribution to hurricane winds. The analysis found that the damage data for Hurricane Rita due to wind speed follows a lognormal distribution. 
Hurricane fragility curves show the probability of failure of a structural member or structural system for a range of wind speeds. The probability of failure for the fragility curves is estimated with a Monte Carlo Simulation (MCS), as stated previously, which involves counting the number of times the load $(\mathrm{S})$ exceeds the resistance $(\mathrm{R})$. When creating the fragility curves, the wind speed (3-sec gust wind speed, V) is assumed to be a deterministic value which increases monotonically.

\subsubsection{Hurricane Risk for Residential Construction}

The expected annual probability of failure $\left(\mathrm{P}_{\mathrm{f}}\right)$ due to hurricane wind hazard can be determined by convolving the hurricane vulnerability function $F_{D}(v)$ and the probability density function (PDF) of the hurricane wind field model $\mathrm{f}_{\mathrm{v}}(\mathrm{v})$ (Li and Ellingwood 2006).

$$
P_{f}=\int F_{D}(V) \cdot f_{v}(V) d V
$$

\subsubsection{Hurricane Wind Field Model}

Wind field models estimate hurricane wind speeds. The most acceptable approach to estimating hurricane wind speeds is mathematical simulation (Vickery et al. 2000), and this approach is used in developing design wind speed maps for the U.S., which are used in structural design (e.g. ASCE 1996). The simulation technique was first proposed by Russell (1968), and has been improved upon by Batts (1980), Georgiou et al. (1983), Georgiou (1985), Neumann (1991), Vickery and Twisdale (1995), and Huang (1999). The underlying approach is similar for these studies. The first step is identifying and obtaining statistical models of several site-specific key parameters (i.e. central pressure deficit, radius to maximum winds, heading, translation speed, and the coast crossing position). A Monte Carlo Simulation (MCS) then samples the parameters generating a mathematical representation of a hurricane. The hurricane wind speeds are then recorded as the simulated hurricane passes through the site (Vickery et al. 2000).

As stated previously, the fundamental approach to the models is similar, but differences lie within the physical models of the hurricane, e.g. filling rate model and wind field (Vickery and Twisdale 1995, Vickery et al. 2000). In addition, other differences between

the models include the size of the region in which the hurricane climatology is assumed 
to be uniform and the use of a coast segment crossing approach versus a circular subregion approach (Vickery et al. 2000).

The models do not model the entire track of the hurricane; therefore Vickery et al. (2000) pioneered the empirical track method (ETM) to simulate the full track of hurricanes from formation to dissipation. Recent research in the field (e.g. Lee and Rosowsky 2005, Powell et al. 2005, Emanuel et al. 2006, Rumpf et al. 2007, and Vickery et al. 2009) has improved upon the ETM approach. The ETM approach involves modeling the central pressure deficit as a function of sea surface temperature. As the storm evolves, the key parameters (listed above) are updated at pre-determined intervals, and at each interval the wind speed is recorded at all locations within the region. The ETM approach therefore allows for the modeling of larger areas, while previously wind speeds could only be modeled at specific locations where the statistical models of the key parameters were valid. However, a disadvantage of the ETM approach is that it results in an excessive amount of simulated hurricane events, from which it may be difficult to estimate regional damage risks within hurricane risk assessments.

Despite the variations between hurricane wind field models, there is some consensus that hurricane wind speed in the U.S. can be modeled with a Wiebull distribution (Georgiou 1985, Vickery and Twisdale 1995, Li and Ellingwood 2006). Therefore, to estimate damage risks due to hurricane wind speed, the framework developed herein will employ the Wiebull distribution. Site-specific Wiebull distribution parameters will be estimated from the latest wind contour maps available for the U.S. (Vickery et al. 2009) to estimate hurricane wind speed.

Unfortunately modeling hurricane wind speeds with the Wiebull distribution does not account for hurricane occurrence rates. Therefore, the hurricane risk assessment framework developed herein will also model hurricane wind speeds with a Generalized Pareto Distribution (GPD). The GPD allows for the inclusion of hurricane frequency in estimations of hurricane wind speed. In the following, a brief description of the GPD and its applications within wind modeling are provided. 
The "peaks-over-threshold" method involves the analysis of events that exceed a given threshold. The events above the given threshold can be described with the GPD (Palutikof et al. 1999). An adequately chosen threshold will result in only true peaks, and these peaks have a Poisson arrival rate. Therefore, it is possible to model the occurrence rate of the events that exceed the threshold with a Poisson distribution (Elsner et al. 2008, Jagger and Elsner 2006, Malmstadt et al. 2010, Palutikof et al. 1999, Parisi and Lund 2008).

\subsubsection{Hurricane Wind Vulnerability Models}

The most common approach for hurricane wind damage prediction models (i.e. hurricane vulnerability models) is to develop vulnerability curves for structures. A hurricane vulnerability curve presents the most likely mean damage a structure may sustain as a function of mean wind speed. For the development of vulnerability curves, the level of damage of the structure must be defined, e.g. whether looking at damage states (e.g. roof failure) or the percentage of overall damage as a function of wind speed.

Vulnerability curves for structures are often derived from post-disaster damage data (e.g. claims data or damage surveys). This method however requires a large data set. In order to circumvent the need for large post-disaster damage data sets, probabilistic models have been developed to generate vulnerability curves for structures by making assumptions on the structures and environment. The generated curves can be validated with pre-existing data. This method can aid in generating damage curves for structures that have not yet experienced hurricane damage, but it is limited to the engineering judgment of the individual creating the model.

For instance, Leicester et al. (1979) and Leicester (1981) produced one of the first hurricane vulnerability models, creating vulnerability curves for various structures in Australia based on cyclone damage surveys. Sparks et al. (1994) established the relationship between the gradient wind speed and damage ratio, by utilizing insurance data. Mitsuta et al. (1996) utilized insurance claim information from Typhoons Mireille and Flo to establish a relationship between wind speed and damage. Similarly, Bhinderwala (1995) used insurance data from Hurricane Andrew to develop a 
vulnerability function as a percentage of loss as a function of mean wind speed at gradient height. Unfortunately, the direct applicability of these functions is limited, because these models are not equipped to take into account how building codes, materials, etc. have changed over time. Furthermore, these models are limited to application within the location from where the insurance information was obtained to create the vulnerability model (e.g. Mitsuta et al. (1996) in Japan and Bhinderwala (1995) in Southern Florida).

Holmes (1996) used a probability based simulation model to generate the vulnerability curve for a fully engineered building, assuming that the resistance capacity of the building is lognormally distributed; therefore, this model is solely applicable to fully engineered structures not residential construction. Sill and Kozlowski (1997) estimated damage as a function of various hurricane parameters (i.e. gradient wind speed, gust factor), mean house value, and two empirically derived values that determine how the rate of damage increase with wind speed. Because the empirically derived values were based on the experience and judgment of the researchers and not defined explicitly, this study is difficult to replicate.

Huang et al. (2001) developed a hurricane damage model for single family housing units using Southeastern U.S. insurance data from Hurricanes Hugo and Andrew. This particular model predicts the damage ratio which is the total amount paid by the insurer versus the total insured value. To develop the vulnerability model, the damage ratio is related to the recorded average mean surface speed of the hurricane. This model is limited in that it was derived from only two hurricane events; a much larger data set is required to more accurately predict future losses expected due to hurricane events.

Khanduri and Morrow (2003) broke the vulnerability curve into several curves to represent individual building types, translating known vulnerabilities for one region to another region by combining actual data and building inventory information for the region. This model is relatively simple, but as it is based on claims information, it is limited to the type of construction the claims data pertains to. 
Hurricane vulnerability models developed from regressive curve-fitting methods often have the capacity to estimate damage to only one specific type of construction (e.g. residential or timber), whereas the building inventory of most regions is comprised of many different types of construction. Hurricane damage prediction models should, ideally, be capable of accounting for potential changes within building inventory due to, for example, new codes, evolving building practices, and retrofit measures to reduce the vulnerability of existing structures. This has led to the development of component based hurricane vulnerability models, in which the vulnerability of individual components are combined.

Stubbs and Perry (1996) set forth a model based on how different building components perform and their corresponding relative importance. Unanwa and McDonald (2000) developed a similar model that can be applied to an even larger area. Because current models assume that vulnerability is constant over time, Davidson et al. (2003b) provide a way to model how the hurricane wind vulnerability of the building inventory of a region changes, due to ageing, upgrading, construction, new technology and new building codes. Pinelli et al. (2004) set forth a component based hurricane damage prediction model for residential structures, focusing on low-rise residential structures of different types that are common in Florida. The model uses Venn diagrams to illustrate the probability of damage for damage modes and sub-damage modes. Jain (2007) proposed a vulnerability model for wood-frame housing. This is an "over-time" model that focuses on the changes that take place within the building inventory.

The HAZUS-MH Hurricane Model was developed to estimate the damage a hurricane event can cause. The track and wind field of a hurricane is modeled using a hurricane hazard model, which has been validated with historic hurricane data (Lavelle et al. 2003, FEMA 2008). The wind speed is calculated as a function of central pressure, translation speed, and surface roughness. The model classifies the building inventory of a region by the characteristics of the building envelope and frame, and is capable of calculating damage loss to building interior and contents (FEMA 2008). This model is component- 
based, accounting for the resistance capacity of building components, giving this model an advantage over previous curve-fitting models (Pinelli et al. 2004).

HAZUS-MH Hurricane Model is a vital tool in assessing the hurricane risk in a region, but it has its shortcomings as well (Jain et al. 2005) The model is restricted to only certain building types and may not be completely representative of a region. HAZUS-MH Hurricane Model calculates only direct economic loss and not the loss anticipated because of business interruption. Vickery et al. (2006) conducted a validation study on the HAZUS-MH Hurricane Model and found that the model tends to overestimate expected losses from a hurricane event. The HAZUS-MH Hurricane Model assumes that wind speeds are stationary over the years, which may cause an inaccurate estimate of hurricane losses when climate change is possible. The HAZUS-MH Hurricane Model is available for public use.

The Florida Public Hurricane Loss Model (FPHLM) is capable of estimating both annual and scenario-based insurance costs to residential structures in Southern Florida (Pinelli et al. 2004). Like the HAZUS model, the FPHLM is component based; however it is not as complex as the HAZUS model. The model utilizes a component-based Monte Carlo Simulation to estimate the probability of damage to various components of a single family house. The model incorporates 217 combined damage states to estimate the percentage of damage given a specific wind speed for a residential structure. This model is comprehensive, and it utilizes a MCS engine that has compiled data for typical residential construction in Florida (e.g. building type and info on the various components: Openings, Shingles, Sheathing, Connections, and Walls). The MCS engine is used to estimate the percentage of damage for each combined damage state. From the damage estimated for each damage state, the mean overall damage for a structure is estimated (Pinelli et al. 2004). Unfortunately, the MCS engine is not available for public use at this time.

In addition, proprietary damage prediction models have been developed within the private sector. Engineering firms were contracted by insurance companies in the aftermath of Hurricane Andrew. The purpose was to gain a better understanding of the 
vulnerability of structures to damage as the result of hurricane hazards. Unfortunately, not a lot of information on these proprietary models is available in the public domain.

Despite the limitations of regressive curve-fitting models, the Huang model (2001) is implemented into the framework developed herein. The model was chosen for a number of reasons, including the fact that it was developed for single-family residential construction in the Southeastern U.S. which is the focus of the framework. Since the framework developed herein is not currently applied to other types of construction, this model is sufficient in estimating damage risks; however, the framework can be modified for other types of construction by modifying the hurricane vulnerability model. Huang's model is also relatively simple in its application. For the purposes of the analysis performed within this research, Huang's model provides an adequate estimate of hurricane damage as a function of wind speed. As more post-disaster data becomes available, models such as Huang et al. (2001), can be modified to more accurately predict hurricane damage costs.

\subsubsection{Hurricane-Induced Storm Surge Height Models}

Hurricane-induced storm surges are difficult to predict due to the numerous variables that intertwine to create the storm surge. However, throughout the years studies have developed methods in an effort to predict future storm surge heights. The first numerical algorithms of storm surge began emerging in the 1960's (e.g. Harper 1969), and evolved with subsequent research (Wurtele et al. 1971, Flather and Heaps 1975, Mastenbroek et al. 1993). These early models used structured grids that are not capable of accurately portraying complex coastlines. This limitation prompted the development of unstructured grids throughout recent years that are able to more accurately represent complex coastlines.

SPLASH was developed in 1972 to estimate storm surge along the east coast of the U.S. (Jelesnianski 1972, Jelesnianski 1974). It has since been replaced with the Sea, Lake, and

Overland Surge from Hurricanes (SLOSH), which is a computerized model developed by the National Weather Service (NWS). SLOSH estimates surge height based on historical, hypothetical, or predicted hurricanes by utilizing certain parameters (i.e. storm pressure, 
size, forward speed, forecast track, wind speeds, and topographical data) (Jelesnianski et al. 1994). A disadvantage of the SLOSH model is that it implements a structured grid which reduces the accuracy of surge height estimations along complex coastlines.

The Advanced Circulation (ADCIRC) model is a finite element method used to simulate the circulation in coastal waters, and for forecasting storm surge height and propagation (Luettich et al. 1992, Westerink et al. 1992, Westerink et al. 1994). The ADCIRC model uses an unstructured grid for more accurate representations of complex coastlines. For example, Westerink et al. (1994) used the ADCIRC model to estimate hurricane surge along the coast of Mississippi. More recently, Westerink et al. (2008) used the ADCIRC model to develop a storm surge model for the Gulf of Mexico and part of the Western Atlantic Ocean. The particularly high resolution of the model allows for the prediction of surge heights with an absolute error that is less than $0.3 \mathrm{~m}$.

The development of storm surge estimation models has been conducted around the world. After the destructive storm surge in the Bay of Bengal in 1970, extensive research has been developed (e.g. Flierl and Robinson 1972, Das et al. 1974, Dube et al. 1997). For example, Flierl and Robinson (1972) found that the shape of the coastline affected the surge height. In addition, Verboom et al. (1992) used a fine grid model to estimate storm surge heights in the North Sea. Hubbert and McInnes (1999) used an inundation algorithm to create a surge model for Australia.

Irish et al. (2008) suggested that storm size has an impact on surge height, and developed a storm surge model that combines the central pressure deficit, storm size, and storm forward speed to estimate surge height. This model is chosen to be implemented within the framework developed herein mainly because of the relatively simple regressive format of the model; furthermore, this model does not require the use of complex computerized models and the input parameters are readily available, therefore it is convenient for the nature of the developed framework.

\subsubsection{Hurricane-Induced Surge Vulnerability Models}

The National Flood Insurance Act (NFIA) of 1968 led to the creation of the National Flood Insurance Program (NFIP). The NFIP made it possible for homeowners to 
purchase insurance to protect against the potential losses caused by flooding (FEMA 2009). After the implementation of the NFIA, flood damage prediction has become increasingly important. Structural damage due to surge is not solely dependent on water depth, but factors such as duration, possible contamination, and flood velocity also contribute to the level of damage experienced by the structure. Because the lack of consistent data available and difficulty in integrating the various factors together, surge damage is generally related solely to water depth (e.g. Green 2003, Van der Sande et al. 2003). As with hurricane wind vulnerability models, hurricane-induced surge vulnerability models involve the development of vulnerability curves, i.e. depth-damage curves, that plot the level of damage versus the surge height (i.e. water depth). The level of damage is often expressed as a percentage of the replacement cost of the structure or component of structure. Furthermore, depth-damage curves are often provided separately for components (e.g. structural components and contents). It is assumed that componentbased vulnerability curves (i.e. providing separate curves for components) are particularly essential in estimating flood damage as the location of components will significantly impact the level of damage experienced.

Depth-damage curves have been developed by the U.S. Army Corps of America (USACE 1970) and the Flood Insurance Administration (FIA 1970). These damage curves are most often used to estimate potential damage as a result of flooding. Grigg and Helweg (1975) compared the USACE and FIA damage curves and found that the FIA curves are more reasonable. The USACE has since improved the FIA damage curves (USACE 2000, 2003). FEMA (2003) developed the Residential Substantial Damage Estimator (RSDE) to estimate substantial damage (i.e. more than 50\% damage), but this approach is highly biased to the individual assessing damage. Skinner (2006) found that the depth ranges within the RSDE were too broad when the methodology was compared to claims data from Hurricane Katrina.

Since, FEMA (2006) has developed HAZUS-MH Flood Model to estimate flood losses. The model estimates water depth as a function of the flood frequency, discharge, and ground elevation. The HAZUS-MH Flood Model includes over 900 depth-damage curves to estimate loss to various types of construction (Scawthorn et al. 2006). The model 
estimates direct damages, i.e. repair and replacement costs, to infrastructure. Current studies are not available on how accurately the HAZUS-MH Flood Model estimates losses due to hurricane-induced surge height, and this could be attributed to the fact that there is a lack of consistent post-disaster data on losses due to surge height (Taggart 2007). However, as with the HAZUS-MH Hurricane Model, this model has the potential to become a vital tool in assessing the hurricane-induced surge vulnerability of a region.

Studies have been conducted in an effort to identify and quantify relationships between water depth and other factors that contribute to surge damage. Pistrika and Jonkman (2010) implemented the depth-damage curves from the HAZUS-MH Flood Model to investigate the relationship between water depth and flow velocity and damage estimates using information available post-Hurricane Katrina. The study concluded that there is not enough information available to identify a clear one-to-one relationship between water depth and flow velocity. In addition, Kelman (2002) concluded that both water depth and flux speed have a role in flood damage estimates for typical buildings in England.

This framework will implement the flood loss methodology developed by Taggart and van de Lindt (2009). The flood loss methodology estimates flood damage to residential construction as a result of hurricane-induced storm surge, by using an assembly-based vulnerability (ABV) approach developed by Porter (2000). The methodology accounts for flood duration in addition to water height. The ABV approach involves dividing a building into components, and generating loss fragilities for each component based on building details and a Monte Carlo Simulation (MCS) for a range of flood depths and durations. From the loss fragilities, damage costs can be generated for each damaged component of the building. Finally, the total damage cost due to hurricane-induced storm surge is obtained by summing the damage costs of the components. This model is chosen because it is component-based, which is essential in flood depth estimations. Taggart (2007) also provides default input values for the methodology for typical single-family residential construction which further underlines why this methodology was chosen to estimate damage risks due to hurricane-induced storm surge within the framework developed herein. 


\subsubsection{Hurricane Risk for Power Distribution Poles}

The power systems include three main components: the generation, the transmission, and the distribution. The generation plants produce power and are generally large facilities, located in a centralized location. The transmission system transports large, city-sized amounts of power long distances from the generation plant to the distribution substations. Transmission systems are comprised of lines that are approximately $150 \mathrm{ft}$ high, strung between steel, lattice patterned towers that are $850 \mathrm{ft}$ apart. The transmission lines carry power at voltage level greater than $34.5 \mathrm{kV}$ and the network is typically parallel (i.e. there are two or more routes between two points for power to flow). The distribution system transports neighborhood-sized amounts of power several miles to individual customers. The distribution system includes lines that are 30 to $50 \mathrm{ft}$ high, strung on timber poles, located 100 to $200 \mathrm{ft}$ apart. The power carried by the distribution lines is at $34.5 \mathrm{kV}$ or lower voltage levels, and the network is radial (i.e. one route between two points for power to flow) (Saadat 2002). Figure 1.2 shows a generalized schematic of the power system.

The vulnerability of these three components to potential damage due to hurricane winds varies. As generation plants are few in number and are often designed to withstand high wind speeds, damage to the plants is rare. Damage to the transmission system is also rare because these lines and towers are designed to withstand high wind intensities, and they usually have large tree setbacks. The parallel network of the transmission lines also insures against lengthy or costly loss of power supply to communities (Davidson et al. 2003a). The distribution systems (lines and poles), on the other hand, are the most susceptible to damage due to high wind intensities. This is mainly because more distribution lines and poles are exposed to hurricane winds than transmission systems, the distribution poles are not often designed to withstand high wind speeds (Davidson et al. 2003a). 


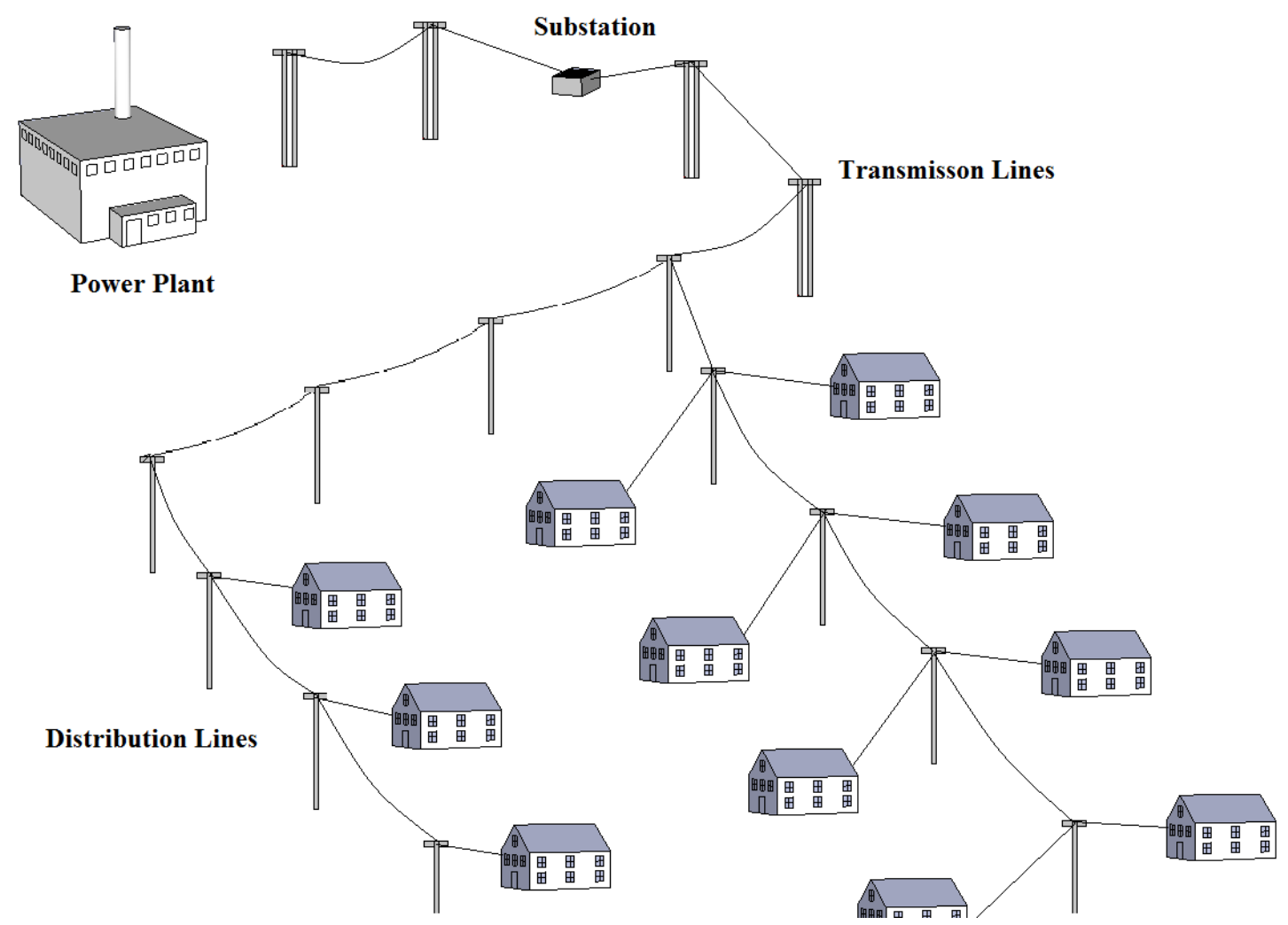

\section{Figure 1.2: Generalized Schematic of Power System}

Current hurricane risk assessments of the power system consider only current climate conditions (Bhuyan and $\mathrm{Li}$ 2006, Li et al. 2006), but studies are suggesting that the hurricane intensity/frequency may change as a result of the warming global climate; therefore, it is becoming increasingly important to explore the effects a changing climate may have on the failure rates of the power system. Existing assessments are also lacking in that they assume that the failure of an individual pole is independent of the failure of other poles within the distribution system (Gustavsen and Rolfseng 2005). As there are a large number of interconnected distribution poles within a distribution system, it is necessary to explore the reliability of the system as a whole.

Furthermore, current hurricane risk assessments do not account for the effects degradation may have on the strength of timber poles. Climatic loads may change as a result of climate change, meanwhile the structural capacity of timber poles deteriorates as a distribution pole ages. Hurricane risk assessments of distribution poles must account 
for both the potential impacts of climate change and the effects degradation may have on distribution pole failure. In the following, an overview of distribution pole design is provided, including the degradation function implement to account for the effects of ageing.

\subsubsection{Design of Timber Distribution Poles}

Historically, distribution poles were designed using the deterministic method prescribed in the NESC standard (NESC 2002). The Allowable Stress Design (ASD) method is based on specific load factors and strength factors that are combined with zonal loading maps (Wolfe et al. 2001). The load and strength factors are determined based on the grade of the construction of the distribution poles.

In order to maintain consistent (or uniform) reliabilities for distribution poles, the Load Resistance Factor Design (LRFD) method was developed by the ASCE (Bhuyan and Li 2006, Dagher 2001), and is now typically used in distribution (utility) pole design (ASCE-111 2006). LRFD is used to assess the performance of a distribution pole at various limit states. Limit states are used to describe a condition at which a structure stops fulfilling its intended purpose. Limit states are categorized as: Strength and Serviceability. Strength limit states define load-carrying capacity and include fracture, buckling, and excessive yielding,. Serviceability limit states define performance and include deflection, cracking, and vibration (McCormac 2008).

The two design methods vary as they are based on different design principles. The following formulation can be used for both methods.

$$
R_{n}>\frac{\gamma}{\varnothing} S_{n}
$$

where $R_{n}$ is the design (nominal) strength of the poles (e.g. design bending moment) and identified using design standards, $\varnothing$ is the strength factor, $S_{n}$ is the design (nominal) load, and $\gamma$ is the load factor.

When designing distribution poles, the design method should be specified and the corresponding load conditions identified (i.e. values for $\varnothing$ and $\gamma$ ). Then the design load $\left(\mathrm{S}_{\mathrm{n}}\right)$ is determined, and consequently the required design strength is determined by using 
Eq. (1.5). By means of the required design strength, the circumference of the pole at ground line can be estimated. Finally, from the circumference the class of the distribution pole can be established, from which the design strength $\left(R_{n}\right)$ can be obtained from design standards (ANSI 2002).

The two methods recommend different values for the strength $(\varnothing)$ and load $(\gamma)$ factors. ASCE-111 (2006) recommends that the strength factor (ø) be 0.79 for a ground line bending moment with a coefficient of variation (COV) of $20 \%$, and that the load factor is $\gamma=1.0$ for wind load. In addition, ASCE requires that the dead load should be adjusted with a factor $\xi=1.1$ when including the P- $\Delta$ effect.

The NESC method also uses strength and load factors for the design of distribution poles (NESC 2002). Both factors are determined based on the grade of construction of the poles and the type of load being designed for. Distribution poles are defined as Grade C construction. The strength factor is $\varnothing=0.85$ when wind load is considered (NESC 2002). There has been much discussion on what the value of the load factor should be. Malmedal and Sen (2003) recommended a load factor of $\gamma=2.2$ for transverse wind loading, while Bingel et al. (2003) suggested a value of $\gamma=1.75$. Furthermore, Brown (2008) stated that distribution poles are typically designed with a load factor of $\gamma=2.2$, but that the design load is reduced by half.

\subsection{Design (Nominal) Load $\left(S_{n}\right)$}

A typical distribution pole system consists of a solid pole, three conductors, one neutral wire, and one communication wire; therefore, the design load of the distribution poles is affected by all these components, and adjusted with an amplification factor to account for the P- $\Delta$ effect:

$$
S_{n}=a m p \cdot \sum_{i=1}^{N} F_{i} h_{i}
$$

where $\mathrm{S}_{\mathrm{n}}$ is the design load (lb-ft), amp is the amplification factor (discussed below), $\mathrm{F}_{\mathrm{i}}$ is the wind force $(\mathrm{N})$ on component $\mathrm{i}$ (Eq. 1.7), and $\mathrm{h}_{\mathrm{i}}(\mathrm{m})$ is the height of component $\mathrm{i}$.

The wind force acting on each component is described with (ASCE-113 2008):

$$
F_{i}=Q k_{i} V^{2} I_{F W} G_{R F} C_{f} A_{i}
$$


where $\mathrm{Q}$ is air density factor, $\mathrm{k}_{\mathrm{i}}$ is terrain exposure coefficient for component $\mathrm{i}, \mathrm{V}$ is the 3-sec gust wind speed, $\mathrm{I}_{\mathrm{FW}}$ is the importance factor, $\mathrm{G}_{\mathrm{RF}}$ is the gust response factor, $\mathrm{C}_{\mathrm{f}}$ is the force coefficient, and $A_{i}$ is the projected wind surface area normal to the direction of wind for component $\mathrm{i}$.

\subsection{Design (Nominal) Resistance $\left(R_{n}\right)$}

The American National Standards Institute (ANSI 2002) categorizes timber distribution poles into different classes based on material. ANSI (2002) assigns each class a permitted bending moment at ground line (i.e. $2.0 \mathrm{~m}$ from the base of the pole) depending on the height and the circumference of the poles. The circumference $\left(\mathrm{C}_{\mathrm{g}}\right)$ of the poles can be estimated from the design load $\left(\mathrm{S}_{\mathrm{n}}\right)$ of the poles and the fiber stress of the species of timber (Brown 2008, Wolfe and Kluge 2005):

$$
C_{g}=\sqrt[3]{\frac{\left(\frac{\gamma}{\phi}\right) S_{n}}{0.000265 \cdot F_{0}}}
$$

where $\gamma$ is the load factor, $\varnothing$ is the strength factor, and $F_{0}$ is the designated fiber stress (ANSI 2002).

\subsection{The P-A Effect}

The P- $\Delta$ effect must be accounted for in both design methods. The P- $\Delta$ effect refers to the deflected unbalance that occurs in the tapered distribution pole (ASCE-111 2006). More specifically, the pole "leans over" to resist the load, and results in additional bending moments that affect the design load $\left(\mathrm{S}_{\mathrm{n}}\right)$ (Bingel et al. 2003). The ASCE-111 (2006) recommends utilizing the Gere-Carter method (1962) to account for the P- $\Delta$ effect in utility pole structures; and for simplicity, the Gere-Carter method will therefore be used to estimate the amplification factor (amp) for both design methods.

The method involves calculating an amplification factor that should be coupled with the design load $\left(S_{n}\right)$ for the distribution pole to account for the deflected unbalance (Eq. 1.6). This method will be utilized in the estimations of the ground line moment for both design methods. 


$$
\begin{aligned}
& a m p=\frac{1}{1-\frac{\xi(D L)}{P_{c r}}} \\
& P_{c r}=P_{c r}{ }^{\prime} \cdot P^{*} \\
& P_{c r}=\frac{\pi^{2}(M O E) I_{t o p}}{(2 \cdot L)^{2}} \\
& P^{*}=\left(\frac{D_{b o t t o m}}{D_{t o p}}\right)^{2}
\end{aligned}
$$

where DL refers to the dead load of the pole system above ground, $\xi$ is the dead load factor, MOE is the modulus of elasticity of the pole, $I_{\text {top }}$ is the moment of inertia at the top, $\mathrm{L}$ is the buckling length of the pole, $\mathrm{D}_{\text {bottom }}$ is the diameter at ground line, and $\mathrm{D}_{\text {top }}$ is the diameter at the top. Note: top in this context refers to at the end of the buckling length.

It must be noted that for the calculations of the amplification factor (amp) for the P- $\Delta$ effect for the ASCE method, the dead loads (DL in Eq. 1.9) are multiplied with a dead load factor $(\xi)$ of 1.1 (ASCE-111 2006); however, for the calculation of the P- $\Delta$ effect for the NESC the dead load is adjusted with a dead load factor $(\xi)$ of 1.0 (NESC 2002).

\subsection{Time-Dependent Deterioration Models}

Wood poles are designed to withstand climatic loads. However, the strength of a pole degrades with age (Stewart and Goodman 1990, Gustavsen and Rolfseng 2000, Haldar and Tucker 2006). Fungal attacks are the main contributor to the deterioration of strength in timber poles, because timber is an organic material (Baraneedaran et al. 2009). The key concern with fungal decay is referred to as in-ground decay, because the pole is in direct contact with the soil creating, in many cases, optimal conditions for fungal attacks (Baraneedaran et al. 2009, Leicester et al. 2003, Wang et al. 2008b).

In order to ensure the integrity of the distribution pole, how the strength of the pole decays with time must be identified. Stewart and Goodman (1990) expressed the degradation of the strength of utility poles in the U.S. as an exponential decay function of the age of the poles. Similarly, Gustavsen and Rolfseng (2000) found that the 
degradation due to the ageing of utility poles in Norway can be represented with an exponential decay function.

To model the degradation of the strength of distribution poles, the resistance within the limit state function (e.g. Eq. 1.1) of the pole must be modified to represent how strength deteriorates over time. The modified resistance (Eq. 1.13) is estimated for a specific age of pole, and used in Eq. (3) to estimate the probability of failure after a specific time frame.

$R(t)=a(t) \cdot M E \cdot R_{n}$

where $\mathrm{R}(\mathrm{t})$ is the resistance after time $\mathrm{t}, \mathrm{a}(\mathrm{t})$ is the degradation function, ME is the model error to take into account that the design values are not equal to the actual values, and $R_{n}$ is the design strength of the pole.

The degradation function $(\mathrm{a}(\mathrm{t}))$ is estimated with Eq. (1.14).

$a(t)=\frac{\pi}{32}(D-d(t))^{3}$

where $\mathrm{D}$ is the initial diameter of the pole and $\mathrm{d}(\mathrm{t})$ is the decay depth after time $\mathrm{t}$.

Leicester et al. (2003) developed an engineering model that estimates the depth of decay in timber poles after a period of time, based on a comprehensive study of timber degradation. Wang et al. (2008b) took the model further and developed a model that estimates the strength of timber poles after a specific time period based on the decay depth. These models were developed based on a survey of timber poles in Australia, but will be used herein as a starting point to estimate the degradation of timber pole strength in the U.S.

Timber poles are typically composed of either solely heartwood or a combination of sapwood and heartwood. For simplicity, it is assumed herein that the timber distribution poles are composed of only untreated heartwood. According to the Australian Standard on Timber Durability (AS 5604-2005), the Durability Class of timber is assigned depending on the expected service life (Morrell 2005), which means that it is a Durability Class 2 according to AS 5604 (2005). The hardness of Southern pine is classified as soft (AS 5604-2005); these characteristics will be assumed to apply to Southern pine timber 
poles in the U.S., as no such data is obtainable in the U.S. When more information becomes available, these assumptions can be modified.

The rate of decay can be estimated:

$r=k_{\text {wood }} k_{\text {climate }} \quad(\mathbf{m m} / \mathbf{y e a r})$

where $\mathrm{k}_{\mathrm{wood}}$ is the wood parameter and $\mathrm{k}_{\mathrm{climate}}$ is the climate parameter. The wood parameter is 0.38 , based on the durability class (i.e. Durability Class 2). The climate parameter is determined based on a hazard map and is assumed to be 1.5 (Climate Class of B) (Wang et al. 2008b).

Wang et al. (2008b) found that decay in timber poles does not commence immediately after a pole has been erected, but there is in fact a period of time where the decay is negligible. This is referred to as the time lag $\left(\mathrm{t}_{\mathrm{lag}}\right)$ :

$t_{\text {lag }}=3 r^{-0.4} \quad$ (year)

Then the time in which decay reaches its threshold can be determined (Wang et al. 2008a):

$t_{d_{0}}=t_{\text {lag }}+\frac{d_{0}}{r} \quad$ (year)

where $\mathrm{d}_{0}$ is the decay threshold. A value of $\mathrm{d}_{0}=5 \mathrm{~mm}$ is recommended when no data is available (Wang et al. 2008a). Once the decay threshold has been reached, the decay depth $(\mathrm{d}(\mathrm{t}))$ is estimated based on the rate of decay.

$d(t)=\left\{\begin{array}{lr}c t^{2} & t \leq t_{d_{0}} \\ \left(t-t_{\text {lag }}\right) r & t>t_{d_{0}}\end{array}\right.$

where $\mathrm{c}=\left(\mathrm{d}_{0} / \mathrm{t}_{\mathrm{d} 0}{ }^{2}\right)$.

\subsubsection{Hurricane Mitigation and Climatic Adaptation}

There is much uncertainty in predicting changes in hurricane hazard patterns; therefore, assessing the potential impacts of climate change on infrastructure involves considerable uncertainty. Due to the potential of increased hurricane activity, the development and assessment of adaptation strategies is warranted. Vital infrastructure needs to be more resilient to climate change. Current building codes do not reflect the non-stationary 
aspects of climate change and may not meet the requirements that may arise due to a changing climate. Therefore, current building codes and standards may need to be reviewed to account for climate change.

Several studies have developed and assessed mitigation strategies for residential construction to reduce hurricane damage costs (Stewart et al. 2003, Pinelli et al. 2009, Kilma et al. 2012). For example, Pinelli et al. (2009) found that all mitigation measures proposed within the study for residential construction could strengthen construction to reduce hurricane damage; however, the cost-effectiveness varies considerably. Unanwa and McDonald (2000) used damage bands to aid in identifying effective mitigation measures. These studies find that certain mitigation measures can reduce hurricane damage costs; however, they do not account for the potential increase in damage costs due to climate change.

Roth (1997) found that if buildings had been up to current standards, approximately $25 \%$ to $40 \%$ of insurance losses from Hurricane Andrew could have been avoided. Stewart et al. (2003) determined that if buildings are retrofitted to comply with ASCE-7 1988, the hurricane vulnerability can be significantly decreased. The Multi-hazard Mitigation Council (2005) estimates that for every dollar spent on mitigation to reduce the risk due to natural hazards translates to four dollars saved. This emphasizes the relevance of exploring mitigation measures to reduce damage costs to residential construction anticipated as the result of hurricane hazards, and it can be assumed that similar conclusions can be made regarding the importance of strategies to mitigate losses to the other forms of infrastructure.

Limited research has been conducted on the climatic adaptation of residential construction in the U.S. However, some preliminary studies have been conducted involving adaptation strategies for transportation and other public infrastructure (CCSP 2008, Larsen et al. 2007). The CCSP (2008) finds that adaptation measures could reduce the vulnerability of transportation systems in the U.S. to the increased hurricane activity that may be expected due to the changing global climate. However, the study does not 
recommend specific adaptation measures, stating that more research is needed in the field.

\subsubsection{Hurricane Risks and Social Vulnerability}

The social dynamics of a community or region have an impact on the hurricane vulnerability of that region. There are many aspects and factors that contribute to the social makeup of a community, and though they are difficult to quantify, there is some consensus as to what factors influence social vulnerability (Cutter et al. 2003).

Agencies, worldwide, have tried to quantify the vulnerability of various hurricane-prone regions (NRC 2000, UNDP 2000, World Bank 2001). Cutter et al. (2003) created the Social Vulnerability Index (SoVI) by using demographic information for the United States. The SoVI involves quantifying the dominant social factors that have the greatest impact on the vulnerability of the region to a natural hazard. Finally, the "place vulnerability" of each county was found by combining the dominant social factors with the probability of a natural hazard and regional exposure (i.e. the biophysical vulnerability). Davidson and Lambert (2001) established the Hurricane Disaster Risk Index (HDRI). The HDRI was calculated by identifying certain characteristics within a region, such as probability of a hurricane hazard, the demographic makeup of the individuals residing within the region (e.g. ethnicity, gender, age), and the exposure of construction within the region.

Existing metrics of social vulnerability consider only current climate conditions (Davidson and Lambert 2001), but because studies are suggesting that the hurricane intensity/frequency may change as a result of the warming global climate, it is imperative to evaluate the potential effects of climate change on social vulnerability. In order to account for the affects of climate change, existing metrics will be utilized and modified to create an index of vulnerability that accounts for the non-stationary aspects of hurricanes, i.e. hurricane intensity and hurricane-induced surge.

The Coastal Community Social Vulnerability Index (CCSVI) differs from existing metrics (e.g. Cutter et al. 2003, Davidson and Lambert 2001). The hurricane intensity is measured in wind speed in order to utilize stochastic wind field models (i.e. the Weibull 
distribution) to effectively represent the time-dependent aspects of hurricane wind speed under the impacts of climate change. The hurricane-induced surge is measured as surge height because the height of the surge is directly related to the vulnerability of a region. Surge models will be utilized as a starting point to represent the variation in surge height under various parameters of climate change. The social aspects of the CCSVI are accounted for by conducting a principal components analysis (PCA). The PCA identifies the social factors that have the most influence in a specific region, resulting in an index that is based on site-specific social parameters which is more representative of a region than an index which is composed of the same social parameters despite location.

\subsubsection{Critical Appraisal}

In the following, a brief summary of the critical appraisal of the state-of-the-art is provided. A more detailed appraisal is found within the literature review.

\subsubsection{Hurricane Risk for Residential Construction}

- Comprehensive hurricane risk assessments for residential construction should combine the risks of various parameters of hurricanes, such as hurricane wind speed, hurricane-induced storm surge, and hurricane frequency

- Hurricane risk assessments should be capable of accounting for the potential effects climate change may have on hurricane damage risks

\subsubsection{Hurricane Risk for Power Distribution Poles}

- Hurricane risk assessments for distribution poles should consider the potential effects of climate change

- Risk assessment models for timber distribution poles should also account for the effects degradation may have on pole strength

\subsubsection{Hurricane Mitigation and Climatic Adaptation}

- If hurricane hazard patterns may change as a result of climate change, effective mitigation/adaptation measures should be developed

- The cost-effectiveness of these measures should also be evaluated 
- Climatic adaptation should be developed for various forms of infrastructure

\subsubsection{Hurricane Risks and Social Vulnerability}

- Social vulnerability metrics should account for non-stationary aspects of hurricanes

- Social vulnerability metrics should implement methodologies (such as a Principle Components Analysis) to ensure that the social components of the metrics are site-specific

\subsection{Research Objectives}

The overall objective of this research is to propose a framework for a comprehensive hurricane risk assessment to account for the potential impact of climate change. As stated above, studies have shown that increased hurricane activity is possible as a result of the changing global climate, therefore hurricane risk assessment models must be able to account for non-stationary parameters of hurricanes (i.e. wind speed and surge height). Hurricane damage is caused by hurricane intensity, hurricane frequency, and hurricaneinduced storm surge. Therefore, this research develops a hurricane risk assessment framework that accounts for the potential changes in hurricane hazard patterns that may occur as a result of climate change. Furthermore, the proposed risk assessment framework includes a combination of hurricane intensity, hurricane frequency, and hurricane-induced storm surge in damage cost estimations.

Another step in a comprehensive hurricane risk assessment is to adapt the proposed framework to other vital infrastructure, such as the power systems. The power system often experiences failure because of extreme weather events (such as hurricanes) that cause loads that exceed the criteria of the power system design (Peters et al. 2007). With the potential increases in the intensity and frequency of hurricanes, it can be expected that the system may experience more failure; thus, resulting in an increased repair and/or replacement cost. This research has applied the proposed hurricane risk assessment framework to include power distribution poles, in an effort to produce a comprehensive hurricane risk assessment. Furthermore, this research will explore the cost-effectiveness 
of various adaptation/mitigation strategies for residential construction and distribution poles.

Finally, a comprehensive hurricane risk assessment may include the social vulnerability of a region to hurricane hazards. As hurricane intensity and/or frequency may change as a result of climate change, it can be anticipated that the social vulnerability of a region may change as well. Therefore, in an attempt to quantify social vulnerability, this research has developed an index of vulnerability. The Coastal Community Social Vulnerability Index (CCSVI) is developed with the aid of existing metrics and is capable of accounting for the non-stationary aspects of hurricanes, i.e. hurricane intensity and hurricane-induced surge.

\subsection{Overview}

The dissertation is structured as follows:

Chapter 2 presents the published journal paper entitled "A Probabilistic-based Framework for Impact and Adaptation Assessment of Climate Change on Hurricane Damage Risks and Costs". This paper presents a probabilistic-based framework to assess the potential hurricane risks to residential construction under various wind speed change scenarios due to potential climate change. The framework includes probabilistic models of hurricane intensity and conditional damage state probabilities (vulnerability model) for typical residential construction in the U.S., and an assessment of the cost-effectiveness of various climate change adaptation strategies. A case study of Miami-Dade County, Florida is presented to illustrate the framework under various scenarios of change in maximum annual wind speed over 50 years. This study shows that climate change may have a substantial impact on the damage and loss estimation in coastal areas, and that certain adaptation strategies can cost effectively decrease the damage, even if the wind speed does not change.

Chapter 3 presents the submitted journal paper entitled "Regional Loss Estimation Due to Hurricane Wind and Hurricane-Induced Surge Considering Climate Variability". This paper presents a framework to assess the potential hurricane damage risks to residential construction. The framework includes a hurricane wind field model, hurricane-induced 
surge height model, and hurricane vulnerability models. Three case study locations (Miami-Dade County, Florida, New Hanover County, North Carolina, Galveston County, Texas) are presented for two types of analyses: Annual Regional Loss Estimation and Event-Based Regional Loss Estimation. Through both analyses it was found that climate change may have a significant impact on regional hurricane damage losses.

Chapter 4 presents the published journal paper entitled "Hurricane Risk Assessment of Power Distribution Poles Considering Impacts of a Changing Climate". This paper proposes a probabilistic framework to evaluate the vulnerability of power distribution poles to hurricanes under the potential impact of a changing climate. Two methods for the design of distribution poles in the U.S., the National Electric Safety Code (NESC) method and the American Society of Civil Engineers (ASCE) method, are considered to investigate the difference of the vulnerability of a distribution pole subjected to hurricane hazard. The framework includes a reliability analysis of the designed power distribution poles using fragility analysis, the effects of degradation of timber poles, probabilistic wind models, and an assessment of the potential impacts of climate change on the annual failure probability of power distribution poles. This paper finds that climate change may have a significant effect on the structural failure probabilities of distribution poles.

Chapter 5 presents the accepted journal paper entitled "Risk-Based Economic Assessment of Mitigation Strategies For Power Distribution Poles Subjected to Hurricanes". This paper presents a risk-based framework to assess the hurricane damage risks to distribution poles and investigates the risks, costs, and benefit of different mitigation strategies. This paper describes the reliability analysis of typical timber distribution poles and probabilistic wind models to determine failure probabilities for specific locations. Furthermore, in order to more accurately portray the behavior of distribution poles, the proposed framework includes the degradation and service-proven reliability of timber distribution poles. Four mitigation strategies are developed, and the cost-effectiveness of each strategy is evaluated. In order to assess the cost-effectiveness, a life-cycle cost analysis is conducted for each mitigation strategy. This paper finds that appropriate mitigation strategies can reduce replacement costs of distribution poles associated with hurricane wind by 2060 . 
Chapter 6 presents the published journal paper entitled "Social Vulnerability Index for Coastal Communities at Risk to Hurricane Hazard and a Changing Climate". This paper presents the development of the Coastal Community Social Vulnerability Index (CCSVI) in order to quantify the social vulnerability of hurricane-prone areas under various scenarios of climate change. The CCSVI combines the intensity of hurricanes and hurricane-induced surge to create a comprehensive index that considers the effects of a changing climate. The main contributing factors of social vulnerability (such as race, age, gender, socioeconomic status) in hurricane-prone areas are identified through a principal components analysis. The impact of social characteristics on the potential hurricane damage under various scenarios of climate change is evaluated using MiamiDade County, Florida as a case study location. This study finds that climate change may have a significant impact on the CCSVI.

Chapter 7 outlines proposed avenues of future work for the research developed in this dissertation. This chapter does not propose an exhaustive list of all potential future applications of the work developed herein, rather outlines the directions the author believes are the most promising for prospective research.

The main conclusions of this research are summarized in Chapter 8.

Appendices I through III include supplements to various chapters of work. This work has not been published, but is included for the interested reader.

Appendix I includes a supplement to Chapter 2, where the annual damage risks and costs due to hurricane wind are estimated for New Hanover County, North Carolina and Galveston County, Texas, in addition to Miami-Dade County, Florida. In addition, the appendix includes an evaluation of the cost-effectiveness of various adaptation strategies for all three counties. The regional assessment within this appendix is a useful tool in evaluating and comparing the effects climate change may have on hurricane damage costs.

Appendix II consists of a supplement to Chapter 5. Chapter 5 included the evaluation of various mitigation measures that may aid in reducing hurricane damage costs to timber distribution poles. The evaluation was conducted with a Life-Cycle Cost (LCC) analysis 
that assesses the cost-effectiveness of mitigation on an annual basis. In addition to the LCC, a scenario-based analysis was conducted to evaluate mitigation on a scenario-type basis (e.g. damage estimates due to a specific wind speed), which can be found in this appendix. Assessments of this nature can be a useful tool for decision-makers in conveying mitigation decisions to constituents.

Appendix III includes a supplement to Chapter 6. Within this appendix, a preliminary analysis on whether or not direct losses can be directly connected to social dynamics was conducted. A regression analysis was implemented to establish the potential connection. Identifying this potential relationship (if present) could aid in the reduction of damage costs to residential construction through the implication of social mitigation measures.

\subsection{References}

American Society of Civil Engineers (ASCE) (1996) Minimum design loads for buildings and other structures. ASCE 97-5, New York.

American Society of Civil Engineers (ASCE-111) (2006) Reliability-Based Design of Utility Pole Structures (No. 111). ASCE manuals and reports on engineering practices.

American Society of Civil Engineers (ASCE-113) (2008) Substation structure design guide (No. 113). ASCE manuals and reports on engineering practices.

ANSI (2002) Wood Poles Specifications and Dimensions, 05.1.

AS 5604 (2005) Timber-Natural Durability Ratings, Australia. Standards Australia: 2005.

Baraneedaran, S., Gad, E.F., Flatley, I., Kamiran, A., and Wilson, J.L. (2009) Review of In-service Assessment of Timber Poles. Proceedings of the Australian Earthquake Engineering Society, Newcastle 2009.

Batts, M., Cordes, M., Russell, C., Shaver, J., and Simiu, E. (1980) Hurricane wind speeds in the United States. National Bureau of Standards Report no. BSS-124, U.S. Department of Commerce, Washington, D.C. 
Bender, M. A., Knuston, T.R., Tuleya, R.E., Sirutis, J.J., Vecchi, G.A., Garner, S.T., and Held, I.M. (2010) Modeled impact of anthropogenic warming of the frequency of intense Atlantic hurricanes, Science, 327, 454-458.

Bhunderwala, S. (1995) "Insurance loss of single family dwellings damages in Hurricane Andrew", M.S., Clemson University.

Bhuyan, G., and Li, H. (2006) Achieved Reliability of the North American Design Approaches for Transmission Overhead Structures. Probabilistic Methods Applied to Power Systems 11-15 June 2006, 1-5.

Billinton R., and Allan, R. N. (1996) Reliability Evaluation of Power Systems, 2nd Edition, Plenum Press, New York, 1996.

Bingel, N., Dagher, H., Randle, R., Wolfe, R., Slavin, L., Voda, M., and Wong, J. (2003) Panel session: structural reliability-based design of utility poles and the national electrical safety code. Transmission and Distribution Conference and Exposition, Sept.2003 IEEE PES, 3, 1088- 1093

Brown, R.E. (2008) Electric Power Distribution Reliability. CRC Press: Boca Raton, FL. Climate Change Science Program (CCSP) (2008) Impacts of Climate Change and Variability on Transportation Systems and Infrastructure: Gulf Coast Study, Phase I. A Report by the U.S. Climate Change Science Program and the Subcommittee on Global Change Research. Savonis, M. J., V.R. Burkett, and J.R. Potter, Eds. Department of Transportation, Washington, DC, USA.

Crosset, K.M., Culliton, T. J., Wiley, P. C., and Goodspeed, T. R. (2004) Population Trends along the Coastal United States: 1980-2008. National Oceanic and Atmospheric Administration: Silver Spring, MD.

Cutter, S.L., Bornuff, B.J., and Shirley, W.L. (2003) Social Vulnerability to Environmental Hazards. Social Science Quarterly, 84, 242-261.

Dagher, H.J. (2001) Reliability of poles in NESC grade C construction, Rural Electric Power Conference, 2001. 
Dagher, H.J., Lu, Q., and Peyrot, A.H. (1998) Reliability of Transmission Structures Including Nonlinear Effects, Journal of Structural Engineering, 124, 966-973.

Das, P.K., Sinha, M.C., and Balasubramanyam, V. (1974) Storm surges in the Bay of Bengal, Quarterly Journal of the Royal Meteorological Society, 100, 437-449.

Davidson, R. A., Liu, H. I., Sarpong, K., Sparks, P., and Rosowsky, D. V. (2003a) Electric power distribution system performance in Carolina hurricanes, Natural Hazards Review, 4, 36-45.

Davidson, R., and Lambert, K. (2001) Comparing the Hurricane Disaster Risk of U.S. Coastal Counties, Natural Hazards Review, 2, 132-142.

Davidson, R., Zhao, H., Jain, V.K. (2003b) Quantitative Model to Forecast Changes in Hurricane Vulnerability of Regional Building Inventory, Journal of Infrastructure Systems, 9, 55-64.

Dube, A. T., Rao, A.D., Sinha, P.C., Murty, T.S., and Bahulayan, N. (1997) Storm surge in the Bay of Bengal and Arabian Sea: The problem and its prediction, Mausam, 48, 283290.

Ellingwood, B.R., and Kinali, K. (2008) Quantifying and communicating uncertainty in seismic risk assessment, Structural Safety, 31, 179-187.

Elsner, J.B. (2006) Evidence in support of the climate change-Atlantic hurricane hypothesis, Geophysical Research Letters, 33.

Elsner, J.B., Kossin, J.P., and Jagger, T.H. (2008). The increasing intensity of the strongest tropical cyclones, Nature, 455, 92-95.

Emanuel, K. (2005) Increasing destructiveness of tropical cyclones over the past 30 years, Nature, 436, 686-688.

Emanuel, K., Ravela, S., Vivant, E., and Risi, C. (2006) A statistical-deterministic approach to hurricane risk assessment, Bull. Am. Meteorol. Soc., 19, 299-314.

FEMA (1999). HAZUS-MH Hurricane Model. [cited 2009 April 7]; Available from: http://www.fema.gov/plan/prevent/hazus/hz wind.shtm. 
FEMA (2003) RSDE field workbook: preparing structure inventories using Residential Substantial Damage Estimator Software Program RSDE 2.0. Federal Emergency Management Agency: Washington, D.C.

FEMA (2006) Multi-hazard loss estimation methodology-flood model. Federal Emergency Management Agency: Washington, D.C.

FEMA (2009) Midwest Floods of 2008 in Iowa and Wisconsin, Federal Emergency Management Agency (FEMA).

Flather, R., and Heaps, N.S. (1975) Tidal computations for Morecambe Bay, Geophysical Journal of the Royal Astronomical Society, 42, 489-517.

Flierl, G. R., and Robinson, A.R. (1972) Deadly Surges in the Bay of Bengal: Dynamics and Storm-tide Tables, Nature, 239, 213-215.

Georgiou, P.N. (1985) Design wind speeds in tropical cyclone-prone regions. $\mathrm{PhD}$ dissertation, University of Western Ontario.

Georgiou, P.N., Davenport, A.G., and Vickery, B.J. (1983) Design Wind Speeds in Regions Dominated by Tropical Cyclones, Journal of Engineering and Industrial Aerodynamics, 13, 139-152.

Gere, J., and Carter, W. (1962) Critical Buckling loads for tapered columns, Journal of Structural Engineering, 88, 1-11.

Goldenberg, S. B., Landsea, C. W., Mestas-Nunez, A. M., and Gray, W. M. (2001) The recent increase in Atlantic hurricane activity: causes and implications, Science, 293, 474479.

Government Accountability Office (GAO) (2007) Climate Change: Financial Risks to Federal and Private Insurers in Coming Decades are Potentially Significant, Unites States Accountability Office: Washington, D.C.

Green, C. (2003) Handbook of Water Economics: Principles and Practice, Wiley: Chicester. 
Grigg, N.S, and Helweg, O.J. (1975) State-of-the-Art of Estimating Flood Damage in Urban Areas, Water Resources Bulletin, 11, 379-390.

Gustavsen, B., and Rolfseng, L. (2000) Simulation of wood pole replacement rate and its application to life cycle economy studies. IEEE Transactions on Power Delivery, 15, 300-306.

Gustavsen, B., and Rolfseng, L. (2005) Asset management of wood pole utility structures. International Journal of Electrical Power \& Energy Systems, 27, 641-646.

Haldar, A., and Tucker, K. (2006)Condition Based Management of Wood Pole Transmission Lines Using Structural Reliability Analysis, ASCE Conf. Proc. 218, 28, 304-316.

Holmes, J. (1996) Vulnerability curves for buildings in tropical cyclone regions, Probabilistic Mechanics and Structural Reliability: Proceedings of the 7th Specialty Conference, $78-81$.

Huang, Z., Rosowsky, D. V., and Sparks, P. R. (2001) Long-term hurricane risk assessment and expected damage to residential structures. Reliability engineering \& system safety, 74, 239-249.

Hubbert, G.D., and McInnes, K. (1999) A Storm Surge Inundation Model for Coastal Planning and Impact Studies. Journal of Coastal Research, 15, 168-185.

Intergovernmental Panel on Climate Change (IPCC) (2007) Climate Change 2007: The Physical Science Basis. Contribution of Working Group I to the Fourth Assessment Report of the Intergovernmental Panel on Climate Change. Solomon, S., Qin, D., Manning, M., Chen, Z., Marquis, M., Averyt, K.B., Tignor, M., and Miller, H.L. (eds.). Cambridge: Cambridge University Press.

Irish, J.L., Resio, D.T., and Ratcliff, J.J. (2008) The Influence of Storm Size on Hurricane Surge. Journal of Physical Oceanography, 38, 2003-2013.

Jagger, T., and J. Elsner, (2006) Climatology models for extreme hurricane winds in the United States. J. Climate, 19, 3220-3236. 
Jain, V.K., and Davidson, R. (2007) Forecasting Changes in the Hurricane Wind Vulnerability of Regional Inventory of Wood-Frame Houses. Journal of Infrastructure Systems, 13, 31-42.

Jain, V.K., Davidson,R., and Rosowsky, D. (2005) Modeling changes in hurricane risk over time, Natural Hazards Review, 6, 88-96.

Jelesnianski, C. P., Chen, J., and Shaffter, W.A. (1994) SLOSH: Sea, Lake, and Overland Surges from Hurricanes, NOAA Technical Report NWS, 48, U.S. Department of Commerce, Sliver Springs, MD.

Jelesnianski, C.P. (1972) SPLASH: Special Program to List Amplitudes of Surges from Hurricanes I: Landfall storms. NOAA Technical Memo NWS-TDL-46, U.S. Department of Commerce, Sliver Springs, MD.

Jelesnianski, C.P. (1974) SPLASH: Special Program to List Amplitudes of Surges from Hurricanes I: Landfall General track and variant storm conditions. NOAA Technical Memo NWS-TDL-52, U.S. Department of Commerce, Sliver Springs, MD.

Johnson, B. (2005) After the Disaster: Utility Restoration Cost Recovery. Edison Electricity Institute, Washington D.C.

Kelman I. (2002). Physical Flood Vulnerability of Residential Properties in Coastal, Eastern England. Thèse, Université de Cambridge.

Khanduri, A.C., and Morrow, G.C. (2003) Vulnerability of buildings to windstorms and insurance loss estimation, Journal of wind engineering and industrial aerodynamics, 91, 455-467.

Klima, K., Lin, N., Emanuel, K., Morgan, M.G., and Grossmann, I. (2012) Hurricane Modification and adaptation in Miami-Dade County, Florida, Environ. sci. Technol, 46, 636-642.

Klotzbach, P.J. (2006) Trends in global tropical cyclone activity over the past twenty years (1986-2005), Geophys. Res. Letters, 33. 
Knuston, T.R., McBride, J.L., Chan, J., Emanuel, K., Holland, G., Landsea, C., Held, I., Kossin, J.P., Srivastava, A.K., and Sugi, M. (2010) Tropical Cyclones and Climate Change, Nature Geoscience, 3, 157-163.

Knutson, T. R., Sirutis, J. J., Garner, S. T., Vecchi, G. A., and Held, I. (2008) Simulated reduction in Atlantic hurricane frequency under twenty-first-century warming conditions, Nature Geosci., 1, 359-364.

Knutson, T.R., and Tuleya, R.E. (1999) Increased hurricane intensities with CO2 induced warming as simulated using the GFDL hurricane prediction system, Climate Dynamics, $15,503-519$.

Knutson, T.R., Tuleya, R.E., and Kurihara, Y. (1998) Simulated Increase of Hurricane Intensities in a CO2 Warmed Climate, Science, 279, 1018-1021.

Landsea, C.W. (2007) Counting Atlantic tropical cyclones back to 1990. EOS Trans. Am. Geophysical Union, 88, 197-208.

Landsea, C.W., Harper, B.A., Hoarau, K., and Knaff, .JA. (2006) Can we detect trends in extreme tropical cyclones? Science, 313, 452-454.

Larsen, P., Goldsmith, S., Smith, O., Wilson, M., Strzepek, K., Chinowsky, P., and Saylor, B. (2007) Estimating Future Costs for Alaska Public Infrastructure at Risk from Climate Change. Institute of Social and Economic Research, University of Alaska Anchorage..

Lavelle, F., Vickery, P. J., Schauer, B., Twisdale, L. A., and Laatsch, E. (2003) HAZUSMH Hurricane Model, Proc., $11^{\text {th }} I C W E$, Texas Tech, Lubbock, TX.

Lee, K., and Rosowsky, D. (2007) Synthetic hurricane wind speed records: development of a database for hazard analyses and risk studies, Nat. Hazard. Rev., 8, 23-34.

Leicester, R.H. (1981) A risk model for cyclone damage to dwellings, in Proc. 3rd Int. Conf. on Structural Safety and Reliability, 761-771. 
Leicester, R.H., Bubb, C.T.J., Dorman, C., and Beresford, F.D. (1979) An assessment of potential cyclone damage to Dwellings in Australia, in Proc. 5th Int. Conf. on Wind Engineering, J.E. Cermak, Editor. Pergamon: New York, United States, 23-36.

Leicester, R.H., Wang, C.H., Minh, M.N., Thornton, J.D., Johnson, G.C., and Gardner, D. (2003) An engineering model for the decay of timber in ground contact. IRG/WP/03, 34th annual meeting, Brisbane, Australia, 19-23 May 2003.

Li, H., Zhang, J. and Bhuyan, G. (2006) Reliability Assessment of Electrical Overhead Distribution Wood Poles, Probability Methods Applied to Power Systems, International Conference, 11-15 June, 2006, Stockholm.

Li, Y., and Ellingwood, B.R. (2006) Hurricane damage to residential construction in the US: Importance of uncertainty modeling in risk assessment. Engineering Structures, 28, 1009-1017.

Luettich Jr., R., Westerink, J., and Scheffner, N. (1992) ADCIRC: an advanced threedimensional circulation model for shelves coasts and estuaries, Report 1: Theory and methodology of ADCIRC-2DDI and ADCIRC-3DL, Dredging Research Program Tech. Rep. DRP-92-6, U.S. Army Engineers Waterways Experiment Station, Vicksburg, MS.

Malmedal, K., and Sen, P.K. (2003) Structural loading calculations of wood transmission structures. Rural Electric Power Conference, May 2003, 4-6.

Malmstadt, J.C., Elsner, J.B., and Jagger, T.J., (2010). Risk of Strong Hurricane Winds to Florida Cities. J. Appl. Meteor. Climatol., 49, 2121-2132.

Mann, M., and Emanuel, K. (2006) Atlantic hurricane trends linked to climate change, Eos 87, 233-241.

Mastenbroek, G., Burger, and Jansson, P. (1993) The dynamical coupling of wave model and a storm surge model through the atmospheric boundary layer, Journal of Physical Oceanography, 23, 1856-1866.

McCormac, J.C. (2008) Structural Steel Design. Pearson: New Jersey. 
Mitsuta, Y., Fujii, T., and Nagashima, I. (1996) A Predicting method of typhoon wind damages, Probabilistic Mechanics and Structural Reliability: Proceedings of the 7th Specialty Conference, 970-973.

Morrell, J. (2005) Estimated Service Life of Wood Poles. Technical Bulletin for the NAWPC (North American Wood Pole Council).

Multi-hazard Mitigation Council (2005) Natural hazard mitigation saves: An independent study to assess the future savings from mitigation activities. National Institute of Building Sciences, Washington, D. C.

National Electrical Safety Code (NESC) (2002) IEEE Standard. Piscataway, New Jersey. National Research Council (NRC) (2000). Ecological Indicators for the Nation. National Academy Press: Washington D.C.

National Weather Service (NWS) (2009) Flood Losses: Compilation of Flood Loss Statistics. [cited 2010 August 04]; Available from: http://www.weather.gov/oh/hic/flood_stats/Flood_loss_time_series.shtml

Neumann, C.J. (1991) The National Hurricane Center Risk Analysis Program (HURISK), NOAA Technical Memo, HWS-NHC-22, U.S. Department of Commerce, Washington D.C.

New York City Panel on Climate Change (2009) Climate Change Adaptation in New York City: Building a Risk Management Response. New York Academy of Sceinces, 1196, May 2010.

P.J. Vickery, P.F. Skerlj, J. Lin, L.A. Twisdale Jr., M.A. Young, F.M. Lavelle (2006) HAZUS-MH Hurricane Model Methodology. II: Damage and Loss Estimation, Natural Hazards Review, 7, 94-103.

Palutikof, J.P., Brabson, B.B., Lister, D.H., and Adcock, S.T. (1999) A reveiw of methods to calculate extreme winds, Meteorological Applications, 6, 119-132.

Parisi, F., and R. Lund, (2008): Return periods of continental U.S. hurricanes. J. Climate, $21,403-410$. 
Pielke, R.A.J., and Pielke, R.A.S. (1997) Hurricanes: Their nature and impacts on society. Wiley, U.K.: Chichester.

Pielke, R.A.J., Gratz, J., Landsea, C.W., Collins, D., Saunders, M.A., and Musulin, R. (2008) Normalized Hurricane Damage in the United States: 1900--2005. Natural Hazards Review, 9, 29-42.

Pinelli, J.P., Simiu, E., Gurley, K., Subramanian, C., Zhang, L., Cope, A., Filliben, J.J., and Hamid, S. (2004) Hurricane Damage Prediction Model for Residential Structures, Journal of Structural Engineering, 130, 1685-1691.

Pinelli, J.P., Torkian, B.B., Gurley, K., Subramanian, C., and Hamid, S. (2009) Cost Effectiveness of Hurricane Mitigation Measures for Residential Buildings, The 11th Americas Conference on Wind Engineering (ACWE), San Juan, Puerto Rico.

Pistrika A. and Jonkman S. (2010). Damage to residential buildings due to flooding of New Orleans after hurricane Katrina. Nat Hazards (2010) 54:413-434.

Porter, K.A. (2000) Assembly-based vulnerability of buildings and its uses in seismic performance evaluation and risk-management decision-making, Doctoral disserta-tion, Stanford University, Stanford CA.

Powell, M., Soukup, G., Cocke, S., Gulati, S., Morisseau-Leroy, N., Hamid, S., Dorst, N., and Axe, L. (2005) State of Florida hurricane loss projection model: atmospheric science component, J. Wind Eng. Ind. Aerodyn., 93, 651-674.

Reed, D.A. (2008) Electric utility distribution analysis for extreme winds, Journal of Wind Engineering and Industrial Aerodynamics, 96, 123-140.

Reed, D.A., Powell, M.D., and Westerman, J.M. (2010) Energy Infrastructure Damage Analysis for Hurricane Rita, Natural Hazards Review, 11, 102-109.

Roth, R.J. (1997) Insurable risks, regulation, and the changing insurance environment, in Hurricanes: Climates and socioeconomic impacts, H.F. Diaz and R.S. Pulwarthy, Editors. Springer: Berlin, Germany, 261-272. 
Rumpf, J., Weindl, H., Hoppe, P., Rauch, E., and Schmidt, V. (2007) Stochastic modeling of tropical cyclone tracks, Math. Meth. Oper. Res., 66, 475-490.

Russell, L.R. (1968) "Probability distribution for Texas Gulf Coast hurricane efforts of engineering interest", Ph.D. thesis, Stanford University.

Saadat, H. (2002) Power System Analysis. McGraw Hill: New York City

Sanders, C. H., and Phillipson, M. C. (2003). UK adaptation strategy and technical measures: the impacts of climate change on buildings, Building Research \& Information. Building Research \& Information, 31, 210-221.

Scavia, D., Field, J.C., Boesch, D.F., Buddemeier, R., Burkett, V., Canyan, D., Fogarty, M., Harwell, M.A., Howarth, R.W., Mason, C., Reed, D.J., Royer, T.C., Sallenger, A.H. and Titus, J.G. (2002) Climate change impacts on U.S. coastal and marine ecosystems, Estuaries, 25, 149-164.

Scawthorn, C., Blais, N., Seligson, H., Tate, E., Mifflin, E., Thomas, W., Murphy, J., and Jones, J. (2006) HAZUS-MH Flood Loss Estimation Methodology 1: Overview and Flood Hazard Consideration, Natural Hazards Review, 60-71.

Sill, B.L., and Kozlowski, R.T. (1997) Analysis of storm damage factors for low-rise structures, Journal of Performance of Constructed Facilities, 11, 168-176.

Skinner, R.L. (2006) Review of Hurricane Katrina Activities, Department of Homeland Security: Washington, D.C.

Sparks, P.R., Schiff, S.D., and Reinhold, T.A. (1994) Wind damage to envelopes of houses and consequent insurance losses, Journal of wind engineering and industrial aerodynamics, 53, 145-155.

Stainforth, D. A. (2005) Uncertainty in predictions of the climate response to rising levels of greenhouse gases, Nature, 433, 403-406.

Stewart, A.H. and Goodman, J.R. (1990) Life cycle economics of wood pole utility structures, Power Delivery, IEEE Transactions, 5,1040-1046. 
Stewart, M. G. and Wang, X. (2011b) Risk Assessment of Climate Adaptation Strategies for Extreme Wind Events in Queensland, CSIRO Climate Adaptation Flagship, Canberra, May 2011b [cited 2012 February 30]; Available from: http://www.csiro.au/resources/ /media/CSIROau/Flagships/Climate\%20Adaptation/Extre meWind_CAF_pdf\%20Standard.pdf

Stewart, M.G. and Wang, X. (2011a), Risk assessment and economic viability of climate adaptation measures for Australian housing subject to extreme wind events, MODSIM, $19^{\text {th }}$ International Congress on Modelling and Simulation, Perth, 2852-2858.

Stewart, M.G., and Li, Y. (2010) Methodologies for Economic Impact and Adaptation Assessment of Cyclone Damage Risks Due to Climate Change, Australian Journal of Structural Engineering, 10, 121-136.

Stewart, M.G., Rosowsky, D.V., and Huang, Z. (2003) Hurricane Risks and Economic Viability of Strengthened Construction, Natural hazards review, 4, 12-19.

Stubbs, N., and Perry, D.C. (1996) A damage simulation model for buildings and contents in a hurricane environment, in Building an International Community of Structural Engineers- Proc. Structures Congress S.K. Ghosh and J. Mohammadi, Editors., ASCE: New York, United States, 989-996.

Taggart, M. and van de Lindt, J.W. (2009) Performance-Based Design of Residential Wood-Frame Buildings for Flood Based on Manageable Loss, Journal of Perfor-mance of Constructed Facilities, ASCE, 23, 2, 56-64.

Taggart, M. (2007) Performance-Based Design of Woodframe Structures for Flooding. M.Sc. Thesis, Colorodo State University, Fort Collins, CO.

Unanwa, C.O., and McDonald, J.R. (2000) Building wind damage prediction and mitigation using damage bands, Natural Hazards Review, 4, 197-203.

United Nations Development Program (UNDP) (2000) Human Development Report 2000, Oxford Press: New York.

US Federal Insurance Administration (FIA) (1970) Flood Hazard Factors, Depth-Damage Curves, Elevation Frequency Curves, Standard Tables. 
USACE (1970) Guidelines for Flood Insurance Studies. U.S. Army Corps of Engineers: Washington, D.C.

USACE (2000) Generic depth-damage relationships. U.S. Army Corps of Engineers: Washington, D.C.

USACE (2003) Generic depth-damage relationships for residential structure with basements. U.S. Army Corps of Engineers: Washington, D.C.

Van der Sande, C.J., de Jong, S.M., and de Roo, A.P.J. (2003) A segmentation and classification approach of IKONOS-2 imagery for land cover mapping to assist flood risk and flood damage assessment, International Journal of Applied Earth Observation and Geoinformation, 217-229.

Verboom, G.K., de Ronde, J.G., and van Dijk, R.P. (1992) A fine grid tidal flow and storm surge model of the North Sea. Continental Shelf Research. 12, 213-233.

Vickery, P.J. and Twisdale, L.A.Jr (1995) Wind-Field and Filling Models for Hurricane Wind-Speed Predictions. Journal of Structural Engineering, 121, 1700-1709.

Vickery, P.J., Skerlj, P.F., and Twisdale, L.A.Jr (2000) Simulation of Hurricane Risk in the U.S. Using Empirical Track Model. Journal of structural engineering, 126, 12221237.

Vickery, P.J., Wadhera, D., Twisdale, L.A.Jr., and Lavelle, F.M. (2009) U.S. Hurricane Wind Speed Risk and Uncertainty, Journal of Structural Engineering, 135, 301-320.

Walsh, K., Cai, W.J., Hennessy, K., Jones, R., McInnes, K., Nguyen, K., Page, C., and Whetton, P. (2002) Climate change in Queensland under enhanced greenhouse conditions: Final Report, 1997-2002., ed. A.R. Australian Commonwealth Scientific and Research Organization (CSIRO), Australia.

Wang, C.-h., Leicester, R.H., and Nguyen, M. (2008a) Decay in ground. Forest and Wood Products Austrailia. CSIRO. 
Wang, C.-h., Leicester, R.H., and Nguyen, M. (2008b) Probabilistic procedure for design of untreated timber poles in-ground under attack of decay fungi, Reliability Engineering \& System Safety, 93, 476-481.

Westerink, J., Luettich Jr., R., Feyen, J., Atkinson, J., Dawson, C., Powell, M., Dunion, J., Roberts, H., Kubatko, E., and Pourtaheri, H. (2008) A basin-to-channel-scale unstructured grid hurricane storm surge model as implemented for Southern Louisiana, Mon. Weather Rev., 136, 833-864.

Westerink, J.J., Luettich, R.A., Baptista, A.M., Scheffner, N.W., and Farrar, P. (1994) Tide and Storm Surge Predictions using the Finite Element Model. J. Hydraul. Eng., 118, 373-1390.

White House (2009) Global Climate Change Impacts in the United States, U.S. Global Change Research Program. Washington, D.C. http://downloads.globalchange.gov/usimpacts/pdfs/climate-impacts-report.pdf.

Wolfe, R., Bodig, J., and Lebow, P. (2001) Derivation of Nominal Strength for Wood Utility Poles, Forest Products Laboratory. U.S. Department of Agriculture.

Woods and Poole Economics, Inc. (W\&PE) (2003) 2003 Desktop Data Files. W\&PE, Washington, DC.

World Bank. (2001). World Development Indicators. <www.worldbank.org/wdi2001/enviornment.htm>

Wu, S-Y., Yarnal, B., and Fisher, A. (2002) Vulnerability of coastal communities to sealevel rise: a case study of Cape May County, New Jersey, USA, Climate Research, 22, 255-270.

Wurtele, M., Paegle, J., and Sielecki, A. (1971) The use of open boundary conditions with the storm-surge equations, Monthly Weather Review, 99, 537-544. 


\title{
Chapter 2
}

\section{A Probabilistic-based Framework for Impact and Adaptation Assessment of Climate Change on Hurricane Damage Risks and Costs ${ }^{1}$}

\author{
Sigridur Bjarnadottir ${ }^{1}$, Yue $^{2}{ }^{2}$, Mark G. Stewart ${ }^{3}$ \\ ${ }^{1}$ Ph.D. Candidate \\ Department of Civil and Environmental Engineering \\ Michigan Technological University, Houghton, Michigan, USA, sobjarna@mtu.edu \\ ${ }^{2}$ Associate Professor \\ Department of Civil and Environmental Engineering \\ Michigan Technological University, Houghton, Michigan, USA, yueli@mtu.edu \\ ${ }^{3}$ Professor and Director \\ Center for Infrastructure Performance and Reliability, \\ School of Engineering, The University of Newcastle, Callaghan, NSW, Australia \\ mark.stewart@newcastle.edu.au
}

1 The material contained in this chapter was previously published in the journal Structural Safety. Bjarnadottir, S., Li, Y. and Stewart, M.G. (2011) A Probabilistic-based Framework for Impact and Adaptation Assessment of Climate Change on Hurricane Damage Risks and Costs, Structural Safety, 33(3), 173-185. See Appendix IV for documentation of permission to republish this material. 


\subsection{Abstract}

This paper presents a probabilistic-based framework to assess the potential hurricane risks to residential construction under various wind speed change scenarios due to potential climate change. Every year hurricane (cyclone) hazards cause extensive economic losses and social disruption around the world. Annual hurricane damage in the United States (U.S.) is around $\$ 6$ billion in recent years. Hurricane intensity or/and frequency may change due to the increase in sea surface temperature as a result of climate change. Implications of the changing hazard patterns on hurricane risk assessment warrants an investigation to evaluate the potential impact of climate change. The framework includes probabilistic models of hurricane occurrence and intensity and conditional damage state probabilities (vulnerability model) for typical residential construction in the U.S., and an assessment of the cost-effectiveness of various climate change adaptation strategies. A case study of Miami-Dade County, Florida is presented to illustrate the framework under various scenarios of change in maximum annual wind speed over 50 years. Demographic information, such as median house value and changes in house numbers, and distribution of houses on different exposure, is used to estimate the time-dependent probable damage with or without possible climate change induced change in wind speed. This study shows that climate change may have a substantial impact on the damage and loss estimation in coastal areas, and that certain adaptation strategies can cost effectively decrease the damage, even if the wind speed does not change.

Keywords: Climate change; Hurricane; Damage; Decision making; Loss estimation; Retrofit; Risk assessment; Uncertainty; Vulnerability.

\subsection{Introduction}

Every year hurricanes and tropical cyclones cause extensive damage worldwide. From the period 1950-1989, the US averaged \$1.6 billion dollars annually in hurricane damage; this figure has increased dramatically for the period 1989-1995, to $\$ 6$ billion dollars annually in hurricane damage [1]. It is estimated that the damage caused by Atlantic hurricanes in 2004 to 2005 was more than $\$ 150$ billion dollars [2], mainly due to the 
devastating effect of Hurricane Katrina in 2005. The population in hurricane prone areas of the US is increasing steadily; for example, insured coastal property values in Florida have increased by 55\% from the year 1988 to 1993 , from $\$ 566$ billion to $\$ 872$ billion [3]. With this steady increase in population and wealth to the coastal areas of the US, there is an evident increase in risk of potential hurricane damage.

Due to the increase in sea surface temperature (SST), hurricane intensity and frequency may be affected, as indicated in the report by the Intergovernmental Panel on Climate Change (IPCC) [4]. However, whether a rising SST as a result of climate change alters hurricane (cyclone) intensity or/and frequency is still a matter for debate, mainly due to the lack of consistent data [5]. Some studies $[6,7,8,9]$ show a direct connection between climate change and hurricane intensity. For example, it was suggested that every increase in temperature of $1{ }^{\circ} \mathrm{C}$ could result in an increase of the peak wind speed of a tropical cyclone by 5\% [7]. The destructiveness of hurricanes, defined by an index based on the power dissipation of hurricanes, has significantly increased since the 1970's due to an increase in SST [7]. On the other hand, some have suggested that the increased hurricane activities in recent decades is a result of a natural cycle in Atlantic cyclone activity, rather than a long-term trend due to climate change [10,11, 12, 13].

Current hurricane risk assessment models [e.g. 3, 14] assume that wind speeds are stationary with time, meaning that the past is representative of the future. Climate change effects, by definition, must take into account non-stationary aspects of wind climatology. There are storm parameters other than wind speed that are subject to change due to sea surface temperature changes, for example, average translation speed (i.e. wind speed duration on structures), radius to maximum winds (i.e. size of the wind field and impact zone), trajectory, probability of impacting land, rate of inland decay, rainfall rates, etc.It has been suggested that the destructive potential of tropical cyclones could be indexed by a tropical cyclone Integrated Kinetic Energy scale [15]. However, the National Hurricane Center [16] believes that such scales will be ineffective in communicating the storm surge threat, as these scales do not consider the local factors that are critical in determining the actual impacts of the storm surge. For example, when Hurricane Ike made landfall on the upper Texas coast in 2008, the resulting storm surge was $20 \mathrm{ft}$. On 
the other hand, if Hurricane Ike had made landfall in Palm Beach Florida instead, the resulting storm surge would have been $8 \mathrm{ft}$. This variation is due to the local bathymetry (i.e. the shallow waters of the Gulf of Mexico enhance storm surge, while the ocean depths off southeastern Florida reduce the storm surge). Li and Stewart [17] proposed a risk-based framework for assessment of economic damage risks and costs caused by tropical cyclones in Queensland, Australia due to the possible change in wind speeds resulting from climate change. Stewart and $\mathrm{Li}$ [18] evaluated the cost-effectiveness of adaptation strategies for cyclone damage risks due to climate change.

The HAZUS-MH Hurricane Model was developed to estimate hurricane building damages. The track and wind field of a hurricane is modeled using a hurricane hazard model, which has been validated with historic hurricane data [19]. The wind speed is calculated as a function of the following parameters: central pressure, surface roughness, and translation speed. The model classifies the building inventory of a region by the characteristics of the building envelope and frame, and has the capabilities to calculate damage loss to the building interior and contents [20]. However, the model assumes that wind speeds are stationary over time, which cannot be used to estimate of hurricane losses when climate change is possible.

The purpose of this paper is not to examine whether there is direct relationship between climate change and wind hazard, nor to endorse any specific scenario of climate change (or lack thereof). Instead, we aim to refine the process of hurricane risk assessment to account for the potential impact of climate change using scenario-based analyses, and to explore the cost effectiveness of various adaptation strategies that take the potential effects of climate change into account, including the cost-effectiveness of adaptation strategies when there is no change in wind field statistics. As the vulnerability model and wind contour map use wind speed, this paper focuses on using wind speed as the control variable for wind intensity as a starting point to look into this complex problem. The economic losses can be determined by convolving the hurricane wind model and the hurricane vulnerability model. 
There is a great uncertainty, both aleatoric and epistemic, in the hurricane risk assessment [17], in particular under the impact of climate change. Despite the uncertainty on the possible change of wind speeds, the Australian Greenhouse Office (AGO) [21] suggests that there will be an increase in wind speed of $5 \%$ to $10 \%$ by 2050 in Queensland, Australia, and Vickery et al. [22] indicates that 5\% to10\% increase in wind speed. It is also important to explore the scenario of regional decrease in wind speed to account for the high variation in wind speed and a shift the regions of strong surface winds towards the poles. Pryor et al. [23] analyzed wind speed trends over the US for the twentieth and twenty-first centuries. They suggested that decrease in annual mean wind speeds is possible. In the paper, increases of $-5 \%$ to $10 \%$ in mean annual maximum wind speed over 50 years are considered to account for the uncertainty in investigating the potential impact of climate change.

\subsection{Hurricane Wind and Vulnerability Models}

Various hurricane wind field models have been developed in the last three decades $[8,24$, 25, 26]. The Weibull distribution is an appropriate model of the 3-sec gust wind speed, at a height of $10 \mathrm{~m}$ on open terrain for hurricanes in the US [14]. When non-stationary wind speed is assumed due to climate change, probability density function (PDF) of the distribution is:

$f_{v}(v, t)=\frac{a(t)}{u(t)} \cdot\left(\frac{v}{u(t)}\right)^{a(t)-1} \exp \left[-\left(\frac{v}{u(t)}\right)^{a(t)}\right]$

where $\mathrm{v}$ is the 3 -sec gust wind speed, $\alpha$ and $\mathrm{u}$ are time dependent parameters for the Weibull distribution.

Miami-Dade County, Florida is the eighth largest county in the US, with a population of 2.4 million, making it the most populous county in Florida. It was chosen to illustrate the potential impact of enhanced greenhouse gases. In this study, wind contour maps from Vickery et al. [19] were used to calculate the parameters of the Weibull distribution. The parameters were found to be $u(1)=27.36$ and $\alpha(1)=1.77$, corresponding to a mean maximum annual wind speed of $24.3 \mathrm{~m} / \mathrm{s}$, which is assumed to be the stationary wind 
speed if there is no climate change. The coefficient of variation (COV) of the maximum annual wind speed is 0.584 .

As there is no projection on how the change of wind speed will occur over time, it was assumed that the wind speed over a 50 year time period changes linearly regardless of climate change scenario. If wind speed increases by $10 \%$ in a 50 year time period, the mean maximum annual wind speed by year 50 is $26.7 \mathrm{~m} / \mathrm{s}$. The corresponding Weibull parameters are $u(50)=30.0$ and $\alpha(50)=1.77$. The COV of 0.584 in year 1 was assumed to be constant for all the years in the 50 years time period. The Weibull parameters and the maximum annual wind speed for each year in the time period can be determined accordingly. Wind speed change between $-5 \%$ to $10 \%$ in 50 years due to different climate change scenarios were explored in this study

A hurricane vulnerability model estimates the building damage caused by hurricanes and various vulnerability models have been developed [27, 28, 29]. Huang et al. [30] developed a damage model for single family housing units using Southeastern US insurance data from Hurricanes Hugo and Andrew. This particular model predicts the damage ratio which is the total amount paid by the insurer versus the total insured value. To develop the vulnerability model, the damage ratio is related to the recorded average mean surface speed of the hurricane.

Huang's damage ratio model is:

$$
\begin{array}{ll}
F_{D}(v)=\exp (0.252 v-5.823) & v \leq 41.1 \mathrm{~m} / \mathrm{s} \\
F_{D}(v)=100 & v \geq 41.1 \mathrm{~m} / \mathrm{s}
\end{array}
$$

where $\mathrm{v}$ is the mean surface wind speed .

Huang's damage model and the Weibull distribution of maximum annual wind speeds are used to illustrate the probabilistic framework of estimating the damage hurricanes with the potential impact of climate change. Huang's model is relatively simple. There is a source of epistemic uncertainty associated with the fact that this model is used for both old and new construction, as new construction could be built to withstand higher design wind speeds. However, when more sophisticated vulnerability models become available, 
they can be incorporated into the framework developed herein to update loss estimates. Moreover, the analyses conducted herein are primarily aimed at assessing the comparative effects of possible climate change scenarios, such as percentage change in wind damages. This suggests that although the wind field and vulnerability models may be relatively simple, their use for comparative analyses is instructive and suitable for initial climate impact and adaptation screening.

\subsection{Annual and Cumulative Damage}

The expected annual damage can be determined by convolving the vulnerability function and the PDF of wind field model [14]. The expected cumulative damage is then found by summing the expected annual damage for a defined time frame.

$$
D(v, t)=\int F_{D}(v) \cdot c_{1} c_{2} \cdot f_{v}(v, t) d v
$$

The model in Huang et al. [30] was developed based on the mean surface wind speed with a 10-min duration. The wind contour maps in ASCE-7 are for 3-sec gust and a conversion factor of $c_{2}=0.7$ was used to adjust the 3 -sec gust stipulated in wind speed maps to surface wind speed for all the exposure categories, according to ASCE-7 [31].

To take into account the effects of exposure on wind speed, the location of houses was identified within this study. Huang et al. [30] identified three exposure categories: Foreshore (within $1 \mathrm{~km}$ from coast), with a gradient-to-surface conversion factor of $\mathrm{c}_{1}=$ 0.90, Locations within $10 \mathrm{~km}$ inland, with a gradient-to-surface conversion factor of $\mathrm{c}_{1}=$ 0.80 , and all other locations further inland, with a gradient-to-surface conversion factor of $\mathrm{c}_{1}=0.72$. These factors were accounted for in the damage model herein.

- Foreshore: $\mathrm{c}_{1}=0.90 \mathrm{c}_{2}=0.70$

- Within $10 \mathrm{~km}$ from the shore: $\mathrm{c}_{1}=0.80 \mathrm{c}_{2}=0.70$

- Further than $10 \mathrm{~km}$ inland: $\mathrm{c}_{1}=0.72 \mathrm{c}_{2}=0.70$

Figure 2.1 represents the expected annual damage, $\mathrm{D}(\mathrm{t})$, for Miami-Dade County, for an increase in wind speed of $5 \%$ and $10 \%$, no change in wind speed, and for a decrease in wind speed of 5\%. The expected annual damage was calculated with Eq. (2.4) for all exposure categories over a 50 year time period. The expected annual damage for 
foreshore locations, when there is no increase in wind speed, is $2.7 \%$, which is consistent with the $2-3 \%$ predicted by Huang et al. [30]. The expected annual damage remains constant for each exposure category when no increase in wind speed is assumed, and decreases and increases accordingly when decreases and increases in wind speed are assumed.

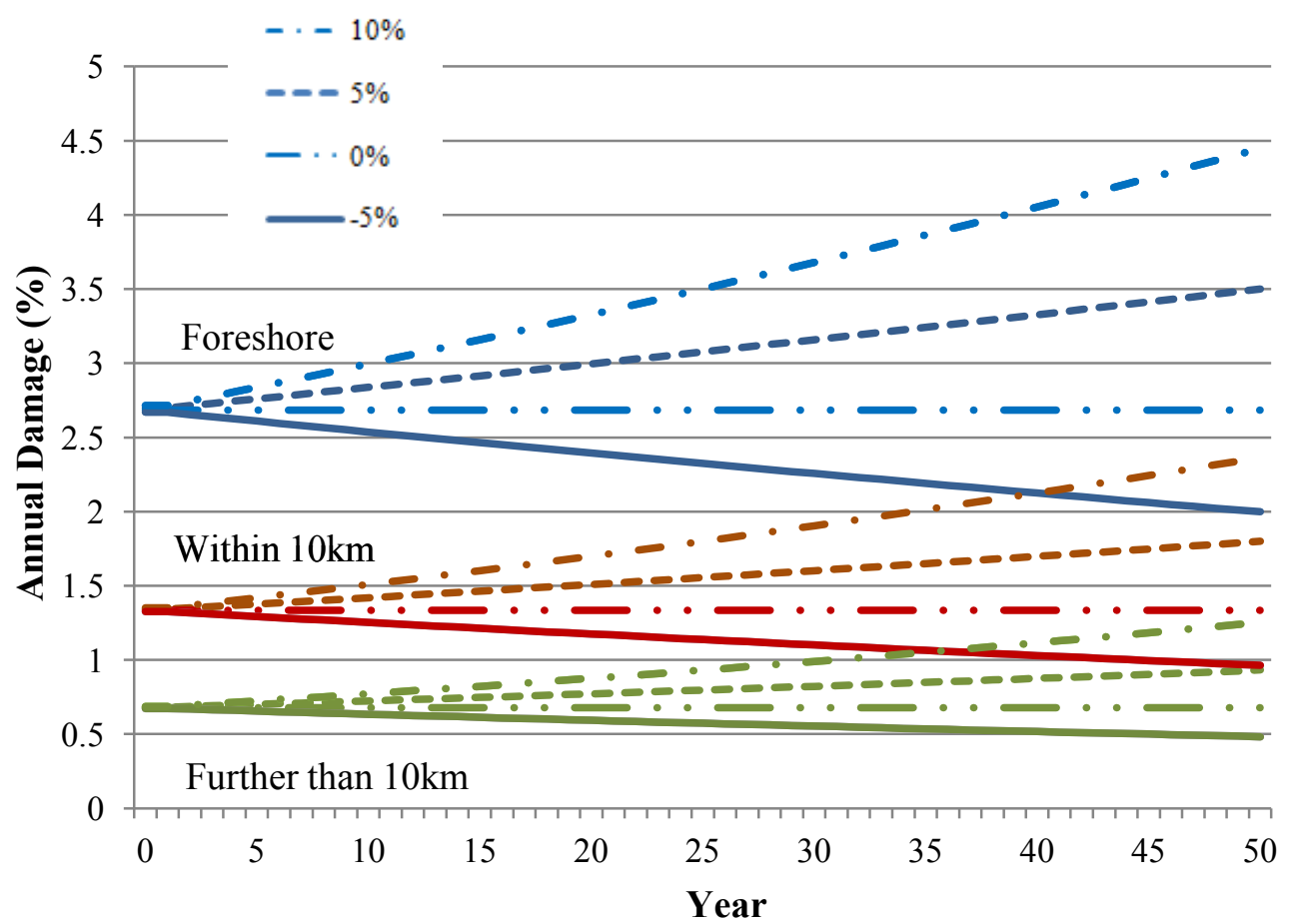

Figure 2.1: Expected annual damage at each location, assuming changes in wind speed of $-5 \%, 0 \%, 5 \%$, and $10 \%$ over 50 years

Figure 2.2 shows the expected cumulative damage for an increase in wind speed of $10 \%$, $5 \%$ increase in wind speed, no change in wind speed, and a 5\% decrease in wind speed. The expected cumulative damage was calculated for all three exposure categories over a 50 year time period. When it is assumed that there will be no change in wind speed, the expected cumulative damage is $97.5 \%$ for foreshore locations, and $48.5 \%$ and $24.6 \%$ for locations within 10 inland and locations further than $10 \mathrm{~km}$ inland, respectively.

Under an assumed increase in wind speed of 5\% over a 50 year time period, the expected cumulative damage for foreshore locations is $113 \%$. Similarly, an increase in wind speed of $10 \%$, results in an expected cumulative damage of $132.3 \%$ for foreshore locations. 
These are increases of $15.9 \%$ and $35.7 \%$, respectively, over the expected cumulative damage under no change in wind speed. On the other hand, a decrease in wind speed of $5 \%$ results in an expected cumulative damage of $83.0 \%$, or a $14.9 \%$ decrease when compared to no change in wind speed.

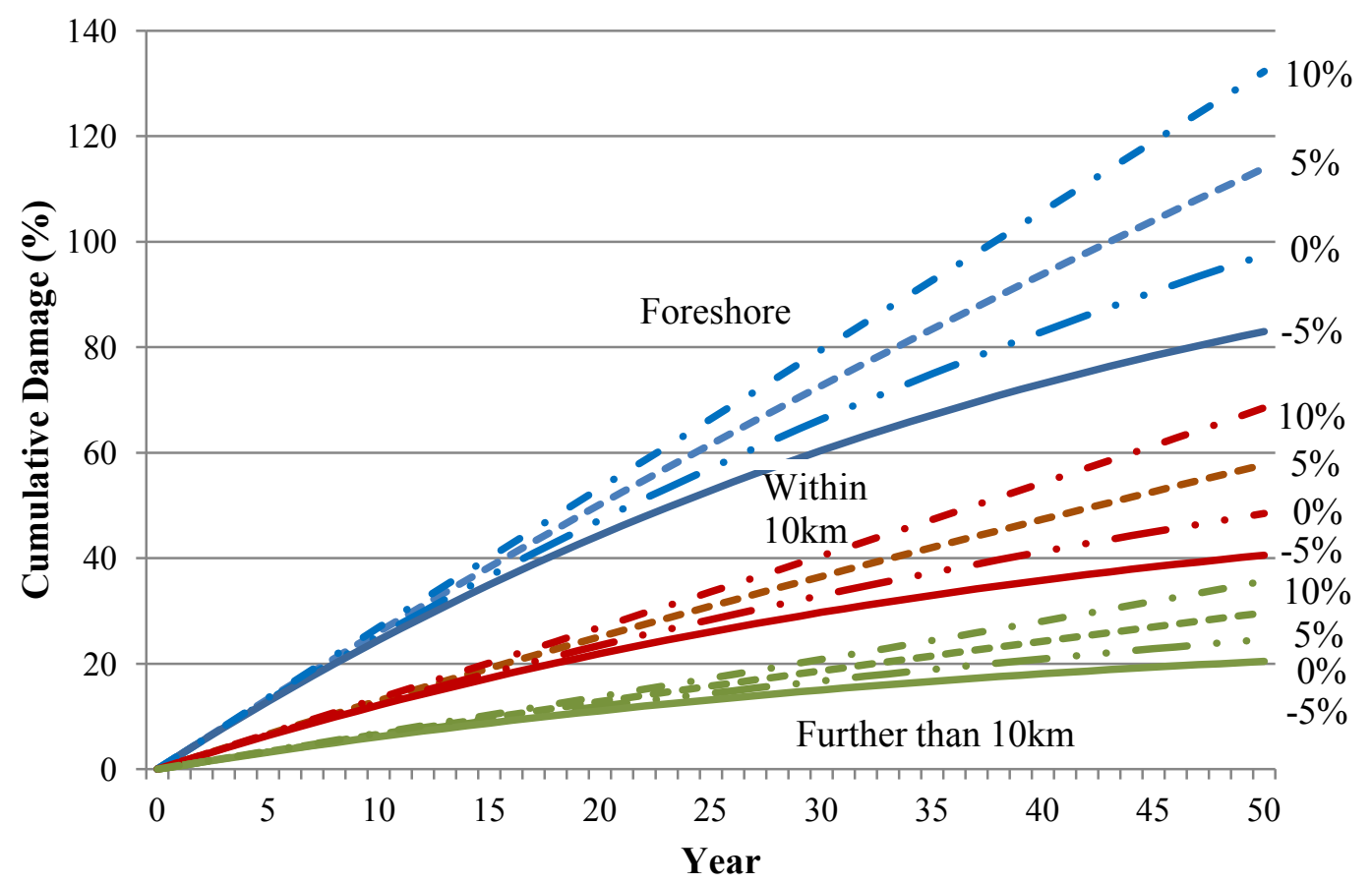

Figure 2.2: Expected cumulative damage at each location, assuming changes of $-5 \%$, $0 \%, 5 \%$ and $10 \%$ in wind speed over 50 years

\subsection{Impact Assessment Considering Regional hurricane risk}

The annual hurricane damage risk $\left(\mathrm{D}_{\text {annual }}\right)$ can be estimated by combining the building inventory of a region and damage risk for building at each exposure site, as shown below:

$$
D_{\text {annual }}(t)=\sum_{j=1}^{M} \gamma_{E j} M(t) D(v, t)
$$

where $\mathrm{j}$ represents the exposure sites, $\gamma_{\mathrm{Ej}}$ is the proportion of houses located within each site, $M(t)$ is the number of houses, and $D(t)$ is the expected annual damage for a specific site at time $t$. 
The cumulative regional loss estimation $(\mathrm{L}(1, \mathrm{~T}))$ is found by summing the annual regional loss estimation ( $D_{\text {annual }}$ ) over a time period, $T$.

$L(1, T)=\sum_{t=1}^{T} D_{\text {annual }}(t)$

The insured value of a house $\left(\mathrm{C}_{\mathrm{I}}\right)$ can be used to estimate the expected damage costs $\left(\mathrm{L}_{\mathrm{c}}(1, \mathrm{~T})\right)$ in monetary units.

$L_{C}(1, T)=\sum_{t=1}^{T}\left[D_{\text {annual }}(t)\right] \frac{C_{I}}{(1+r)^{t}}$

where $\mathrm{r}$ is the discount rate at year t. The discount rate was assumed to be $3 \%$ for the results in this paper, unless stated otherwise.

\subsection{Case Study}

The US Census Bureau estimates that there are approximately 972,000 residential housing units located in Miami-Dade County, in 2007; 53\% of these housing units are single-family units according to a 2008 report by the Greater Miami Chamber of Commerce [32]. Reports have stated that the majority of hurricane damage occurs to single-family units [33]. Therefore, within this study, damage is calculated for singlefamily units within each exposure category. According to [34], 20\% of residential houses are located within $1 \mathrm{~km}$ of the shore, $60 \%$ of houses are located within $10 \mathrm{~km}$ from the shore, and the remaining $20 \%$ are located further than $10 \mathrm{~km}$ from the shore.

The annual rate of new housing construction is calculated from information from the US Census Bureau for years 2000 and 2006 [35]. The annual growth rate was found to be $1.97 \%$, or approximately $\mathrm{m}=2 \%$. Therefore, the number of single-family units will increase from approximately 452,000 in 2000 to $1,216,000$ units by the year 2050 if the annual growth rate is assumed to be constant at $\mathrm{m}=2 \%$. These assumptions are used to perform a comparative risk analysis.

The approximate median value of a single-family unit is $\$ 196,000$ in Miami-Dade County [36]. The land price is assumed to be approximately $50 \%$ of the median value [37]. Therefore, the replacement house value is $\$ 98,000$. Huang et al. [30] found that because homeowners often hold contents insurance, the insured value of a household is 
$50 \%$ greater than the house replacement value. Therefore, it is assumed that the insured value is $150 \%$ that of the replacement value, so the median insured value is $C_{I}=$ $\$ 147,000$ in 2009 US dollars.

Figure 2.3 shows the percentage change in the expected damage cost $\mathrm{L}_{\mathrm{c}}(1, \mathrm{~T})$ at the three exposure categories in Miami-Dade County when compared to the situation assuming no change in wind speed. These are compared to illustrate the impact different exposure sites has on risk assessment. Figure 2.3 demonstrates that the percentage change in the expected damage costs is highest for the exposure category located farthest from the shore. Figure 2.3 shows that the relative (i.e. percentage) change in damage is highest for locations farther than $10 \mathrm{~km}$ from shore, even though, the absolute damage is highest for foreshore locations. Locations farthest from shore have a lower damage risk than foreshore locations, therefore the relative change is much greater there than at foreshore locations.

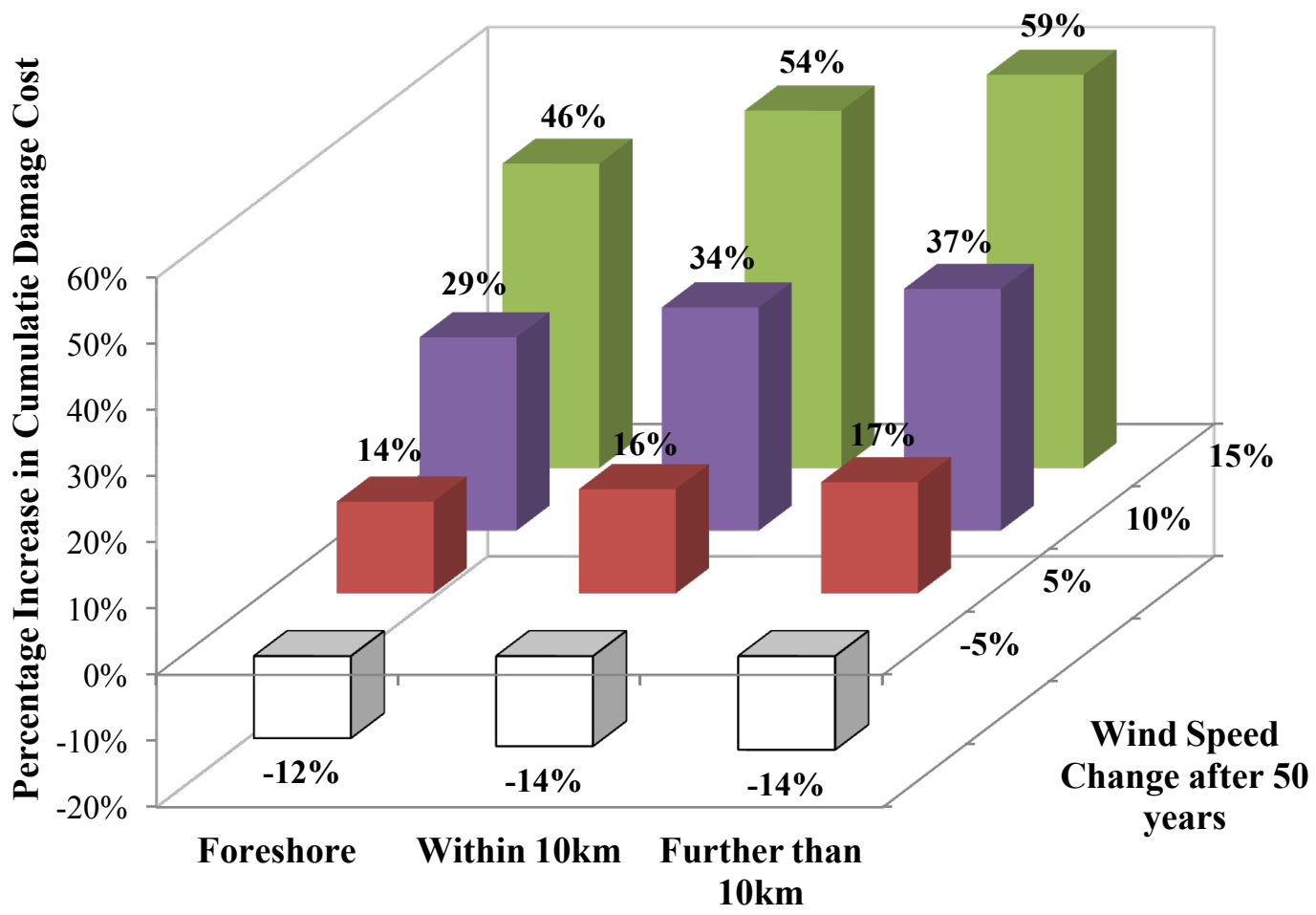

Figure 2.3: Percentage change at each exposure site in cumulative damage cost in 50 years from the case of no change in wind speed to changes in wind speed $(-5 \%$ to $10 \%)$ 
Figure 2.4 shows the expected damage costs $\mathrm{L}_{\mathrm{c}}(1, \mathrm{~T})$ for wind speed change scenarios ranging from $-5 \%$ to $10 \%$ and various time periods. If there is no change in wind speed, it can be estimated that damage costs will be $\$ 38$ billion over 50 years. This value changes to $\$ 33, \$ 44$, and $\$ 51$ billion for a change in wind speed of $-5 \%, 5 \%$, and $10 \%$, respectively. The potential economic impacts of climate change are clearly significant if the wind speed increases with time. The figure also shows that total regional damage accelerates over time.

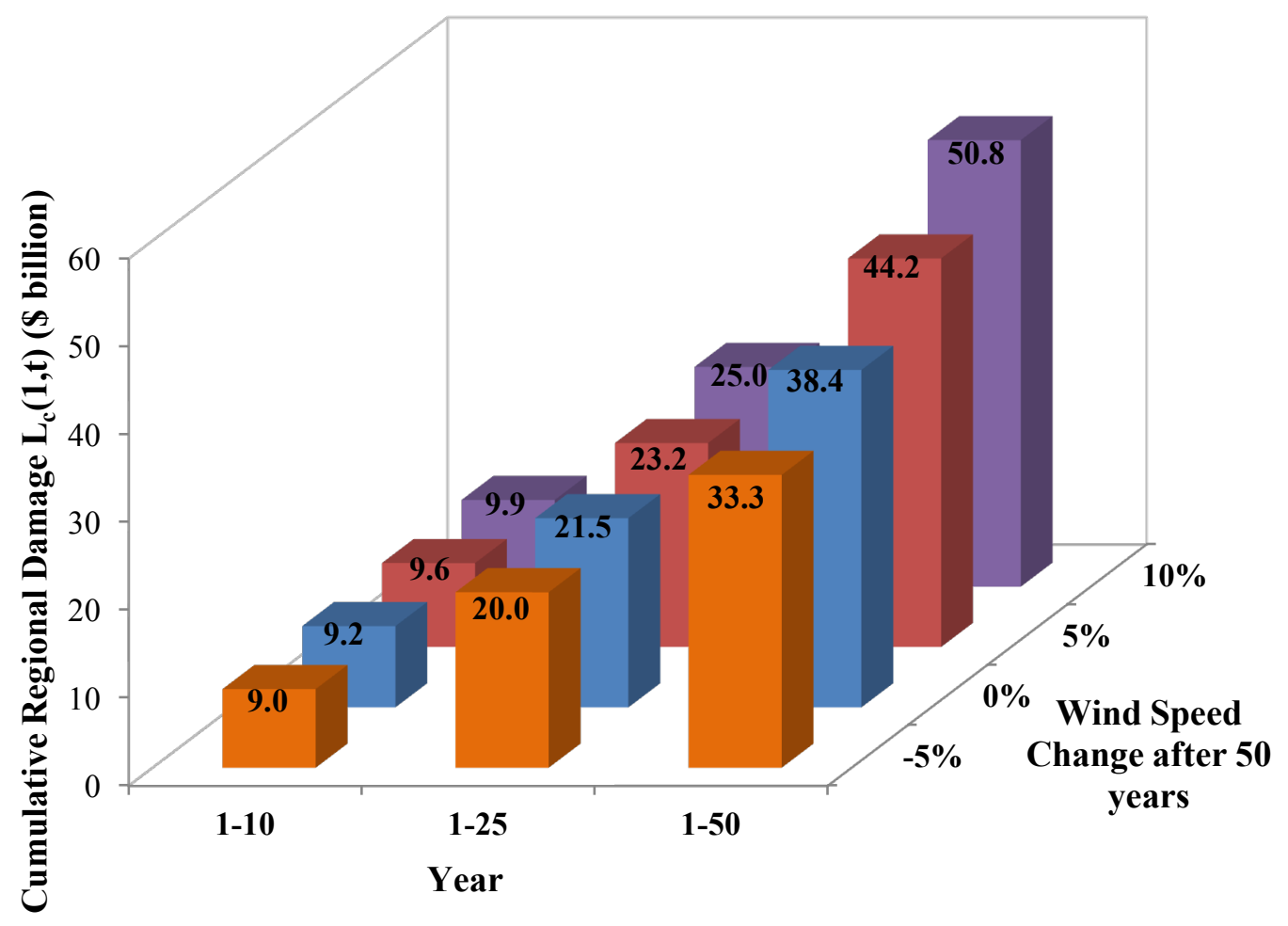

Figure 2.4: Cumulative damage cost to single-family units in Miami-Dade County under different changes in wind speeds

Note that in Figs. 3 and 4, the wind speed change was assumed to be deterministic, e.g. a $5 \%$ change in wind speed over 50 years. A Monte Carlo Simulation (MCS) can be used to estimate the damage risk to incorporate the epistemic uncertainty in change in hurricane wind speed, i.e. the wind increase is a variable. How climate change will affect regional climates and pertinent variables (epistemic uncertainty) is not well known, limiting the ability to predict consequential effects. Figure 2.5 shows the results of the MCS for the annual damage in Miami-Dade County Florida, assuming a mean increase in 
wind speed of $5 \%$ with $\mathrm{COV}$ of 0.50 in year 50 . This figure is for illustration purposes only, as significant refinement is required to estimate probability distributions for future mean temperatures or other climatic variables (e.g. the COV for changes in wind speed) when new information is available [38]. A presentation like this figure can also be modified to represent the cumulative damage of a region to allow for make statements with certain confidence level, such as "I am 95\% confident that the wind damage for this region will be under $\$ 1.0$ billion for an increase in wind speed of $5 \%$ over 50 years". Such statement can be very useful in risk communication for decision making.

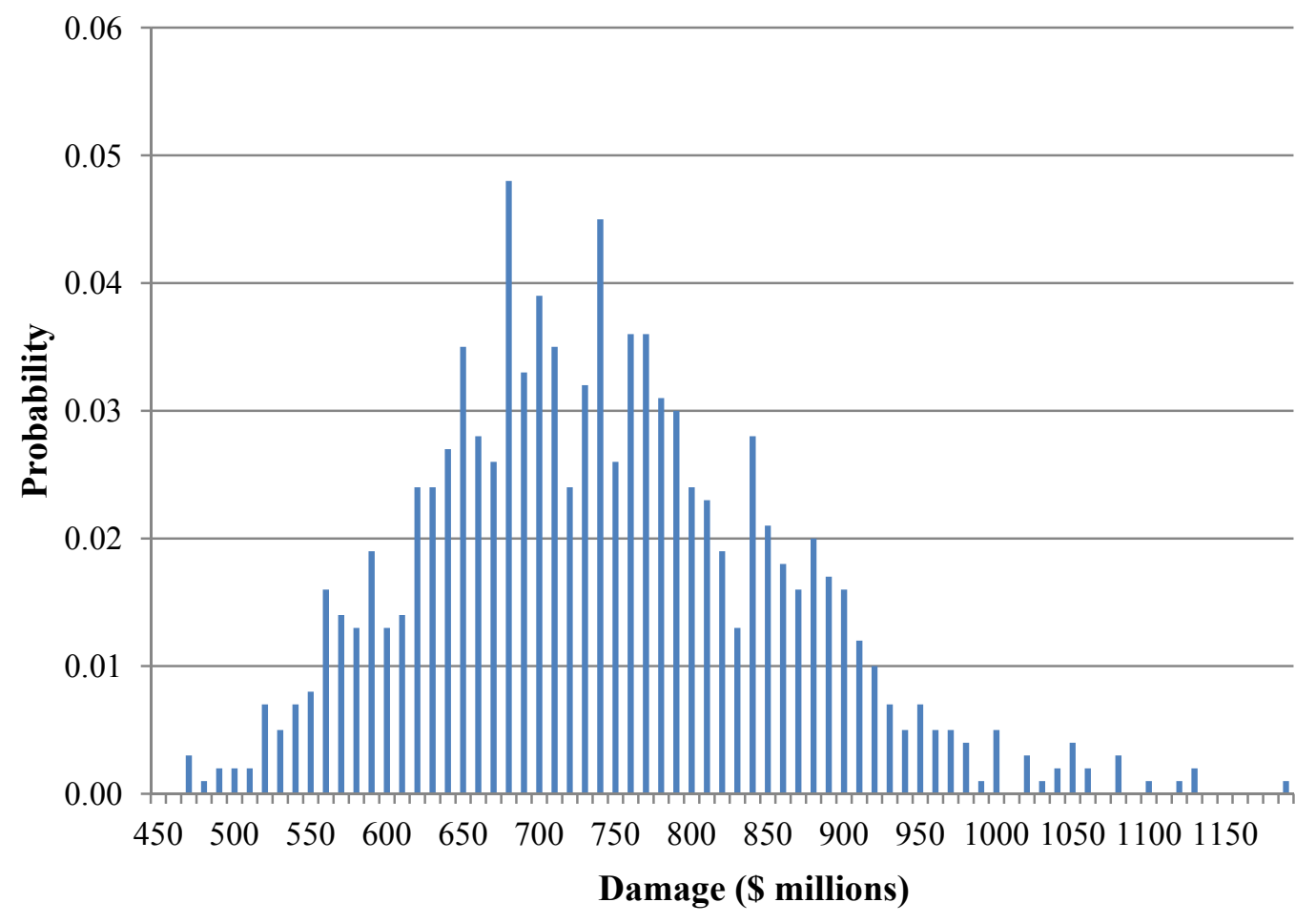

Figure 2.5: Simulation histogram of annual damage losses in year 50

\subsection{Comparison with HAZUS-MH Hurricane and Florida Public Hurricane Loss Model (FPHLM)}

The HAZUS-MH Hurricane Model was used in this study to compare damage risks for Miami-Dade County, Florida when wind speed increase is assumed to be $0 \%$ with the annual damage risks found through the methodology proposed in this paper. The HAZUS-MH Hurricane Model predicts annual damage by hurricanes within the region is 
approximately $\$ 1.49$ billion, with about $\$ 666$ million damage to single family construction. The HAZUS program uses US Census data from 2000, so the average single-family house value is $\$ 124,000$. This paper focuses on single-family units and uses current demographic data $[19,39]$.

In comparison, using the framework proposed in this paper, it was found that in year 0 , the annual regional damage to single family housing is about $\$ 966$ million when calculating with the current median house value of $\$ 196,000$. For comparison purposes, the annual regional damage is calculated again with data from 2000, and found that the annual regional damage is $\$ 613$ million. The difference between the estimated value and the prediction found in HAZUS is approximately $8 \%$, which is not unreasonable given the large uncertainty associated with regional hurricane loss estimation [17]. In addition, for the comparative purposes of this study and the assumption that the mean annual wind speed is applied to the whole region, the estimation using the proposed framework can be viewed as acceptable.

Chen et al. [40] used the Florida Public Hurricane Loss Model (FPHLM) to estimate the damage hurricanes may potentially cause in Miami, Florida. The FPHLM is an interdisciplinary online tool designed to estimate hurricane losses in Florida. The model estimates that a category 4 hurricane could potentially cause $\$ 12.8$ billion in damages and a category 3 could cause $\$ 3.1$ billion in damages to the city of Miami, using 2003 data. In comparison, the framework of this study was modified with demographic data for the city of Miami for 2003, and found that a category 4 hurricane, with wind speeds ranging from $58.3 \mathrm{~m} / \mathrm{s}$ to $69 \mathrm{~m} / \mathrm{s}$, could cause up to $\$ 12.9$ billion in damage, and a category 3 hurricane, with wind speeds ranging from $49.4 \mathrm{~m} / \mathrm{s}$ to $58 \mathrm{~m} / \mathrm{s}$, could cause up to $\$ 3.2$ billion in damage. The results from the FPHLM are within the ranges established with the framework of this paper.

\subsection{Sensitivity Analysis}

To identify what are the dominant factors that affect the cumulative damage costs, a sensitivity study was conducted. The effects of strengthening and deterioration of buildings, effects of regional annual growth rate of houses, inventory of houses in 
different exposure sites, difference in median house prices on the foreshore site, discounted rates are investigated.

\subsubsection{Strengthened and Deteriorated Buildings}

Structural vulnerability can be affected by either strengthening or weakening the construction located within a certain area, and so the vulnerability models in Eq. (2.2) and (2.3) are modified by an enhancement/reduction factor R, expressed as a percentage of existing vulnerability. For the results previously presented herein, $\mathrm{R}=0 \%$, because the vulnerability function did not distinguish the year of construction.

$F_{D}(v)=\left(\frac{100-R}{100}\right) \exp (0.252 v-5.823) \quad \mathrm{F}_{\mathrm{D}}(\mathrm{v}) \leq 100 \%$

Jain and Davidson [41] divided the building inventory of North Carolina into four classes: pre-1970, 1970-1985, 1985-1995, and post-1995. Similarly, Pinelli et al. [42] classified buildings in Florida into four groups: Weak, constructed in 1970, Medium, constructed in 1986, Strong, constructed in 1998, and Strong, constructed after 2000. The existing structures of Miami-Dade County within this study are assumed to be:

- Weak houses built before $1970 \quad(\mathrm{R}=-15 \%)$

- $\quad$ Medium houses built 1970-1985 ( $\mathrm{R}=0 \%)$

- Strong houses built 1986-1997 ( $\mathrm{R}=20 \%)$

- $\quad$ Stronger houses built after $1998 \quad(\mathrm{R}=30 \%)$

Reducing the vulnerability of new construction is assumed herein to be represented by two classes: Strengthened Type I $(\mathrm{R}=50 \%)$, and Strengthened Type II $(\mathrm{R}=80 \%)$. Strengthened construction can significantly reduce the vulnerability of a structure.

Reducing the vulnerability of construction was investigated to identify the effect it may have on the cumulative damage costs in Miami-Dade County for $0 \%$ and $5 \%$ wind speed change scenarios over 50 years. This was calculated with Eqs. (2.7) and (2.8). If strengthened construction were to be implemented, the cumulative damage cost to a region could experience a significant reduction. For example, strengthened construction with $\mathrm{R}=20 \%, 30 \%, 50 \%$, and $80 \%$, could potentially decrease the cumulative damage cost by around $15 \%, 21 \%, 37 \%$, and $58 \%$, respectively, for both climate change 
scenarios. The reduced cumulative damage is not linearly proportional to $\mathrm{R}$ because maximum damage is limited to $\mathrm{F}_{\mathrm{D}}=100 \%$.

\subsubsection{Regional annual growth rate}

Three regional growth rates other than $\mathrm{m}=2 \%$ were explored to reflect the uncertainty in population growth. The rates are $\mathrm{m}=0 \%, \mathrm{~m}=1 \%$ and $\mathrm{m}=2.5 \%$. As expected, the potential for higher damage to a region increases as the population of the coastal areas continues to grow, because more property is exposed to hurricane damage. When the annual growth rate is assumed to be $2.5 \%$ instead of $2 \%$, the cumulative regional damage increases by $13 \%$ under an increase in wind speed of 5\%. However, if the annual growth rate is assumed to be only $1 \%$ the cumulative regional damage decreases by $36 \%$.

\subsubsection{Discount rate}

Not all damage will occur at the same point in time; therefore it is necessary to discount future damage costs to present values. The results presented previously were calculated with a discount rate of 3\% [43]. Wen [44] investigated the sensitivity of optimal design against multi-hazards to discount rates varying from $0 \%$ to $9 \%$. Similarly, to explore the effects of the discounted rate, two cases where explored: $r=0 \%$ and $r=8 \%$, and then compared with $\mathrm{r}=3 \%$. The discount rate has a significant value on the present value of future losses considerably. For example, for a discount rate of $0 \%$, the cumulative regional damage would increase by $119 \%$ for no change in wind speed compared to when $\mathrm{r}=3 \%$ is assumed. While, increasing the discount rate from $3 \%$ to $8 \%$ would result in an increase in expected cumulative costs of about $60 \%$, assuming no change in wind speeds. The effect of change on cumulative damage is independent of the assumed increase in wind speed.

\subsubsection{Inventory of houses in different exposure sites}

The results presented earlier were based on the inventory of $20 \%$ foreshore, $60 \%$ within $10 \mathrm{~km}$ inland, and $20 \%$ further than $10 \mathrm{~km}$ inland [34]. To investigate the sensitivity of this distribution due to damage costs, three different cases for building inventory composition were explored. Table 1 represents the cases and their affects on the percentage change of the cumulative regional damage cost. The expected cumulative 
damage costs can be reduced by around $25 \%$ by redistributing the housing so that more than half of single family units are located further than $10 \mathrm{~km}$ form the shore.

Table 2.1: Percentage change in cumulative damage for the different inventory assumptions under various changes in wind speed

\begin{tabular}{|l|c|c|c|}
\cline { 2 - 4 } \multicolumn{1}{c|}{} & \multicolumn{3}{c|}{$\begin{array}{c}\text { Changes in wind speed over } \\
\mathbf{5 0} \text { years }\end{array}$} \\
\hline Foreshore-10km within-10km beyond & $\mathbf{0} \%$ & $\mathbf{5 \%}$ & $\mathbf{1 0} \%$ \\
\hline $\mathbf{1 0} \%-\mathbf{3 0} \%-\mathbf{6 0} \%$ & $-27 \%$ & $-27 \%$ & $-26 \%$ \\
\hline $\mathbf{2 0} \%-\mathbf{5 0} \%-\mathbf{3 0} \%$ & $-4 \%$ & $-4 \%$ & $-4 \%$ \\
\hline $\mathbf{3 0} \%-\mathbf{4 0} \%-\mathbf{3 0} \%$ & $5 \%$ & $5 \%$ & $4 \%$ \\
\hline
\end{tabular}

\subsubsection{Non-uniform housing values}

Coastal properties are usually priced considerably higher than those located farther inland, due to higher property taxes and a higher demand of houses located near the beach. A report by RealtyTrac [45], which compiled the median house value for singlefamily units in Miami-Dade County, found that the median house value for Miami Beach is $\$ 246,000$. This is an increase of $25 \%$ when compared to the county average house value of $\$ 196,000$. To explore the effect of non-uniform housing prices, an increase in median house value in foreshore locations of $10 \%, 25 \%$, and $40 \%$ are considered.

For the case in which foreshore locations were assumed to have median house values that are $10 \%$ higher than the regional average, cumulative damage increases by only $0.3 \%$ for an increase in wind speed of 5\%. Assuming that foreshore locations have a median house value that is $40 \%$ higher than average only increases the cumulative damage cost by only $1.5 \%$. Raising the house price of foreshore locations does not have a very dramatic affect on the cumulative damage costs, and this is because only $20 \%$ of houses are located within the foreshore exposure category. 


\subsection{Cost Effectiveness of Adaptation Strategies}

Roth [46] concluded that $25 \%$ to $40 \%$ of all insurance losses from Hurricane Andrew could have been avoided if the structures had been built in accordance with the current building code of that time. Stewart et al. [3] suggested that building vulnerability to hurricane damage can be decreased by retrofitting existing structures to current building standards. The study found that upgrading retrofitted structures or designing new structures to comply with ASCE- 71989 design wind speeds significantly decreases vulnerability. This underlines the importance of recognizing and identifying efficient adaptation strategies.

The economic viability of adaptation measures related to retrofitted (strengthened) construction is investigated under an increase in wind speed of 5\% over 50 years, which includes modifications of the vulnerability model to help account for the effects of aging (deterioration) and other time-dependent changes in building vulnerability not well captured by existing vulnerability models.

A life cycle cost analysis (LCC) is conducted to evaluate the cost-effectiveness of retrofit. The retrofit case involves combining the reduction in structural vulnerability and the cost associated with strengthening construction [3]. After the LCC has been calculated with a reduced vulnerability factor $\mathrm{R}$ and the cost of retrofit has been established, the costeffectiveness of the retrofit scenario can be identified by comparing LCC to the case of "do nothing", i.e. existing vulnerability without retrofit.

In Miami-Dade County, there are currently 452,000 single family housing units, with an annual growth rate of $2 \%$ (approximately 9,000 per year) [35]. According to [34], about $42 \%$ of buildings were built before 1970 , about $30 \%$ built $1970-1985$, about $17 \%$ built between 1986 and 1997, and 11\% were built after 1998, which represent 189,800, $135,600,76,800$, and 49,700 houses, respectively. The adaptation strategies explored are:

1. Strengthening a percentage of construction built before $1970(\mathrm{R}=-15 \%)$ at high vulnerability locations (i.e. foreshore);

2. Strengthening a percentage of construction built before $1970(\mathrm{R}=-15 \%)$ within the whole region; 
3. Strengthening a percentage of construction built before $1986(\mathrm{R}=-15 \%$ and $\mathrm{R}=0 \%$ ) at high vulnerability locations;

4. Strengthening a percentage of construction built before $1986(\mathrm{R}=-15 \%$ and $\mathrm{R}=0 \%$ ) within the whole region;

5. Reducing the vulnerability of new construction at high vulnerability locations

For strategies 1 and 2, the buildings built before 1970 are retrofitted to post-1998 standards $(\mathrm{R}=30 \%)$, while the units built $1970-1997$ are left as is $(\mathrm{R}=0 \%$ and $\mathrm{R}=20 \%)$. Strategies 3 and 4, however, investigate the economic viability of retrofitting structures built before $1986(\mathrm{R}=-15 \%$ and $\mathrm{R}=0 \%)$ to the standards of buildings built after 1998, while the buildings built 1986-1997 ( $\mathrm{R}=20 \%)$ are left as is. The 9,000 new units built every year are assumed to be built to post-1998 standards. For strategy 5, new construction located in foreshore exposures is built to enhanced standards, with $\mathrm{R}=50 \%$ and $\mathrm{R}=80 \%$.

The cost-effectiveness of these adaptation strategies is explored, by using the life cycle cost equations found in the Appendix (Eq. A2.1-A2.3), for a 5\% increase in wind speed. The cost of retrofit $\left(\mathrm{C}_{\mathrm{st}}\right)$ is assumed to be $1 \%$ to $50 \%$ [18] of the median insured house value, $\mathrm{C}_{\mathrm{I}}$, for this analysis, which is assumed to be an additional cost, and the discount rate is set as $3 \%$ as before. The net benefit is:

$E_{b}=L_{c}(t, T)-L_{c-a d a p t}(t, T)$

where the 'do nothing' $\mathrm{L}_{\mathrm{c}}(\mathrm{t}, \mathrm{T})$ is given by Eq. (A2.4).

The cost of retrofitting $\left(\mathrm{C}_{\mathrm{st}}\right)$ depends on the required reduction in vulnerability, structural configuration, current design and construction practices, and local labor cost and availability of retrofit material; therefore it is difficult to estimate costs accurately [43]. A number of studies have found that the additional cost to new housing for increased cyclone (hurricane) resistance is in the range of $1 \%$ to $10 \%$ of the initial (replacement) value of the home (contents not included) [47]. Stewart et al. [3] estimated a cost of approximately $5 \%$ for installing Australian cyclone resistant systems for new construction. There is very little data on the costs of retrofitting an existing house for increased hurricane resistance in the US. If $5 \%$ is assumed for strengthening a new 
housee in Miami-Dade County, then this equates to around $\$ 7,500$. In comparison, there is a relatively wide range of retrofit costs $\left(\mathrm{C}_{\mathrm{st}}\right)$ for retrofitting existing housing construction. For example, according to Pinelli et al. [42], the mitigation cost for existing gable roof timber residential construction built before 1970s in Florida is around 15\% to $25 \%$ of replacement value, depending on the region and retrofit details (e.g. shingle, roofto-wall connection, impact class, etc). Leicester [48] has observed that 'estimated' additional costs for houses in Australia range from 15\% to 50\% for retrofit of existing houses.

\subsubsection{Adaptation Strategy 1: Strengthening construction built before 1970 at foreshore locations}

The expected annual damage at high vulnerability locations is much higher than that of locations further from the shore. Every year a percentage ( $\mathrm{n}=1 \%$ to $10 \%$ ) of construction built before $1970(\mathrm{R}=-15 \%)$ and located in foreshore locations was assumed to be retrofitted to the standards of construction built after $1998(\mathrm{R}=30 \%)$. Figure 2.6 shows that this strategy is cost effective for $\mathrm{n}=1$ to $10 \%$ and $\mathrm{C}_{\mathrm{st}}=1$ to $25 \%$. This strategy is not cost effective if the cost of retrofit is greater than $26 \%$. For example, if $5 \%$ of construction built before 1970 is retrofitted annually to after 1998 standards and the cost of retrofit is $15 \%$, the net benefit is about $\$ 500$ million. If only $2 \%$ of construction is retrofitted annually but the cost of retrofit is still $15 \%$, the net benefit drops to $\$ 233$ million. The cost of retrofit for existing houses is very unpredictable, and the cost of retrofitting is likely to be greater than $15 \%$ of the house replacement value [48]. Therefore, in practice it may not to be possible to implement adaptation strategy 1 and obtain the desired reduction of vulnerability for $\mathrm{C}_{\mathrm{st}}$ less than or to equal to $26 \%$. More cost data is needed for further study the relationship between retrofit cost and vulnerability. 


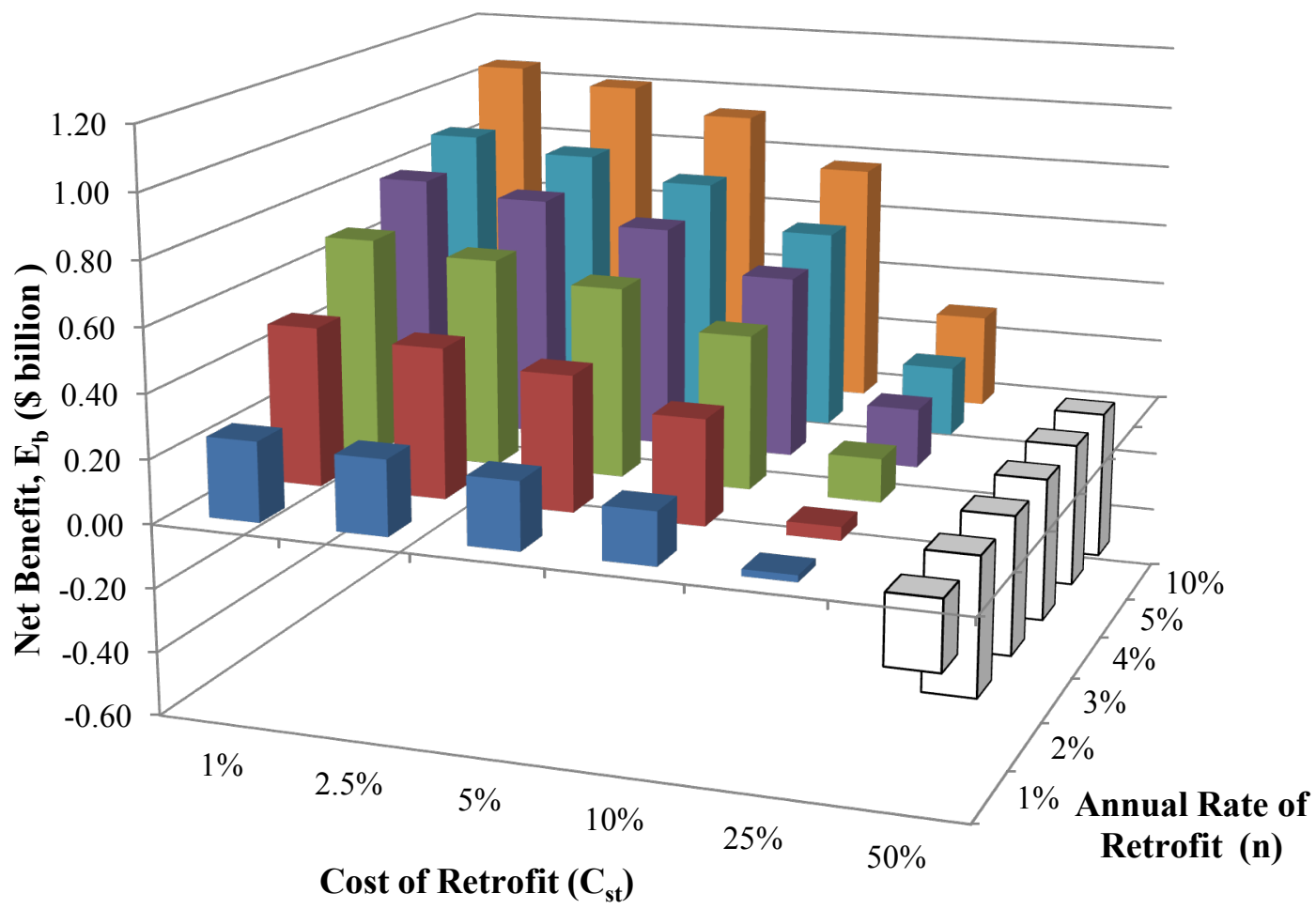

Figure 2.6: Net benefit for adaptation strategy 1 over 50 years

\subsubsection{Adaptation Strategy 2: Strengthening construction built before 1970 within the whole region}

Adaptation strategy 2 involved retrofitting all construction, within the whole region, built before 1970 to post-1998 standards. Again, it was assumed that every year a percentage ( $\mathrm{n}=1$ to $5 \%$ ) of all housing was retrofitted from pre-1970 construction ( $\mathrm{R}=-15 \%)$ to that of post-1998 construction ( $\mathrm{R}=30 \%$ ). Figure 2.7 shows that this strategy is cost effective if the cost of retrofit is less than $17 \%$. Similarly, because of the variable and high nature of the cost of retrofit, it is unlikely that a retrofit can be undertaken at such a cost. 


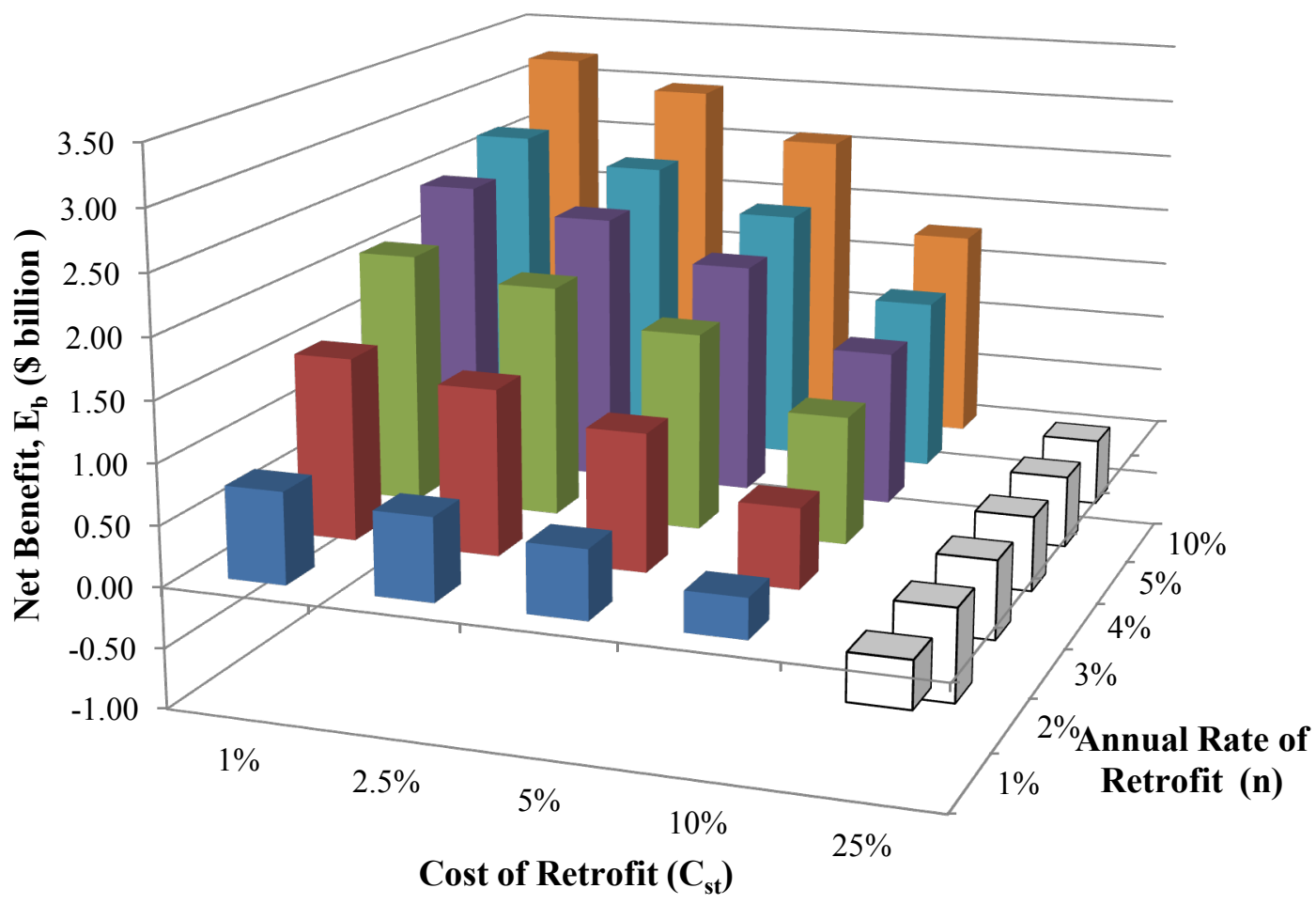

Figure 2.7: Net benefit for adaptation strategy 2 over 50 years $(5 \%$ increase in wind speed)

\subsubsection{Adaptation Strategy 3: Strengthening construction built before 1986 at foreshore locations}

For adaptation strategy 3, all construction built before $1986(\mathrm{R}=-15 \%$ and $\mathrm{R}=0 \%$ ) was retrofitted to post-1998 standards $(\mathrm{R}=30 \%)$, within the foreshore location. Figure 2.8 shows the net benefit through the implementation of this strategy. This strategy is economically viable for $\mathrm{n}=1 \%$ to $10 \%$ and $\mathrm{C}_{\mathrm{st}}=1 \%$ to $10 \%$, and is cost effective for $\mathrm{C}_{\mathrm{st}}=25 \%$ if $\mathrm{n}$ is greater than $2 \%$. The net benefit for $\mathrm{n}=5 \%$ and $\mathrm{C}_{\mathrm{st}}=15 \%$ could be potentially $\$ 650$ million over 50 years. 


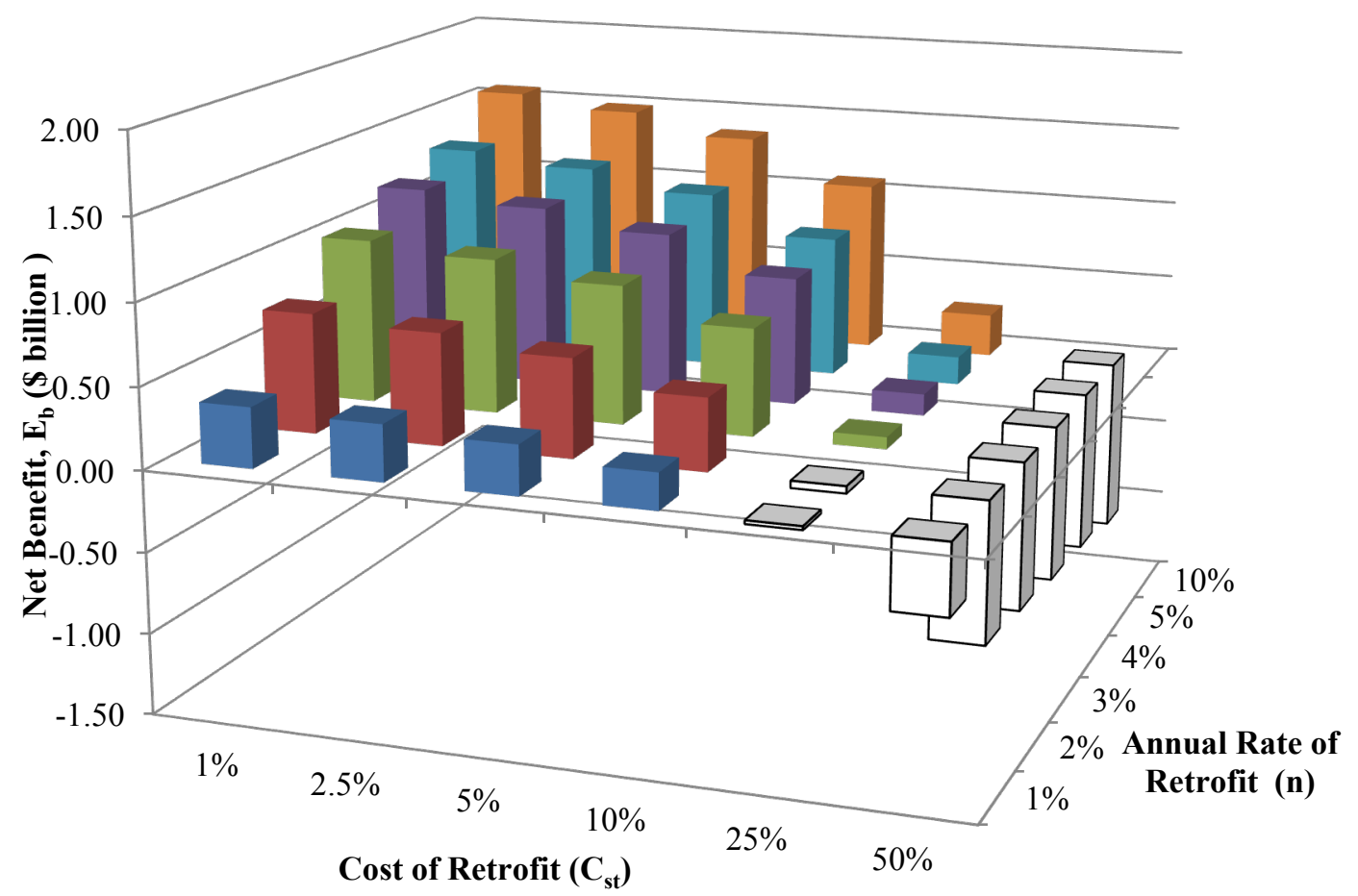

Figure 2.8: Net benefit for adaptation strategy 3 over 50 years

\subsubsection{Adaptation Strategy 4: Strengthening construction built before 1986 within the whole region}

For strategy 4, all construction within the whole region built before 1986 was retrofitted to post-1998 standards. Figure 2.9 shows the net benefit considering $\mathrm{n}=1 \%$ to $10 \%$ and $\mathrm{C}_{\mathrm{st}}=1 \%$ to $50 \%$. This strategy is not cost effective if the cost of retrofit is greater than about $14 \%$. It is difficult to assess whether this strategy can be implemented at lower costs of retrofit, because of the unpredictable nature of retrofit costs. 


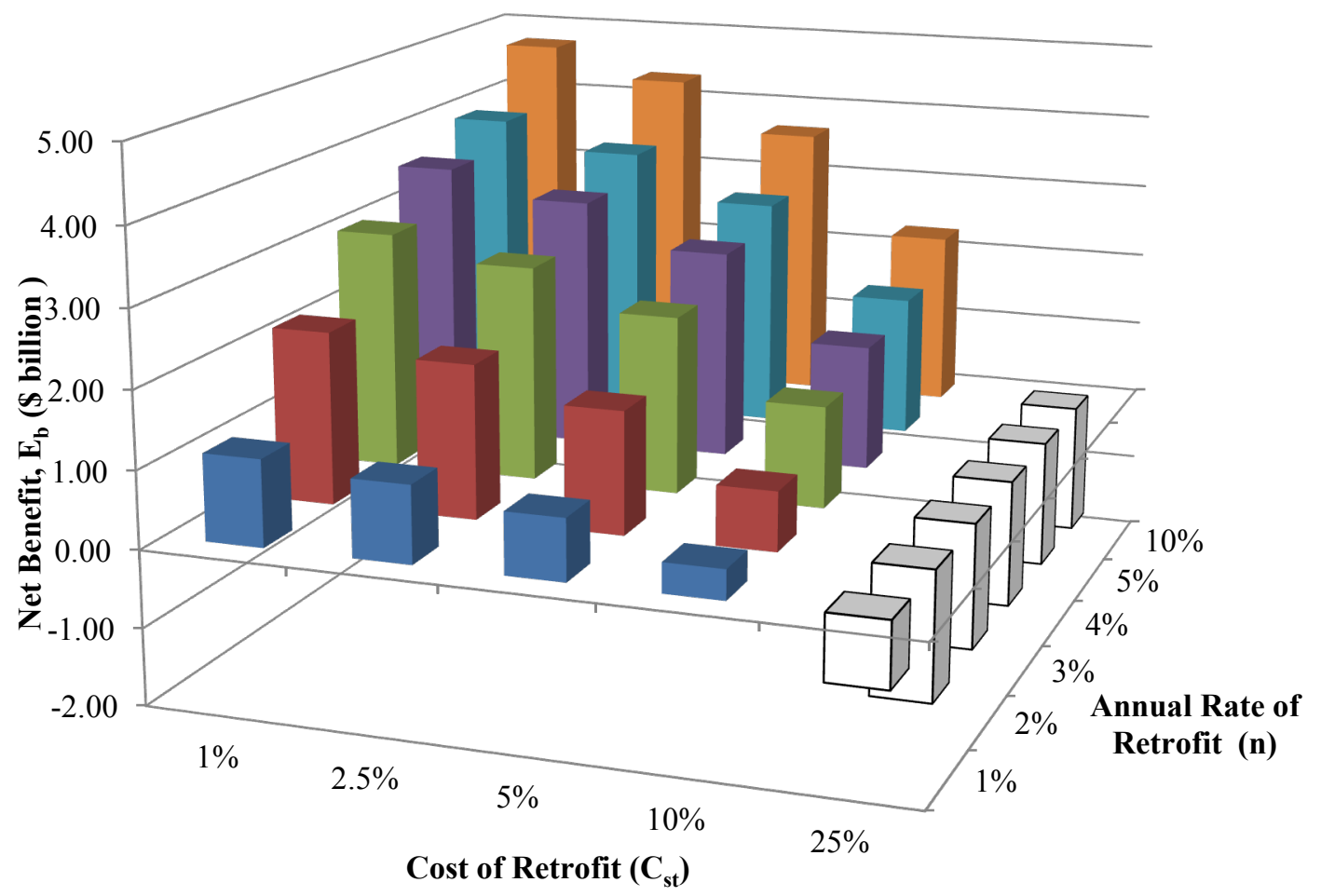

Figure 2.9: Net benefit for adaptation strategy 4 over 50 years (5\% increase in wind speed)

\subsubsection{Adaptation Strategy 5: Enhancing new construction at foreshore locations}

This strategy involved exploring the effects that strengthening only new construction located in the foreshore category may have on the expected cumulative damage to the region, as this would cause no disruption to existing home owners, and it is far cheaper to reduced vulnerability for new construction

Figure 2.10 shows the net benefit for reduced vulnerability for new foreshore construction. As expected, reducing the vulnerability of new construction by $80 \%$ is more cost effective than reducing the vulnerability of new housing by $50 \%$ if the cost of strengthening stays the same. This strategy is not cost effective for $\mathrm{R}=50 \%$ if the cost of strengthening is greater than $10 \%$. Given that the additional cost to new housing for increased hurricane resistance is in the range of $1 \%$ to $10 \%$ then achieving a reduction in vulnerability for new construction for a strengthening cost of $10 \%$ would seem to be practical and worthy of further study. 
Figure 2.11 shows adaptation strategy 5 when there is no change in wind speed. This figure shows that adaptation strategy 5 can be cost effective if wind speed characteristics in Miami-Dade County remain constant over a 50 year time frame. This strategy is not cost effective for $\mathrm{R}=50 \%$ if the cost of strengthening is greater than $\mathrm{C}_{\mathrm{st}}=15 \%$ and for $\mathrm{R}=80 \%$ when the cost of strengthening is greater than about $36 \%$. The reduction of vulnerability in new construction by $50 \%$, with a cost of strengthening of $5 \%$, could reduce potential damages by $\$ 350$ million even though there is no change in wind speed. Hence, even if there is climate change predictions turn out to be incorrect, some adaptation strategies will be cost-effective even if there is no change in wind field characteristics over time. This implies that this adaptation strategy could result in a "winwin" situation for society.

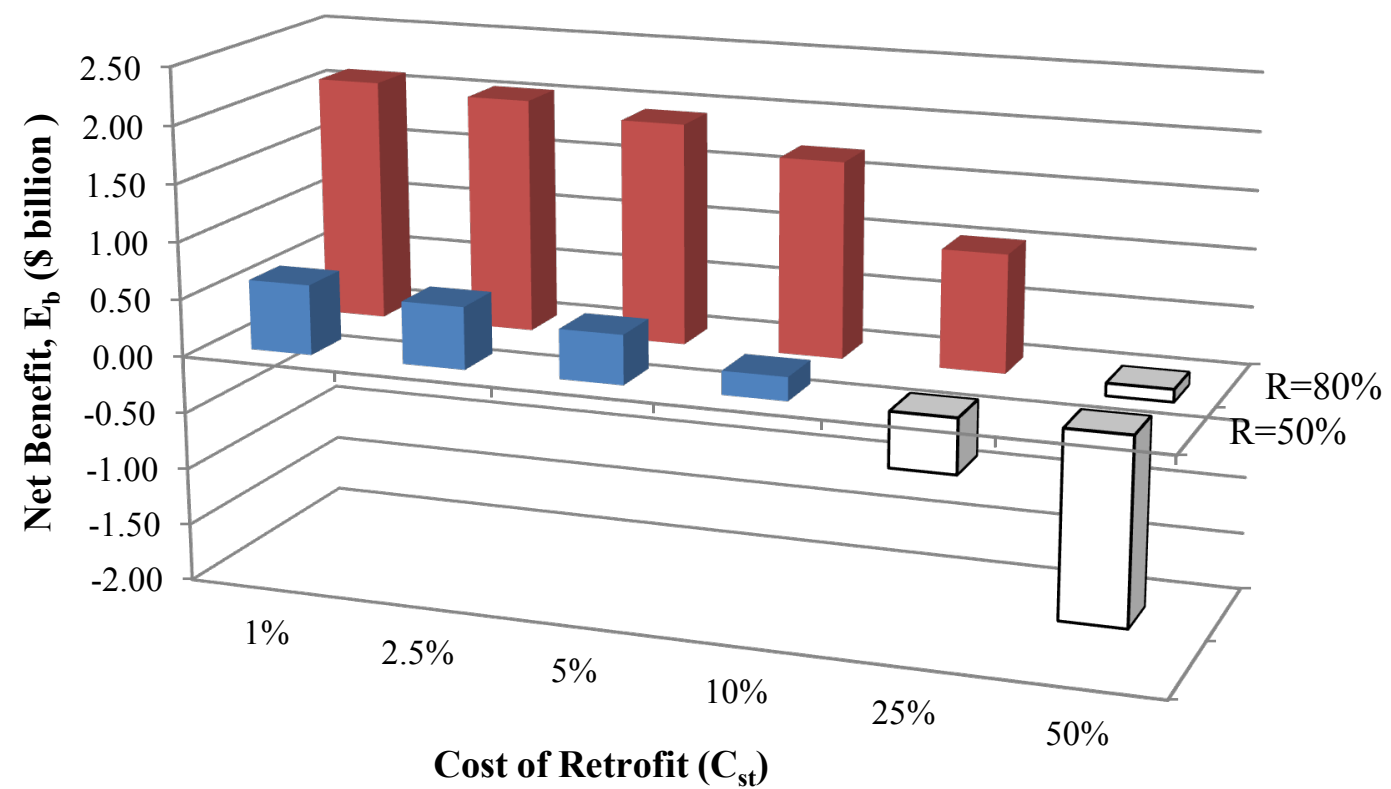

Figure 2.10: Net benefit for adaptation strategy 5 over 50 years (5\% increase in wind speed) 


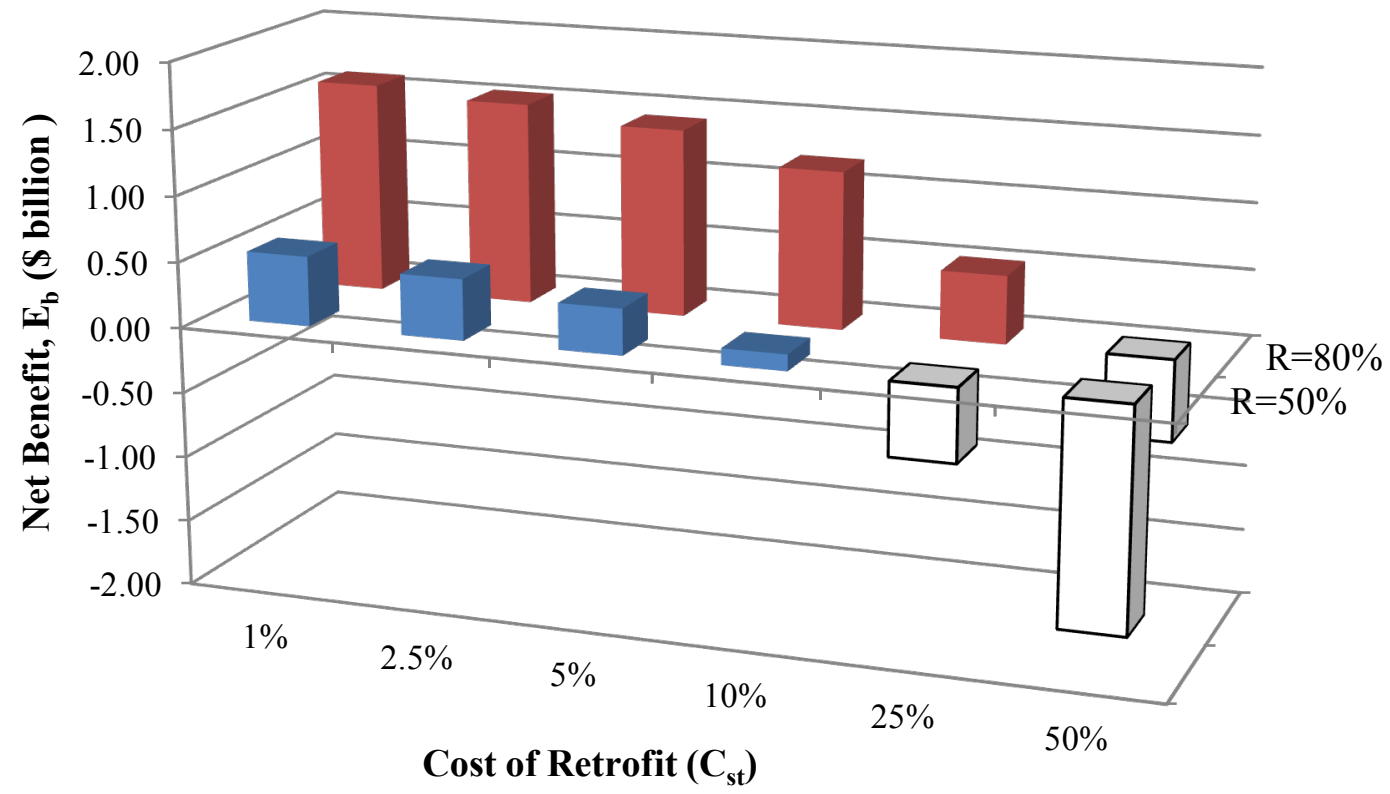

Figure 2.11: Net benefit for adaptation strategy 5 over 50 years ( $0 \%$ increase in wind speed)

\subsubsection{Comparison of various adaptation strategies}

Figure 2.12 shows the differences in cost-effectiveness between four of the strategies, which are useful in risk-informed decision making. Figure 2.12 shows what combinations of cost of retrofit $\left(\mathrm{C}_{\mathrm{st}}\right)$ and percentage of houses being retrofitted $(\mathrm{n})$ the net benefit is zero, for the time period of 50 years, under an assumed increase in wind speed of $5 \%$. The area above each line shows for what combinations the strategy is not cost effective, while the area below represents the cost effective combinations. Figure 2.13 shows the cost effectiveness of the four adaptation strategies if there is no change in wind speed over 50 years. In this case, the maximum cost of retrofit is reduced by up to $5 \%$ for the adaptation strategies to be cost effective. It is not a straightforward process to rank the cost effectiveness of these adaptation strategies, but the following observations can be made. Adaptation strategy 2 is predicted to be the most economical, because it focuses on the retrofit of all pre-1970 construction within the region, or $42 \%$ of the housing units, even though strategy 4 has a greater net benefit. Strategy 4 is perhaps less practical 
because of the sheer number of housing requiring retrofit, or $72 \%$ of the housing population. Adaptation strategy 5 may be the most suitable method of reducing the vulnerability of this area, because it focuses on strengthening new construction at foreshore locations, without the inconvenience or disruption to occupants when retrofitting existing buildings, and experience suggests that substantial reduction in vulnerability can be achieved if the cost of strengthening new construction is no more than $10 \%$, as seen from Figures 2.10 and 2.11 .

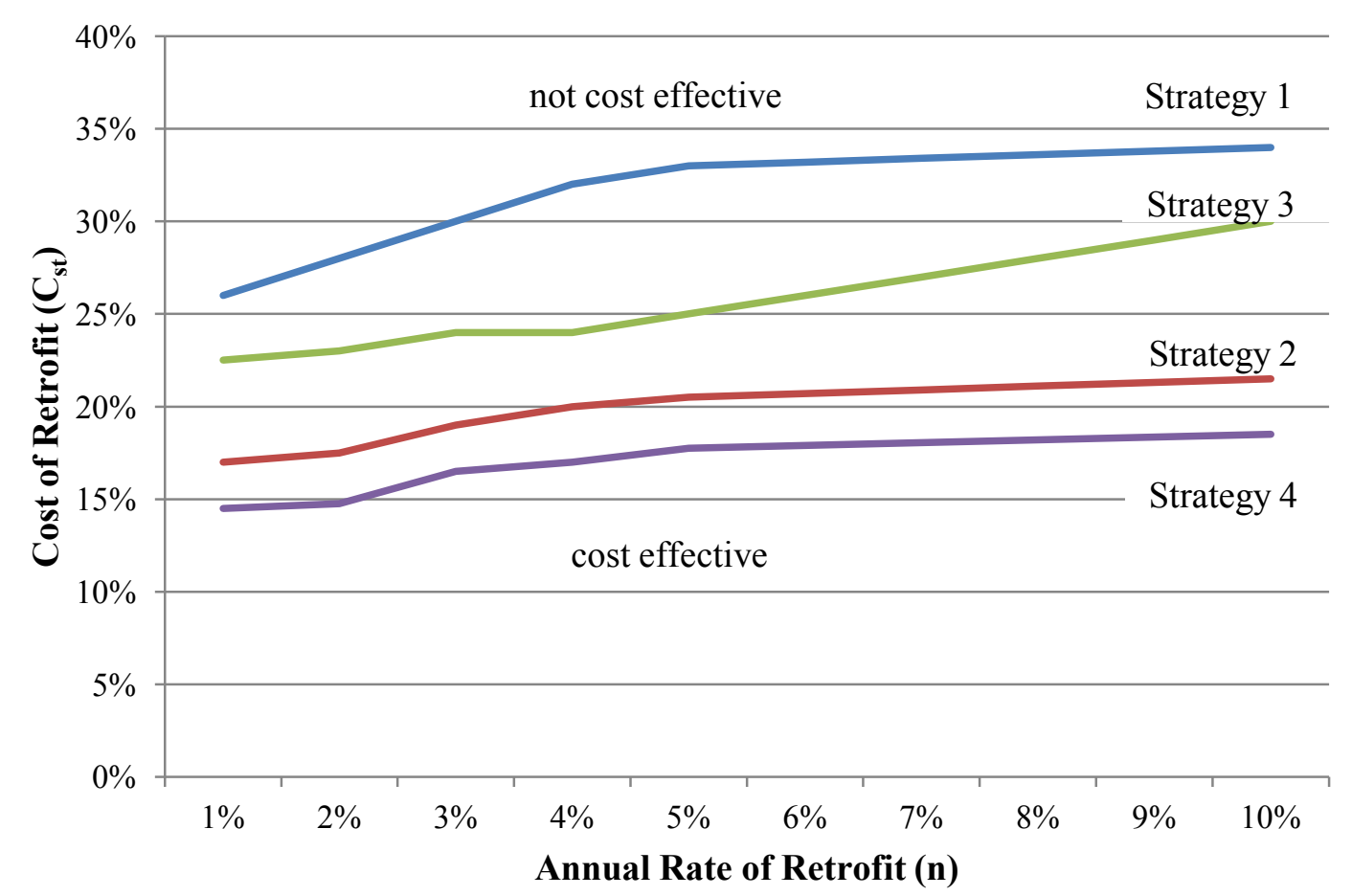

Figure 2.12: Combinations of $\mathrm{C}_{\mathrm{st}}$ and $\mathbf{n}$ in which the net benefit is zero over 50 years for each of the adaptation strategies assuming (5\% increase in wind speed) 


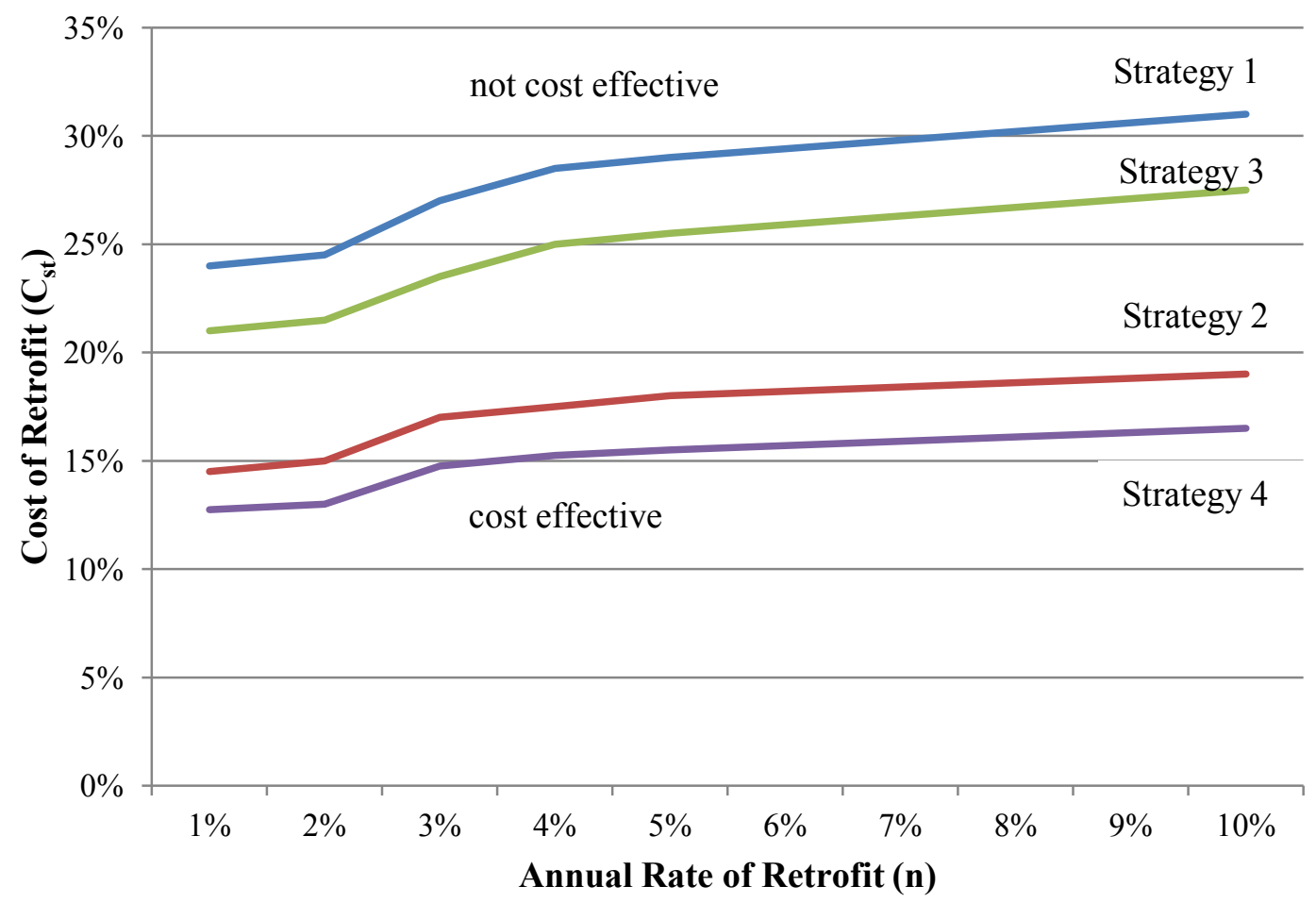

Figure 2.13: Combinations of $\mathrm{C}_{\mathrm{st}}$ and $\mathrm{n}$ in which the net benefit is zero over 50 years for each of the adaptation strategies $(0 \%$ increase in wind speed)

\subsection{Conclusions}

This analysis has considered benefits in terms of reduced building damage costs to homeowners. However, there are other benefits that, although difficult to monetise, such as reduced social disruption, reduced business losses, reduced need for emergency services and other economic and social benefits that would make adaptation strategies more costeffective than shown herein. The proposed framework includes probabilistic models of hurricane occurrence and intensity and vulnerability model for typical U.S. residential construction. It is possible that hurricane patterns may change as a result of climate change and so the proposed framework will provide a tool to evaluate the potential impact of such change on hurricane damage risks assessment. Notwithstanding the relative simple wind field and vulnerability models, mainly due to the proprietary nature of such models, the framework is appropriate for comparative studies to explore the potential impact of climate change on hurricane risk assessment. 
An increase of $5 \%$ and $10 \%$ in wind speed due to climate change could potentially increase the cumulative damage cost to single-family units in Miami-Dade County in 50 years by $17 \%$ and $37 \%$, respectively, compared to the case of no wind speed change. While a decrease in wind speed of 5\% may result in a decrease in cumulative cost of $14 \%$. In monetary terms, the increase in annual regional damage to housing units may reach $\$ 120$ million per year if wind speeds increase by 5\% over 50 years. If this or other scenarios are believed likely then, it is necessary to assess the economic viability of mitigation (adaptation) strategies to strengthen or retrofit construction in hurricane-prone zones.

The adaptation strategies considered herein were all cost effective if the cost of retrofit is less than $10 \%$, when a $5 \%$ increase in wind speed is assumed. An adaptation strategy that entailed strengthening pre-1970 construction within the whole region proved to be more cost effective than focusing solely on the foreshore locations, decreasing the expected cumulative damage to the region by an average of $4.0 \%$. An adaptation strategy involving strengthening new construction at foreshore locations also proved to be very cost effective and to cause the least disruption because it did not require the retrofit of older buildings. These adaptation strategies were found to be cost effective even if there is no change in wind speed, which implies that the strategies could result in a "win-win" situation. In comparison, similar adaptation strategies may not be economical for building in Queensland, Australia, mainly due to the relatively low hurricane intensity in the area.

\subsection{Acknowledgments}

The authors thank Yuejun Yin, doctoral candidate at MTU, for his assistance in performing some of the analyses. Some of this work was undertaken while the second author was supported by a Centre for Infrastructure Performance and Reliability Visiting Fellowship. The second author appreciates the financial support provided by the Centre for Infrastructure Performance and Reliability at The University of Newcastle, Australia.

\subsection{Appendix A2}

The LCC for adaptation strategy 1 and 2 are: 


$$
\begin{aligned}
& L_{\text {c-adapt }}(t, T)=\sum_{t=t_{0}}^{T} \sum_{j=1}^{N} \gamma_{E j}\left(189,800\left[\left(\frac{100-n t}{100}\right) D_{R=-15}(t)+\left(\frac{n t}{100}\right) D_{R=30}(t)+\frac{n}{100}\left(\frac{C_{s t}}{1.5}\right)\right]+\right. \\
& \left.135,600 D_{R=0}(t)+76,800 D_{R=20}(t)+49,700 D_{R=30}(t)+9,000 t D_{R=30}(t)\right) \times \frac{C_{I}}{(1+r)^{t}} \\
& n t<100 \\
& \begin{array}{l}
L_{c-\text { adapt }}(t, T)=\sum_{t=t_{0}}^{T} \sum_{j=1}^{N} \gamma_{E j}\left(239,600 D_{R=30}(t)+135,600 D_{R=0}(t)+76,800 D_{R=20}(t)+\right. \\
\left.9,000 t D_{R=30}(t)\right) \times \frac{C_{I}}{(1+r)^{t}} \\
n t>100
\end{array}
\end{aligned}
$$

The LCC for adaptation strategy 3 and 4 are:

$$
\begin{aligned}
& L_{\text {c-adapt }}(t, T)=\sum_{t=t_{0}}^{T} \sum_{j=1}^{N} \gamma_{E j}\left(189,900\left[\left(\frac{100-n t}{100}\right) D_{R=-15}(t)+\left(\frac{n t}{100}\right) D_{R=30}(t)+\frac{n}{100}\left(\frac{C_{s t}}{1.5}\right)\right]+\right. \\
& 135,600\left[\left(\frac{100-n t}{100}\right) D_{R=0}(t)+\left(\frac{n t}{100}\right) D_{R=30}(t)+\frac{n}{100}\left(\frac{C_{s t}}{1.5}\right)\right]+76,800 D_{R=20}(t)+ \\
& \left.49,700 D_{R=30}(t)+9,000 t D_{R=30}(t)\right) \cdot \frac{C_{l}}{(1+r)^{t}} \\
& \text { nt }<100 \\
& \text { (A2.2a) } \\
& L_{\text {c-adapt }}(t, T)=\sum_{t=t_{0}}^{T} \sum_{j=1}^{N} \gamma_{E j}\left(375,200 D_{R=30}(t)+76,800 D_{R=20}(t)+9,000 t D_{R=30}(t)\right) * \\
& \frac{C_{l}}{(1+r)^{t}}
\end{aligned}
$$

$$
n t>100
$$

The LCC for adaptation strategy 5 is:

$$
\begin{aligned}
& L_{c \text {-adapt }}(t, T)=\sum_{t=t_{0}}^{T} \sum_{j=1}^{N} \gamma_{E j}\left(189,800 D_{R=-15}(t)+135,600 D_{R=0}(t)+76,800 D_{R=20}(t)+\right. \\
& \left.49,700 D_{R=30}(t)+9,000 t \frac{100-R}{100} D_{R=30}(t)+9,000 \frac{C_{s t}}{1.5}\right) \cdot \frac{c_{l}}{(1+r)^{t}}
\end{aligned}
$$

(A2.3)

The LCC for the "do nothing" case is:

$$
\begin{aligned}
& L_{c}(t, T)=\sum_{t=t_{0}}^{T} \sum_{j=1}^{3} \gamma_{E j}\left(189,800 D_{R=-15}(t)+135,600 D_{R=0}(t)+76,800 D_{R=20}(t)+\right. \\
& \left.49,700 D_{R=30}(t)+9,000 t D_{R=30}(t)\right) \cdot \frac{C_{l}}{(1+r)^{t}}
\end{aligned}
$$

where $D_{R=-15}(t)$ is the expected annual damage for buildings built before $1970, D_{R=0}(t)$ is the expected annual damage for buildings built 1970-1985, $D_{R=20}(t)$ is the expected annual damage for buildings built 1986-1997, $\mathrm{D}_{\mathrm{R}=30}(\mathrm{t})$ is the expected annual damage for buildings built after 1998, $\mathrm{n}$ is the percentage of houses being retrofitted each year, $\mathrm{R}$ is 
the reduction factor $(50 \%$ or $80 \%), \mathrm{C}_{\mathrm{st}}$ is the additional cost of retrofit in terms of percentage of replacement value, and $\mathrm{C}_{\mathrm{I}}$ is the median insured house value.

\subsection{References}

[1] Pielke RAJ, Pielke RAS. Hurricanes: Their nature and impacts on society. Wiley: Chichester, U.K., 1997.

[2] Pielke RAJ, Gratz J, Landsea CW, Collins D, Saunders MA, Musulin R. Normalized Hurricane Damage in the United States: 1900--2005. Natural Hazards Review 2008; 9: $29-42$.

[3] Stewart MG, Rosowsky DV, Huang Z. Hurricane Risks and Economic Viability of Strengthened Construction. Natural hazards review 2003; 4: 12-19.

[4] IPCC: Climate Change 2007: The Physical Science Basis. Contribution of Working Group I to the Fourth Assessment Report of the Intergovernmental Panel on Climate Change. Solomon S, Qin D, Manning M, Chen Z, Marquis M, Averyt KB, Tignor M, Miller HL (eds.). Cambridge: Cambridge University Press; 2007.

[5] Webster PJ, Holland GJ, Curry JA, Chang HR. Changes in Tropical Cyclone Number, Duration, and Intensity in a Warming Environment. Science 2000; 309: 1844-1846.

[6] Elsner, JB, Kossin, JP, Jagger, TH. The increasing intensity of the strongest tropical cyclones. Nature 2008; 455: 92-95.

[7] Emanuel K. Increasing destructiveness of tropical cyclones over the past 30 years. Nature 2005; 436: 686-688.

[8] Vickery PJ, Twisdale LA. Wind-Field and Filling Models for Hurricane Wind-Speed Predictions. Journal of Structural Engineering 1995; 121: 1700-1709.

[9] White House. Global Climate Change Impacts in the United States. U.S. Global Change Research 2009 Program Washington, D.C. http://downloads.globalchange.gov/usimpacts/pdfs/climate-impacts-report.pdf.

[10] Klotzbach, PJ. Trends in global tropical cyclone activity over the past twenty years (1986-2005). Geophys. Res. Lett. 2006; 33. 
[11] Landsea CW. Counting Atlantic tropical cyclones back to 1990. EOS Trans. Am. Geophysical Union 2007; 88: 197-208.

[12] Landsea CW, Harper BA, Hoarau K, Knaff JA. Can we detect trends in extreme tropical cyclones? Science 2006; 313: 452-454.

[13] Pielke RAJ, Landsea C, Mayeld M, Laver J, Pasch R. Hurricanes and global warming. Bull. Am. Meteorol. Soc 2005; 86: 1571-1575.

[14] Li Y, Ellingwood BR. Hurricane damage to residential construction in the US: Importance of uncertainty modeling in risk assessment. Engineering Structures 2006; 28: 1009-1017.

[15] Powell MD, Reinhold TA. Tropical cyclone destructive potential by integrated kinetic energy. Bulletin of the American Meteorological Society 2007; 88: 513-526.

[16] NOAA Storm surge scales and storm surge forecasting. 2009 [cited 2011 February 24]; Available from: http://www.nhc.noaa.gov/sshws_statement.shtml

[17] Li, Y., and Stewart, M.G. Cyclone Damage Risks Caused by Enhanced Greenhouse Conditions and Economic Viability of Strengthened Residential Construction, Natural Hazards Review, ASCE, 2010 (In press, preview available online, DOI:10.1061/(ASCE)NH.1527-6996.0000024).

[18] Stewart MG, Li Y. Methodologies for Economic Impact and Adaptation Assessment of Cyclone Damage Risks Due to Climate Change, Australian Journal of Structural Engineering 2010, Vol. 10, No. 2, pp. 121-135.

[19] Vickery PJ, Skerlj PF, Twisdale LA. Simulation of Hurricane Risk in the US Using Empirical Track Model. Journal of structural engineering 2000; 126: 1222-1237.

[20] FEMA. HAZUS-MH Hurricane Model, 2008. [cited 2009 April 7]; Available from: http://www.fema.gov/plan/prevent/hazus/hz_wind.shtm.

[21] Pryor SC, Barthelmie RJ, Takle GS. Wind speed trends over the contiguous USA, IOP Conference Series: Earth and Environmental Science 2009. 
[22] AGO. An Assessment of the Need to Adopt Buildings for the Unavoidable Consequences of Climate Change. Final Report, Australian Greenhouse Office, Commonwealth of Australia, August 2007.

[23] Vickery PJ, Wadhera D, Twisdale LAJr, Lavelle FM. U.S. Hurricane Wind Speed Risk and Uncertainty. Journal of Structural Engineering 2009; 135: 301-320.

[24] Georgiou PN. Design wind speeds in tropical cyclone-prone regions. PhD dissertation, University of Western Ontario; 1985.

[25] Huang Z. Stochastic models for hurricane hazard analysis. PhD dissertation, Clemson University; 1999.

[26] Batts M, Cordes M, Russell C, Shaver J, Simiu E. Hurricane wind speeds in the United States. National Bureau of Standards Report no. BSS-124, U.S. Department of Commerce, Washington, D.C., 1980.

[27] Leicester RH, Bubb CTJ, Dorman C, Beresford FD. An assessment of potential cyclone damage to Dwellings in Australia, in Proc. 5th Int. Conf. on Wind Engineering, J.E. Cermak, Editor. Pergamon: New York, United States, 1979; 23-36.

[28] Sparks PR, Schiff SD, Reinhold TA. Wind damage to envelopes of houses and consequent insurance losses. Journal of wind engineering and industrial aerodynamics 1994; 53: 145-155.

[29] Khanduri AC, Morrow GC. Vulnerability of buildings to windstorms and insurance loss estimation. Journal of wind engineering and industrial aerodynamics 2003; 91: 455467.

[30] Huang Z, Rosowsky DV, Sparks PR. Long-term hurricane risk assessment and expected damage to residential structures. Reliability engineering \& system safety 2001 ; 74: 239-249.

[31] ASCE-7. Minimum Design Loads for Buildings and Other Structures. (ASCE Standard 7-05), Am. Soc. of Civil. Engineers, Reston, 2006. 
[32] Moreno D, Murray N, Lerma V, Gorski A, Kerr O, Gonzalez D, Hurtado C, Smith S. Miami-Dade County Workforce Housing Needs Assessment. Greater Miami Chamber of Commerce: Miami, 2008.

[33] NAHB. Assessment of Damage to Single-Family Homes Caused By Hurricane Andrew and Iniki, NAHB Research Center Report: Upper Marlboro, MD, 1993.

[34] Miami-Dade County Department of Planning and Zoning. Housing in Miami-Dade County 2000. Planning Research Section: Miami, 2003.

[35] US. Census Bureau: State and County Quick Facts, 2009. [cited 2009 April 14]; Available from: http://quickfacts.census.gov/qfd/states/12/12086.html.

[36] Hatcher M. The Price is Right for Many First-time Home Buyers. The Miami Herald 2009. [cited 2009 April 21]; Available from: http://www.miamiherald.com/251/story/964599.html.

[37] Zigomanis A. Land Prices Still Challenge for New Housing Market. Property Council of Australia, 2007 [cited 2009 April 21]; Available from: http://www.propertyoz.com.au/Article/NewsDetail.aspx?id=15.

[38] Solomon S, Qin, D, Manning M, Chen Z, Marquis M, Averyt KB, Tignor M, Miller HL (eds.). Climate Change 2007: The Physical Science Basis. Contribution of WG I to the 4th Assessment Report of the IPCC. Cambridge: Cambridge University Press; 2007.

[39] Vickery PJ, Skerlj PF, Lin J, Twisdale LAJr, Young MA, Lavelle FM. HAZUS-MH Hurricane Model Methodology. II: Damage and Loss Estimation. Natural Hazards Review 2006; 7: 94-103.

[40] Chen S-C, Chen M, Zhao N, Hamid S, Chatterjee K, Armella M. Florida public hurricane loss model: Research in multi-disciplinary system integration assisting government policy making. Government Information Quarterly 2009; 26:285-294.

[41] Jain VK, Davidson R. Forecasting Changes in the Hurricane Wind Vulnerability of Regional Inventory of Wood-Frame Houses. Journal of Infrastructure Systems, 2007; 13: $31-42$. 
[42] Pinelli JP, Torkian BB, Gurley K, Subramanian C, Hamid S. Cost Effectiveness of Hurricane Mitigation Measures for Residential Buildings, The 11th Americas Conference on Wind Engineering (ACWE), San Juan, Puerto Rico, June, 2009.

[43] Li Y, Ellingwood BR. Risk-based Decision Making for Multi-hazard Mitigation for Wood-frame Residential Construction. Australian Journal of Structural Engineering 2009; 9: 17-26.

[44] Wen YK. Minimum lifecycle cost design under multiple hazards. Reliability and System Saftey 2001; 73: 223-231.

[45] RealtyTrac Inc. Miami Beach, 2008. [cited 2009 June 11]; Available from: http://www.realtytrac.com/states/Florida/Miami-Dade-County/Miami-Beach.html

[46] Roth RJ. Insurable risks, regulation, and the changing insurance environment, in Hurricanes: Climates and socioeconomic impacts, H.F. Diaz and R.S. Pulwarthy, Editors. Springer: Berlin, Germany, 1997; 261-272.

[47] Reardon GF, Henderson D. Cyclone risk assessment of houses in North Queensland. J. Butterworth (ed.), Australasian Structural Engineering Conference 1988, Vol. 2, Structural Engineering Society of New Zealand, Auckland, 1007-1014.

[48] Leicester RH. A risk model for cyclone damage to dwellings, in Proc. 3rd Int. Conf. on Structural Safety and Reliability 1981; 761-771. 


\title{
Chapter 3
}

\section{Regional Loss Estimation Due to Hurricane wind and Hurricane-Induced Surge Considering Climate Variability ${ }^{2}$}

\author{
Sigridur Bjarnadottir ${ }^{1}$, Yue $\mathrm{Li}^{2}$, Mark G. Stewart ${ }^{3}$ \\ ${ }^{1}$ Ph.D. Candidate \\ Department of Civil and Environmental Engineering \\ Michigan Technological University, Houghton, Michigan, USA, sobjarna@mtu.edu \\ ${ }^{2}$ Associate Professor \\ Department of Civil and Environmental Engineering \\ Michigan Technological University, Houghton, Michigan, USA, yueli@mtu.edu \\ ${ }^{3}$ Professor and Director \\ Center for Infrastructure Performance and Reliability, \\ School of Engineering, The University of Newcastle, Callaghan, NSW, Australia \\ mark.stewart@newcastle.edu.au
}

2 The material contained in this chapter has been submitted to the journal Structure and Infrastructure Engineering. Bjarnadottir, S., Li, Y. and Stewart, M.G. (2012) Regional Loss Estimation Due to Hurricane Wind And Hurricane-Induced Surge Considering Climate Variability, Structure and Infrastructure Engineering, (submitted). See Appendix IV for documentation of permission to republish this material. 


\subsection{Abstract}

This paper presents a framework to assess the potential hurricane damage risks to residential construction. Studies show that hurricane wind, frequency and/or hurricaneinduced surge may change as a result of climate change; therefore, hurricane risk assessments should be capable of accounting for the impacts of climate change. The framework includes a hurricane wind field model, hurricane-induced surge height model, and hurricane vulnerability models. Three case study locations (Miami-Dade County, Florida, New Hanover County, North Carolina, Galveston County, Texas) are presented for two types of analyses: Annual Regional Loss Estimation and Event-Based Regional Loss Estimation. In order to estimate the probability of damage (with or without climate change), demographic information, such as median house value and changes in house numbers, and distribution of houses for different exposures, is implemented. Through both analyses it was found that climate change may have a significant impact on regional hurricane damage losses.

Keywords: Climate change; Hurricane; Damage; Surge; Loss estimation; Risk assessment; Vulnerability.

\subsection{Introduction}

Every year hurricanes cause extensive damage in the United States (U.S.). It is estimated that private and federal insurers have paid in excess of $\$ 320$ billion in losses due to weather-related hazards in the period 1980-2007, and one third of these losses are attributed to hurricane events (GAO 2007). The 2004-2005 Atlantic hurricane season alone was estimated to have caused $\$ 150$ billion dollars in damages (Pielke et al. 2008). The coastal population in the U.S. continues to grow despite this increase in damage costs. Approximately $50 \%$ of the population of the U.S. lives in coastal regions (Cullition 1998), and it is estimated that the populations of these coastal regions will increase by about $25 \%$ in the next 25 years (Boesch et. al 2000).

Increases in sea surface temperatures (SST) are acknowledged to be a result of global climate change (IPCC 2007). Hurricane activity in the Atlantic Ocean has increased in 
recent years (Goldenberg et al. 2001). However, whether or not the increasing SST are affecting hurricane patterns is a matter of debate. Some studies (e.g. Elsner et al. 2008, Mann and Emanuel 2006, Emanuel 2005, White House 2009) show that there is a connection between increasing hurricane activity in the Atlantic Ocean and the rising SST of the Atlantic Ocean. On the other hand, Klotzbach (2006), Landsea et al. (2006), Landsea (2007), and Pielke et al. (2005) find that this altered hurricane activity is due to the natural climate variability of the Atlantic Ocean.

Emanuel (2005) found that the peak wind speeds of tropical cyclones could increase by $5 \%$ for every increase in SST of $1{ }^{\circ} \mathrm{C}$. Elsner (2006) stated that climate change causes higher SST; warmer SST results in more energy which is converted to stronger hurricane winds. Knutson et al. (1998) and Knutson and Tuleya (1999) estimated that hurricane intensity may increase by $5 \%$ to $10 \%$ if SST increase by $2.2^{\circ} \mathrm{C}$. Increases in hurricane intensity of this magnitude could translate to an increase in the destructive power of hurricanes by approximately 25\% (Scavia et al. 2002). Knutson et al. (2010) found that hurricane wind speeds may increase by $2 \%$ to $11 \%$ in the 21 st century globally. Furthermore, Steenbergen et al. (2012) found that annual mean maximum wind speeds with a return period of 50 years may experience increases of up to $2.3 \%$ as a result of climate change. As hurricane wind speeds increase, the CCSP (2008) stated that the frequency of hurricanes may increase as well. However, Knutson et al. (2008) and Knutson et al. (2010) predict that hurricane frequency will decrease as a result of global climate change; finding that the frequency of hurricanes globally may decrease by $-6 \%$ to $-34 \%$ as a result of climate change (Knutson et al. 2010). Although, Knutson et al. (2010) also states that the frequency of higher intensity hurricanes (Category 4 and 5) may increase. Bender et al. (2010) confirms the finding that there may be an increase in very intense hurricanes, while the overall number of hurricanes may decrease as a result of the changing climate.

In addition to changes in hurricane wind and frequency, hurricane-induced storm surge may also change as a result of climate change. The IPCC (2007) estimates that the global average sea level may increase by approximately $40 \mathrm{~cm}$ in the $21 \mathrm{st}$ century due to climate change, and has already estimated that global sea levels have increased by 10 to $20 \mathrm{~cm}$ 
over the last 100 years. For example, it is estimated that the sea level along the Atlantic Florida coast may increase at a rate of $2 \mathrm{~mm}$ per year over the next 100 years. Increasing sea levels mean that hurricane-induced storm surge will be riding on higher sea levels, resulting in higher surges that are able to travel further inland (Scavia et al. 2002). Wu et al. (2002) found that the vulnerability of coastal communities in the U.S. to flooding will increase as a result of higher sea levels due to climate change. The New York City Panel on Climate Change (2009) found that rising sea levels as a result of climate change could lead to a significant increase in structural damage.

Hurricane risk assessment models must be able to account for the non-stationary aspects of hurricanes, to account for the potential effects of climate change on hurricane damage costs. However, existing models, such as Stewart et al. (2003) and Li and Ellingwood (2006), that estimate hurricane damage costs as a function of wind speed, assume that wind speed is non-stationary (i.e. does not change with time). Hurricane damage costs within a region are not solely affected by the intensity of the hurricanes that make landfall. Hurricane frequency and hurricane-induced storm surge can also account for a portion of damage costs. For example, in 2004, during a six week period, four hurricanes made landfall in Florida (Johnson 2005), indicating the necessity of accounting for hurricane frequency, and it is estimated that about $60 \%$ of damage costs due to Hurricane Katrina in 2005 are credited to the hurricane-induced storm surge (NWS 2006), indicating the need for including hurricane-induced storm surge in a comprehensive hurricane risk assessment.

Li and Stewart (2011) developed a framework for tropical cyclone risk assessment in Queensland, Australia. The framework assessed the impacts the changing global climate may have on damage costs, and found that increasing hurricane wind speeds could increase damage costs. Bjarnadottir et al. (2011) proposed a conceptual framework for estimating hurricane damage risks to residential construction in Florida considering the change in wind speed as a result of climate change. However, these studies do not consider the affects climate change may have on hurricane frequency or hurricaneinduced storm surge. 
Larsen et al. (2007) conducted a study that estimated the cost of Alaska's public infrastructure when subjected to climate change. The study found that between now and 2030 a changing weather climate could potentially add $\$ 3.6$ to $\$ 6.1$ billion to infrastructure damage costs. If a larger time frame is assumed, between now and 2080, it could add $\$ 5.6$ to $\$ 7.6$ billion, assuming that government agencies adapt infrastructure to changing conditions. These are increases of approximately $10 \%$ to $20 \%$ from normal repair and replacement costs. Bjarnadottir et al. (2012) found that climate change may pose a significant threat to power distribution poles subjected to hurricane winds. These studies show that climate change may have adverse effects on various types of infrastructure; however the present study will focus on residential construction.

This paper proposes a framework for regional hurricane loss assessment of residential construction. The framework includes probabilistic models of hurricane wind speed and hurricane-induced storm surge and vulnerability functions to estimate damage costs as a result of both hurricane wind and hurricane-induced storm surge. Furthermore, this framework assesses the potential impacts climate change may have on hurricane damage costs to residential construction. The purpose of this paper is not to endorse any specific scenario of climate change, rather to put forth a framework that may aid in assessing the potential impacts climate change may have on hurricane risk assessments.

\subsection{Hurricane Hazard}

\subsubsection{Hurricane Wind and Frequency Considering Climate Variability}

Previous work (Bjarnadottir et al. 2011) used the Weibull distribution to describe annual maximum wind speed. However, within the previous study hurricane frequency was not considered. Therefore, the framework developed herein utilizes the Generalized Pareto Distribution (GPD) to describe annual maximum wind speed in order to account for hurricane frequency within the annual regional loss estimation. In the following, a brief description of the GPD and its application is provided.

The "peaks-over-threshold" method involves the analysis of events that exceed a given threshold. The events above the given threshold can be described with the GPD (Palutikof et al. 1999). An adequately chosen threshold will result in only true peaks, and 
these peaks have a Poisson arrival rate. Therefore, it is possible to model the occurrence rate of the events that exceed the threshold with a Poisson distribution (Palutikof et al. 1999).

The GPD has been used to model hurricane wind speeds that exceed a threshold in the U.S.; furthermore, the frequency of the hurricane wind speeds exceeding the threshold are modeled with the Poisson distribution (Elsner et al. 2008, Jagger and Elsner 2006, Malmstadt et al. 2010, Parisi and Lund 2008). Because studies are finding that climate change may have an effect on both hurricane wind and frequency (Knutson et al. 2010), the GPD will be used to model hurricane wind speed. As there are no projections available on how hurricane wind and/or frequency may change as a result of climate change, linear increases over a 50 year time-frame will be explored as a starting point.

The cumulative density function of the for the annual maximum wind speed, accounting for non-stationary wind speed due to climate change, is given as (Stewart and Wang 2011a,b):

$F_{v}(V, t)=1-\lambda\left[1+\frac{\gamma_{\mathrm{f}}(\mathrm{t})}{100}\right]\left[1-\frac{\xi}{\sigma_{\mathrm{p}}}\left[\frac{\mathrm{v}}{1+\frac{\gamma_{\mathrm{i}}(\mathrm{t})}{100}}-\mathrm{u}_{\mathrm{p}}\right]\right]^{\frac{1}{\xi}}$

where $\mathrm{v}$ is the gust wind speed, $\lambda$ is the occurrence rate (hurricanes/year), $\zeta$ is the shape parameter, $\sigma_{p}$ is the scale parameter, $u_{p}$ is the threshold value $(\mathrm{m} / \mathrm{s}), \gamma_{\mathrm{f}}(\mathrm{t})$ is the change in hurricane frequency over time $t$, and $\gamma_{i}(t)$ is the change in hurricane wind over time $t$. For

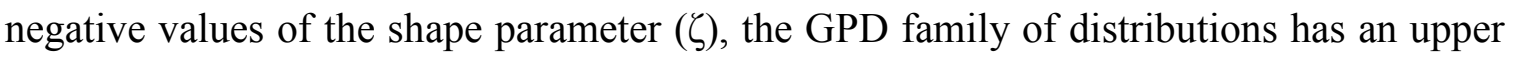
limit of $W_{\max }$ (Malmstadt et al. 2010).

\subsubsection{Hurricane-Induced Storm Surge Considering Climate Variability}

Various models are available to estimate the surge height of hurricanes given specific parameters (Hubbert and McInnes 1997, NOAA 2009, Verboom et al. 1992, Westerink et al. 1994). A model developed by Irish et al. (2008) is adapted to estimate surge height in this paper. Irish et al. (2008) estimate hurricane surge height based on three parameters of hurricanes, i.e. the central pressure deficit, storm size, and storm forward speed. This model is chosen to be utilized within the proposed framework because of its 
straightforward regressive format. Eqs. (3.2a) through. (3.2d) are used to estimate the surge height (m) (Irish et al. 2008):

$$
\begin{aligned}
& \widehat{\Delta p}(t)=\frac{\Delta p(t)}{p_{a t m}} \\
& \widehat{R_{\max }}(t)=\frac{R_{\max }(t) \cdot g}{V_{\max }(t)^{2}} \\
& \sqrt{\widehat{\omega}(t)}=\left[\begin{array}{ll}
\sqrt{R_{\max }(t)} & 1
\end{array}\right]\left\{\begin{array}{c}
- \\
C\left(S_{0}\right) \\
-
\end{array}\left\{\begin{array}{c}
\widehat{\Delta p}(t)^{2} \\
\widehat{\Delta p}(t) \\
1
\end{array}\right)\right\} \\
& \widehat{\omega}(t)=\frac{\omega(t) \cdot g}{V_{\max }(t)^{2}}
\end{aligned}
$$

where $\Delta \mathrm{p}$ is the central pressure deficit (millibars, or mb) at year $\mathrm{t}, \omega$ is the surge height (m) at year $\mathrm{t}, \mathrm{R}_{\max }$ is the radius to maximum wind speed $(\mathrm{km})$ at year $\mathrm{t}, \mathrm{V}_{\max }$ is the peak 1minute wind at $10 \mathrm{~m}, \mathrm{C}\left(\mathrm{S}_{0}\right)$ is the $2 \times 3$ curve fitting coefficient matrix for the ocean slope, $\mathrm{p}_{\mathrm{atm}}$ is the atmospheric pressure $(1013.2 \mathrm{mb}$, standard value), and $\mathrm{g}$ is the gravitational constant $\left(9.813 \mathrm{~m} / \mathrm{s}^{2}\right)$. Within the equations ${ }^{\wedge}$ refers to dimensionless quantities.

In order to estimate the surge height, the hurricane parameters (i.e. $V_{\max }, R_{\max }, \Delta p$ ) are obtained from data on 25 recent hurricanes (Irish et al. 2008, NOAA 2009). For each of the three hurricane parameters, various statistical distributions were examined for goodness-of-fit using both the Kolmogorov-Smirnov test and the Anderson-Darling test (Ang and Tang 2007), which were both performed at a 5\% significance level. Appropriate distributions were identified; see Table 3.1, and the mean and the COV for the three parameters were determined from the historical data (Irish et al. 2008, NOAA 2009).

Table 3.1: Parameters for Surge Model

\begin{tabular}{|c|c|c|c|}
\hline Parameter & Distribution & Mean & COV \\
\hline $\mathrm{V}_{\max }(\mathrm{m} / \mathrm{s})$ & Gumbel & 56.7 & $20 \%$ \\
\hline $\mathrm{R}_{\max }(\mathrm{km})$ & Normal & 39.4 & $46 \%$ \\
\hline$\Delta \mathrm{p}(\mathrm{mb})$ & Lognormal & 70.4 & $22 \%$ \\
\hline
\end{tabular}


The parameters in Table 3.1 are implemented into Eq. (3.2) to estimate the hurricaneinduced storm surge height. For example, assuming an ocean bed slope of 1:250, the average surge height was estimated at $2.14 \mathrm{~m}$ with a $\mathrm{COV}$ of $34 \%$. By conducting the Kolmogorov-Smirnov test and the Anderson-Darling test, the surge height is found to be appropriately described with the lognormal distribution. Two limitations of the surge height model are noted. First, a site-specific parameter of the ocean bed slope is used to generate surge heights in Irish et al. (2008); however, more site-specific models of hurricane surge height are desirable for loss estimations of this nature. Second, the hurricane surge height estimation is based on historical hurricane data, which means an event-based analysis (where wind speed and surge height are known based on historical information) needs to be conducted to estimate the regional loss as a result of combined hurricane wind and surge, in comparison to the annual damage analysis that can be conducted for hurricane wind alone. However, when more sophisticated hurricane surge models are developed they can be incorporated into the proposed framework.

\subsection{Vulnerability of Residential Buildings}

\subsubsection{Loss due to Hurricane Wind}

The damage a structure can sustain due to a wind speed can be estimated through the use of a hurricane vulnerability model. Several such vulnerability models have been developed over the last three decades (Leicester et al. 1979, Sparks et al. 1994). For example, Stubbs and Perry (1996) created a vulnerability curve based on how different building components perform corresponding to their relative importance. On the other hand, Khanduri and Morrow (2003) divided the vulnerability curve into several curves to represent individual building types.

Using available insurance data from Hurricanes Hugo and Andrew, Huang et al. (2001) developed a hurricane vulnerability model for single family housing units in the Southeastern U.S. Within this model, the damage risk is estimated, as the total amount paid by the insurer versus the total insured value, and related to the wind speed of the hurricane. Huang's damage risk model is:

$F_{D}(v, t)=\exp (0.252 \cdot v(t)-5.823) \quad v \leq 41.4 \mathrm{~m} / \mathrm{s}$ 
$F_{D}(v, t)=100 \quad v \geq 41.1 \mathrm{~m} / \mathrm{s}$

where $\mathrm{v}(\mathrm{t})$ is the mean surface wind speed at time $\mathrm{t}$. The model is relatively simple; however, as more sophisticated vulnerability models become available, they can be incorporated into the framework developed herein to update loss estimates.

\subsubsection{Loss due to Hurricane-Induced Storm Surge}

This framework will implement the flood loss methodology developed by Taggart and van de Lindt (2009). The flood loss methodology estimates flood damage to residential construction as a result of hurricane-induced storm surge, by using an assembly-based vulnerability (ABV) approach developed by Porter (2000). The ABV approach involves dividing a building into components, and generating loss fragilities for each component based on building details and a Monte Carlo Simulation (MCS) for a range of flood depths and durations. From the loss fragilities, damage costs can be generated for each damaged component of the building. Finally, the total damage cost due to hurricaneinduced storm surge is obtained by summing the damage costs of the components. The interested reader is directed to Taggart (2007) for details on the development of the loss fragilities for the individual building components. Furthermore, it is noted that wave action can result in a considerable amount of damage; however this paper is limited to flood damage due to hurricane-induced storm surge.

\subsubsection{Exposure of Hurricane Hazard}

An exposure factor must be incorporated within the vulnerability models to account for the effects different exposure has on wind speed and surge height (i.e. structures located closer to the shore will experience higher wind speeds and higher hurricane-induced storm surge heights). Three exposure categories are identified (Bjarnadottir et al. 2011): Foreshore (within $1 \mathrm{~km}$ from coast), with an exposure factor of 0.90 , Locations within 10 $\mathrm{km}$ inland, with an exposure factor of 0.80 , and all other locations further inland, with a an exposure factor of 0.72 (Huang et al. 2001). Studies (NAHB 1993) have shown that hurricane damage primarily affects single-family housing units; therefore the proposed framework is applied to single-family housing units. 


\subsection{Regional Loss Estimation Considering Climate Variability}

As stated previously, the regional loss estimation will be conducted considering two methods of analysis. First, the annual and cumulative regional loss estimation will be conducted considering the potential impacts of climate change on hurricane wind and frequency. Second, in order to conduct a comprehensive hurricane risk assessment, the potential impacts of climate change on hurricane wind speed and hurricane-induced storm surge will be examined by estimating the regional loss through an event-based analysis where changes in wind speed and surge height are known. Once models of hurricane surge height are available that are capable of estimating an annual surge height (not a surge height based solely on historical data), they can be incorporated into the annual regional loss estimation in a similar manner as the event-based analysis combines hurricane wind and hurricane-induced storm surge for a combined annual regional loss estimation.

\subsubsection{Annual Regional Loss Estimation due to Hurricane Wind}

The annual damage risk at time $t\left(D_{\text {wind, } 1}(v, t)\right)$ due to hurricane wind speed can be determined by convolving the hurricane fragility $\mathrm{F}_{\mathrm{D}}(\mathrm{v})$ and the probability density function (PDF) of the hurricane wind speed model (Li and Ellingwood 2006).

$$
D_{w i n d, 1}(v, t)=\int F_{D}(V) \frac{d F(V, t)}{d v} d V
$$

Within the hurricane wind speed vulnerability model, in addition to the exposure factor, a wind speed conversion factor must also be accounted for (Bjarnadottir et al. 2011). The wind conversion factor is assumed to be 0.70 , to account for the fact that the vulnerability model is based on the mean surface wind speed, not the strongest wind speed as described with the GPD.

In order to estimate the annual hurricane damage risk for the entire region, the annual damage risk is determined for each exposure category, and combined with the building inventory of the region (i.e. number of single family residential housing units located within each exposure category):

$$
D_{1}(t)=\sum_{j=1}^{3} \gamma_{E j} N(t) D_{\text {wind }, 1}(v, t)
$$


where $\mathrm{j}$ represents the exposure sites, $\gamma_{\mathrm{Ej}}$ is the proportion of houses located within each site, $\mathrm{N}(\mathrm{t})$ is the number of houses, and $\mathrm{D}_{\text {wind, } 1}(\mathrm{v}, \mathrm{t})$ is the expected annual damage for a specific exposure site at time t.

The annual regional loss estimation $\left(\mathrm{L}_{1}(1, \mathrm{~T})\right)$ is determined by incorporating the insured value of the house $\left(\mathrm{C}_{\mathrm{st}}\right)$.

$L_{1}(1, T)=\sum_{t=1}^{T}\left[D_{1}(t)\right] \frac{C_{s t}}{(1+r)^{t}}$

where $r$ is the discount rate at year $t$. The discount rate is assumed to be $3 \%$, unless stated otherwise (Li and Ellingwood 2009).

\subsubsection{Event-Based Regional Loss Estimation due to Hurricane Wind and Surge}

An event-based analysis involves estimating the regional loss considering a specific event (e.g. Saffir-Simpson Hurricane Category 5 or a wind speed with a specific return period). Analyses of this nature can be an important tool for decision makers (Adachi and Ellingwood 2010, Li 2012). The damage risk due to a specific wind speed at time $t$ $\left(\mathrm{D}_{\text {wind,2 }}(\mathrm{t})\right)$ is determined in a similar manner as the annual damage risk is determined, i.e. incorporating a specific wind speed into the hurricane wind speed vulnerability model to estimate damage risk. On the other hand, the damage risk associated with the predetermined surge height at time $t\left(D_{\text {surge }}(t)\right)$ is estimated with the flood loss estimation methodology from Taggart and van de Lindt (2009).

In order to conduct the event-based regional loss estimation, a snapshot of the housing inventory (i.e. number of houses located in each exposure category) is taken at the year in which a specific wind speed and surge height is assumed to occur. Using the inventory and insured house value $\left(\mathrm{C}_{\mathrm{st}}\right)$, it is possible to estimate the regional loss that can be expected as a result of a specific wind speed $\left(\mathrm{L}_{\mathrm{wind}, 2}(\mathrm{v}, \mathrm{t})\right)$ and specific surge height $\left(\mathrm{L}_{\text {surge }}(\mathrm{t})\right)$.

$$
\begin{aligned}
& L_{\text {wind }, 2}(t)=\left[\sum_{j=1}^{3} \gamma_{E j} N(t) D_{\text {wind }, 2}(t)\right] \frac{C_{s t}}{(1+r)^{t}} \\
& L_{\text {surge }}(t)=\left[\sum_{j=1}^{3} \gamma_{E j} N(t) D_{\text {surge }}(t)\right] \frac{C_{s t}}{(1+r)^{t}}
\end{aligned}
$$


where $\mathrm{j}$ represents the exposure sites, $\gamma_{\mathrm{Ej}}$ is the proportion of houses located within each site, $N(t)$ is the number of houses, $D_{\text {wind,2 }}(t)$ is the damage risk due to hurricane wind speed at time $t, D_{\text {surge }}(t)$ the damage risk to hurricane surge at time $t$, and $r$ is the discount rate at year $\mathrm{t}$.

The event-based regional loss estimation $\left(\mathrm{L}_{2}(\mathrm{t})\right)$ of combined hurricane wind speed and hurricane-induced storm surge is the sum of the two loss estimations.

$L_{2}(t)=L_{\text {wind }, 2}(v, t)+L_{\text {surge }}(t)$

The insured house value $\left(\mathrm{C}_{\mathrm{st}}\right)$ is assumed to be $150 \%$ of the replacement value of the house. This is attributed to two factors: first, it is typically assumed that the land price is $50 \%$ of the median house value, translating to a replacement house value of $50 \%$ of the original house value (Zigomanis 2007); and second, the insured value of a house is estimated to be $50 \%$ higher than the house replacement value, due to the fact that homeowners often have contents insurance (Huang et al. 2001).

\subsection{Illustrated Case Studies}

Miami-Dade County in Florida, New Hanover County in North Carolina, and Galveston County in Texas will be used as case study locations to investigate the possible impacts climate change may have on regional hurricane loss estimation. Figure 3.1 shows the locations of these counties. This section includes:

1. Annual Regional Loss Estimation

2. Event-Based Regional Loss Estimation 


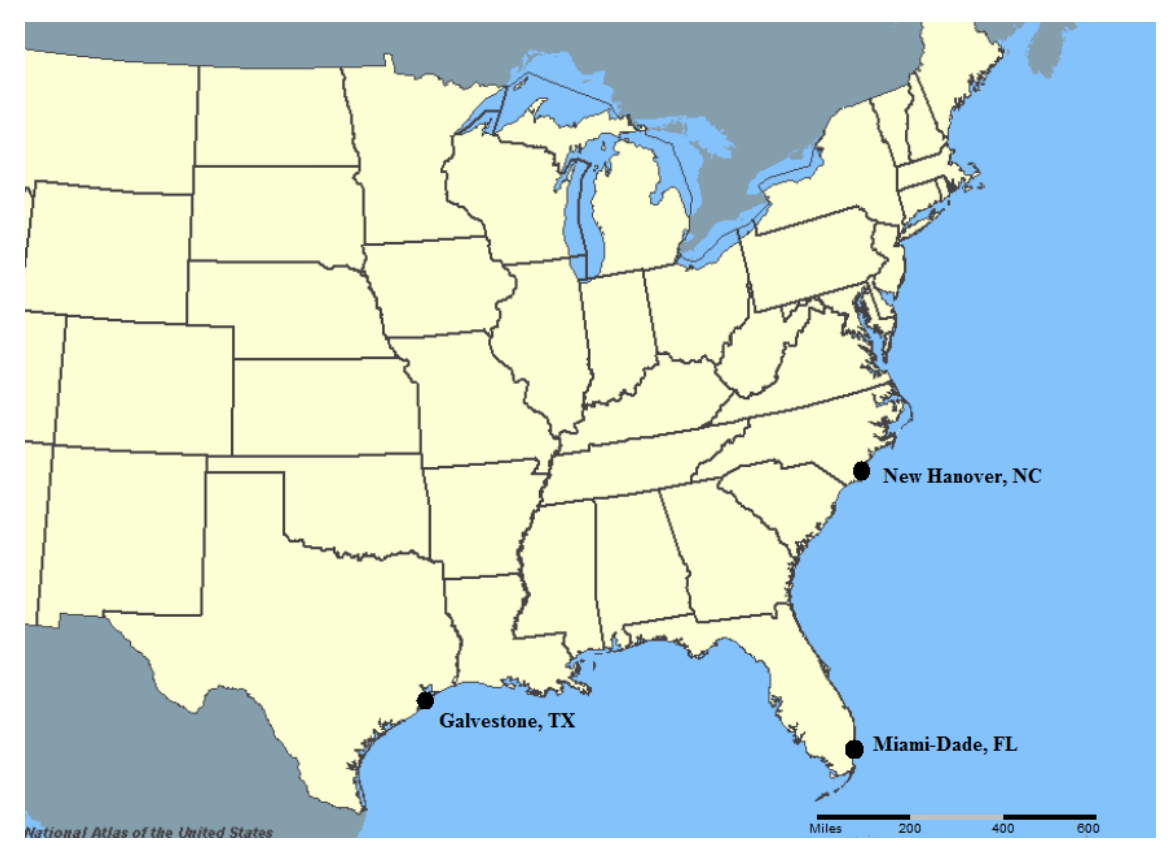

Figure 3.1: Map of United States with case study locations (C) 2009 National Atlas of the United States ${ }^{\circledR}$ (See Appendix IV for documentation that this material is in the public domain)

In order to estimate damage costs, the demographic information from the U.S. Census Bureau (2009) is compiled for each county. The demographic information and economic characteristics are summarized in Table 3.2. The number of single-family housing units, the housing distribution, and the median insured house value are included for each county.

Table 3.2: Demographic Information for Each County used to Estimate the Hurricane Damage Cost

\begin{tabular}{|c|c|c|c|}
\hline Parameter & $\begin{array}{l}\text { Miami-Dade } \\
\text { County }\end{array}$ & $\begin{array}{l}\text { New Hanover } \\
\text { County }\end{array}$ & $\begin{array}{l}\text { Galveston } \\
\text { County }\end{array}$ \\
\hline $\begin{array}{l}\text { Single-family Housing } \\
\text { Units }\end{array}$ & 452,000 & 58,200 & 56,300 \\
\hline Housing Distribution $^{1}$ & $20-60-20$ & $20-70-10$ & $20-30-50$ \\
\hline Insured House Value & $\$ 147,000$ & $\$ 191,100$ & $\$ 82,000$ \\
\hline
\end{tabular}

Note: 1: represents $\%$ of houses located foreshore- $\%$ of houses located within $10 \mathrm{~km}-\%$ of houses located further than $10 \mathrm{~km}$. 


\subsubsection{Annual Regional Loss Estimation Considering Climate Variability}

\subsubsection{Hurricane Wind and Frequency}

To determine the hurricane damage risk for each of the three counties, the parameters for the GPD must be determined. The parameters can be determined using a mean residual life plot, probability-weighted moments, and maximum likelihood estimation (MLE) (Jagger and Elsner 2006). Grigoriu (2006) outlines a procedure involving probabilityweighted moments to determine the GPD parameters (i.e. $\zeta$ and $\sigma_{p}$ ) for 150 mileposts located on the Atlantic Coast of the U.S., ranging from Texas to Maine. The parameters are based on simulated extreme wind speed data, provided by NIST (2009), for each milepost. The parameters for the proposed framework will be estimated in a similar manner as outlined in Grigoriu (2006). In addition, the threshold is fixed for all three counties (Parisi and Lund 2008). The annual occurrence rate $(\lambda)$ for each county is found based on historical hurricane data (NOAA 2009). Table 3.3 presents the parameters for the GPD and the annual occurrence rate for all three counties.

Table 3.3: Parameters for the GPD

\begin{tabular}{|c|c|c|c|}
\hline Parameters & $\begin{array}{c}\text { Miami-Dade } \\
\text { County }\end{array}$ & $\begin{array}{c}\text { New Hanover } \\
\text { County }\end{array}$ & $\begin{array}{c}\text { Galveston } \\
\text { County }\end{array}$ \\
\hline$\lambda$ (hurricanes/year) & 0.22 & 0.15 & 0.12 \\
\hline$\zeta$ & -0.589 & -0.258 & -0.282 \\
\hline$\sigma_{\mathrm{p}}$ & 37.5 & 21.1 & 24.9 \\
\hline $\mathrm{u}_{\mathrm{p}}(\mathrm{m} / \mathrm{s})$ & 35.0 & 35.0 & 35.0 \\
\hline
\end{tabular}

\subsubsection{Climate Change Scenarios}

To start off nine climate change scenarios, occurring over a 50 year time frame, are examined for the annual regional loss estimation:

No climate change $\left(\gamma_{\mathrm{f}}=0.0, \gamma_{\mathrm{i}}=0.0\right)$

1. $5 \%$ decrease in frequency, $10 \%$ increase in wind $\left(\gamma_{\mathrm{f}}=-0.001, \gamma_{\mathrm{i}}=0.002\right)$

2. $10 \%$ decrease in frequency, $10 \%$ increase in wind $\left(\gamma_{\mathrm{f}}=-0.002, \gamma_{\mathrm{i}}=0.002\right)$ 
3. $25 \%$ decrease in frequency, $10 \%$ increase in wind $\left(\gamma_{\mathrm{f}}=-0.005, \gamma_{\mathrm{i}}=0.002\right)$

4. $0 \%$ change in frequency, $5 \%$ increase in wind $\left(\gamma_{\mathrm{f}}=0.0, \gamma_{\mathrm{i}}=0.001\right)$

5. $0 \%$ change in frequency, $10 \%$ increase in wind $\left(\gamma_{\mathrm{f}}=0.0, \gamma_{\mathrm{i}}=0.002\right)$

6. $10 \%$ increase in frequency, $0 \%$ increase in wind $\left(\gamma_{\mathrm{f}}=0.002, \gamma_{\mathrm{i}}=0.0\right)$

7. $10 \%$ increase in frequency, $5 \%$ increase in wind $\left(\gamma_{\mathrm{f}}=0.002, \gamma_{\mathrm{i}}=0.001\right)$

8. $10 \%$ increase in frequency, $10 \%$ increase in wind $\left(\gamma_{\mathrm{f}}=0.002, \gamma_{\mathrm{i}}=0.002\right)$

\subsubsection{Damage Risk Considering Hurricane Wind and Frequency}

Once the parameters for the GPD have been established, the annual damage risk can be estimated for each exposure category for each county. The annual damage risk can be estimated for any scenario of climate change. Table 3.4 shows the annual damage risk for each exposure category within each county after 50 years. These results are determined for the no climate change scenario (i.e. no change in frequency and no change in wind), and are presented to show the difference in damage risk between the three locations. Miami-Dade County has the highest annual damage risk for all exposure categories, which was expected because of its location on the Atlantic Coast. New Hanover County has the second highest annual damage risk, and this is attributed to the fact that the annual occurrence rate of hurricanes is higher for this county than for Galveston County.

Table 3.4: Annual damage risk (No Climate Change)

\begin{tabular}{|c|c|c|c|}
\cline { 2 - 4 } \multicolumn{1}{c|}{} & $\begin{array}{c}\text { Miami-Dade } \\
\text { County }\end{array}$ & $\begin{array}{c}\text { New Hanover } \\
\text { County }\end{array}$ & $\begin{array}{c}\text { Galveston } \\
\text { County }\end{array}$ \\
\hline Foreshore & 0.0260 & 0.0204 & 0.0164 \\
\hline $\begin{array}{c}\text { Within 10 km of } \\
\text { shore }\end{array}$ & 0.0103 & 0.0082 & 0.0066 \\
\hline Further than 10 km & 0.0043 & 0.0035 & 0.0028 \\
\hline
\end{tabular}

Table 3.5 shows the annual damage risk at year 50 considering the nine scenarios of climate change for foreshore locations for all three counties. For example, the annual damage risk for foreshore locations for the no climate change scenario (i.e. no change in 
wind or frequency) is $0.0260,0.0204$, and 0.0167 for Miami-Dade County, New Hanover County, and Galveston County, respectively. From the table it is evident that decreases in frequency (Climate Change Scenarios 2, 3, and 4) tend to reduce the effect increasing the hurricane wind may have on the annual damage risk estimates. For example, Climate Change Scenario 4 which involves decreasing the frequency of hurricanes by $25 \%$ and increasing the hurricane wind by $10 \%$ over 50 years results in an annual damage risk that is lower than for the no climate change scenario for Miami-Dade County and Galveston County; in contrast, the damage risk for New Hanover County is slightly higher for Climate Change Scenario 4 than for the no climate change scenario. These variations are attributed to the variations within the GPD parameters which are estimated based on data from each individual county. These results show that there is an evident geographical variation in damage risk between the three counties. 
Table 3.5: Annual Damage Risk at year 50 considering Scenarios of Climate Change for all Three Counties (Foreshore Exposure)

\begin{tabular}{|c|c|c|c|c|}
\hline \multirow{2}{*}{$\begin{array}{c}\text { Change in } \\
\text { Frequency }\end{array}$} & \multirow{2}{*}{$\begin{array}{c}\text { Change in } \\
\text { Wind Speed }\end{array}$} & $\begin{array}{c}\text { Miami-Dade } \\
\text { County }\end{array}$ & $\begin{array}{c}\text { New Hanover } \\
\text { County }\end{array}$ & $\begin{array}{c}\text { Galveston } \\
\text { County }\end{array}$ \\
\cline { 3 - 5 } & $\mathbf{3} \%$ & 0.0260 & 0.0204 & 0.0167 \\
\hline $\mathbf{5 \%}$ & $\mathbf{1 0 \%}$ & 0.0291 & 0.0254 & 0.0197 \\
\hline $\mathbf{- 1 0 \%}$ & $\mathbf{1 0 \%}$ & 0.0277 & 0.0241 & 0.0187 \\
\hline $\mathbf{- 2 5 \%}$ & $\mathbf{1 0 \%}$ & 0.0238 & 0.0208 & 0.0161 \\
\hline $\mathbf{0 \%}$ & $\mathbf{5 \%}$ & 0.0280 & 0.0234 & 0.0184 \\
\hline $\mathbf{0 \%}$ & $\mathbf{1 0 \%}$ & 0.0306 & 0.0267 & 0.0207 \\
\hline $\mathbf{1 0} \%$ & $\mathbf{0 \%}$ & 0.0282 & 0.0226 & 0.0181 \\
\hline $\mathbf{1 0 \%}$ & $\mathbf{5 \%}$ & 0.0309 & 0.0258 & 0.0203 \\
\hline $\mathbf{1 0 \%}$ & $\mathbf{1 0 \%}$ & 0.0334 & 0.0295 & 0.0229 \\
\hline
\end{tabular}

Figure 3.2 shows the percentage change in the annual damage risk for all climate change scenarios from the no climate change scenario at year 50. The results are presented for foreshore locations for each of the three counties. New Hanover County and Galveston County experience proportionally higher changes in annual damage risk than MiamiDade County. This is because New Hanover and Galveston Counties had lower annual damage risks initially than Miami-Dade County, which therefore resulted in a higher change in annual damage risk. On the other hand, all three counties experience the greatest changes in the annual damage risk when the frequency is assumed not to change or when it is assumed that the frequency increases in addition to increasing hurricane wind. For example, the "worst case scenario" (i.e. Climate Change Scenario 9) involves 
increasing the frequency of hurricanes by $10 \%$ and increasing the hurricane wind speed by $10 \%$, which results in an annual damage risk ranging from $28 \%$ to $45 \%$ higher than that of the no climate change scenario for the three counties.

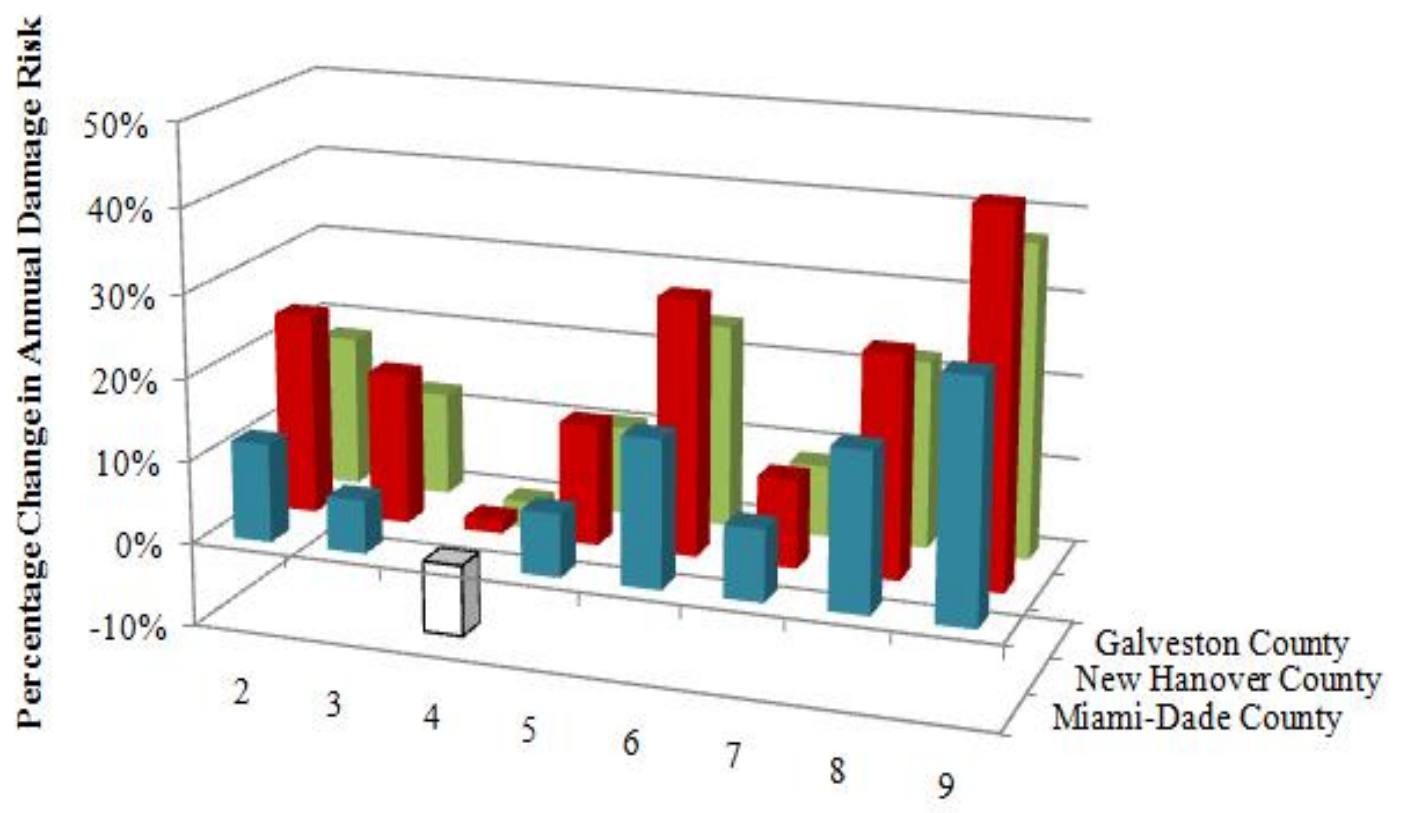

Climate Change Scenario

Figure 3.2: Percentage Change in Annual Damage Risk at year 50 Considering Scenarios of Climate Change for all three counties (Foreshore)

\subsubsection{Regional Loss Estimation Considering Hurricane Wind and Frequency}

Figure 3.3 shows the cumulative damage costs summed over 50 years for each climate change scenario for each of the three counties. For example, for the no climate change scenario, the cumulative damage cost at year 50 is $\$ 31.50$ billion, $\$ 3.35$ billion and $\$ 1.20$ billion for Miami-Dade County, New Hanover County, and Galveston County, respectively. For a moderate climate change scenario, such as Climate Change Scenario 3 , the cumulative damage costs increase to $\$ 32.70$ billion, $\$ 3.63$ billion and $\$ 1.29$ billion for Miami-Dade County, New Hanover County, and Galveston County, respectively. On the other hand, for the "worst cast" climate change scenario, i.e. Climate Change Scenario 
9 , the cumulative damage costs increase to $\$ 36.00$ billion, $\$ 4.00$ billion and $\$ 1.43$ billion for Miami-Dade County, New Hanover County, and Galveston County, respectively; or increase by $15 \%, 20 \%$, and $19 \%$ for Miami-Dade County, New Hanover County, and Galveston County, respectively, from the no climate change scenario.

From the figure it is evident that the cumulative damage costs for Miami-Dade County are considerably higher than those for the other two counties. This can be attributed to a few factors. First the annual occurrence rate of hurricanes is higher from Miami-Dade County than the other two counties, and the GPD parameters determined for Miami-Dade County are based on wind speeds that are higher than those found for the other two counties. Furthermore, the number of single-family housing units that are exposed to a hurricane event in Miami-Dade County are approximately 452,000 units, while in New Hanover County there are 58,500 units and in Galveston County there are 56,300 units. The number of housing units in Miami-Dade County is considerably higher than that of the other two counties, which results in the significantly higher exposure and damage costs for the region. The number of exposed housing units has a considerable effect on the potential damage cost to a region, and Miami-Dade County has about seven times the number of exposed housing units than both other counties. Therefore, the expected damage cost for Miami-Dade County is significantly higher than those in the other two counties. However, New Hanover County and Galveston County experience a greater percentage of increase because the annual damage risk was initially lower, resulting in proportionally higher increases. 


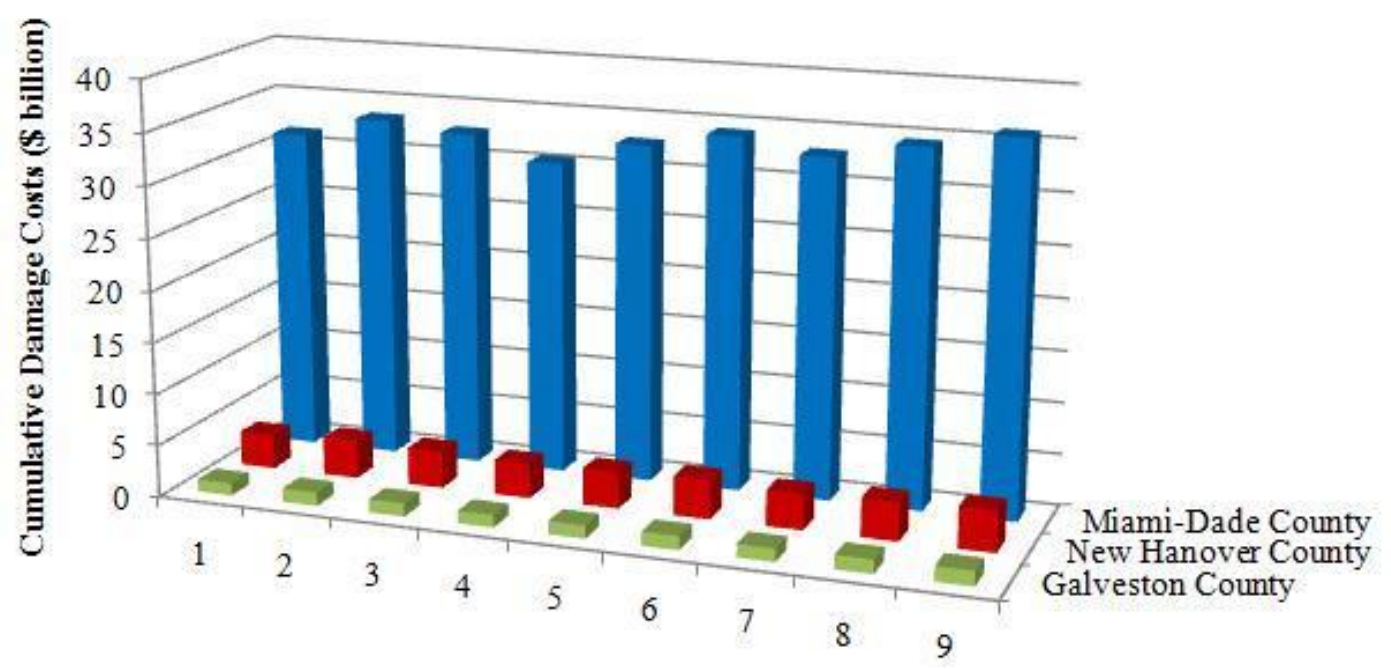

Climate Change Scenario

Figure 3.3: Cumulative Damage Costs for the Climate Change Scenarios (\$ billion)

Figure 3.4 shows the increase in cumulative damage costs for each climate change scenario from the no climate change scenario. For example, for Miami-Dade County, the moderate climate change scenarios, such as Climate Change Scenario 2, 3, 5 and 6, that involve a decrease in frequency not greater than $10 \%$ and an increase in hurricane wind that is not greater than $10 \%$, could result increases in cumulative damage costs ranging from $\$ 1.2$ billion to $\$ 2.9$ billion over 50 years. This translates to increases in damage costs of approximately $\$ 24$ million to $\$ 58$ million annually. As for New Hanover County, damage costs could increase by $\$ 287$ million to $\$ 458$ million for the moderate climate change scenarios listed above. For Galveston County, the damage costs could increase by $\$ 85$ million to $\$ 150$ million by year 50 for the moderate climate change scenarios.

Climate Change Scenario 4, which involves a 25\% decrease in hurricane frequency over 50 years, could result in a decrease in cumulative damage costs of $\$ 1,000$ million for Miami-Dade County, an increase in cumulative damage costs of \$26 million for New Hanover County, and a decrease in cumulative damage costs of \$5 million for Galveston County. However, despite this insignificant changes in damage costs, the estimated 
cumulative damage cost for Climate Change Scenario 4 is approximately $\$ 30.46$ billion, $\$ 3.38$ billion, and $\$ 1.20$ billion from Miami-Dade County, New Hanover County, and Galveston County, respectively, over 50 years, and these high damage estimates warrant an investigation into appropriate adaptation measures that may mitigate damage cost even if there is no climate change.

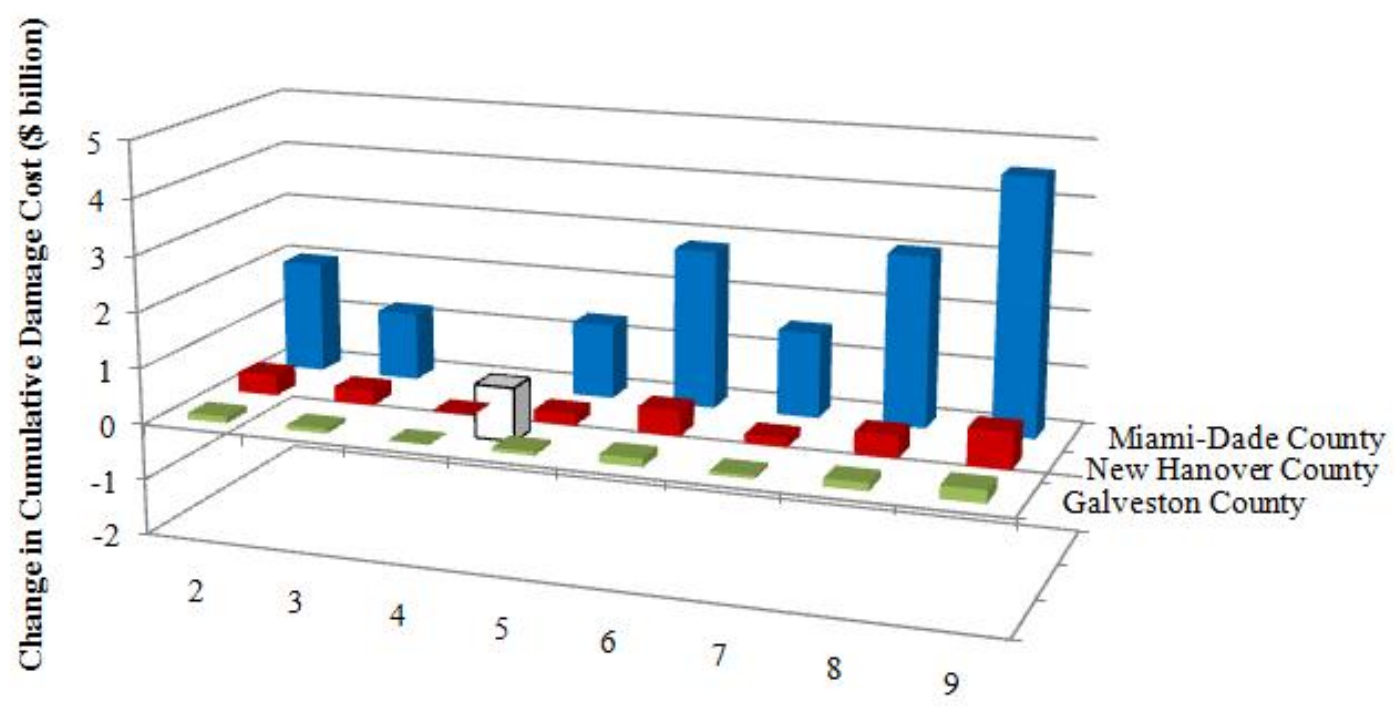

Climate Change Scenario

Figure 3.4: Increase in Cumulative Damage Costs from the No Climate Change Scenario ( $\$$ billion)

To normalize the damage risk, Figure 3.5 shows the cumulative damage cost after 50 years per 100,000 residents for all three counties under various scenarios of climate change. From this figure it can be seen that New Hanover County has a higher expected cumulative damage cost per 100,000 residents than the other two counties. If no climate change is assumed, the cumulative damage costs is $\$ 1,310$ million per 100,000 residents in Miami-Dade County, \$1,680 million per 100,000 residents in New Hanover County, and $\$ 400$ million per 100,000 residents in Galveston County. These figures increase to $\$ 1,360$ million, $\$ 1,820$ million, and $\$ 430$ million for Miami-Dade County, New Hanover County, and Galveston County, respectively, for Climate Change Scenario 3, and to \$1,500 million, \$2,000 million, and \$475 million for Miami-Dade County, New Hanover County, and Galveston County, respectively, for Climate Change Scenario 9. The 
replacement house value is $\$ 98,000, \$ 143,000$, and $\$ 82,000$ for Miami-Dade County, New Hanover County, and Galveston County, respectively. The house replacement value in New Hanover County is $45 \%$ higher than in Miami-Dade County; therefore, even though the total cumulative damage cost in Miami-Dade County is significantly higher, the cumulative damage cost per 100,000 residents is higher for New Hanover County.

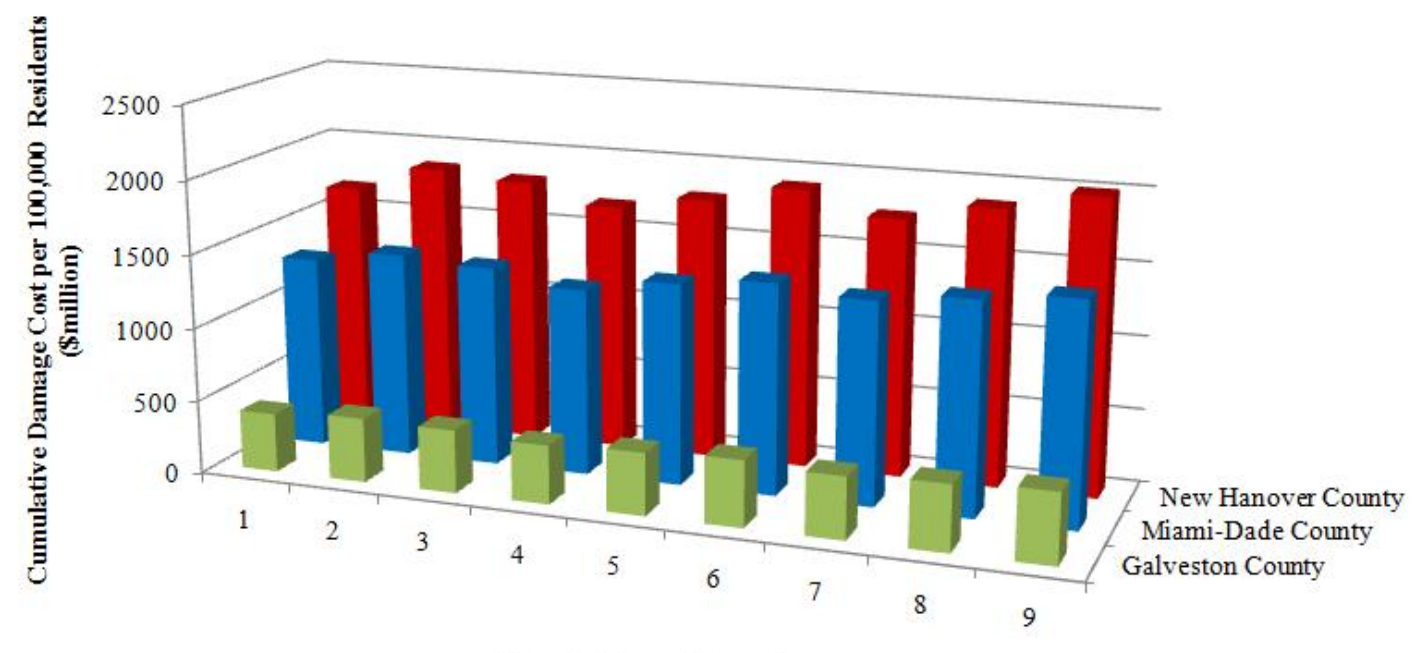

Climate Change Scenario

Figure 3.5: Cumulative Damage Cost per 100,000 Residents to Single-Family Units under Various Climate Change Scenarios (\$ million)

\subsubsection{Event-Based Regional Loss Estimation Considering Climate Variability}

\subsubsection{Hurricane Wind and Hurricane-Induced Storm Surge}

The event-based analysis involves investigating the hurricane risk due to combined hurricane wind and hurricane-induced storm surge. The illustrative example herein includes three different locations, and certain parameters must be identified for each location. First, it is assumed that the radius to maximum wind speed and central pressure deficit is constant between the three locations, because little information is available on how these parameters vary between locations. Furthermore, it is assumed that the values of these parameters correspond to the mean value and COV found in Table 3.1.

Once the radius to maximum wind speed and central pressure deficit have been identified, the site-specific parameters, such as wind speed and ocean slope, can be 
identified. The wind speed is assumed to correspond to a maximum gust wind speed with a return period of 50 years (Vickery et al. 2009). By implementing a wind speed specific to a certain return period, it is possible to incorporate the site-specific differences between hurricane wind for the three locations. This wind speed will be used to estimate the combined damage due to hurricane wind speed and hurricane-induced storm surge. The ocean slope of Miami-Dade County and Galveston County is assumed to be 1:250 corresponding to an ocean slope of $4^{\circ}$ (Pratson and Haxby 1996); on the other hand, New Hanover County is assumed to have an ocean slope of 1:500 because the continental slope off the coast of North Carolina is steeper than for the other two locations (USGS 2007). Table 3.6 shows the mean slope and mean wind speed associated with each location in 2010 assuming no climate change, and the resulting mean surge height. From the table it is evident that the surge height for Miami-Dade County is the highest, due to the fact that Miami-Dade County has a wind speed that is $23 \%$ and $15 \%$ higher than the wind speeds associated with New Hanover County and Galveston County, respectively. However, New Hanover County has a higher estimated surge height than Galveston County, despite the fact that Galveston County has a higher wind speed than New Hanover County, and this is attributed to the fact that New Hanover County as a steeper ocean slope than Galveston County.

Table 3.6: Parameters for the Event-Based Analysis

\begin{tabular}{|c|c|c|c|}
\hline Location & Slope & Wind Speed $(\mathbf{m} / \mathbf{s})$ & Surge Height $(\mathbf{m})$ \\
\hline Miami-Dade County & $1: 250$ & 58.1 & 2.2 \\
\hline New Hanover County & $1: 500$ & 44.7 & 1.7 \\
\hline Galveston County & $1: 250$ & 49.2 & 1.9 \\
\hline
\end{tabular}

\subsubsection{Climate Change Scenarios}

The NCHRP (2009) published a report on the impacts of climate change on highway transportation systems within the U.S. The report includes predictions on the sea level rise along the coast for three different climate change scenarios that are derived from the emission scenarios found in IPCC (2007): mild, moderate, and severe. The report found 
that the sea level rise may vary along the coast, i.e. the northeast coast may expect a higher sea level rise than the southeast coast. Table 3.7 shows the expected increase in sea level (cm) by 2050 (i.e. in 40 years) for all three counties. These values are obtained from NCHRP (2009) and account for the expected uplift over the next 40 years. These three scenarios of climate change for hurricane-induced storm surge will be explored under both a $0 \%$ increase in wind speed and a $5 \%$ increase in wind speed over the next 40 years (i.e. in 2050) to explore the effects of climate change on both hurricane wind and hurricane-induced storm surge.

Table 3.7: Expected Increase in Sea Level (cm) by 2050

\begin{tabular}{|c|c|c|c|}
\hline & Mild & Moderate & Severe \\
\hline Miami-Dade County & 4.50 & 12.78 & 24.94 \\
\hline New Hanover County & 4.52 & 12.90 & 25.04 \\
\hline Galveston County & 4.12 & 11.99 & 23.29 \\
\hline
\end{tabular}

\subsubsection{Hurricane Damage Risk Considering Hurricane Wind and Hurricane- Induced Storm Surge}

Once the parameters for the Irish model (2008) have been identified, the hurricane damage risk considering a specific wind speed and surge height can be estimated for each of the three exposure categories. As a starting point it is assumed that hurricane-induced storm surge only affects the highest vulnerability locations (i.e. foreshore), while it is assumed that hurricane wind speed will affect all three exposure categories (Bjarnadottir et al. 2012, Li et al. 2012). The same factors that are applied to wind speed within the annual damage estimates to account for exposure are assumed to apply within the eventbased analysis.

Estimating the damage risk due to combined hurricane wind speed and hurricane-induced storm surge involves two steps. First, the damage risk due to the hurricane wind speed is estimated by incorporating the wind speed into Huang's damage model (2001). Second, the damage risk due to hurricane-induced storm surge is estimating by utilizing the $\mathrm{ABV}$ approach outlined by Taggart and van de Lindt (2009). The ABV approach involves 
identifying a typical residential building (i.e. material, dimensions, etc.). Dao (2010), Dao and van de Lindt (2009), and Li et al. (2012) identified a typical residential building, and this building will be used as a starting point for this analysis. It is assumed that the following typical building represents an average building within the selected region. The building is assumed to be $12.2 \mathrm{~m}$ wide, $18.3 \mathrm{~m}$ long and $3.7 \mathrm{~m}$ high. The roof slope is $1: 3$, and sheathed with $12 \mathrm{~mm}$ thick Oriented Strand Board (OSB). The walls are made of 2x4 SPF placed $61 \mathrm{~cm}$ on-center. Furthermore, in determining the hurricane risk due to hurricane surge, the building is assumed to be positioned near the shoreline (i.e. within 1 $\mathrm{km}$ of the shore), 1 meter above the sea level.

Table 3.8 shows the wind damage risk and the surge damage risk for the various climate change scenarios for foreshore locations. The framework presented herein estimates that the hurricane damage risk due to hurricane wind is $0.316,0.037$, and 0.076 and due to hurricane-induced storm surge is $0.253,0.273$, and 0.237 for the no climate change scenario (i.e. $0 \%$ change in wind speed and $0 \%$ change in sea level) for Miami-Dade County, New Hanover County, and Galveston County, respectively. It is evident from the table that the hurricane damage risk due to hurricane wind speed increases more rapidly than the hurricane risk due to hurricane-induced storm surge. This can be attributed to the fact that increasing wind speeds cause exponential damage according to Huang's damage model (2001), while surge damage estimates increase more steadily for the first 3 meter surge heights (Taggart and van de Lindt 2009). In addition, it should be noted that the surge damage risk for New Hanover County is slightly higher than for Miami-Dade County, despite the fact that the surge height estimated for Miami-Dade County was higher. This is attributed to the fact that the ABV approach outlined by Taggart and van de Lindt (2009) considers the insured house value within its damage estimates, and from Table 3.2 it is evident that the insured house value for New Hanover County is higher than that of Miami-Dade County. 
Table 3.8: Combined Hurricane Damage Risk for Foreshore Locations

\begin{tabular}{|c|c|c|c|c|c|c|}
\hline \multicolumn{7}{|c|}{ 0\% Increase in Wind Speed } \\
\hline \multirow[b]{2}{*}{$\begin{array}{l}\text { Change in } \\
\text { Sea Level }\end{array}$} & \multicolumn{2}{|c|}{ Miami-Dade County } & \multicolumn{2}{|c|}{ New Hanover County } & \multicolumn{2}{|c|}{ Galveston County } \\
\hline & $\begin{array}{c}\text { Wind } \\
\text { Damage } \\
\text { Risk }\end{array}$ & $\begin{array}{c}\text { Surge } \\
\text { Damage } \\
\text { Risk }\end{array}$ & $\begin{array}{c}\text { Wind } \\
\text { Damage } \\
\text { Risk }\end{array}$ & $\begin{array}{c}\text { Surge } \\
\text { Damage } \\
\text { Risk }\end{array}$ & $\begin{array}{c}\text { Wind } \\
\text { Damage } \\
\text { Risk }\end{array}$ & $\begin{array}{c}\text { Surge } \\
\text { Damage } \\
\text { Risk }\end{array}$ \\
\hline No Change & 0.316 & 0.253 & 0.037 & 0.273 & 0.076 & 0.237 \\
\hline Mild & 0.316 & 0.256 & 0.037 & 0.277 & 0.076 & 0.238 \\
\hline Moderate & 0.316 & 0.281 & 0.037 & 0.281 & 0.076 & 0.241 \\
\hline Severe & 0.316 & 0.282 & 0.037 & 0.284 & 0.076 & 0.250 \\
\hline \multicolumn{7}{|c|}{$5 \%$ Increase in Wind Speed } \\
\hline \multirow[b]{2}{*}{$\begin{array}{l}\text { Change in } \\
\text { Sea Level }\end{array}$} & \multicolumn{2}{|c|}{ Miami-Dade County } & \multicolumn{2}{|c|}{ New Hanover County } & \multicolumn{2}{|c|}{ Galveston County } \\
\hline & $\begin{array}{c}\text { Wind } \\
\text { Damage } \\
\text { Risk }\end{array}$ & $\begin{array}{c}\text { Surge } \\
\text { Damage } \\
\text { Risk }\end{array}$ & $\begin{array}{c}\text { Wind } \\
\text { Damage } \\
\text { Risk }\end{array}$ & $\begin{array}{c}\text { Surge } \\
\text { Damage } \\
\text { Risk }\end{array}$ & $\begin{array}{c}\text { Wind } \\
\text { Damage } \\
\text { Risk }\end{array}$ & $\begin{array}{c}\text { Surge } \\
\text { Damage } \\
\text { Risk }\end{array}$ \\
\hline No Change & 0.503 & 0.282 & 0.053 & 0.281 & 0.113 & 0.245 \\
\hline Mild & 0.503 & 0.282 & 0.053 & 0.282 & 0.113 & 0.247 \\
\hline Moderate & 0.503 & 0.284 & 0.053 & 0.289 & 0.113 & 0.250 \\
\hline Severe & 0.503 & 0.292 & 0.053 & 0.315 & 0.113 & 0.253 \\
\hline
\end{tabular}

\subsubsection{Regional Loss Estimation Considering Hurricane Wind and Hurricane-Induced Storm Surge}

Figure 3.6 shows the percentage change in damage costs from the no climate change scenario (i.e. no change in wind speed and no change in sea level), considering both $0 \%$ and $5 \%$ increase in wind speed and various changes in sea level. For example, if winds speeds remain constant and sea levels experience a moderate change due to climate change, damage costs for all three counties are not significantly impacted. However, 
from the figures it is apparent that if climate change effects wind speed (i.e. Figure 3.6b), the damage costs may increase considerably from the no climate change scenario. It is apparent from the figure that the damage estimates for Miami-Dade County experience the greatest amount of change considering the various climate change scenarios, while the damage estimates for New Hanover County experience the least amount of change due to climate change. This is due to the fact that the damage risk due to wind speed for New Hanover County is considerably lower than that of the other two counties, initially, and thus experiences the less changes due to changes in the wind speed. Furthermore, it can be concluded from this figure, that for the proposed framework, wind speed has a considerably greater influence on the damage estimates than surge height. The varying surge height alone does not have a considerable impact on the damage costs (Figure 3.6a), but varying both the wind speed and the surge height has a significant effect on damage costs; therefore, it is evident that wind speed has a significant role in estimating damage costs due to hurricane hazard within the proposed framework. 


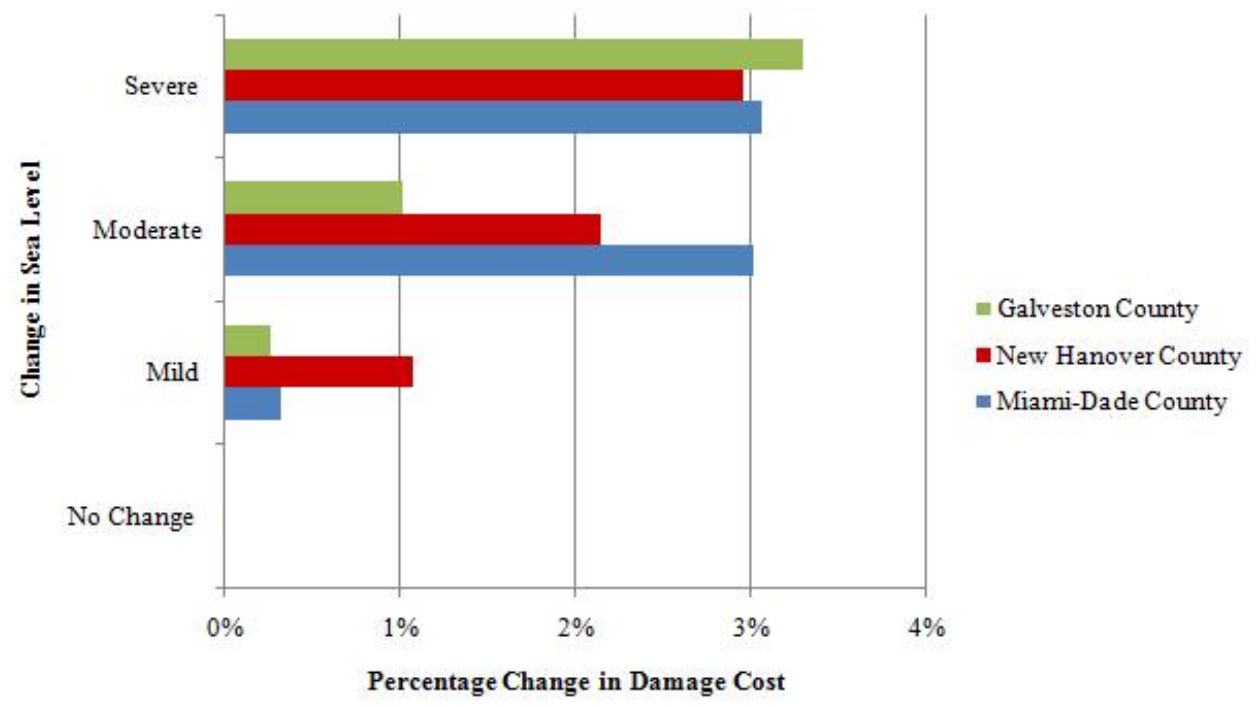

(a) $0 \%$ Increase in Wind Speed

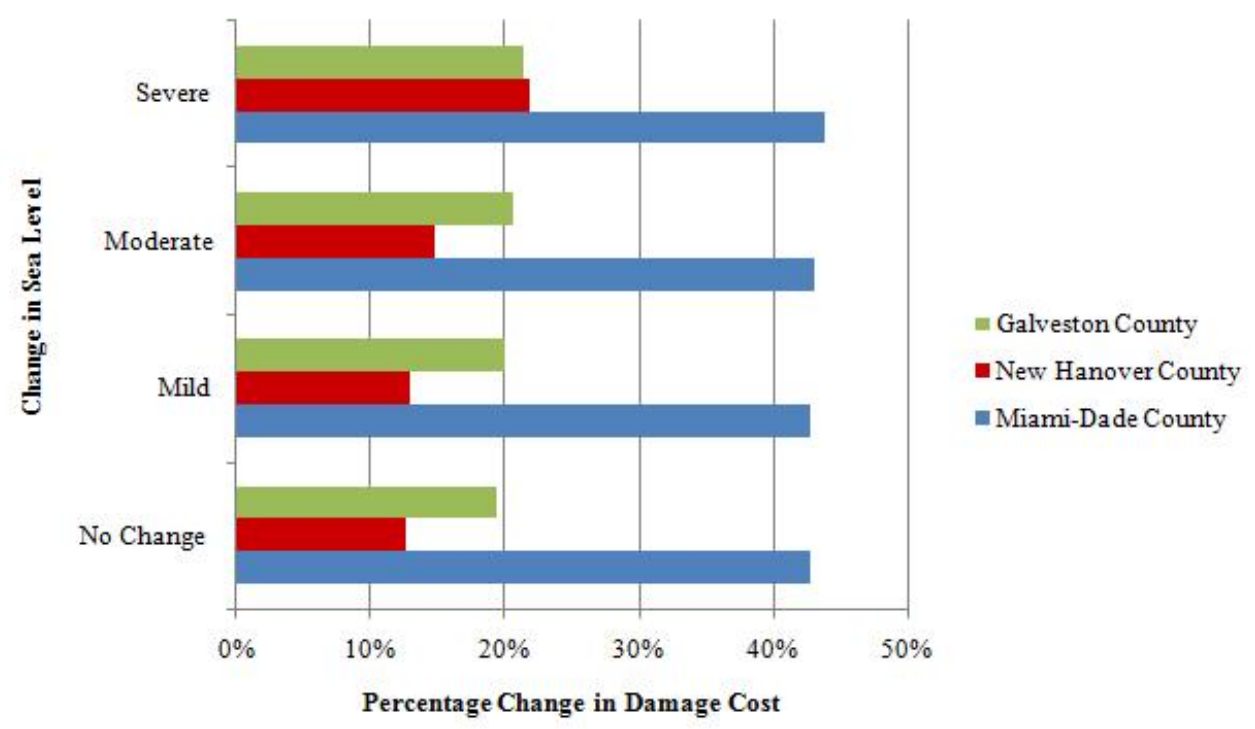

(b) $5 \%$ Increase in Wind Speed

Figure 3.6: Percentage Change in Damage Costs from the No Climate Change Scenario 


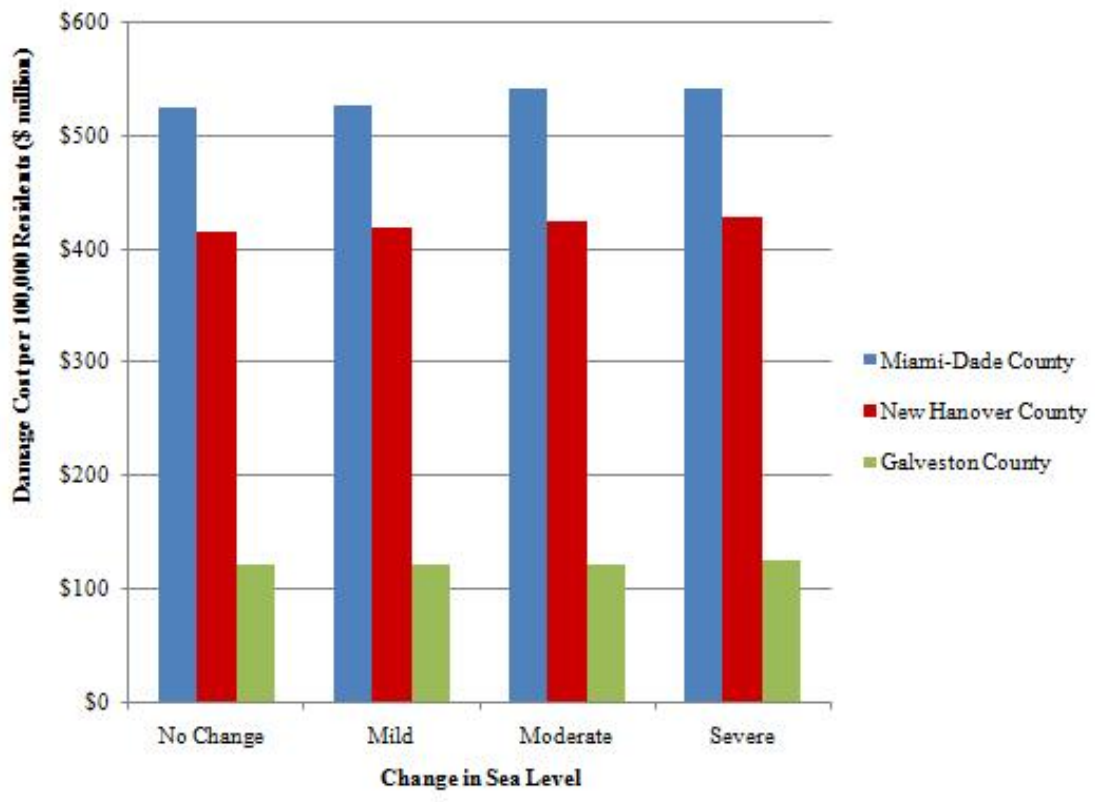

(a) $0 \%$ Increase in Wind Speed

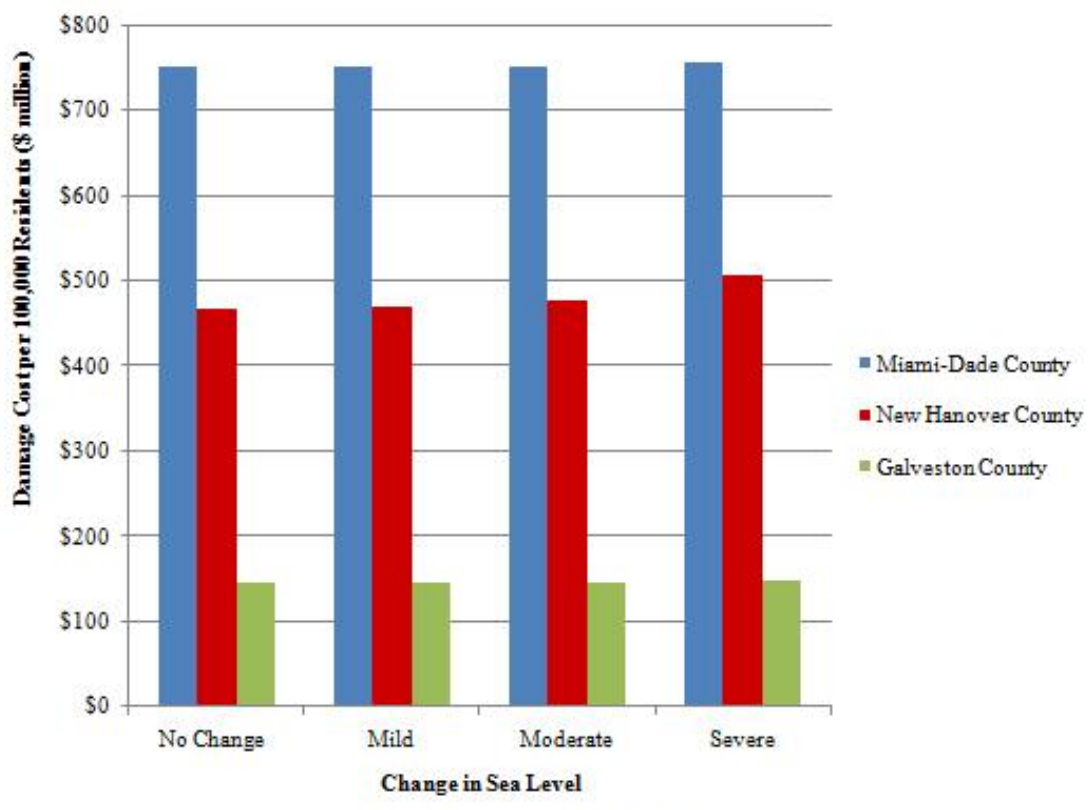

(b) $5 \%$ Increase in Wind Speed

Figure 3.7: Damage Cost per 100,000 Residents to Single-Family Units under Various Climate Change Scenarios (\$ million)

Figure 3.7 presents the damage costs per 100,000 residents for the various scenarios of climate change. If no climate change is assumed, the damage costs is $\$ 525$ million per 100,000 residents in Miami-Dade County, \$420 million per 100,000 residents in New 
Hanover County, and \$120 million per 100,000 residents in Galveston County. In contrast to the results presented for the annual damage analysis presented earlier, MiamiDade County has a higher expected damage cost per 100,000 residents than the other two counties. This can be attributed to several factors. First, Miami-Dade County has a significantly higher expected damage risk due to wind, or $88 \%$ higher than New Hanover County and $76 \%$ higher than Galveston County. Second, similar to the annual damage analysis conducted earlier, Miami-Dade County has a significantly larger number of houses exposed to hurricane hazard than the other two counties. However, on the other hand, these results show that New Hanover County has a higher expected damage cost per 100,000 residents than Galveston County. This is expected because the insured house value for New Hanover County is higher than that of Galveston County as stated earlier.

\subsection{Conclusions}

It is possible that hurricane patterns and resulting damage losses may change as a result of climate change. The proposed framework provides a tool to evaluate the potential impact of such change on hurricane damage risks assessment. This paper investigates the potential impacts of climate change through two forms of analysis, i.e. the annual regional loss estimation and the event-based regional loss estimation. These two forms are chosen because the surge model does not have the capacity to estimate annual surge heights, but when more complex surge models are available they can be incorporated into the annual regional loss estimation in the same manner as into the event-based regional loss estimation. Both analyses are conducted for three locations: Miami-Dade County, Florida, New Hanover County, North Carolina, and Galveston County, Texas. Through both analyses it was found that climate change may have a significant impact on hurricane damage costs.

The annual regional loss estimation involved investigating the potential impacts climate change may have on damage costs due to both hurricane wind and hurricane frequency. The cumulative damage costs due to hurricanes were estimated for each of the three locations over a 50-year time frame for various climate change scenarios. Nine different climate change scenarios, that involved changing both the wind and frequency of 
hurricanes over 50 years, were considered. On the other hand, the event-based analysis involved determining the potential effects climate change may have on the damage costs within a region considering a specific wind speed and surge height. In order to account for climate change, linear changes in both hurricane wind speed and hurricane-induced storm surge height were explored. Given the proposed framework and the assumptions made within this paper, it was found that climate change may have a considerable impact on hurricane damage costs.

\subsection{Acknowledgements}

The research described in this paper was supported, in part, by the National Science Foundation (NSF) Catalyzing New International Collaborations Program, and Infrastructure Management and Extreme Events Program under Grant No. NSF 1050443. This support is gratefully acknowledged. However, the writers take sole responsibility for the views expressed in this paper, which may not represent the position of the NSF or their respective institutions.

\subsection{References}

Adachi, T. and Ellingwood, B. R. (2010) Comparative assessment of civil infrastructure network performance under probabilistic and scenario earthquakes, J. Infrastructure Systems ASCE 16, 1-10.

Ang, A.H-S., and Tang, W.H. (2007) Probability Concepts in Engineering. Wiley: New York.

ASCE-7 (2007) Minimum Design Loads for Buildings and Other Structures. (ASCE Standard 7-05), Am. Soc. of Civil. Engineers, Reston.

Bender, M. A., Knuston, T.R., Tuleya, R.E., Sirutis, J.J., Vecchi, G.A., Garner, S.T., and Held, I.M. (2010) Modeled impact of anthropogenic warming of the frequency of intense Atlantic hurricanes, Science 327, 454-458. 
Bjarnadottir, S., Li, Y. and Stewart, M.G, (2012) Hurricane Risk Assessment Of Power Distribution Systems Considering Impacts Of A Changing Climate, Journal of Infrastructure Systems, ASCE (In press).

Bjarnadottir, S., Li, Y. and Stewart, M.G., (2011) A Probabilistic-based Framework for Impact and Adaptation Assessment of Climate Change on Hurricane Damage Risks and Costs, Structural Safety, 33, 173-185.

Boesch, D.F., Field, J.C., Scavia, D. (2000) The Potential Consequences of Climate Variability and Change on Coastal Areas and Marine Resources. Report of the coastal areas and marine resources sector team, U.S. National Assessment of the Potential Consequences of the Climate Variability and Change. U.S. Global Change Research Program. National Oceanic and Atmospheric Administration Coastal Ocean Program Decision Analysis Series No. 21. Silver Spring, Maryland.

Climate Change Science Program (CCSP) (2008) Impacts of Climate Change and Variability on Transportation Systems and Infrastructure: Gulf Coast Study, Phase I. A Report by the U.S. Climate Change Science Program and the Subcommittee on Global Change Research [Savonis, M. J., V.R. Burkett, and J.R. Potter, Eds. Department of Transportation, Washington, DC, USA.

Culliton, T.J. (1998) Population: distribution, density and growth. National Oceanic and Atmospheric Administration State of the Coast Report. Silver Spring, Maryland. Available: http://state-of-coast.noaa.gov/topics/html/pressure.html

Dao, T.N. (2010) "The Development of Performance-Based Wind Engineering for Residential Structures: From Concept to Application", Ph.D. Dissertation, Colorado State University, Fort Collins, CO, USA.

Dao, T.N., and van de Lindt, J.W. (2010) Methodology for Wind-Driven Rainwater Intrusion Fragilities for Light-Frame Wood Roof Systems, Journal of Structural Engineering, 136, 700-706.

Elsner, J.B. (2006) Evidence in support of the climate change-Atlantic hurricane hypothesis, Geophysical Research Letters, 33. 
Elsner, J.B., Kossin, J.P., and Jagger, T.H. (2008) The increasing intensity of the strongest tropical cyclones. Nature, 455, 92-95.

Emanuel, K. (2005) Increasing destructiveness of tropical cyclones over the past 30 years. Nature, 436: 686-688.

Government Accountability Office (GAO) (2007) Climate Change: Financial Risks to Federal and Private Insurers in Coming Decades are Potentially Significant. Unites States Accountability Office: Washington, D.C.

Goldenberg, S. B., Landsea, C. W., Mestas-Nunez, A. M. \& Gray, W. M. (2001) The recent increase in Atlantic hurricane activity: causes and implications, Science 293, 474479.

Grigoriu, M. (2006) Probabilistic Models for Directionless Wind Speeds in Hurricanes. National Institute of Standards and Technology, U.S. Department of Commerce: NIST GCR 06-906.

Huang, Z., Rosowsky, D.V., and Sparks, P.R. (2001). Long-term hurricane risk assessment and expected damage to residential structures. Reliability engineering \& system safety, 74, 239-249.

Hubbert, G.D., and McInnes, K. (1999) A Storm Surge Inundation Model for Coastal Planning and Impact Studies. Journal of Coastal Research, 15, 168-185.

Intergovernmental Panel on Climate Change (IPCC) (2007) Climate Change 2007: The Physical Science Basis. Contribution of Working Group I to the Fourth Assessment Report of the Intergovernmental Panel on Climate Change. Solomon, S., Qin, D., Manning, M., Chen, Z., Marquis, M., Averyt, K.B., Tignor, M., and Miller, H.L. (eds.). Cambridge University Press, Cambridge.

Irish, J.L., Resio, D.T., and Ratcliff, J.J. (2008) The Influence of Storm Size on Hurricane Surge. Journal of Physical Oceanography, 38, 2003-2013.

Jagger, T., and Elsner, J. (2006) Climatology models for extreme hurricane winds in the United States. J. Climate, 19, 3220-3236. 
Johnson, B. (2005) After the Disaster: Utility Restoration Cost Recovery. Edison Electricity Institute, Washington D.C.

Khanduri, A.C., and Morrow, G.C .(2003) Vulnerability of buildings to windstorms and insurance loss estimation. Journal of wind engineering and industrial aerodynamics, 91, 455-467.

Klotzbach, P.J (2006) Trends in global tropical cyclone activity over the past twenty years (1986-2005), Geophys. Res. Letters, 33.

Knuston, T.R., McBride, J.L., Chan, J., Emanuel, K., Holland, G., Landsea, C., Held, I., Kossin, J.P., Srivastava, A.K., and Sugi, M. (2010) Tropical Cyclones and Climate Change. Nature Geoscience, 3, 157-163.

Knutson, T. R., Sirutis, J. J., Garner, S. T., Vecchi, G. A., and Held, I. (2008) Simulated reduction in Atlantic hurricane frequency under twenty-first-century warming conditions. Nature Geosci., 1, 359-364.

Knutson, T.R., and Tuleya, R.E. (1999) Increased hurricane intensities with CO2 induced warming as simulated using the GFDL hurricane predication system, Climate Dynamics, $15,503-519$.

Knutson, T.R., Tuleya, R.E., and Kurihara, Y. (1998) Simulated Increase of Hurricane Intensities in a CO2 Warmed Climate, Science, 279, 1018-1021.

Landsea, C.W. (2007) Counting Atlantic tropical cyclones back to 1990. EOS Trans. Am. Geophysical Union, 88, 197-208.

Landsea, C.W., Harper, B.A., Hoarau ,K., and Knaff, J.A. (2006) Can we detect trends in extreme tropical cyclones? Science, 313, 452-454.

Larsen, P., Goldsmith, S., Smith, O., Wilson, M., Strzepek, K., Chinowsky, P., and Saylor, B. (2007) Estimating Future Costs for Alaska Public Infrastructure at Risk from Climate Change. Institute of Social and Economic Research, University of Alaska Anchorage. Available from: <http://dx.doi.org/10.1016/j.gloenvcha.2008.03.005>. 
Leicester, R.H., Bubb, C.T.J., Dorman, C., and Beresford, F.D. (1979) An assessment of potential cyclone damage to Dwellings in Australia, in Proc. 5th Int. Conf. on Wind Engineering, J.E. Cermak, Editor. Pergamon, New York, United States, 23-36.

Li, Y., and Ellingwood, B.R. (2006) Hurricane damage to residential construction in the US: Importance of uncertainty modeling in risk assessment. Engineering Structures, 28, 1009-1017.

Li, Y., and Ellingwood, B.R. (2009) Risk-based Decision Making for Multi-hazard Mitigation for Wood-frame Residential Construction. Australian Journal of Structural Engineering, 9, 17-26.

Li ,Y., and Stewart, M.G. (2011) Cyclone Damage Risks Caused by Enhanced Greenhouse Conditions and Economic Viability of Strengthened Residential Construction, Natural Hazards Review, ASCE, 12, 9-18.

Li, Y. (2012) Assessment of Damage Risks to Residential Buildings and Cost-Benefit of Mitigation Strategies Considering Hurricane and Earthquake Hazards, Journal of Performance of Constructed Facilities, ASCE, 26, 7-16.

Li, Y., van de Lindt, J.W., Dao, T., Bjarnadottir, S., and Ahuja, A. (2012) Loss Analysis for Combined Wind and Surge in Hurricanes, Natural Hazards Review, ASCE, 13, 1-10.

Malmstadt, J.C., Elsner, J.B., and Jagger, T.J., (2010). Risk of Strong Hurricane Winds to Florida Cities. J. Appl. Meteor. Climatol., 49, 2121-2132.

Mann, M., and Emanuel, K. (2006) Atlantic hurricane trends linked to climate change. Eos 87, 233-241.

National Association of Home Builders (NAHB) (1993) Assessment of Damage to Single-Family Homes Caused By Hurricane Andrew and Iniki, NAHB Research Center Report, Upper Marlboro, MD.

National Atlas of the United States [cited 2009 August 24]; Available from: http://nationalatlas.gov 
National Cooperative Highway Research Program (NCHRP) (2009) NCHRP \#20-83(5): Synthesis of Information on Projections of Change in Regional Climates and Recommendation of Analysis Regions. [cited 2012 February 12]; Available from: http://onlinepubs.trb.org/onlinepubs/nchrp/docs/NCHRP20-83\%2805\%29_Task2-

4TechnicalReport.pdf

National Institute of Standards and Technology (NIST) (2009) Hurricane wind speeds. [cited 2011 August 30]; Available from: http://www.nist.gov/wind

National Weather Service (NWS) (2009) Flood Losses: Compilation of Flood Loss Statistics. [cited 2010 August 04]; Available from: http://www.weather.gov/oh/hic/flood_stats/Flood_loss_time_series.shtml

New York City Panel on Climate Change (2009) Climate Change Adaptation in New York City: Building a Risk Management Response. New York Academy of Sciences, 1196, May 2010.

National Oceanic and Atmospheric Administration (NOAA) (2009) Historical Hurricane Data. [cited 2010 September 10]; Available from: http://www.noaa.gov/

Palutikof, J.P., Brabson, B.B., Lister, D.H., and Adcock, S.T. (1999) A review of methods to calculate extreme winds, Meteorological Applications, 6, 119-132.

Parisi, F., and R. Lund, (2008) Return periods of continental U.S. hurricanes. J. Climate, 21, 403-410.

Pielke, R.A.J., Landsea, C., Mayeld, M., Laver, J., and Pasch, R. (2005) Hurricanes and global warming. Bulletin of the American Meteorological Society, 86, 1571-1575.

Pielke, R.A.J., Gratz, J., Landsea, C.W., Collins, D., Saunders, M.A., and Musulin, R. (2008) Normalized Hurricane Damage in the United States: 1900--2005. Natural Hazards Review, 9, 29-42.

Porter, K.A. (2000) "Assembly-based vulnerability of buildings and its uses in seismic performance evaluation and risk-management decision-making", Doctoral dissertation, Stanford University, Stanford CA. 
Pratson, L.F., and Haxby, W.F. (1996) What is the slope of the U.S. continental slope? Geology, 24, 3-6.

Scavia, D., Field, J.C., Boesch, D.F., Buddemeier, R., Burkett, V., Canyan, D., Fogarty, M., Harwell, M.A., Howarth, R.W., Mason, C., Reed, D.J., Royer, T.C., Sallenger, A.H. and Titus, J.G. (2002) Climate change impacts on U.S. coastal and marine ecosystems. Estuaries, 25, 149-164.

Sparks, P.R., Schiff, S.D., and Reinhold, T.A. (1994) Wind damage to envelopes of houses and consequent insurance losses. Journal of wind engineering and industrial aerodynamics, 53, 145-155.

Steenbergen, R.D.J.M., Koster, T., and Geurts, C.P.W. (2012) The effect of climate change and natural variability on wind loading values for buildings. Building and Environment, 55, 178-188.

Stewart, M.G., and Li, Y. (2010) Methodologies for Economic Impact and Adaptation Assessment of Cyclone Damage Risks Due to Climate Change, Australian Journal of Structural Engineering, 10, 121-136.

Stewart, M.G., Rosowsky, D.V., and Huang, Z. (2003) Hurricane Risks and Economic Viability of Strengthened Construction. Natural hazards review, 4, 12-19.

Stewart, M.G. and Wang, X. (2011a), Risk assessment and economic viability of climate adaptation measures for Australian housing subject to extreme wind events, MODSIM, $19^{\text {th }}$ International Congress on Modelling and Simulation, Perth, 2852-2858.

Stewart, M. G. and Wang, X. (2011b) Risk Assessment of Climate Adaptation Strategies for Extreme Wind Events in Queensland, CSIRO Climate Adaptation Flagship, Canberra, May 2011b [cited 2012 February 30]; Available from: http://www.csiro.au/resources/ /media/CSIROau/Flagships/Climate\%20Adaptation/Extre meWind_CAF_pdf\%20Standard.pdf

Stubbs, N., and Perry, D.C .(1996) A damage simulation model for buildings and contents in a hurricane environment, in Building an International Community of 
Structural Engineers- Proc. Structures Congress S.K. Ghosh and J. Mohammadi, Editors., ASCE, New York, United States, 989-996.

Taggart, M. and van de Lindt, J.W. (2009) Performance-Based Design of Residential Wood-Frame Buildings for Flood Based on Manageable Loss, Journal of Performance of Constructed Facilities, ASCE, 23, 56-64.

Taggart, M. (2007) "Performance-Based Design of Wood frame Structures for Flooding". M.Sc. Thesis, Colorado State University, Fort Collins, CO.

U.S. Geological Survey (USGS) (2007) U.S. EEZ Atlantic Continental Margin GLORIA. [cited 2012 May 25]; Available http://coastalmap.marine.usgs.gov/gloria/eastcst/geology.html

US Census Bureau (2009): State and County Quick Facts. [cited 2009 April 14]; Available from: http://quickfacts.census.gov/qfd/states/12/12086.html.

Verboom, G.K., de Ronde, J.G., and van Dijk, R.P. (1992) A fine grid tidal flow and storm surge model of the North Sea. Continental Shelf Research. 12, 213-233.

Vickery, P.J., Adhere, D., Teasdale, L.A.Jr., and Lavelle, F.M. (2009) U.S. Hurricane Wind Speed Risk and Uncertainty. Journal of Structural Engineering, 135, 301-320.

Westerink, J.J., Luettich, R.A., Baptista, A.M., Scheffner, N.W., \& Farrar, P. (1994). Tide and Storm Surge Predictions using the Finite Element Model. J. Hydraul. Eng., 118, 373-1390.

White House (2009) Global Climate Change Impacts in the United States. U.S. Global Change Research Program. Washington, D.C. [cited 2010 April 2]; Available from: http://downloads.globalchange.gov/usimpacts/pdfs/climate-impacts-report.pdf.

Wu, S-Y., Yarnal, B., and Fisher, A. (2002) Vulnerability of coastal communities to sealevel rise: a case study of Cape May County, New Jersey, USA, Climate Research, 22, 255-270. 
Zigomanis, A. (2007) Land Prices Still Challenge for New Housing Market. Property Council of Australia. [cited 2009 April 21]; Available from: http://www.propertyoz.com.au/Article/NewsDetail.aspx?id=15. 


\title{
Chapter 4
}

\section{Hurricane Risk Assessment of Power Distribution Poles Considering Impacts of a Changing Climate $^{3}$}

\author{
Sigridur Bjarnadottir ${ }^{1}$, Yue $\mathrm{Li}^{2}$, Mark G. Stewart ${ }^{3}$ \\ ${ }^{1}$ Ph.D. Candidate \\ Department of Civil and Environmental Engineering \\ Michigan Technological University, Houghton, Michigan, USA, sobjarna@mtu.edu \\ ${ }^{2}$ Associate Professor \\ Department of Civil and Environmental Engineering \\ Michigan Technological University, Houghton, Michigan, USA, yueli@mtu.edu \\ ${ }^{3}$ Professor and Director \\ Center for Infrastructure Performance and Reliability, \\ School of Engineering, The University of Newcastle, Callaghan, NSW, Australia \\ mark.stewart@newcastle.edu.au
}

\footnotetext{
${ }^{3}$ The material contained in this chapter was previously published in the journal Journal of Infrastructure Systems, ASCE. Bjarnadottir, S., Li, Y. and Stewart, M.G. (2012) Hurricane Risk Assessment of Power Distribution Poles Considering Impacts of A Changing Climate, Journal of Infrastructure Systems, ASCE (In press). With permission from ASCE. See Appendix IV for documentation of permission to republish this material.
} 


\subsection{Abstract}

Storm related power outages cause approximately $\$ 270$ million per year in repair costs in the United States (U.S.). As a result of increasing sea surface temperatures due to the changing climate, hurricane patterns (i.e. intensity/frequency) may change; however, there is much uncertainty as to how climate change may affect hurricane patterns. Implications of the changing hazard patterns on hurricane risk warrants an investigation to evaluate the potential impact of climate change on power distribution pole failure. This paper proposes a probabilistic framework to evaluate the vulnerability of power distribution poles to hurricanes under the potential impact of a changing climate. Two methods for the design of distribution poles in the U.S., the National Electric Safety Code (NESC) method and the American Society of Civil Engineers (ASCE) method, are considered to investigate the difference of the vulnerability of a distribution pole subjected to hurricane hazard. The framework includes a reliability analysis of the designed power distribution poles using fragility analysis, the effects of degradation of timber poles, probabilistic wind models, and an assessment of the potential impacts of climate change on the annual failure probability of power distribution poles. This paper finds that climate change may have a significant effect on the structural failure probabilities of distribution poles. The age of the poles has a significant impact on the reliability of power distribution poles, which warrants the exploration of cost effective methods to determine when a distribution pole should be replaced to ensure adequate strength to withstand wind loads.

Keywords: Climate Change, Power Distribution Poles, Degradation, Power Infrastructure, Hurricanes, Reliability Analysis, Risk Assessment, Vulnerability.

\subsection{Introduction}

Storm related power outages cause approximately $\$ 270$ million in repair costs, annually, in the U.S. (Johnson 2005). Hurricane Rita in 2005 left 500,000 customers without power in Louisiana (LPSC 2005) and 1.5 million customers without power in Texas (PUCT 2006). After Hurricane Katrina in 2005, approximately $82 \%$ of customers in the Gulf Coast region lost power (Guikema et al. 2010), and approximately $50 \%$ of 
customers in New Orleans, Louisiana were without power for six weeks after the hurricane made landfall (Kwasinski et al. 2009). In 2004, during a six week period, four hurricanes made landfall in Florida, causing over $\$ 1$ billion in damages to power systems, making it the most destructive hurricane season in Florida for utility companies (Johnson 2005). In 1992, Hurricane Andrew caused the failure of approximately $10.1 \%$ timber distribution poles, resulting in the loss of power to $44 \%$ of Florida Power and Light Company’s customers (FP\&LC 2006, Larsen et al. 1996).

Reed (2008) investigated damage to power systems as a result of winter storms that were accompanied by strong wind flows. The study found that hurricanes and winter storms produce similar failure probabilities to power systems. Reed et al. (2010) also found, through an analysis of the damage to the infrastructure of the power system after Hurricane Rita, that high hurricane winds caused the majority of the damage. Despite the evident vulnerability of the power system to hurricane damage, approximately $53 \%$ of the U.S. population lives in coastal counties (Crosset et al. 2008). Florida utility companies have experienced a 20\% increase in customers from 1994 to 2004 (Johnson 2005).

The distribution systems (lines and poles) are the most susceptible to damage due to high wind. Reliability-based design methods for distribution poles were introduced in 1990 , and have since been integrated into design standards (Dagher 2001). However, the performance of the distribution poles remained unknown, resulting in non-uniform reliabilities in time and space (Bhuyan and $\mathrm{Li}$ 2006, Li et al 2006). Furthermore, the effect of pole strength degradation on hurricane risk assessment for distribution poles is not clear. Windborne debris and trees can also cause a considerable amount of damage to the power system (Winkler et al. 2010). Debris includes anything that has been broken or destroyed. Debris and fallen trees combined with intense hurricane winds can be a serious problem to surrounding infrastructure. However, debris will not be included in the proposed framework, but it will be incorporated into this framework at a later time.

Lastly, current hurricane risk assessments of the power system consider only current climate conditions (Bhuyan and Li 2006, Li et al. 2006), but various studies (e.g. Elsner et al. 2008, Emanuel 2005, White House 2009) are suggesting that the hurricane 
intensity/frequency may change as a result of the warming global climate, which may result in an increased repair and/or replacement cost of distribution poles. For example, Peters et al. (2006) found that elevated $\mathrm{CO}_{2}$ levels due to enhanced greenhouse conditions could result in an increase in hurricane wind speeds of $10 \%$, which could in turn result in loads on power distribution lines that are $15 \%$ to $20 \%$ higher than the design criteria. Therefore, it is becoming increasingly important to explore the effects a changing climate may have on the failure probability of the power system.

This paper develops a probabilistic method to evaluate the risk of hurricanes on the failure and reliability of timber power distribution poles. Two methods dominate the design of distribution poles in the U.S. (Malmedal and Sen 2003). The first method is a deterministic approach outlined in the National Electric Safety Code (NESC 2002). The second method was developed by the American Society of Civil Engineers (ASCE-111 2006). The framework proposed in this paper is threefold: design, reliability analysis, and assessing the potential impacts of climate change.

A typical distribution pole will be designed considering both design methods taking into account various loading conditions. Fragility curves will be developed for the distributions poles considering both new poles and existing distribution poles that have been subjected to degradation. Finally, both design methods will be used to assess the impacts climate change may have on the annual structural failure probability of the distribution pole. The purpose of this paper is not to examine whether there is a direct relationship between climate change and changing patterns of wind hazard, nor to endorse any specific scenario of climate change (or lack thereof). Instead, we aim to propose a framework for hurricane risk assessment of power distribution poles to account for the potential impact of climate change.

\subsection{Design of Power Distribution Poles: ASCE and NESC}

A typical timber distribution pole system is seen on Figure 4.1 that consists of a solid pole, three conductors, one neutral wire, and one communication wire. Wood materials account for approximately $99 \%$ of distribution poles in the U.S. (USWAG 2005), and 
Southern pine is the most common material for distribution poles, accounting for $75 \%$ of poles in the U.S. (Wolfe and Moody 1997).

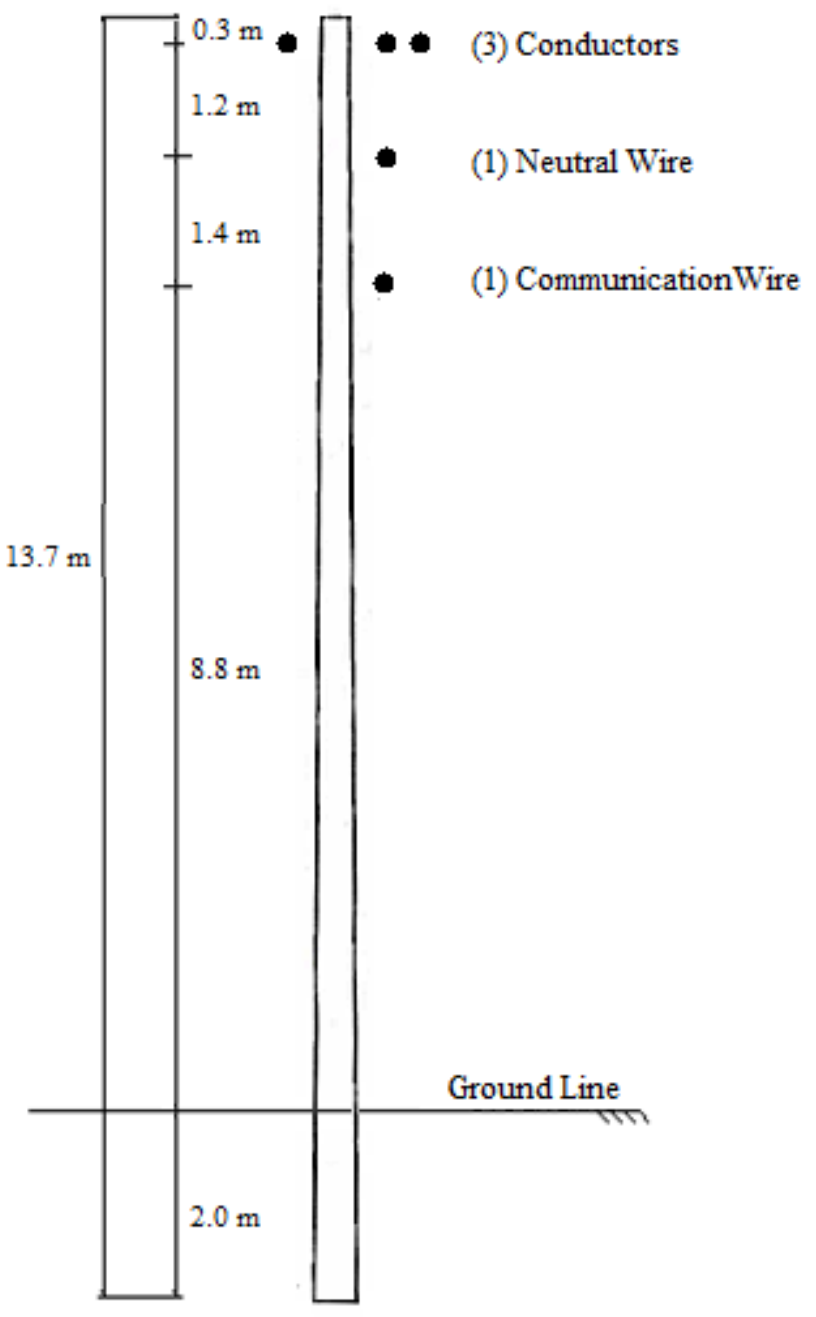

Figure 4.1: Typical Distribution Pole System

\subsection{Design based on ASCE vs. NESC}

Historically, distribution poles were designed using the deterministic method prescribed in the NESC standard (NESC 2002). This Allowable Stress Design (ASD) method is based on specific load factors and strength factors that are combined with zonal loading maps (Wolfe et al. 2001). The load and strength factors are determined based on the grade of the construction of the distribution poles. In order to maintain consistent (or 
uniform) reliabilities for distribution poles, the Load Resistance Factor Design (LRFD) method was developed by the ASCE (Bhuyan and Li 2006, Dagher 2001), and is now typically used in distribution (utility) pole design (ASCE-111 2006). LRFD is used to assess the performance of a distribution pole at various limit states. Though the ASCE design method is now often used in the design of new distribution poles, the NESC method is still used in the design of new distribution poles by some utilities in the U.S., which is why both methods will be investigated. This paper will explore the differences between designing distribution poles with the ASCE and NESC design methods. The following formulation can be used for both methods.

$R_{n}>\sum \frac{\gamma_{j}}{\emptyset_{j}} S_{n, j}$

where $R_{n}$ is the design (nominal) strength of the poles (e.g. design bending moment) and identified using design standards, $\varnothing_{j}$ is the strength factor for load effect $j, S_{n, j}$ is the design (nominal) load for load effect $\mathrm{j}$, and $\gamma_{\mathrm{j}}$ is the load factor for load effect $\mathrm{j}$.

When designing distribution poles, the design method should be specified and the corresponding partial safety factors identified (i.e. values for $\varnothing$ and $\gamma$ ). Then the design load $\left(\mathrm{S}_{\mathrm{n}}\right)$ is determined, and consequently the required design strength is determined by using Eq. (4.1). By means of the required design strength, the circumference of the pole at ground line can be estimated. From the required circumference, design standards (ANSI 2002) are used to determine the required class of pole and the corresponding design strength $\left(\mathrm{R}_{\mathrm{n}}\right)$.

The two methods recommend different values for the strength $(\varnothing)$ and load $(\gamma)$ factors. ASCE-111 (2006) recommends that the strength factor (ø) be 0.79 , for a ground line bending moment with a coefficient of variation (COV) of $20 \%$, and that the load factor is $\gamma=1.0$ for wind load. In addition, ASCE requires that the dead load should be adjusted with a factor of 1.1 when including the P- $\Delta$ effect. This case is referred to as Design Case 1 (Case 1 for brevity) in this paper.

The NESC method also uses strength and load factors for the design of distribution poles (NESC 2002). Both factors are determined based on the grade of construction and the 
type of load being designed for. Distribution poles are defined as Grade C construction. The strength factor is $\varnothing=0.85$, when wind load is considered (NESC 2002). There has been much discussion on what the value of the load factor should be. Malmedal and Sen (2003) recommended a load factor of $\gamma=2.2$ for transverse wind loading (Design Case 2), while Bingel et al. (2003) suggested a value of $\gamma=1.75$ (Design Case 3). Furthermore, Brown (2008) stated that distribution poles are typically designed with a load factor of $\gamma=2.2$, but that the design load is reduced by half (i.e. $\gamma=1.1$ ) (Design Case 4). Table 4.1 presents the four design cases based on wind load conditions that will be investigated in this paper.

Table 4.1: Four Design Cases

\begin{tabular}{|c|c|c|c|}
\hline Design Method & Design Case & $\boldsymbol{\sigma}$ & $\boldsymbol{\gamma}$ \\
\hline \multirow{2}{*}{ ASCE } & 1 & 0.79 & 1 \\
\hline \multirow{2}{*}{ NESC } & 2 & 0.85 & 2.2 \\
\cline { 2 - 4 } & 3 & 0.85 & 1.75 \\
\cline { 2 - 4 } & 4 & 0.85 & 1.1 \\
\hline
\end{tabular}

\subsubsection{Design (Nominal) Load $\left(\mathrm{S}_{\mathrm{n}}\right)$}

As shown in Figure 4.1, the example pole system consists of a solid pole, three conductors, one neutral wire, and one communication wire; therefore, the design load of the distribution poles is affected by all these components, and adjusted with an amplification factor to account for the P- $\Delta$ effect:

$$
S_{n}=a m p \cdot \sum_{i=1}^{N} F_{i} h_{i}
$$

where $S_{n}$ is the design load $(\mathrm{N}-\mathrm{m})$, amp is the amplification factor, $F_{i}$ is the wind force (N) on component $\mathrm{i}$ (Eq. 4.3), and $\mathrm{h}_{\mathrm{i}}$ is the distance (m) from ground line to the centroid of component i. The P- $\Delta$ effect refers to the deflected unbalance that occurs in a tapered distribution pole (ASCE-111 2006). More specifically, the pole "leans over" to resist the load, resulting in additional bending moments that affect the applied wind load (Bingel et al. 2003). ASCE-111 (2006) recommends utilizing the Gere-Carter method (1962) to 
account for the P- $\Delta$ effect in utility pole structures. The method involves determining an amplification factor that accounts for the additional bending moments due to the P- $\Delta$ effect (Gere and Carter 1962), and this method is used herein.

The wind force acting on each component is described with (ASCE-113 2008):

$F_{i}=Q k_{i} V^{2} I_{F W} G_{R F} C_{f} A_{i}$

where $\mathrm{Q}$ is air density factor, $\mathrm{k}_{\mathrm{i}}$ is terrain exposure coefficient for component $\mathrm{i}, \mathrm{V}$ is the 3 -sec gust wind speed, $\mathrm{I}_{\mathrm{FW}}$ is the importance factor, $\mathrm{G}_{\mathrm{RF}}$ is the gust response factor, $\mathrm{C}_{\mathrm{f}}$ is the force coefficient, and $A_{i}$ is the projected wind surface area normal to the direction of wind for component $i$.

\subsubsection{Design (Nominal) Resistance $\left(R_{n}\right)$}

The American National Standards Institute (ANSI 2002) categorizes timber distribution poles into different classes based on material. ANSI (2002) assigns each class a permitted bending moment at ground line (i.e. $2.0 \mathrm{~m}$ from the base of the pole, see Figure 4.1) depending on the height and the circumference of the poles. The circumference $\left(\mathrm{C}_{\mathrm{g}}\right)$ of the poles is estimated from the required diameter $\left(D_{\text {req }}\right)$, where the required diameter is estimated from the design load $\left(\mathrm{S}_{\mathrm{n}}\right)$ of the poles and the fiber stress of the species of timber (Brown 2008, Wolf and Kluge 2005):

$D_{\text {req }}=\sqrt[3]{\frac{32\left(\frac{\gamma}{\phi}\right) s_{n}}{\pi \cdot F_{0}}}$

where $\gamma$ is the load factor, $\varnothing$ is the strength factor, and $F_{0}$ is the designated fiber stress (ANSI 2002).

Once the circumference at ground line has been determined, the class of the poles is determined from design standards, and from the pole class the design resistance $\left(R_{n}\right)$ is found (ANSI 2002). Figure 4.2 presents a flowchart of how the distribution poles are designed. 


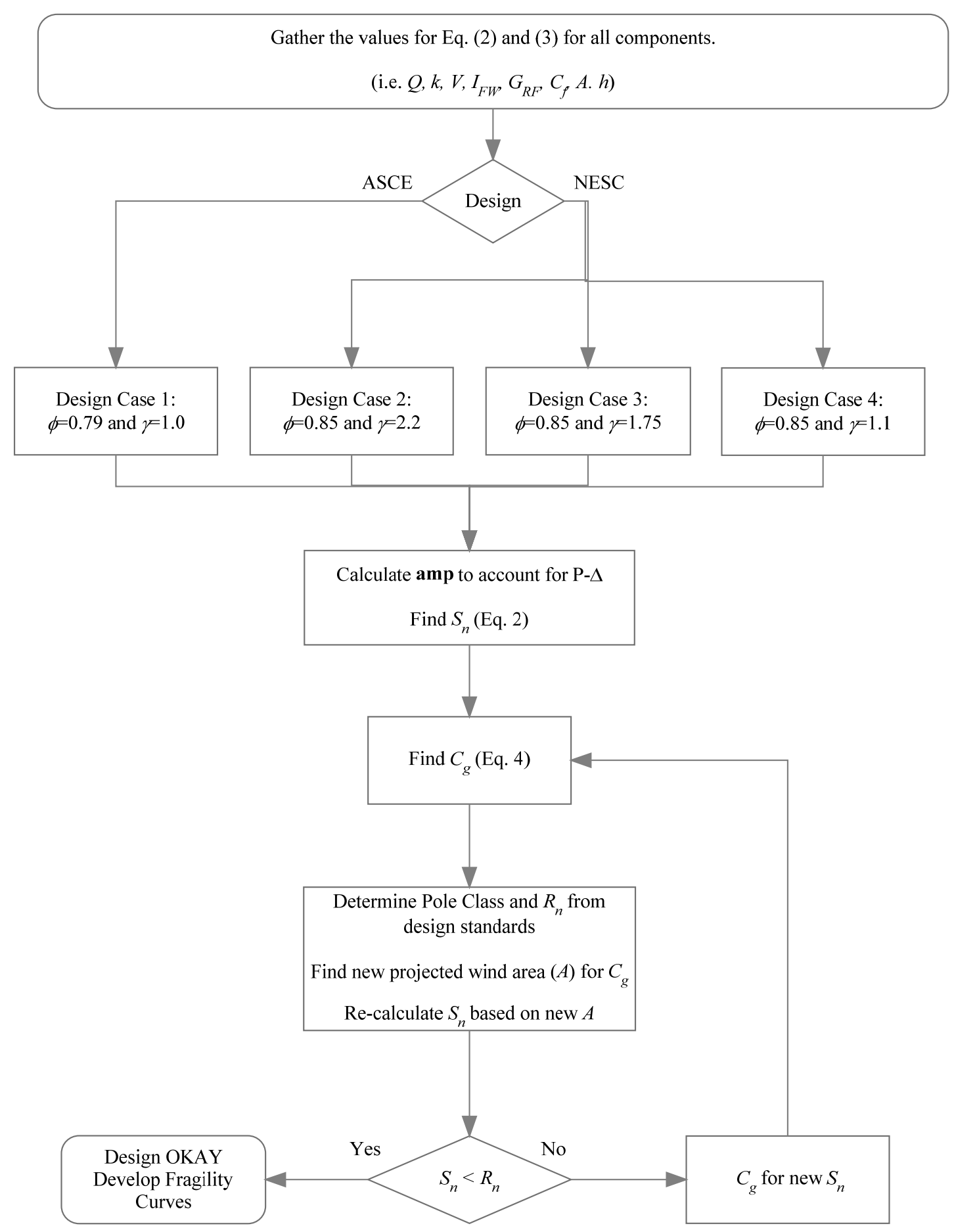

Figure 4.2: Flowchart of the Design Process of the Distribution Pole 


\subsubsection{Degradation of timber poles}

The strength of distribution poles degrades with age (Stewart and Goodman 1990, Gustavsen and Rolfseng 2000, Haldar and Tucker 2006). Fungal attacks are the main contributor to the deterioration of strength in timber poles, because timber is an organic material (Baraneedaran et al. 2009). The key concern with fungal decay is referred to as in-ground decay, because the poles are in direct contact with the soil creating, in many cases, optimal conditions for fungal attacks (Baraneedaran et al. 2009, Leicester et al. 2003, Wang et al. 2008b).

The modified resistance (Eq. 4.5) is estimated for a specific age of pole to represent how strength deteriorates over time.

$R(t)=a(t) \cdot M E \cdot R_{n}$

where $R(t)$ is the resistance after time $t, a(t)$ is the degradation function, ME is the model error, and $R_{n}$ is the design strength of the pole. The design strength (found in design standards) is not equal to the actual strength of timber distribution poles, because no distribution poles are identical, which can be attributed to factors such as the cutting and material properties of each individual distribution pole. Within the estimations of the resistance at time t (Eq. 4.5), this uncertainty is accounted for by including ME, which is relative to the design strength (Lupoi et al. 2006, Zhai and Stewart 2010).

Leicester et al. (2003) developed an engineering model that estimates the depth of decay in timber poles after a period of time, based on a comprehensive study of timber degradation. Wang et al. (2008b) took the model further and developed a model that estimates the strength of timber poles after a specific time period based on the decay depth. These models were developed based on a survey of timber poles in Australia, but will be used herein as a starting point to estimate the degradation of timber pole strength in the U.S.

The degradation function $(a(t))$ from Wang et al. (2008b) is used herein to represent how the strength of distribution poles deteriorates over time. In the following, the derivation

of the degradation function is outlined; the interested reader is directed to Wang et al. (2008b) for details. The degradation function is estimated as (Wang et al. 2008b): 
$a(t)=\frac{\pi}{32}(D-d(t))^{3}$

where $\mathrm{D}$ is the initial diameter $(\mathrm{mm})$ of the pole and $\mathrm{d}(\mathrm{t})$ is the decay depth $(\mathrm{mm})$ after time t.

Timber poles are typically composed of either solely heartwood or a combination of sapwood and heartwood. For simplicity, it is assumed herein that the timber distribution poles are composed of only untreated heartwood, so the degradation model can be implemented directly (Wang et al. 2008b). The future work will involve modifying the degradation model to account for a combination of sapwood and heartwood. According to the Australian Standard on Timber Durability (AS 56042005), the Durability Class of timber is assigned depending on the expected service life. The average service life of distribution poles in the U.S. is estimated at 32 years (Morrell 2005), corresponding to a Durability Class 2 according to AS 5604 (2005). The hardness of Southern pine is classified as soft (AS 5604-2005); these characteristics will be assumed to apply to Southern pine timber poles in the U.S., as no such data are obtainable in the U.S. When more information becomes available, these assumptions can be modified.

The rate of decay can be estimated:

$r=k_{\text {wood }} k_{\text {climate }} \quad(\mathrm{mm} /$ year $)$

where $\mathrm{k}_{\mathrm{wood}}$ is the wood parameter and $\mathrm{k}_{\mathrm{climate}}$ is the climate parameter. The wood parameter is 0.38 , based on Durability Class 2. The climate parameter is assumed to be 1.5 (Climate Class of B) (Wang et al. 2008b). According to the Köppen-Geiger Climate Classification, Climate Class B refers to a temperate subtropical climate, and as MiamiDade County, Florida is the location chosen for the illustrative example included herein, this climate class is assumed to be appropriate, because Miami-Dade County has a subtropical climate (Peel et al. 2007).

Wang et al. (2008b) found that decay in timber poles does not commence immediately after a pole has been erected, but there is in fact a period of time where the decay is negligible. This is referred to as the time lag $\left(\mathrm{t}_{\mathrm{lag}}\right)$ :

$t_{\text {lag }}=3 r^{-0.4}$

(year) 
Then the time in which decay reaches its threshold can be determined (Wang et al. 2008a):

$t_{d_{0}}=t_{\text {lag }}+\frac{d_{0}}{r}$

where $\mathrm{d}_{0}$ is the decay threshold. A value of $\mathrm{d}_{0}=5 \mathrm{~mm}$ is recommended when no data is available (Wang et al. 2008a). Once the decay threshold has been reached, the decay depth $(d(t))$ is estimated based on the rate of decay.

$d(t)= \begin{cases}c t^{2} & t \leq t_{d_{0}} \\ \left(t-t_{\text {lag }}\right) r & t>t_{d_{0}}\end{cases}$

where $\mathrm{c}=\left(\mathrm{d}_{0} / \mathrm{t}_{\mathrm{d} 0}{ }^{2}\right)$.

Figure 4.3 shows the decay depth $(\mathrm{mm})$ over time, using the abovementioned assumptions for the decay rate (see Eq. (4.7)) and Climate Class B. The figure clearly shows the time lag in which the decay depth is negligible, which is estimated to be 3.8 years. After the decay threshold has been obtained $(5 \mathrm{~mm})$, the rate of decay is constant, or $0.50 \mathrm{~mm} /$ year for this example.

For illustration purposes, Figure 4.4 shows how the pole bending strength may change over time considering a hypothetical Class 5 Southern Pine pole. The designated fiber stress of a Class 5 pole is $55.4 \mathrm{MPa}$ with an initial diameter of $263 \mathrm{~mm}$ according to design standards (ANSI 2002). The bending strength during the time lag is approximately $98,900 \mathrm{~N}-\mathrm{m}$, which is consistent with the design bending moment found in ANSI (2002) for this particular size and type of pole. Similar figures were developed for various classes of poles, and it was found that the bending strength estimated during the time lag with Eq. (4.5) is consistent with the design bending moment provided in the design standards (ANSI 2002). 


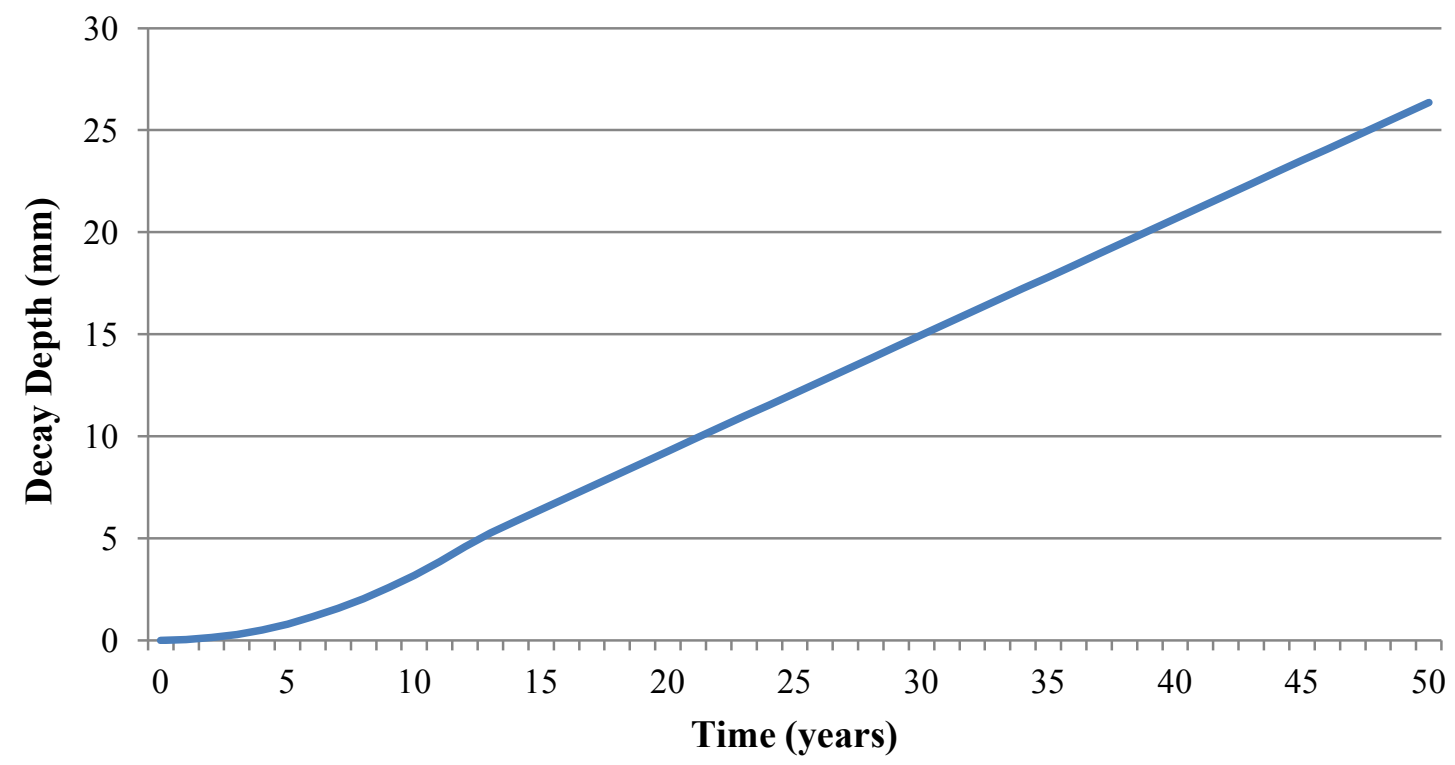

Figure 4.3: Decay Depth over Time

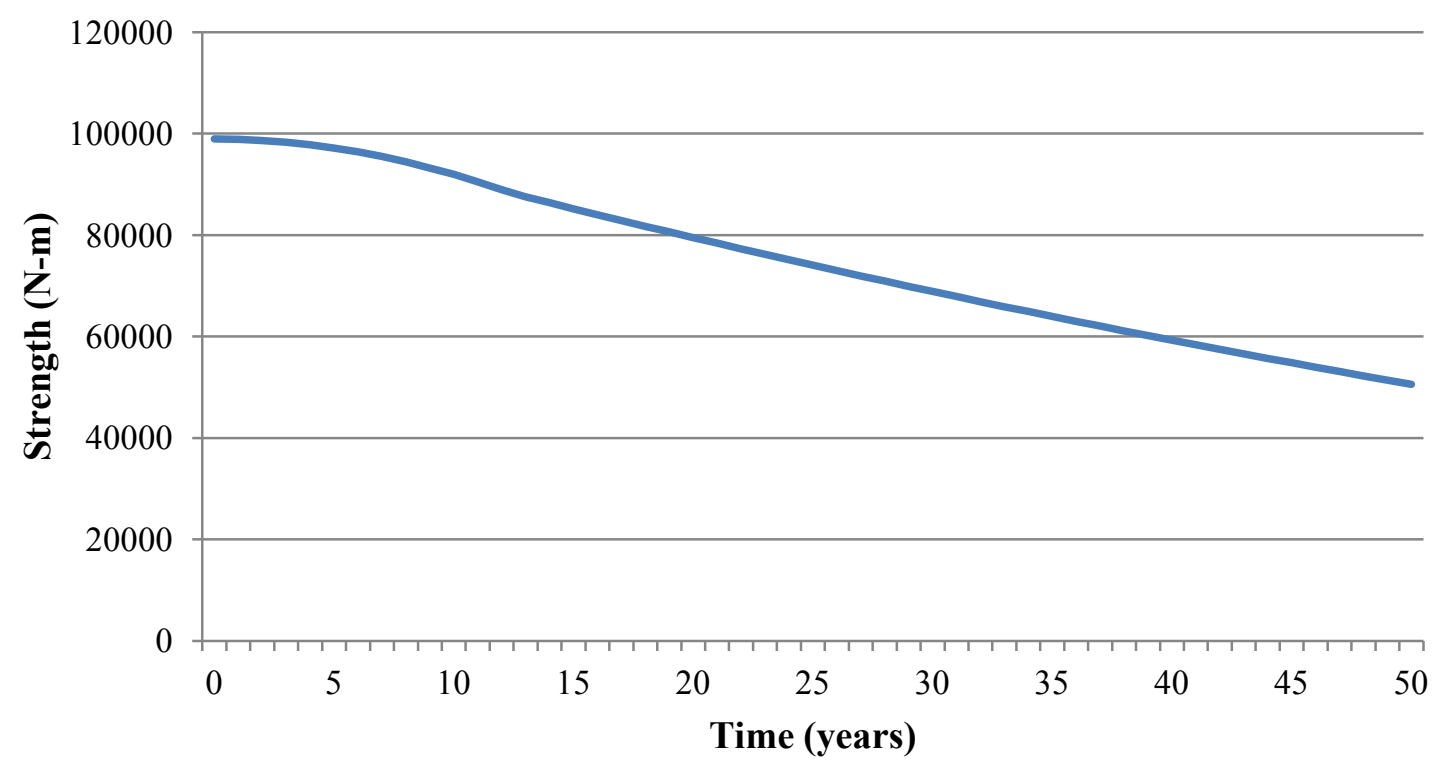

Figure 4.4: Bending Strength over Time

The uncertainty which arises from using this predictive model to estimate the degradation of the strength must be accounted for. Wang et al. (2008a) stated that the uncertainty within the decay model (Eq. (4.6)), the timber and the climate parameters contribute to the uncertainty of the decay depth $\left(\mathrm{COV}_{\mathrm{d}}\right)$. 
$\operatorname{COV}_{d}=\sqrt{\operatorname{COV}_{\text {wood }}^{2}+\operatorname{COV}_{\text {climate }}^{2}+\operatorname{COV}_{d m}^{2}}$

where $\mathrm{COV}_{\mathrm{d}}, \mathrm{COV}_{\text {wood }}, \mathrm{COV}_{\text {climate, }}$, and $\mathrm{COV}_{\mathrm{dm}}$ are the $\mathrm{COV}$ of the decay depth $(\mathrm{d}(\mathrm{t}))$, the wood parameter $\left(\mathrm{k}_{\mathrm{wood}}\right)$, the climate parameter $\left(\mathrm{k}_{\mathrm{climate}}\right)$, and the predictive decay model, respectively. $\mathrm{COV}_{\mathrm{dm}}$ accounts for modeling errors within the decay model, similar to the ME found in Eq. (4.5). Based on the extensive testing of timber poles, $\mathrm{COV}_{\text {wood }}=0.55$ for timber poles of Durability Class $2, \mathrm{COV}_{\text {climate }}=0.55$ for all climate classes, and $\mathrm{COV}_{\mathrm{dm}}=0.50$ (Wang et al. 2008b). Therefore, for a Durability Class 2 timber pole, $\mathrm{COV}_{\mathrm{d}}=0.9$. The uncertainty arising within the strength estimations stems from the uncertainty of the decay depth and the initial uncertainty of the pole strength (Wang et al. 2008a). The COV of the pole strength at time $t$ is given (Wang et al. 2008a):

$\operatorname{COV}_{R}(t)^{2}=\operatorname{COV}_{R}(0)^{2}+\left(\frac{6 \operatorname{Cov}_{d} d(t)}{D-2 d(t)}\right)^{2}$

where $\operatorname{COV}_{R}(0)$ is the COV of the initial strength, $\operatorname{COV}_{d}$ is the COV of the decay depth, $\mathrm{d}(\mathrm{t})$ is the decay depth at time $\mathrm{t}$, and $\mathrm{D}$ is the initial diameter of the pole.

\subsection{Risk Assessment}

\subsubsection{Reliability analysis}

The reliability of distribution poles is defined as the probability that the poles will fulfill the performance criteria (i.e. not fail) ( $\mathrm{Li}$ et al. 2006). The performance of distribution poles is dependent on various intervening variables (e.g. wind speed, pole strength) and design parameters (e.g. pole height and size). There is much uncertainty associated with the variables, which must be accounted for in the analysis of the performance of the distribution poles. The general limit state function of the poles for both design methods is given as:

$$
G(t)=R(t)-S(t)
$$

where $R(t)$ is the actual capacity of the poles at time $t$ (Eq. (4.5)) and $S(t)$ is the actual load at time t. The mean of the pole strength is determined from available test data (Vanderbilt et al. 1982). The actual load $(\mathrm{S}(\mathrm{t}))$ is determined by accounting for the uncertainties present within the variables of Eq. (4.2). The $\operatorname{Pr}(G>0)$ is defined as the 
reliability of the pole, while the probability of failure is defined as $\operatorname{Pr}(G<0)$. Monte Carlo Simulation (MCS) is utilized to estimate the probability of failure.

\subsubsection{Hurricane Fragility Analysis}

Hurricane fragility is defined as the conditional probability of failure of a structural member or structural system as a function of wind speed ( $\mathrm{Li}$ and Ellingwood 2006). The structural fragility of infrastructure systems is often modeled as a lognormal cumulative distribution function (CDF) (Li and Ellingwood 2006).

$F_{D}(V)=\Phi\left(\left(\ln \left(V / m_{R}\right) / \xi_{R}\right)\right.$

where $\mathrm{V}$ is the 3 -sec gust wind speed, $\mathrm{m}_{\mathrm{R}}$ is the median capacity or resistance, $\xi_{\mathrm{R}}$ is the logarithmic standard deviation of the capacity or resistance, and $\Phi(\cdot)$ is the standard normal probability integral. Figure 4.5 presents a flowchart of the framework for developing the hurricane fragility curves based on the designed poles (from Figure 4.2). It should be noted that the terminology on Figure 4.5, i.e. "consider statistics", refers to assigning variables a statistical distribution, mean, and COV from either available test data or based on previous studies or assumptions. 


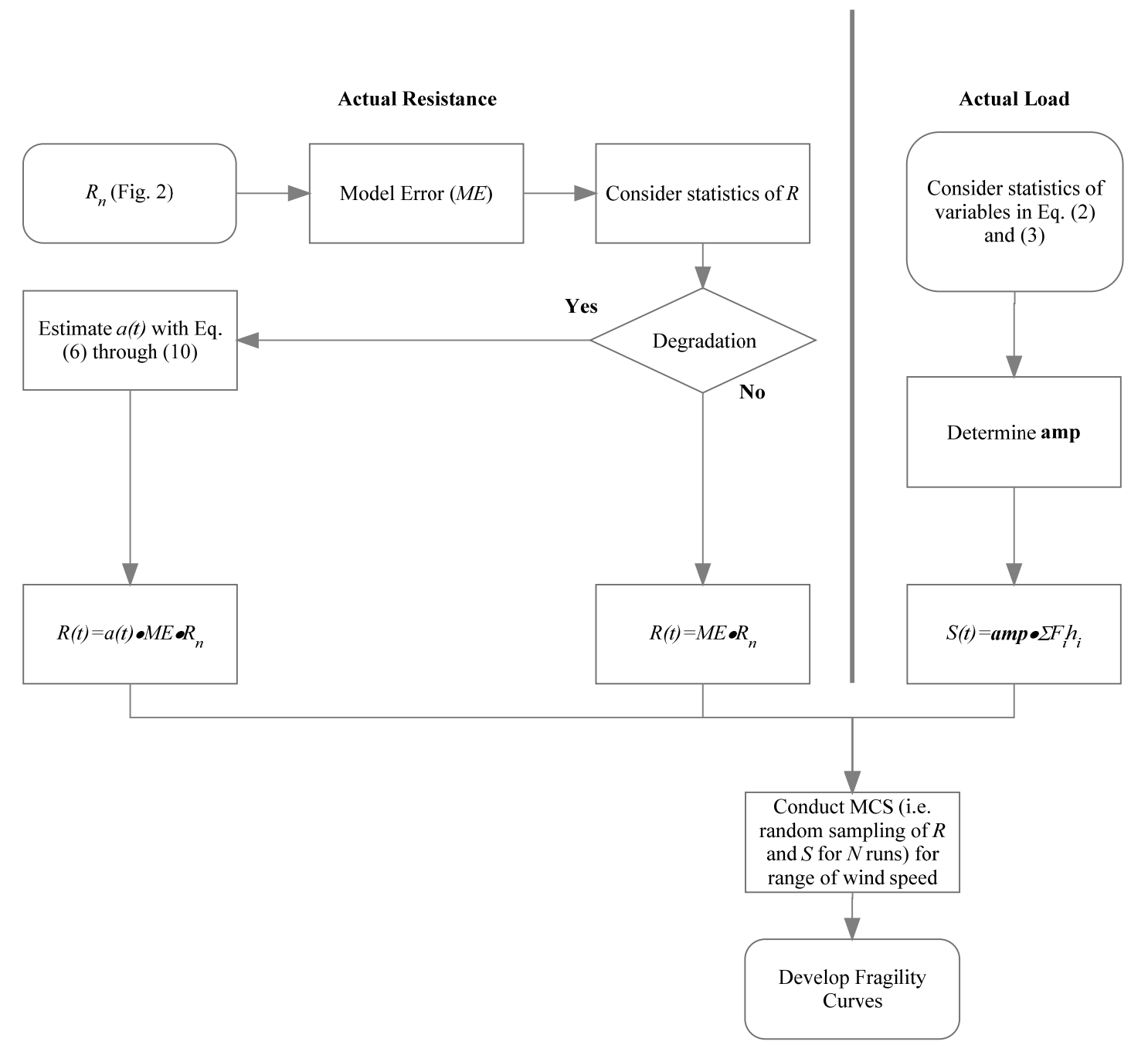

Figure 4.5: Flowchart of the Development of Fragility Curves

\subsubsection{Annual Probability of Failure $\left(P_{f}\right)$}

The expected annual probability of failure $\left(\mathrm{P}_{\mathrm{f}}\right)$ due to hurricane hazard can be determined by convolving the hurricane fragility $\mathrm{F}_{\mathrm{D}}(\mathrm{v})$ and the probability density function (PDF) of the annual hurricane wind speed model $\mathrm{f}_{\mathrm{v}}(\mathrm{v})$ (Li and Ellingwood 2006).

$P_{f}=\int F_{D}(V) \cdot f_{v}(V) d V$

The Weibull distribution is used to model the maximum annual 3-sec gust wind speed in the U.S. (Li and Ellingwood 2006), which is assumed to be at a height of $10 \mathrm{~m}$ on open terrain. The PDF of the Weibull distribution, assuming that wind speeds are nonstationary due to climate change, is given as (Bjarnadottir et al. 2011): 
$f_{v}(V, t)=\frac{\alpha(t)}{u(t)} \cdot\left(\frac{V}{u(t)}\right)^{\alpha(t)-1} \exp \left[-\left(\frac{V}{u(t)}\right)^{\alpha(t)}\right]$

where $\mathrm{V}$ is the 3-sec gust wind speed, and $\alpha$ and $\mathrm{u}$ are time-dependent and site-specific parameters.

\subsubsection{Potential impacts of climate change}

Some studies have indicated that hurricane activity in the Atlantic Ocean has increased significantly since 1995 (Goldenberg et al. 2001). Emanuel (2005) found that an increase in sea surface temperature (SST) of $1^{\circ} \mathrm{C}$ could produce an increase of $5 \%$ in the peak wind speed of a tropical cyclone. The frequency of hurricanes may increase as well (CCSP 2008). Broccoli and Manabe (1990) found that if $\mathrm{CO}_{2}$ levels double, the frequency of hurricanes may increase by $6 \%$.

There is a great uncertainty in assessing the impact of climate change on hurricane intensity/frequency in the U.S. (Stainforth 2005). However information on how climate change may affect hurricane patterns is available from other regions of the world. Studies have found that there may be an increase in high precipitation events (e.g. tropical cyclones) in Southeast Asia and Japan (Chang 2010, Webersik et al. 2010). Studies (AGO 2007, Walsh et al. 2002) have found that wind speeds may increase by $5 \%$ to $10 \%$ in Queensland, Australia by 2050. Similarly, Vickery et al. (2009) suggested that, in the U.S., increases in wind speeds of up to $10 \%$ may be possible. It can be expected that power systems may experience more failure as a result of the changing climate. Therefore, it is imperative to assess the potential impacts climate change may have on the annual $P_{f}$ of distribution poles.

\subsection{Illustrative Example}

Typical Southern pine timber poles (i.e. $14 \mathrm{~m}$ high with spacing of $46 \mathrm{~m}$ ) in Miami-Dade County, Florida are designed using both the ASCE and the NESC design methods to illustrate the proposed framework. It is assumed that the pole supports three conductors, one neutral wire, and one communication cable. Timber poles are classified based on the load capacity of the poles (ANSI 2002). 


\subsubsection{Design of Distribution Poles}

The design load $\left(\mathrm{S}_{\mathrm{n}}\right)$ is assumed to be the total ground line moment of the poles, which is the summation of the ground line moment of each component (i.e. pole, conductors, neutral wire, and communication cable). Table 4.2 shows the design values for typical poles (ASCE-113 2008, NESC 2002). Factors $\mathrm{Q}, \mathrm{I}_{\mathrm{FW}}$, and $\mathrm{C}_{\mathrm{f}}$ are the same for all of the components of the distribution pole systems, but $\mathrm{G}_{\mathrm{RF}}, \mathrm{A}, \mathrm{k}$, and $\mathrm{h}$ vary between the poles and the wires (i.e. conductor, neutral wire, and communication cable) (Malmedal and Sen 2003). Factors $\mathrm{Q}, \mathrm{I}_{\mathrm{FW}}, \mathrm{G}_{\mathrm{RF}}, \mathrm{k}$, and $\mathrm{C}_{\mathrm{f}}$ are found in design standards (ASCE-113 2008), while factors $\mathrm{A}$ and $\mathrm{h}$ are determined based on the geometric properties of the components of the poles.

The projected wind area (A) is defined as the area of each component which is exposed to wind (e.g. the wind area for the wires is determined by multiplying the diameter of the wires with the span of the wires). When designing the distribution poles, the projected wind area of the poles is assumed to be $2.8 \mathrm{~m}^{2}$ initially; however this value will change based on the required circumference of the distribution poles, which will vary between methods. Current design practices assume distribution poles are designed to withstand a wind speed of $40 \mathrm{~m} / \mathrm{s}$ (Malmedal and Sen 2003). The NESC design procedure for extreme wind conditions for distribution poles (i.e. Grade C construction) involves designing structures to withstand extreme winds of $38 \mathrm{~m} / \mathrm{s}$ within loading regions such as Miami-Dade County, Florida (Brown 2008, Quanta 2009); therefore, for simplicity, the design wind speed for both design methods is assumed to be $40 \mathrm{~m} / \mathrm{s}$ to ensure that both methods are consistent.

The amp is determined for both methods using the Gere-Carter method. The amp is estimated to be 1.133 for the distribution poles designed according to the ASCE method and 1.118 for poles designed according to the NESC method. The variation is attributed to the fact that when the amp is estimated using the Gere-Carter method, a dead load factor is implemented within the calculations. The dead load for the ASCE method is 1.1 (ASCE-111 2006), while the NESC (2002) recommends a dead load factor of 1.0, i.e. amp is dependent on which method is being used. 
Table 4.2: Design Variables and Values

\begin{tabular}{|c|c|c|c|}
\hline Variable & Description & Value & Note: \\
\hline$Q$ & Air density factor & 0.00256 & Standard Value \\
\hline$I_{F W}$ & Importance factor & 1 & Utility Poles \\
\hline$G_{R F}$ & Gust response factor & $0.96 / 0.81$ & Pole /Wires \\
\hline$C_{f}$ & Force coefficient & 1 & Circle Shaped Pole \\
\hline$V$ & Wind Speed $(\mathrm{m} / \mathrm{s})$ & 40 & Assumed value \\
\hline$A$ & $\begin{array}{l}\text { Projected wind area } \\
\left(\mathrm{m}^{2}\right)\end{array}$ & Varies/1.5/10/3.2 & $\begin{array}{l}\text { Pole/Conductor/Neutra } \\
1 \text { Wire/Communication } \\
\text { Cable }\end{array}$ \\
\hline$k$ & $\begin{array}{l}\text { Terrain Exposure } \\
\text { Coefficient }\end{array}$ & $0.98 / 1.05$ & Pole/Wires \\
\hline$h$ & $\begin{array}{l}\text { Distance from ground } \\
\text { line to centroid }(\mathrm{m})\end{array}$ & $5.4 / 11.5 / 10.2 / 8.8$ & $\begin{array}{l}\text { Pole/Conductor/Neutra } \\
1 \text { Wire/Communication } \\
\text { Cable }\end{array}$ \\
\hline
\end{tabular}

Table 4.3 shows the required ground line circumference $\left(\mathrm{C}_{\mathrm{g}}\right)$ determined from Eq. (4.4), and the corresponding class of the poles is found in design standards (ANSI 2002). Table 4.3 also presents the design resistance $\left(\mathrm{R}_{\mathrm{n}}\right)$ that is found in design standards given the pole class (ANSI 2002). ANSI (2002) defines the minimum ground line circumferences for a range of pole classes, i.e. Classes H6-H1 and Classes 1-6, where Class H6 is the largest with a minimum circumference of 1,500 $\mathrm{mm}$ and Class 6 is the smallest with a minimum circumference of $762 \mathrm{~mm}$ (based on a $14 \mathrm{~m}$ pole). In Table 4.3, it can be seen that Case 2 yields the largest pole, and this is attributed to the fact that the ratio $\gamma / \varnothing$ is 2.58, while for Case 3 the ratio is 2.06 and for Case 4 the ratio is 1.29. In comparison, for the Case 1, the $\gamma / \varnothing$ ratio is 1.27 , which is similar to Case 4. 
Table 4.3: Required Circumference at Ground Line and Pole Class for Design Cases

\begin{tabular}{|c|c|c|c|c|}
\hline Design Case & Method & $\boldsymbol{C}_{\boldsymbol{g}}$ & Class & Design Resistance $\left(\boldsymbol{R}_{\boldsymbol{n}}\right)$ \\
\hline 1 & ASCE & $775 \mathrm{~mm}$ & 5 & $99,000 \mathrm{~N}-\mathrm{m}$ \\
\hline 2 & NESC & $940 \mathrm{~mm}$ & 2 & $190,900 \mathrm{~N}-\mathrm{m}$ \\
\hline 3 & NESC & $856 \mathrm{~mm}$ & 3 & $151,600 \mathrm{~N}-\mathrm{m}$ \\
\hline 4 & NESC & $777 \mathrm{~mm}$ & 5 & $99,000 \mathrm{~N}-\mathrm{m}$ \\
\hline
\end{tabular}

\subsubsection{No Degradation of Poles}

\subsubsection{Fragility Analysis}

Fragility curves are developed to examine the differences in vulnerability between the two design methods. The design resistance $\left(R_{n}\right)$ listed in Table 4.3 is modified with the model error in order to estimate the actual resistance (R) (Eq. (4.14)). The mean model error (ME) is assumed to be 1.12 , with $\mathrm{COV}_{\mathrm{ME}}=14 \%$, for the design resistance (Vanderbilt et al. 1982). As a starting point, the ME is assumed to be normally distributed. Table 4.4 shows the actual resistance for the four design cases.

The design strength for the four pole classes has a COV of 20\% (ANSI 2002). The ASCE-111 (2006) recommends that the strength of the pole be described by three distributions: normal, lognormal, and Weibull. For this analysis, the strength of the pole will be assumed to have a lognormal distribution, as suggested in Bingel et al. (2003), Li et al. (2006), and Wolfe et al. (2001).

Table 4.4: Actual Resistance for Design Cases

\begin{tabular}{|c|c|c|c|}
\hline Design Case & Method & Class & Actual Resistance $(\boldsymbol{R})$ \\
\hline 1 & ASCE & 5 & $110,900 \mathrm{~N}-\mathrm{m}$ \\
\hline 2 & NESC & 2 & $213,800 \mathrm{~N}-\mathrm{m}$ \\
\hline 3 & NESC & 3 & $169,700 \mathrm{~N}-\mathrm{m}$ \\
\hline 4 & NESC & 5 & $110,900 \mathrm{~N}-\mathrm{m}$ \\
\hline
\end{tabular}


The wind load for the poles is determined based on the projected wind area of the poles (which varies because of different ground line circumferences for the design methods) and the uncertain variables in Eq. (4.2) and (4.3). Air density factor (Q) and importance factor $\left(\mathrm{I}_{\mathrm{FW}}\right)$ are constants; their values are listed in Table 4.2. Table 4.5 summarizes the statistical parameters for the random variables in Eq. (4.2) and (4.3).

To account for the uncertainty within amp, it is assumed to be normally distributed with a mean value which is assumed to be the value estimated with the Gere-Carter method. The COV is determined by running a MCS, assuming that the modulus of elasticity (MOE) has a normal distribution with a COV of $20 \%$ (ANSI 2002) and the geometry of the poles has a normal distribution with a COV of $6 \%$ (Wolfe and Moody 1997). The mean value of amp is estimated to be 1.118 , with a COV of $8 \%$ for the NESC method and to be 1.133 , with a COV of $11 \%$ for the ASCE method. 
Table 4.5: Statistics for Wind Load

\begin{tabular}{|c|c|c|c|c|c|}
\hline $\begin{array}{l}\text { Random } \\
\text { Variable }\end{array}$ & Component & Distribution & Mean Value & $\mathrm{COV}$ & Source \\
\hline \multirow{4}{*}{$A\left(\mathrm{~m}^{2}\right)$} & Pole & Normal & Varies & $6 \%$ & \multirow{4}{*}{$\begin{array}{c}\text { Wolfe and } \\
\text { Moody } \\
1997\end{array}$} \\
\hline & Conductor & Normal & 1.50 & $6 \%$ & \\
\hline & Neutral Wire & Normal & 1.00 & $6 \%$ & \\
\hline & Communication Cable & Normal & 3.20 & $6 \%$ & \\
\hline \multirow{2}{*}{$k$} & Pole & Normal & 0.98 & $6 \%$ & \multirow{2}{*}{$\begin{array}{c}\text { ASCE-111 } \\
2006\end{array}$} \\
\hline & Wires & Normal & 1.05 & $6 \%$ & \\
\hline \multirow{4}{*}{$h(\mathrm{~m})$} & Pole & Normal & 5.40 & $3 \%$ & \multirow{4}{*}{ Assumed } \\
\hline & Conductor & Normal & 11.50 & $3 \%$ & \\
\hline & Neutral Wire & Normal & 10.20 & $3 \%$ & \\
\hline & Communication Cable & Normal & 8.80 & $3 \%$ & \\
\hline \multirow{2}{*}{$G_{R F}$} & Pole & Normal & 0.96 & $11 \%$ & \multirow{2}{*}{$\begin{array}{c}\text { Ellingwood } \\
\text { and Tekie } \\
1999\end{array}$} \\
\hline & Wires & Normal & 0.81 & $11 \%$ & \\
\hline \multirow{2}{*}{$C_{f}$} & Pole & Normal & 1 & $12 \%$ & \multirow{2}{*}{$\begin{array}{c}\text { Ellingwood } \\
\text { and Tekie } \\
1999\end{array}$} \\
\hline & Wires & Normal & 1 & $12 \%$ & \\
\hline
\end{tabular}

Hurricane fragility curves show the probability of failure of a distribution pole conditioned at a specific wind speed, which increases monotonically. The probability of failure for the fragility curves is estimated by a MCS, as stated previously, which involves counting the number of times the load (S) exceeds the resistance (R). The load $(\mathrm{S})$ and resistance $(\mathrm{R})$ are randomly generated with the wind speed being deterministic within the selected range (i.e. from $0 \mathrm{~m} / \mathrm{s}$ to $120 \mathrm{~m} / \mathrm{s}$ ), using the abovementioned 
parameters. Fragility curves are developed from the MCS for the four design cases, and are shown in Figure 4.6.

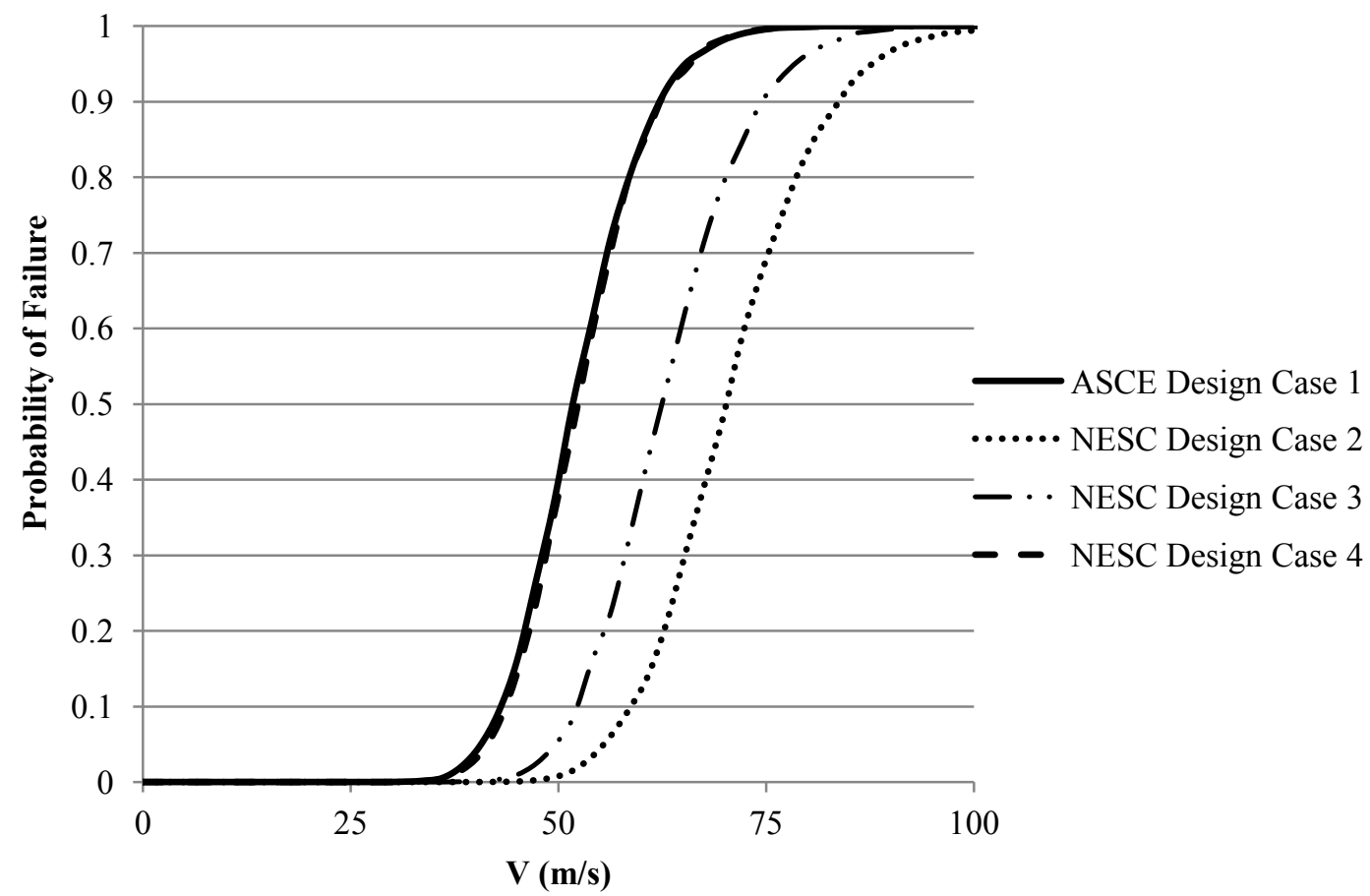

\section{Figure 4.6: Fragility Curve (ASCE vs. NESC)}

The fragility curve for ASCE Design Case 1 and NECS Design Case 4 reach 100\% probability of failure at about $83 \mathrm{~m} / \mathrm{s}$, while NESC Design Cases 2 and 3 reach $100 \%$ probability of failure at $112 \mathrm{~m} / \mathrm{s}$ and $103 \mathrm{~m} / \mathrm{s}$, respectively. Cases 1 and 4 reach $100 \%$ probability of failure at wind speeds that are approximately $35 \%$ and $25 \%$ lower than for Cases 2 and 3, respectively. It is also interesting to examine at what wind speed the distribution poles reach a $50 \%$ probability of failure. Case 1 has a $50 \%$ probability of failure at approximately $51 \mathrm{~m} / \mathrm{s}$, Case 2 at $69 \mathrm{~m} / \mathrm{s}$, Case 3 at $63 \mathrm{~m} / \mathrm{s}$, and Case 4 at $52 \mathrm{~m} / \mathrm{s}$. From the comparison, it can be seen that Case 1 has a $50 \%$ probability of failure at wind speeds that are about $27 \%$ lower than for Case 2 .

These differences are attributed to the fact that Cases 2 and 3 are more conservative than Cases 1 and 4, because they implement a significantly higher ratio of load factor and strength factor $(\gamma / \varnothing)$. Cases 2 and 3 required larger ground line circumferences than 
Cases 1 and 4, which resulted in larger poles for Cases 2 and 3 that are able to withstand higher loads. Furthermore, the ratio of the load factor to the strength factor $(\gamma / \varnothing)$ implemented for Cases 1 and 4 are similar, or 1.27 and 1.29, which yielded the same class of pole; however, the fragility curves are not exactly the same for Case 1 and 4 because the methods resulted in different amp factors.

The statistical distribution of the structural fragility of timber poles needs to be identified in order to estimate the annual $\mathrm{P}_{\mathrm{f}}$ using Eq. (4.15). Kolmogorov-Smirnov test goodness of fit test with a significance level of 5\% is used to find that the lognormal distribution is appropriate for all fragility curves. Table 4.6 shows the lognormal parameters, $\ln \mathrm{m}_{\mathrm{R}}$ and $\xi_{\mathrm{R}}$ in Eq. (4.14) for each design case, for new poles.

Table 4.6: Lognormal Parameters for Hurricane Fragility

\begin{tabular}{|c|c|c|}
\hline Design Case & $\ln \left(\boldsymbol{m}_{\boldsymbol{R}}\right)$ & $\boldsymbol{\xi}_{\boldsymbol{R}}$ \\
\hline $\mathbf{1}$ & 3.95 & 0.146 \\
\hline $\mathbf{2}$ & 4.25 & 0.135 \\
\hline $\mathbf{3}$ & 4.13 & 0.140 \\
\hline $\mathbf{4}$ & 3.96 & 0.137 \\
\hline
\end{tabular}

\subsubsection{Annual Probability of Failure}

To estimate the annual $\mathrm{P}_{\mathrm{f}}$ in Eq. (4.15), the Weibull distribution parameters for wind speed in Miami-Dade County are estimated to be $u(1)=27.36$ and $\alpha(1)=1.77$ using wind contour maps (Vickery et al. 2009). The annual $\mathrm{P}_{\mathrm{f}}$ is calculated as 0.054, 0.009, 0.020, and 0.052 for the four design cases, respectively, at year 1. Quanta (2009) estimates that the timber pole failure rate of distribution poles in Southern Florida is approximately 0.045 considering an extreme wind criteria of $65 \mathrm{~m} / \mathrm{s}$ (FP\&LC 2006). The most common class of timber poles is Class 4 (Foedingur et al. 2002); therefore Case 2 and 3, which resulted in larger classes of poles, have an annual $\mathrm{P}_{\mathrm{f}}$ that is significantly lower than the Quanta estimates, while Case land 4 (which resulted in a smaller class of pole) yield annual $P_{f}$ that are higher than, but albeit closer to, the Quanta estimates. 


\subsubsection{Effect of Degradation on $P_{f}$}

The average age of Southern Pine distribution poles in the U.S. is approximately 32 years (Stewart and Goodman 1990). To investigate a wide range of pole age, fragility curves are developed for poles that are 0, 10, 30, and 50 years old. Eq. (4.5) through (4.10) are used to estimate the strength for all design cases.

The resistance decreases with age, as the degradation results in a decreased diameter of the pole due to decay. Using Eq. (4.10), the decay depth is found to be $0,3,15$, and 26 $\mathrm{mm}$ after $0,10,30$, and 50 years, respectively. Recall that the four design cases resulted in poles of various sizes; therefore, the decay depth will affect the bending stress of the poles differently depending on the design case (i.e. the strength of the smaller poles will be affected more by the decay depth than the strength of the larger poles).

Table 4.7 shows the actual resistance estimated with Eq. (4.5) through (4.10) for each design case, for poles that are $0,10,30$, and 50 years old. The table also includes the COV for the resistance, estimated with Eq. (4.12). For each design case, the table shows that as the poles are assumed to age, the uncertainty within the estimated resistance increases which translates to the increasing $\mathrm{COV}$ with age. It is also evident that the strength of the smallest poles (Cases 1 and 4) experience the greatest increase in uncertainty as the poles age. This is because the decay depth is the same despite the initial size of the pole, resulting in the largest proportional change in diameter for the smallest distribution poles. 
Table 4.7: Mean and $C O V$ of Resistance $R(t)$ for Various Ages

\begin{tabular}{|c|c|c|c|c|c|c|c|c|}
\hline \multirow{2}{*}{$\begin{array}{c}\text { Design } \\
\text { Case }\end{array}$} & \multicolumn{2}{|c|}{ 0 years } & \multicolumn{2}{c|}{ 10 years } & \multicolumn{2}{c|}{ 30 years } & \multicolumn{2}{c|}{ 50 years } \\
\cline { 2 - 9 } & $\begin{array}{c}\text { Resistance } \\
(\mathbf{N}-m)\end{array}$ & $\begin{array}{c}\text { COV } \\
(\%)\end{array}$ & $\begin{array}{c}\text { Mean } \\
\text { Resistance } \\
(\mathbf{N}-m)\end{array}$ & $\begin{array}{c}\text { COV } \\
(\%)\end{array}$ & $\begin{array}{c}\text { Mean } \\
\text { Resistance } \\
(\text { N-m) }\end{array}$ & $\begin{array}{c}\text { COV } \\
(\%)\end{array}$ & $\begin{array}{c}\text { Mean } \\
\text { Resistance } \\
(\text { N-m) }\end{array}$ & $\begin{array}{c}\text { COV } \\
(\%)\end{array}$ \\
\hline $\begin{array}{c}1 \\
(\mathrm{ASCE})\end{array}$ & 99,000 & 20.0 & 91,900 & 21.1 & 68,900 & 40.0 & 50,600 & 70.6 \\
\hline $\begin{array}{c}2 \\
(\mathrm{NESC})\end{array}$ & 190,900 & 20.0 & 180,000 & 20.7 & 143,200 & 33.7 & 112,700 & 55.5 \\
\hline $\begin{array}{c}3 \\
(\mathrm{NESC})\end{array}$ & 151,600 & 20.0 & 142,200 & 20.8 & 111,000 & 35.7 & 85,400 & 60.2 \\
\hline $\begin{array}{c}4 \\
(\mathrm{NESC})\end{array}$ & 99,000 & 20.0 & 91,900 & 21.1 & 68,900 & 40.0 & 50,600 & 70.6 \\
\hline
\end{tabular}

Figures 4.7 to 4.10 show the fragility curves for distribution poles designed using the four design cases considering the effects of ageing. For example, distribution poles designed with Case 1 (Figure 4.7) reach 50\% probability of failure at wind speeds of $51 \mathrm{~m} / \mathrm{s}, 49$ $\mathrm{m} / \mathrm{s}, 43 \mathrm{~m} / \mathrm{s}$, and $34 \mathrm{~m} / \mathrm{s}$ for poles that are $0,10,30$, and 50 years old, respectively. The 30 year old pole and the 50 year old pole designed according to Case 1 have a $50 \%$ probability of failure at wind speeds that are approximately $15 \%$ and $32 \%$ lower, respectively, than for a new pole. On the other hand, distribution poles designed according to Case 2 (Figure 4.8) have a 50\% probability of failure at wind speeds of 70 $\mathrm{m} / \mathrm{s}, 68 \mathrm{~m} / \mathrm{s}, 60 \mathrm{~m} / \mathrm{s}$, and $50 \mathrm{~m} / \mathrm{s}$ for $0,10,30$ and 50 year old distribution poles, respectively. The 30 year old pole and the 50 year old pole designed according to Case 2 have a $50 \%$ probability of failure at wind speeds that are approximately $15 \%$ and $28 \%$ lower, respectively, than the wind speed at which new poles have a $50 \%$ probability of failure.

From Figures 4.7 to 4.10 , it is evident that poles, of various ages, have a $100 \%$ probability of failure for lower wind speeds when using Cases 1 and 4. This is consistent with Figure 4.6, where it is apparent that Cases 1 and 4 resulted in poles which reach $100 \%$ probability of failure at a lower wind speed than the poles designed based on Cases 
2 and 3. This is attributed to the fact that the ratio of load factor and strength factor $(\gamma / \varnothing)$ for Cases 2 and 3 is higher than the ratios implemented to design the pole for Cases 1 and 4. In other words, poles designed according to Cases 2 and 3 are significantly larger than for the other design cases. Moreover, the effects of degradation become apparent after more than 10 years. Hence, as the poles age they become more vulnerable, therefore the differences between the design cases become smaller.

The age of the poles appears, from a comparison of Figure 4.7 to 4.10 , to affect the probability of failure for the poles designed according to Cases 1 and Case 4 more than for the Cases 2 and 3. This is due to the fact that the COV for the bending strength of the poles is higher for Cases 1 and 4 than for the Cases 2 and 3. For example, for a pole that is 50 years old, the COV of the bending strength for Cases 1 and 4 is $70.6 \%$, but for Case 2 the COV of the bending strength is $55.5 \%$ and for Case 3 the COV is $60.2 \%$. The higher COV translates to more uncertainty, which in turn results in the probability of failure for Cases 1 and 4 being higher than for Cases 2 and 3.

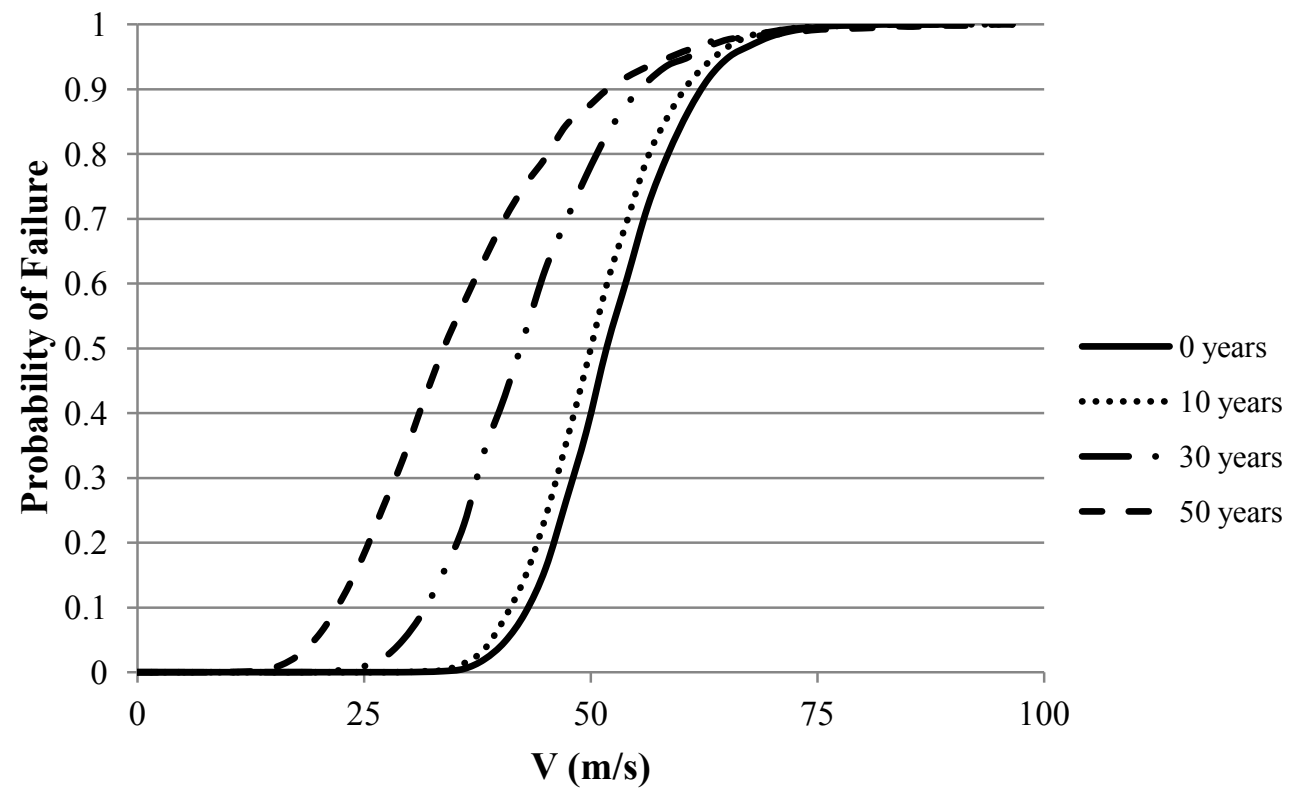

Figure 4.7: Effects of Degradation on the Probability of Failure ASCE Design Case 1 


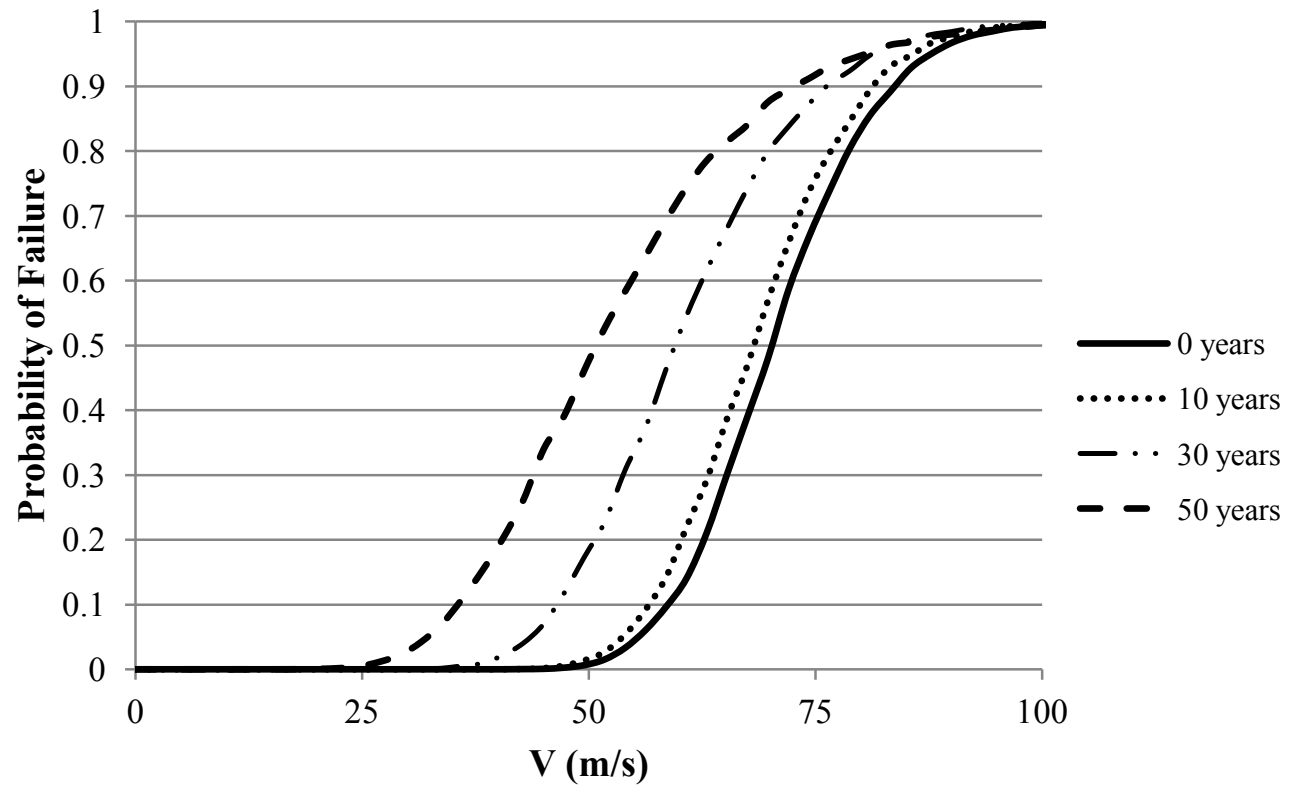

Figure 4.8: Effects of Degradation on the Probability of Failure NESC Design Case 2

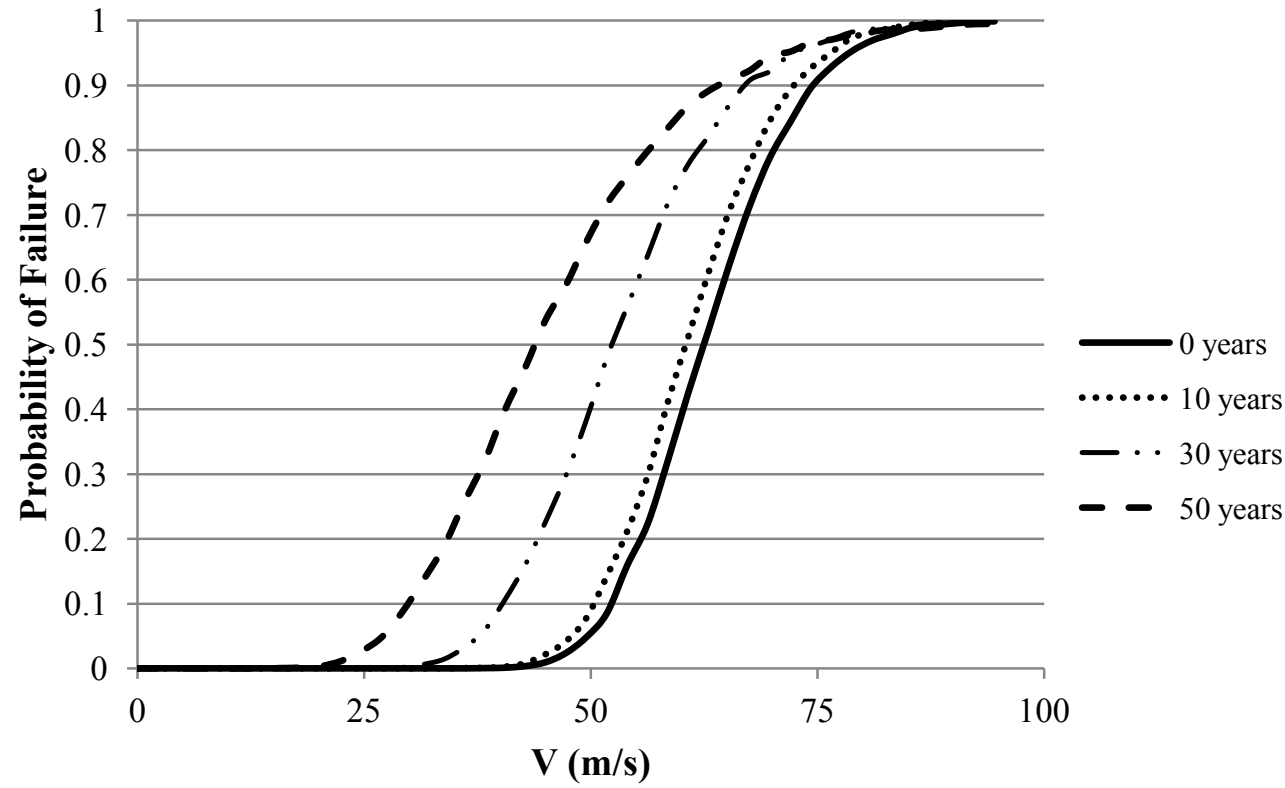

Figure 4.9: Effects of Degradation on the Probability of Failure NESC Design Case 3 


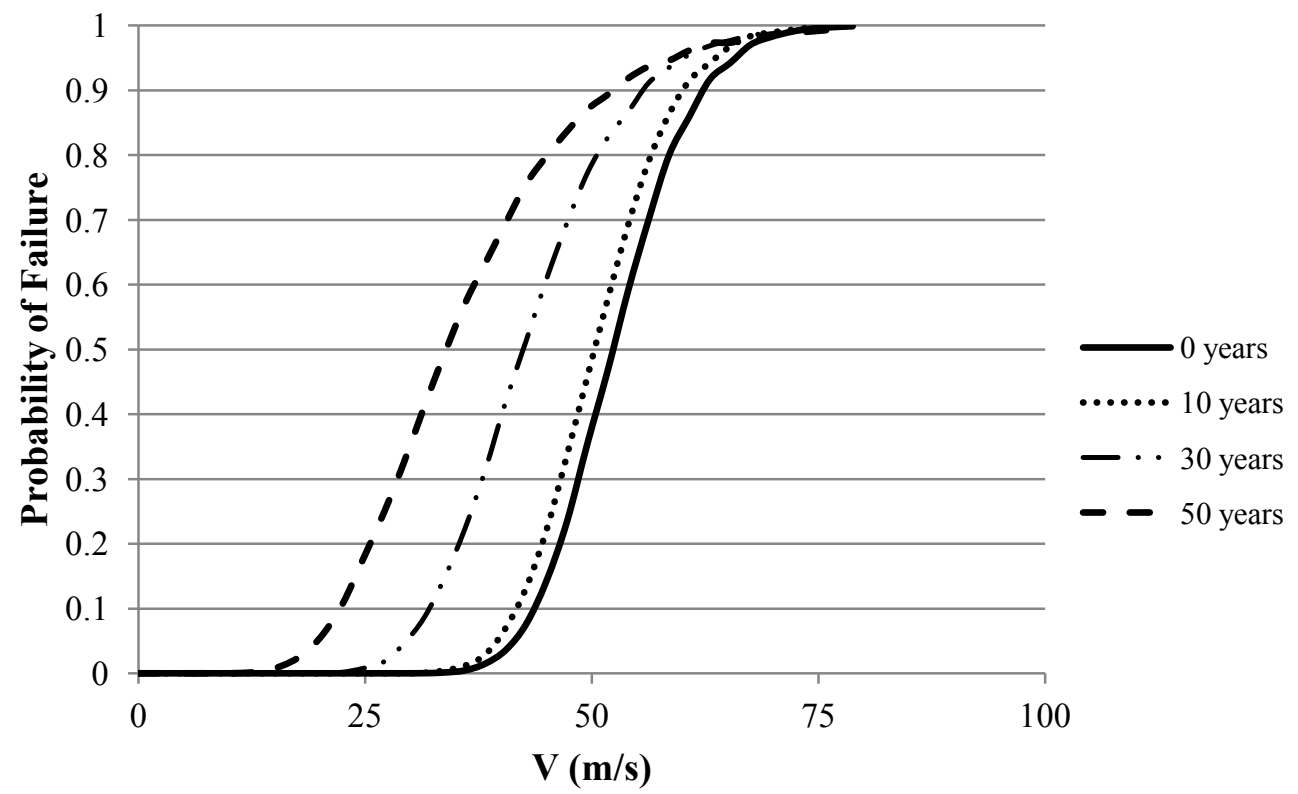

Figure 4.10: Effects of Degradation on the Probability of Failure NESC Design Case 4

\subsubsection{Impact of Climate Change on Annual $P_{f}$}

The annual $\mathrm{P}_{\mathrm{f}}$ will be estimated for all four design cases, considering new distribution poles for 100 years of service. Although, it should be noted that the time frame is irrelevant for the point-in-time analysis given by Eq. (4.15) as this is not path dependant (i.e. the annual $P_{f}$ will depend on the change in wind speed not the number of years being investigated).

To estimate the annual $\mathrm{P}_{\mathrm{f}}$ due to the potential impact of climate change, the mean maximum annual wind speed is assumed to change linearly over the selected time period. The mean maximum annual wind speed is $23 \mathrm{~m} / \mathrm{s}, 24 \mathrm{~m} / \mathrm{s}, 26 \mathrm{~m} / \mathrm{s}$, and $30 \mathrm{~m} / \mathrm{s}$ assuming changes in wind speed of $-5 \%, 0 \%, 10 \%$, and $25 \%$, respectively, over 100 years. The COV for the mean maximum annual wind speed at year 1 is estimated to be 0.584 , which is assumed to be constant for all years within the time frame (Bjarnadottir et al. 2011). Using the mean maximum annual wind speed and the COV, the Weibull parameters can be determined for each change in wind speed in each year during the 100-year time frame. Subsequently, the annual $\mathrm{P}_{\mathrm{f}}$ of distribution poles can be estimated using Eq. (4.15). 
This analysis assesses the impacts of climate change by assuming that the annual maximum hurricane wind speeds are non-stationary (i.e. changing) within Eq. (4.15); although it is possible to assess the impacts of climate change by assuming a changing wind speed within the fragility. For example, the annual maximum wind speed (V) may increase from $24.3 \mathrm{~m} / \mathrm{s}$ to $26.7 \mathrm{~m} / \mathrm{s}$ which would result in an increase in annual $\mathrm{P}_{\mathrm{f}}$ from the fragility analysis.

Table 4.8 shows the annual $\mathrm{P}_{\mathrm{f}}$ after 100 years for the four design cases (not considering deterioration). From the table it is evident that distribution poles designed with Case 2, is the least susceptible to wind damage and this attributed to the fact that this is the largest pole, able to withstand the largest wind load. In comparison, Cases 1 and 4 produced distribution poles that are the most vulnerable to wind speed. An increase in wind speed of $10 \%$ over 100 years could result in annual $\mathrm{P}_{\mathrm{f}}$ of about 0.080 , for Cases 1 and 4 , while the annual $\mathrm{P}_{\mathrm{f}}$ for Case 2 is estimated at 0.017 for the same increase in wind speed.

The larger poles, designed with Cases 2 and 3, experience the greatest change in annual $\mathrm{P}_{\mathrm{f}}$ as the wind speed is assumed to change over a the selected time frame. This is because the annual $\mathrm{P}_{\mathrm{f}}$ was very low for these design cases initially; therefore the changes in wind speed resulted in proportionally higher changes in the annual $\mathrm{P}_{\mathrm{f}}$ than for Cases 1 and 4, which had considerably higher annual $\mathrm{P}_{\mathrm{f}}$ initially. For example, for Case 2, an increase in wind speed of $10 \%$ could result in an increase in the annual $\mathrm{P}_{\mathrm{f}}$ of $90 \%$ from the case of no climate change, while the same increase in wind speed could result in an increase in the annual $\mathrm{P}_{\mathrm{f}}$ of approximately $50 \%$ for Cases 1 and 4 . 
Table 4.8: Annual $P_{f}$ for Design Cases (New Poles)

\begin{tabular}{|c|c|c|c|c|}
\hline $\begin{array}{c}\text { Change in } \\
\text { Wind } \\
\text { Speed }\end{array}$ & $\begin{array}{c}\text { Design Case } \\
\mathbf{1}\end{array}$ & $\begin{array}{c}\text { Design Case } \\
\mathbf{2}\end{array}$ & $\begin{array}{c}\text { Design Case } \\
\mathbf{3}\end{array}$ & $\begin{array}{c}\text { Design Case } \\
\mathbf{4}\end{array}$ \\
\hline $\mathbf{- 5 \%}$ & 0.044 & 0.006 & 0.014 & 0.040 \\
\hline $\mathbf{0 \%}$ & 0.054 & 0.009 & 0.020 & 0.052 \\
\hline $\mathbf{1 0 \%}$ & 0.085 & 0.017 & 0.035 & 0.080 \\
\hline $\mathbf{2 5 \%}$ & 0.136 & 0.036 & 0.065 & 0.130 \\
\hline
\end{tabular}

\subsubsection{Effects of Degradation and Climate Change on Annual $P_{f}$}

The effects of degradation on the annual $\mathrm{P}_{\mathrm{f}}$ considering the impacts of climate change are explored by integrating the reduced strength found in Table 4.7 into the annual $\mathrm{P}_{\mathrm{f}}$ estimations. The annual $\mathrm{P}_{\mathrm{f}}$ of distribution poles for the four design cases are estimated assuming poles that are $0,10,30$, and 50 years old. Figures 4.11 to 4.14 assume that a percentage increase in wind speed occurs over 100 years, and also includes the effects of degradation. As seen with the fragility curves, the distribution poles are more vulnerable to changes in wind speed as the age of the poles increases. As stated earlier, the average age of distribution poles in the U.S. is about 32 years (Stewart and Goodman 1990). If wind speeds are assumed to increase by $10 \%$ in 100 years, the annual $\mathrm{P}_{\mathrm{f}}$ for the 30 year old pole could increase by $30 \%, 60 \%, 50 \%$, and $30 \%$, for Case 1, 2, 3, and 4 , respectively, from the no climate change scenario (i.e. no change in wind speed). Cases 2 and 3 experience the highest change in annual damage probability for all scenarios of climate change, which is consistent with the previous discussion. Figures 4.11 to 4.14 present the annual $\mathrm{P}_{\mathrm{f}}$ for poles of $0,10,30$, and 50 years, for all design cases considering changes in wind speed from $-5 \%$ to $25 \%$ in 100 years. 


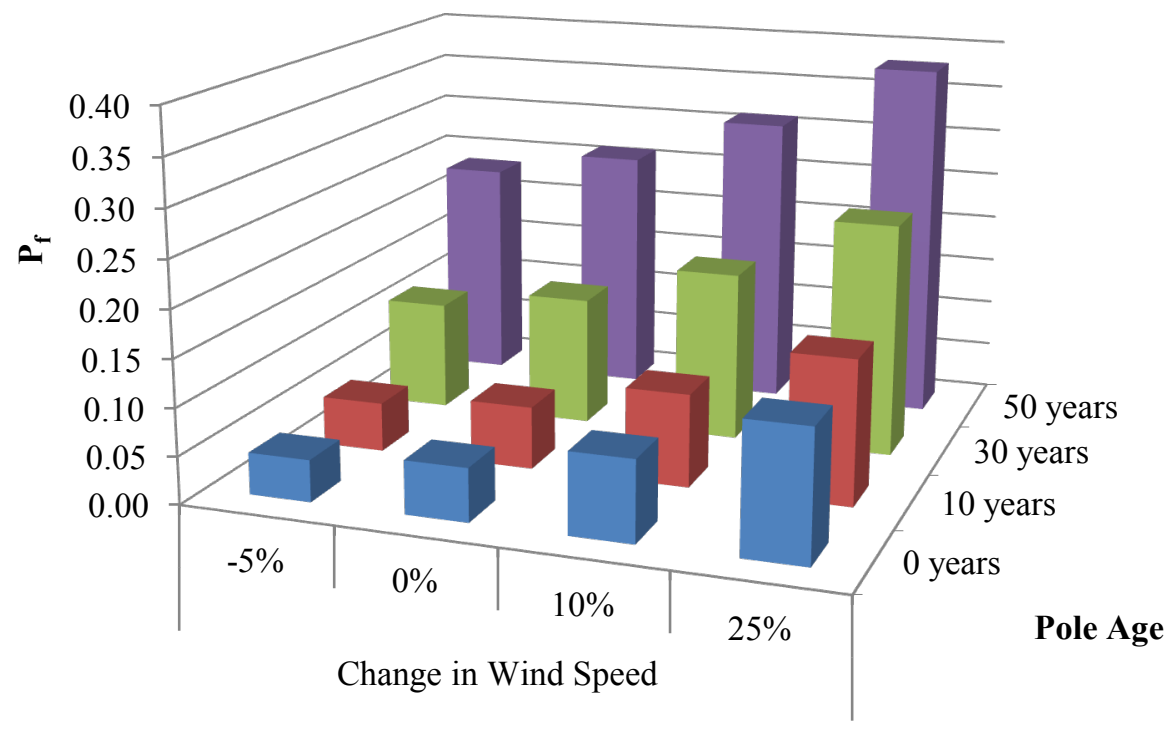

Figure 4.11: Effects of Degradation on Annual Pf for Various Scenarios of Climate Change after 100 years for ASCE Design Case 1

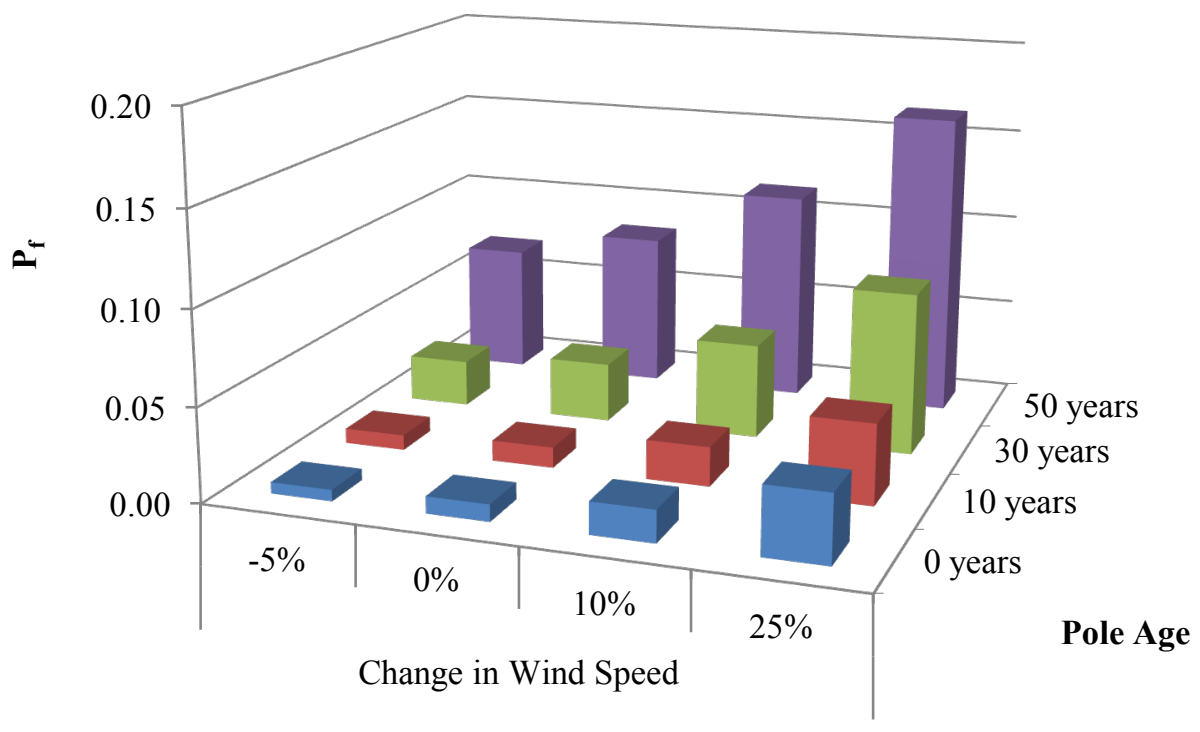

Figure 4.12: Effects of Degradation on Annual Pf for Various Scenarios of Climate Change after 100 years for NESC Design Case 2 


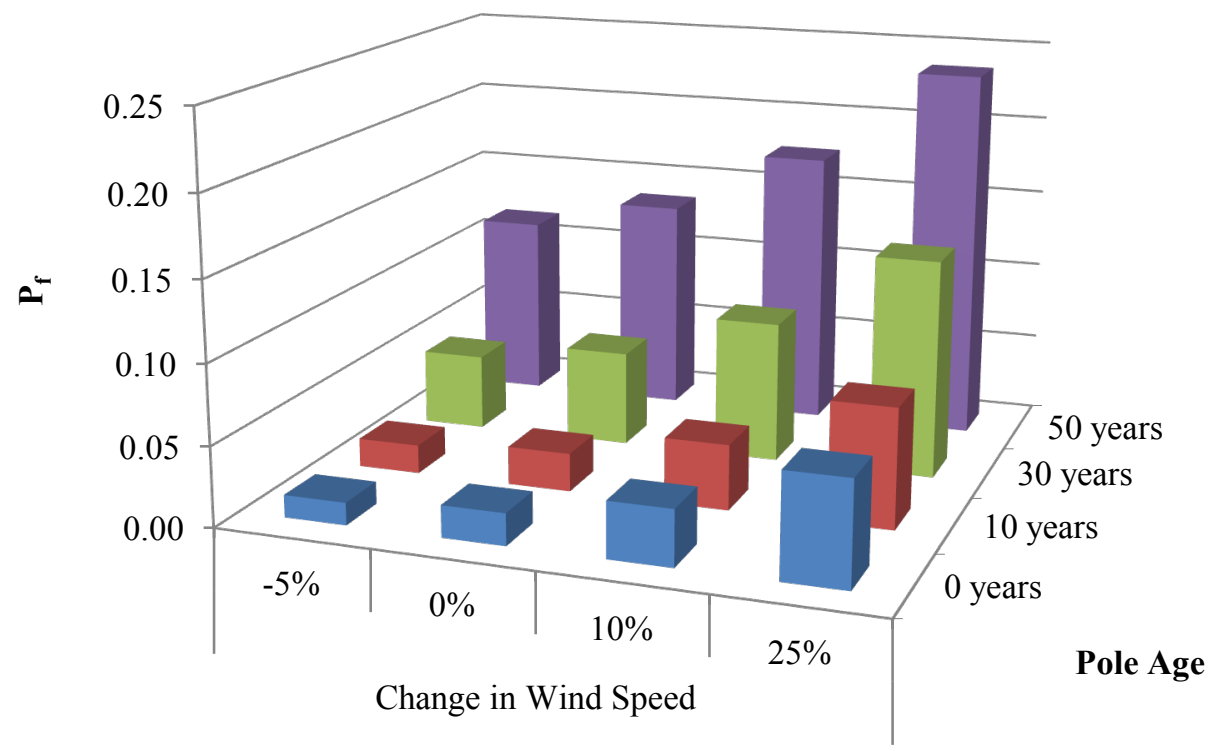

Figure 4.13: Effects of Degradation on Annual Pf for Various Scenarios of Climate Change after 100 years for NESC Design Case 3

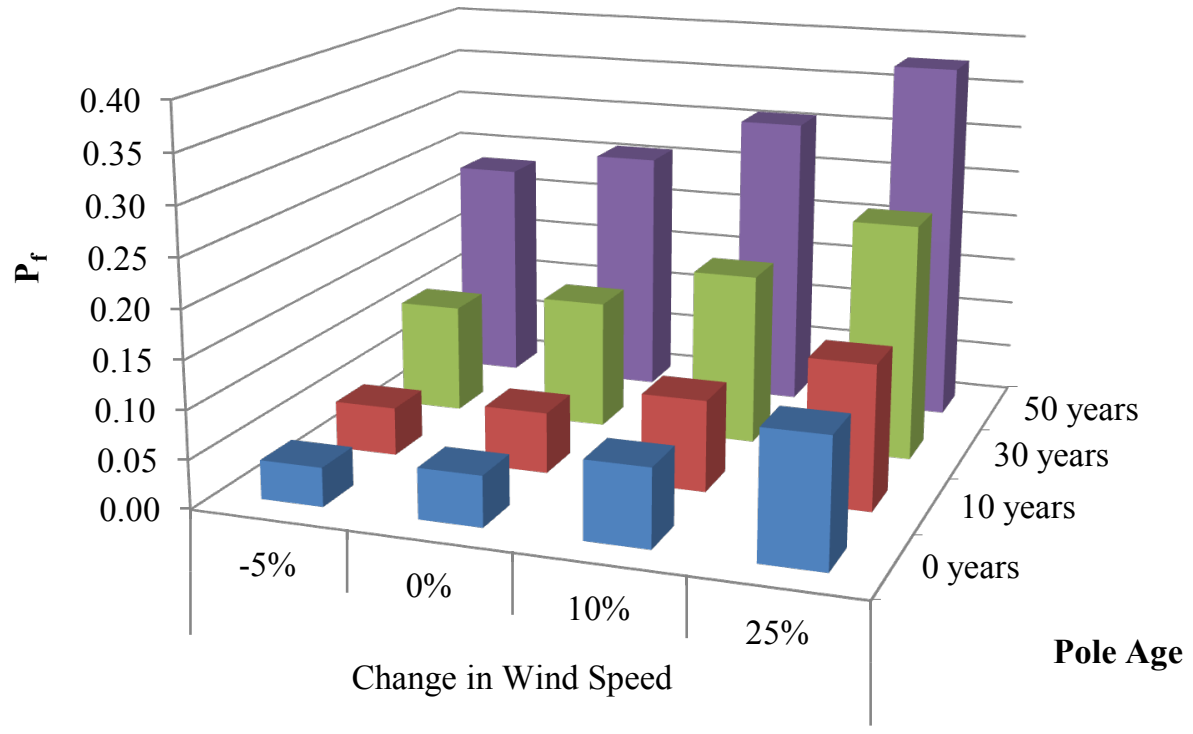

Figure 4.14: Effects of Degradation on Annual Pf for Various Scenarios of Climate Change after 100 years NESC Design Case 4 


\subsubsection{Effects of Degradation and Climate Change on Service Proven Distribution Poles}

It is also important to investigate the service proven reliability of distribution poles, by considering the effects load history may have on their reliability. An assessment of this nature takes into account the fact that the number of years that distribution poles have survived gives an indication as to the minimum structural capacity of the distribution poles. This analysis considers the updated annual $\mathrm{P}_{\mathrm{f}}$ that a distribution pole will fail in the subsequent year given that the distribution pole has survived T years of service (Stewart 1997, Stewart and Val 1999), and the updated annual $P_{f}$ is estimated at each subsequent year of the assessment by conducting a MCS. The MCS estimates the number of distribution poles that fail in a specific year given the load (S) and the resistance (R) of the poles, and then the total number of remaining poles is updated for the next year by subtracting the failed poles for the previous year from the total number of poles. The updated annual $\mathrm{P}_{\mathrm{f}}$ is then estimated at each subsequent year based on the number of failed poles and total number of poles for that specific year. This service proven reliability analysis was conducted for distribution poles, considering climate change scenarios of $0 \%$ and $10 \%$ increases in wind speed over 100 years. For the sake of brevity, one case is presented herein, ASCE Design Case 1.

Figures 4.15 to 4.16 show the updated annual $\mathrm{P}_{\mathrm{f}}$ for distribution poles considering both degradation and no degradation, for two scenarios of climate change. The updated annual $\mathrm{P}_{\mathrm{f}}$, shown on Figures 4.15 and 4.16, is a conditional probability that estimates the likelihood that the distribution poles will fail in year $\mathrm{T}+1$ given that the distribution poles have survived $T$ years:

$p_{f}(1 \mid T)=\frac{p_{f}(T+1)-p_{f}(T)}{1-p_{f}(T)}$

where $p_{f}(t)$ is the cumulative probability of failure up to time $t$ (Stewart and Val 1999). 


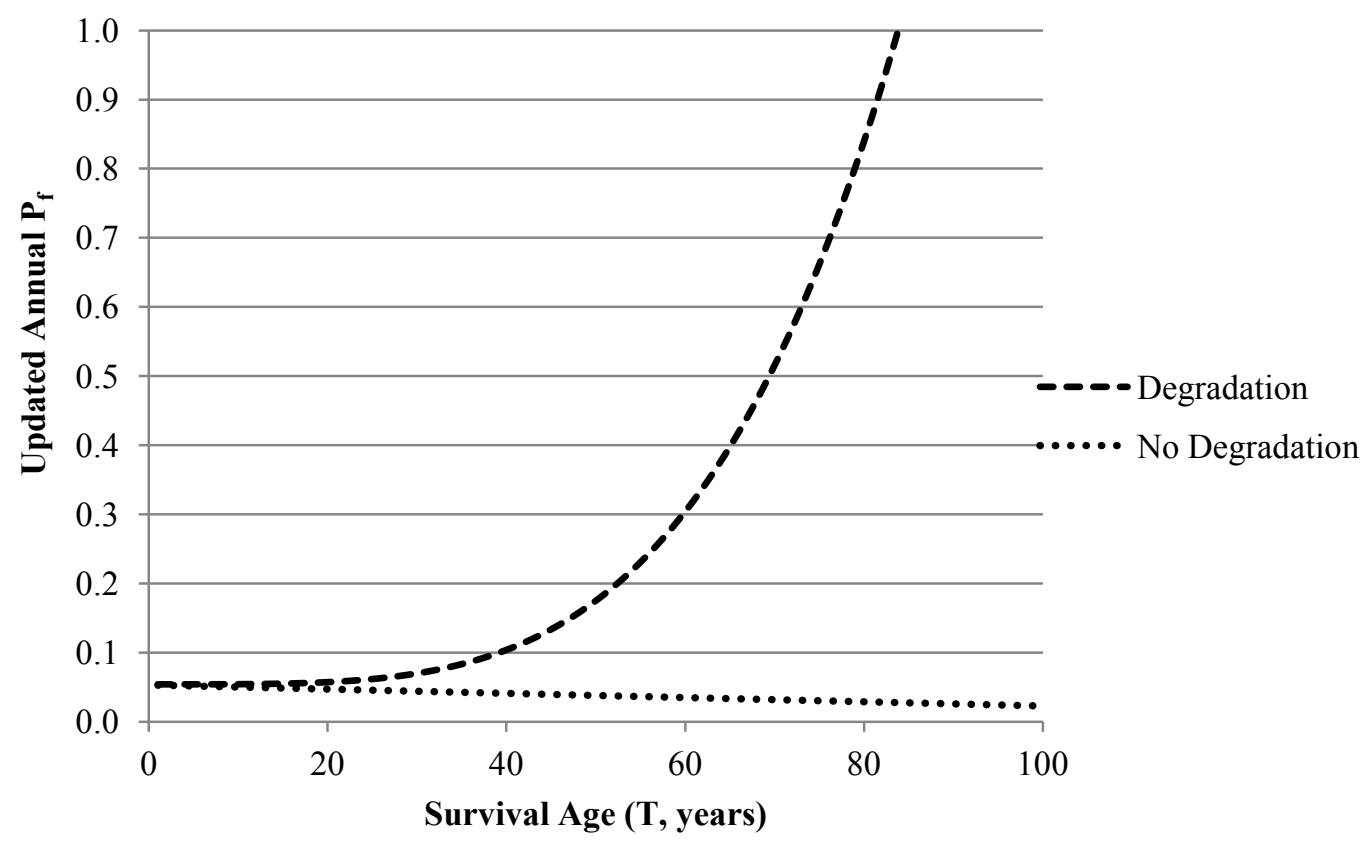

Figure 4.15: Updated Annual $P f$ for no change in wind speed

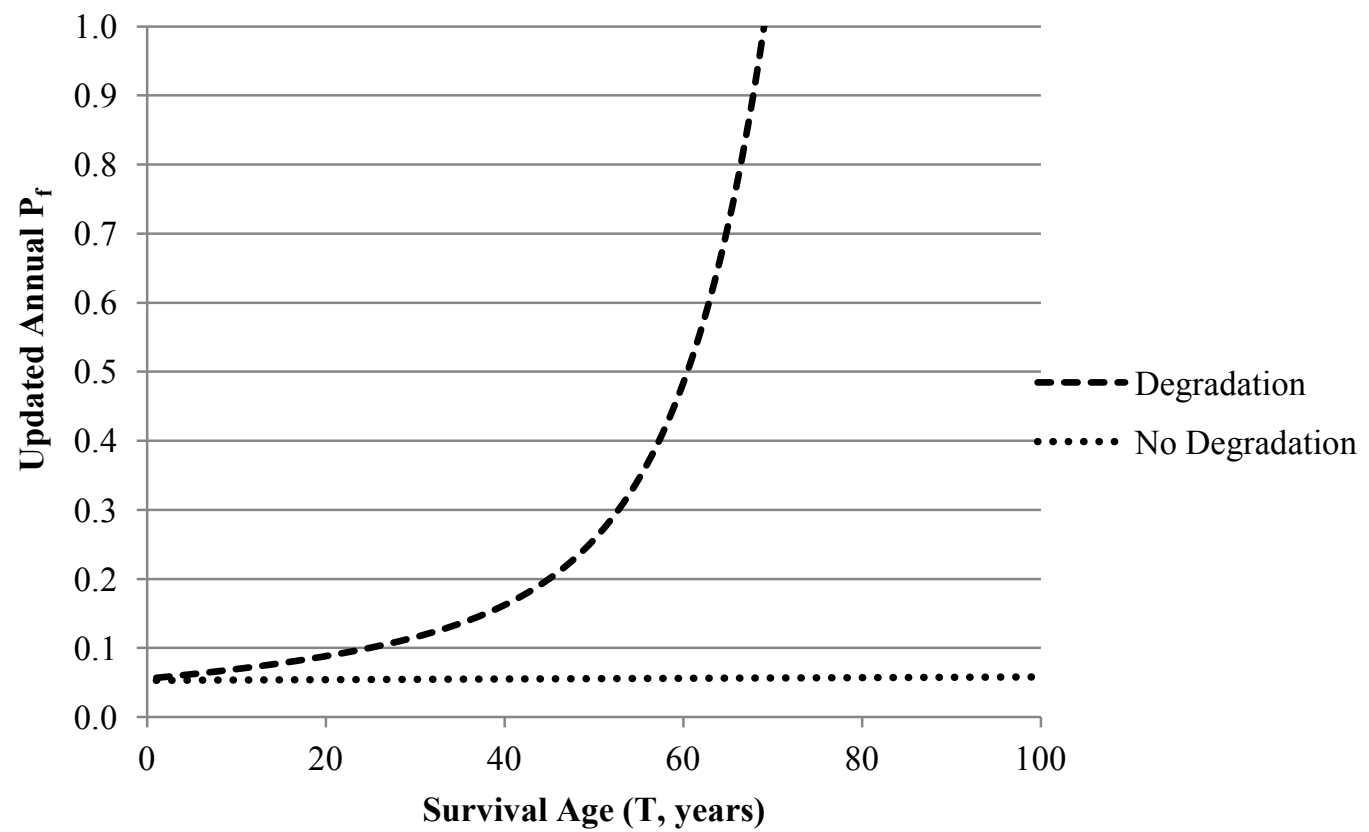

Figure 4.16: Updated Annual $P f$ for $10 \%$ increase in wind speed in 100 years

Therefore, the updated annual $\mathrm{P}_{\mathrm{f}}$ is quite similar for the first years of the assessment. From the figure it can be seen that the updated annual $\mathrm{P}_{\mathrm{f}}$ increases significantly for both climate change scenarios when degradation is accounted for. On the other hand, when 
degradation is not considered, the updated annual $\mathrm{P}_{\mathrm{f}}$ decreases for $0 \%$ increase in wind speed, and this is because, for service proven structures, the reliability should increase if no degradation is accounted for (Stewart 1997, Stewart and Val 1999). However, when wind speeds are assumed to increase by $10 \%$, the decrease in the updated annual $\mathrm{P}_{\mathrm{f}}$ seen initially for $0 \%$ increase in wind speed is counteracted and the updated annual $\mathrm{P}_{\mathrm{f}}$ remains relatively constant for the 100 year service life of the distribution pole. In all cases, the updated annual $\mathrm{P}_{\mathrm{f}}$ shown in Figure 4.15 and 4.16 is less than the annual $\mathrm{P}_{\mathrm{f}}$ shown in Figures 4.11 to 4.14 ; this shows the advantage of updating reliabilities with new information. For example, from Figures 4.11 to 4.14, a 50 year pole may have an annual $\mathrm{P}_{\mathrm{f}}$ of approximately 0.30 if an increase in wind speed of $10 \%$ is assumed; in comparison, from Figure 4.16, the updated annual $\mathrm{P}_{\mathrm{f}}$ for a pole that has survived 49 years is approximately 0.25 for an increase in wind speed of $10 \%$.

For comparison purposes, recall that the annual $\mathrm{P}_{\mathrm{f}}$ for the ASCE Design Case 1, was estimated at 0.054 for any year under current climate conditions (i.e. no climate change and no deterioration). However, the updated annual $\mathrm{P}_{\mathrm{f}}$ at year 20, (i.e. the probability that a distribution pole will fail in year 20, given that it has survived the previous 19 years of service) is 0.047 if there is no degradation and 0.057 if there is degradation, for no change in wind speed. If wind speeds increase by $10 \%$ over 100 years, the updated annual $\mathrm{P}_{\mathrm{f}}$ at year 20 is 0.054 and 0.086 for no degradation and degradation, respectively. For a survival age of 50 years, the updated annual $\mathrm{P}_{\mathrm{f}}$ is 0.038 for no degradation and 0.178 for degradation, for $0 \%$ increase in wind speed, and for $10 \%$ increase in wind speed, the updated annual $\mathrm{P}_{\mathrm{f}}$ is 0.056 when degradation is not accounted for and 0.244 when degradation is accounted for. These are increases in the updated annual $\mathrm{P}_{\mathrm{f}}$ of up to $50 \%$ if there is degradation, under an assumed increase in wind speed of $10 \%$ over 100 years. From this analysis it can be concluded that climate change could have a significant impact on the service proven reliability of distribution poles if there is deterioration, but if there is no deterioration then a $10 \%$ increase in wind speed over 100 years will not increase updated annual probabilities of pole failure. 


\subsection{Conclusions}

This paper proposes a comprehensive framework to analyze the hurricane risk of distribution power (utility) poles, and assesses the potential impacts of climate change on the annual failure probability of the distribution poles. Damage risks of distribution poles designed by both NESC and ASCE methods were evaluated using a fragility analysis. Climate change was found to have a significant impact on the annual failure probability of the distribution poles when they are subjected to changing patterns of hurricane hazard.

Four design cases were explored for the design of the distribution poles, and each design case included varying strength and load factors, that are based on various practices within the design of existing and new distribution poles. Distribution poles designed with the new ASCE method were found to have the highest annual failure probability for all scenarios of climate change. The larger poles, often poles designed to NESC, experience the greatest percentage change in annual $\mathrm{P}_{\mathrm{f}}$ from the case of no climate change (i.e. no change in wind speed), which is attributed to the fact the annual $P_{f}$ was very low for these poles initially. Therefore, any changes in wind speed resulted in proportionally higher changes in the annual $\mathrm{P}_{\mathrm{f}}$ than for the other two design cases. An increase in wind speed of $10 \%$ over 100 years could increase annual failure probabilities by up to $90 \%$, from the case of no climate change and assuming no deterioration of the pole.

Degradation was also found to be an important factor in damage probability. For a pole that is 30 years old, an increase in wind speed of $10 \%$ over 100 years could result in an increase in annual damage probability of $30 \%$ to $60 \%$ from the no climate change scenario. These increases in failure rates are not as dramatic as for newly constructed poles, but an increase in failure probability for the 30 year old poles of approximately $30 \%$ or more, over a 100 -year time frame, could indicate significant increases in replacement costs. Furthermore, the service proven reliability of distribution poles was investigated for distribution poles. It was found that the updated annual $\mathrm{P}_{\mathrm{f}}$ could increase by up to $50 \%$ under an assumed increase in wind speed of $10 \%$ over 100 years, with deterioration, which further indicates increases in replacement costs. Therefore, if this or 
other climate change scenarios are believed to be possible it is necessary to assess the economic viability of adaptation strategies to replace or strengthen distribution poles in hurricane-prone zones.

\subsection{Acknowledgements}

The research described in this paper was supported, in part, by the National Science Foundation (NSF) Catalyzing New International Collaborations Program, and Infrastructure Management and Extreme Events Program under Grant No. NSF 1050443. This support is gratefully acknowledged. However, the writers take sole responsibility for the views expressed in this paper, which may not represent the position of the NSF or their respective institutions. The authors also thank Graduate Student Shurong Fang for performing some of the analysis.

\subsection{References}

American Society of Civil Engineers (ASCE-111) (2006). Reliability-Based Design of Utility Pole Structures (No. 111). ASCE manuals and reports on engineering practices.

American Society of Civil Engineers (ASCE-113) (2008). Substation structure design guide (No. 113). ASCE manuals and reports on engineering practices.

American National Standards Institute (ANSI). (2002) Wood Poles Specifications and Dimensions, 05.1.

Australian Greenhouse Office (AGO) (2007) An Assessment of the Need to Adopt Buildings for the Unavoidable Consequences of Climate Change. Final Report, Australian Greenhouse Office, Commonwealth of Australia.

AS 5604 (2005) Timber-Natural Durability Ratings, Australia. Standards Australia: 2005.

Baraneedaran, S., Gad, E.F., Flatley, I., Kamiran, A., and Wilson, J.L. (2009) Review of In-service Assessment of Timber Poles, Proceedings of the Australian Earthquake Engineering Society, Newcastle 2009. 
Bhuyan, G., and Li, H. (2006) Achieved Reliability of the North American Design Approaches for Transmission Overhead Structures, Probabilistic Methods Applied to Power Systems 11-15 June 2006, 1-5.

Bingel, N., Dagher, H., Randle, R., Wolfe, R., Slavin, L., Voda, M., and Wong, J. (2003) Panel session: structural reliability-based design of utility poles and the national electrical safety code, Transmission and Distribution Conference and Exposition, Sept.2003 IEEE PES, 3, 1088- 1093.

Bjarnadottir, S., Li, Y. and Stewart, M.G. (2011) A Probabilistic-based Framework for Impact and Adaptation Assessment of Climate Change on Hurricane Damage Risks and Costs, Structural Safety, 33, 173-185.

Broccoli, A.J., and Manabe, S. (1990) Can existing Climate Models be used to study Anthropogenic Changes in Tropical Cyclone Climate? Geophys. Res. Letters, 17, 19171920.

Brown, R.E. (2008) Electric Power Distribution Reliability. CRC Press: Boca Raton, FL.

Chang, C.-H. (2010) Preparedness and storm hazards in a global warming world: Lessons from Southeast Asia, Natural Hazards, Available online. http://services.lib.mtu.edu:2127/content/w2p683564371338h/fulltext.pdf

Climate Change Science Program (CCSP) (2008) Impacts of Climate Change and Variability on Transportation Systems and Infrastructure: Gulf Coast Study, Phase I. A Report by the U.S. Climate Change Science Program and the Subcommittee on Global Change Research. Savonis, M. J., V.R. Burkett, and J.R. Potter, Eds. Department of Transportation, Washington, DC, USA.

Crosset, K.M., Culliton, T. J., Wiley, P. C., and Goodspeed, T. R. (2004) Population Trends along the Coastal United States: 1980-2008. National Oceanic and Atmospheric Administration: Silver Spring, MD.

Dagher, H.J. (2001) Reliability of poles in NESC grade C construction, Rural Electric Power Conference, 2001. 
Ellingwood, B. R., and Tekie, P.B. (1999) Wind load statistics for probability-based structural design, Journal of Structural Engineering 125, 453-463.

Elsner, J.B., Kossin, J.P., and Jagger, T.H. (2008) The increasing intensity of the strongest tropical cyclones, Nature, 455, 92-95.

Emanuel, K. (2005) Increasing destructiveness of tropical cyclones over the past 30 years, Nature, 436, 686-688.

Florida Power \& Light Company (FP\&LC) (2006) Technical Report: Post Hurricane Wilma Engineering Analysis, KEMA, Inc.

Foedinger, R., Boozer, J.F., Bronstad, M.E., and Davidson, J.W. (2002) Development of an energy composite utility pole, Transportation Research Board Annual Meeting.

Gere, J., and Carter, W. (1962) Critical Buckling loads for tapered columns, Journal of Structural Engineering, 88, 1-11.

Goldenberg, S. B., Landsea, C. W., Mestas-Nunez, A. M., and Gray, W. M. (2001) The recent increase in Atlantic hurricane activity: causes and implications, Science, 293, 474479.

Guikema, S.D., Quiring, S.M., and Han, S-R. (2010) Prestorms Estimation of Hurricane Damage to Electric Power Distribution Systems, Natural Hazards, 30, 1744-1752.

Gustavsen, B., and Rolfseng, L. (2000) Simulation of wood pole replacement rate and its application to life cycle economy studies, IEEE Transactions on Power Delivery, 15, 300-306.

Gustavsen, B., and Rolfseng, L. (2005) Asset management of wood pole utility structure, International Journal of Electrical Power \& Energy Systems, 27, 641-646.

Haldar, A., and Tucker, K. (2006) Condition Based Management of Wood Pole Transmission Lines Using Structural Reliability Analysis, ASCE Conf. Proc. 218, 28, 304-316.

Johnson, B. (2005) After the Disaster: Utility Restoration Cost Recovery, Edison Electricity Institute, Washington D.C. 
Kwasinski, A., Weaver, W.W., Chapman, P.L., and Krein, P.T. (2009) Telecommunications Power Plant Damage Assessment for Hurricane Katrina- Site Survey and Follow-Up Results, Systems Journal, 3, 277-287.

Larsen, T., Porter, K., Zadeh, M., Van Anne, C., and Scawthorn, C. (1996) Impact of Hurricane Andrew on performance, interaction, and recovery of lifelines, EQE International, San Francisco, CA.

Leicester, R.H., Wang, C.H., Minh, M.N., Thornton, J.D., Johnson, G.C., and Gardner, D. (2003) An engineering model for the decay of timber in ground contact, IRG/WP/03, 34th annual meeting, Brisbane, Australia, 19-23 May 2003.

Li, H., and Bhuyan, G. (2000) Reliability-Based Design of Transmission Line Structures, Structural Design, Analysis, and Testing, 357-366.

Li, H., Zhang, J. and Bhuyan, G. (2006) Reliability Assessment of Electrical Overhead Distribution Wood Poles, Probability Methods Applied to Power Systems, International Conference. 11-15 June, 2006, Stockholm.

Li, Y., and Ellingwood, B.R. (2006) Hurricane damage to residential construction in the US: Importance of uncertainty modeling in risk assessment, Engineering Structures, 28, 1009-1017.

Louisiana Public Service Commission (LPSC) (2005) Emergency operations center, daily service outage repots- September 24, 2005 through October 17, 2005, December 9, 2005.

Lupoi, G., Franchin, P., Lupoi, A., and Pinto, P.E. (2006) Seismic Fragility Analysis of Structural Systems, J. Eng. Mech. 132, 385-396.

Malmedal, K., and Sen, P.K. (2003) Structural loading calculations of wood transmission structures, Rural Electric Power Conference, May 2003, 4-6.

Morrell, J. (2005) Estimated Service Life of Wood Poles, Technical Bulletin for the NAWPC (North American Wood Pole Council).

National Electrical Safety Code (NESC) (2002) IEEE Standard. Piscataway, New Jersey. 
Peel, M. C., Finlayson, B. L., and McMahon, T. A. (2007) Updated world map of the Köppen-Geiger climate classification, Hydrol. Earth Syst. Sci. 11, 1633-1644.

Peters, G., DiGioia, A.M.J., Hendrickson, C., and Apt, J. (2006) Transmission Line Reliability: Climate Change and Extreme Weather, Electrical Transmission Line and Substation Structures, Proceedings of 2006 Electrical Transmission Conference, 12-26.

Public Utility Commission of the State of Texas (PUCT) (2006) PUB investigation of methods to improve electric and telecommunications infrastructure to minimize long term outages and restoration costs associated with Gulf Coast hurricanes, Final Report, Project number 32812, Public Utility Commission of Texas, Austin.

Quanta Technology (2009) Cost-Benefit Analysis of the Deployment of Utility Infrastructure Upgrades and Storm Hardening Programs: Final Report, Public Utility Commission of Texas.

Reed, D.A. (2008) Electric utility distribution analysis for extreme winds, Journal of Wind Engineering and Industrial Aerodynamics, 96, 123-140.

Reed, D.A., Powell, M.D., and Westerman, J.M. (2010) Energy Infrastructure Damage Analysis for Hurricane Rita, Natural Hazards Review, 11, 102-109.

Stainforth, D. A. (2005) Uncertainty in predictions of the climate response to rising levels of greenhouse gases, Nature, 433, 403-406.

Stewart, M.G. (1997) Time-Dependent Reliability of Existing RC Structures, Journal of Structural Engineering, ASCE, 123,896-903.

Stewart, A.H. and Goodman, J.R. (1990) Life cycle economics of wood pole utility structures, Power Delivery, IEEE Transactions, 5,1040-1046.

Stewart, M G., and Val, D.V. (1999) Role of load history in reliability-based decision analysis of aging bridges, Journal of structural engineering, 125, 776-783.

Utility Solid Waste Activities Group (USWAG). (2005) Notice of Availability of the Preliminary Risk Assessment for Wood Preservatives Containing Pentachlorophenol Reregistration Eligibility Decision, 1-13. 
Vanderbilt, M D., Criswell, M.E., Folse, M.D., and Landers, P.G. (1982) ProbabilityBased Design of Wood Transmission Line Structures Electric Power Research Institute Project RP-1352-1: A Status Report, IEEE transactions on power apparatus and systems, 2451-2459.

Vickery, P.J., Wadhera, D., Twisdale, L.A.Jr., and Lavelle, F.M. (2009) U.S. Hurricane Wind Speed Risk and Uncertainty, Journal of Structural Engineering, 135, 301-320.

Walsh, K., Cai, W.J., Hennessy, K., Jones, R., McInnes, K., Nguyen, K., Page, C., and Whetton, P. (2002) Climate change in Queensland under enhanced greenhouse conditions: Final Report, 1997-2002, Ed. A.R. Australian Commonwealth Scientific and Research Organization (CSIRO), Australia.

Wang, C.-h., Leicester, R.H., and Nguyen, M. (2008a) Decay in ground, Forest and Wood Products Australia. CSIRO.

Wang, C.-h., Leicester, R.H., and Nguyen, M. (2008b) Probabilistic procedure for design of untreated timber poles in-ground under attack of decay fungi, Reliability Engineering \& System Safety, 93, 476-481.

Webersik, C., Esteban, M. and Shibayama, T. (2010) The economic impact of future increase in tropical cyclones in Japan, Natural Hazards, 55, 233-250.

White House (2009) Global Climate Change Impacts in the United States, U.S. Global Change Research Program. Washington, D.C. http://downloads.globalchange.gov/usimpacts/pdfs/climate-impacts-report.pdf.

Winkler, J., Dueñas-Osorio, L, Stein, R, and Subramanian, D. (2010) Performance assessment of topologically diverse power systems subjected to hurricane events, Reliability Engineering and System Safety, 95, 323- 336.

Wolfe, R., Bodig, J., and Lebow, P. (2001) Derivation of Nominal Strength for Wood Utility Poles, Forest Products Laboratory. U.S. Department of Agriculture.

Wolfe, R. and Kluge, R. O. (2005) Designated Fiber Stress of Wood Poles, Forest Products Laboratory. U.S. Department of Agriculture. 
Wolfe, R. and Moody, R. (1997) Standard Specifications for Wood Poles, Forest Products Laboratory. U.S. Department of Agriculture.

Zhai, X., and Stewart, M.G. (2010) Structural reliability analysis of reinforced grouted concrete block masonry walls in compression, Engineering Structures, 32, 106-114. 


\title{
Chapter 5
}

\section{Risk-Based Economic Assessment of Mitigation Strategies For Power Distribution Poles Subjected to Hurricanes ${ }^{4}$}

\author{
Sigridur Bjarnadottir ${ }^{1}$, Yue $\mathrm{Li}^{2}$, Mark G. Stewart ${ }^{3}$ \\ ${ }^{1}$ Ph.D. Candidate \\ Department of Civil and Environmental Engineering \\ Michigan Technological University, Houghton, Michigan, USA, sobjarna@mtu.edu \\ ${ }^{2}$ Associate Professor \\ Department of Civil and Environmental Engineering \\ Michigan Technological University, Houghton, Michigan, USA, yueli@mtu.edu \\ ${ }^{3}$ Professor and Director \\ Center for Infrastructure Performance and Reliability, \\ School of Engineering, The University of Newcastle, Callaghan, NSW, Australia
}

mark.stewart@newcastle.edu.au

\footnotetext{
${ }^{4}$ The material contained in this chapter has been accepted for publication in the journal Structure and Infrastructure Engineering. Bjarnadottir, S., Li, Y. and Stewart, M.G. (2012) Risk-Based Economic Assessment of Mitigation Strategies for Power Distribution Poles Subjected to Hurricanes, Structure and Infrastructure Engineering, (accepted). See Appendix IV for documentation of permission to republish this material.
} 


\subsection{Abstract}

This paper presents a risk-based framework to assess the hurricane damage risks to distribution poles and investigates the risks, costs, and benefit of different mitigation strategies. It is estimated that power outages due to storms cause approximately $\$ 270$ million in repair/replacement costs annually in the U.S. Hurricane Irene alone left approximately 6 million residents without power along the east coast of the U.S. in 2011, causing an estimated $\$ 5$ to $\$ 7$ billion in damages. These high repair/replacement costs warrant an investigation of mitigation strategies that may aid in reducing replacement and damage costs. This paper describes the reliability analysis of typical timber distribution poles and probabilistic wind models to determine failure probabilities for specific locations. Furthermore, in order to more accurately portray the behavior of distribution poles, the proposed framework includes the degradation and service-proven reliability of timber distribution poles. Four mitigation strategies are developed, and the costeffectiveness of each strategy is evaluated. In order to assess the cost-effectiveness, a life-cycle cost analysis is conducted for each mitigation strategy. This paper finds that appropriate mitigation strategies can reduce replacement costs of distribution poles associated with hurricane wind by 2060 .

Keywords: Distribution Poles, Degradation, Power Infrastructure, Hurricanes, Timedependent reliability, Risk Assessment, Vulnerability, Life-cycle cost analysis.

\subsection{Introduction}

Every year power outages due to wind storms cause an estimated \$270 million in repair costs in the United States (U.S.) (Johnson 2005). During the 2011 hurricane season, Hurricane Irene left approximately 6 million residents without power along the east coast of the U.S., causing an estimated $\$ 5$ to $\$ 7$ billion in damages (CBS 2011). In December 2011, a wind storm, with wind speeds of up to $45 \mathrm{~m} / \mathrm{s}$, caused power outages to over 400,000 residents in California and Utah (Schwartz 2011). Hurricane Rita in 2005, for example, left 500,000 and 1,500,000 customers without power in Louisiana and Texas, respectively (LPSC 2005, PUCT 2006). In Florida in 2004, damages to the power system accumulated to approximately $\$ 1$ billion due to four hurricanes that made landfall 
(Johnson 2005). Hurricane Andrew, in 1992, resulted in the failure of approximately $10.1 \%$ timber distribution poles, causing loss of power to $44 \%$ of Florida Power and Light Company's customers (FP\&LC 2006, Larsen et al. 1996).

Reed et al. (2010) conducted an analysis of damage to the power system infrastructure after Hurricane Rita, and found that high hurricane winds caused the majority of the damage. The population in hurricane prone areas of the U.S. is increasing steadily each year; for example, insured coastal property values in Florida have increased by 55\% from the year 1988 to 1993 , from $\$ 566$ billion to $\$ 872$ billion (Stewart et al. 2003). Furthermore, Florida utility companies have experienced a $20 \%$ increase in customers from 1994 to 2004 (Johnson 2005). It can be anticipated that more power systems will be needed to provide power to the increasing coastal population, and therefore, more power distribution systems may be exposed to hurricane hazards.

Roth (1997) found that if building codes had been enforced, approximately $25 \%$ to $40 \%$ of insurance losses from Hurricane Andrew could have been avoided. Furthermore, Stewart et al. (2003) found that if buildings are retrofitted to comply with ASCE-7 1988, the hurricane vulnerability can be significantly decreased. This emphasizes the relevance of exploring mitigation measures to reduce damage costs anticipated as the result of hurricane hazards, and it can be assumed that similar conclusions can be made regarding the importance of strategies to mitigate losses to the power distribution system. The purpose of this paper is to refine the hurricane risk assessment of distribution poles considering the affects of degradation on the performance of distribution poles. The paper will assess various hazard mitigation strategies that may aid in reducing the vulnerability of poles to damage due hurricane winds. This paper will assess the economic viability of various mitigation strategies by conducting a life-cycle cost analysis.

\subsection{Design and risk assessment of distribution poles}

The power system includes three main components: generation, transmission, and distribution. Of these three components, the distribution systems (lines and poles) are the most susceptible to wind damage. This is due to the fact that distribution lines and poles 
are more exposed to hurricane winds than the generation plants and the transmission systems. Furthermore, distribution poles are often not designed to withstand high wind speeds (Davidson et al. 2003). A typical timber distribution pole system is seen on Figure 5.1 that consists of a solid pole, three conductors, one neutral wire, and one communication wire. Approximately $99 \%$ of distribution poles in the U.S. are composed of wood materials (USWAG 2005). The Southern pine species accounts for approximately $75 \%$ of timber poles in the U.S. (Wolfe and Moody 1997). Therefore, this paper will focus on the risk and vulnerability of timber distribution poles caused by hurricanes.

The National Electric Safety Code (NESC) outlines a deterministic method to design timber distribution poles (NESC 2002). This method has, however, led to non-uniform reliabilities for distribution poles, which prompted the development of a Load Resistance Factor Design (LRFD) method by the American Society of Civil Engineers (ASCE) to maintain uniform reliabilities (Bhuyan and Li 2006, Dagher 2001). This ASCE design method has been introduced in the field of distribution (utility) pole design and is now used in design (ASCE-111 2006). The following formulation can be used in the design of distribution poles using the ASCE design method. 


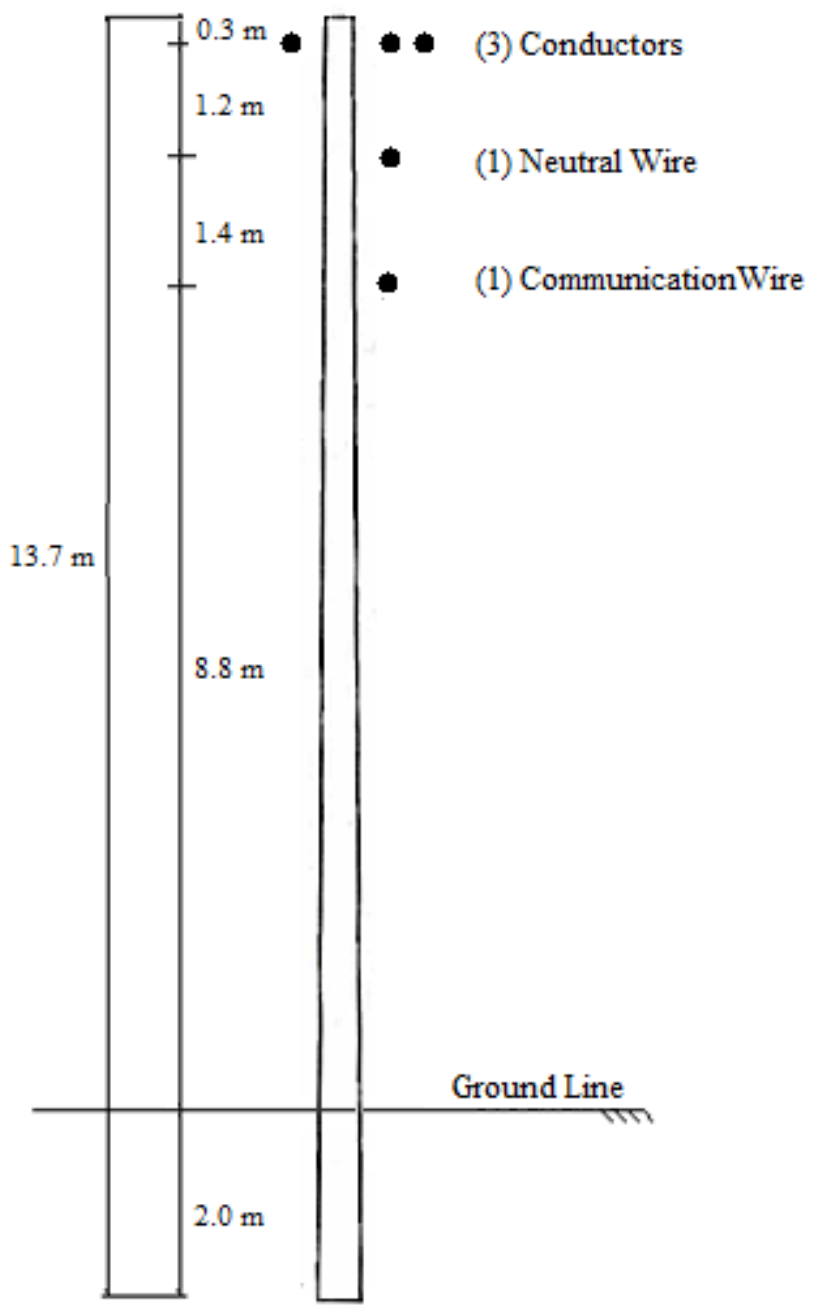

Figure 5.1: Typical Power Distribution Pole System (Bjarnadottir et al. 2012)

$R_{n}>\sum \frac{\gamma_{j}}{\emptyset_{j}} S_{n, j}$

where $R_{n}$ is the nominal strength of the pole (e.g. bending moment) and identified using design standards, $\varnothing_{\mathrm{j}}$ is the strength factor for load effect $\mathrm{i}, \mathrm{S}_{\mathrm{n}, \mathrm{j}}$ is the nominal load for load effect $\mathrm{j}$, and $\gamma_{\mathrm{j}}$ is the load factor for load effect $\mathrm{j}$. ASCE-111 (2006) recommends a strength factor $(\varnothing)$ of 0.79 , for a bending moment with a coefficient of variation (COV) of $20 \%$, and a load factor $(\gamma)$ of 1.0 for wind load.

In order to design a distribution pole, the material of the pole is first decided, and then the required height and ground line circumference $\left(C_{g}\right)$ of the pole are determined based on 
the load being designed for (i.e. wind load for the purpose of this paper). The wind load acting on the distribution pole is affected by the wind load acting on each of the components found in Figure 5.1.

$S_{n}=a m p \cdot \sum_{i=1}^{N} F_{i} h_{i}$

where $S_{n}$ is the nominal load $(\mathrm{N}-\mathrm{m})$, amp is the amplification factor, $F_{i}$ is the wind force (N) on component $\mathrm{i}$ (Eq. 5.3), and $\mathrm{h}_{\mathrm{i}}$ is the distance $(\mathrm{m})$ from ground line to the centroid of component i. The amplification factor is included to account for the P- $\Delta$ effect that occurs in tapered distribution poles (ASCE-111 2006, Bjarnadottir et al. 2012).

The wind force acting on each component is described with (ASCE-113 2008):

$F_{i}=Q k_{i} V^{2} I_{F W} G_{R F} C_{f} A_{i}$

where $\mathrm{Q}$ is air density factor, $\mathrm{k}_{\mathrm{i}}$ is terrain exposure coefficient for component $\mathrm{i}, \mathrm{V}$ is the 3 -sec gust wind speed with a return period of 50 years (Bingle et al. 2003), $\mathrm{I}_{\mathrm{FW}}$ is the importance factor, $G_{R F}$ is the gust response factor, $C_{f}$ is the force coefficient, and $A_{i}$ is the projected wind surface area normal to the direction of wind for component $i$.

Distribution poles are divided into classes based on the material of the pole, and assigned a permitted bending moment at ground line (i.e. $2.0 \mathrm{~m}$ from the base of the pole) based on the class, height, and circumference (ANSI 2002). The circumference of the pole can be estimated from the nominal load $\left(\mathrm{S}_{\mathrm{n}}\right)$ acting on the pole and the fiber stress of the species of timber (Brown 2008, Wolfe and Kluge 2005). Once the circumference has been determined, the class of the pole is determined from design standards, and from the pole class the nominal resistance $\left(\mathrm{R}_{\mathrm{n}}\right)$ is found (ANSI 2002).

The performance of distribution poles is dependent on various intervening variables (e.g. wind speed, pole strength) and design parameters (e.g. pole height and size) (Bjarnadottir et al. 2012). The limit state function for distribution poles is:

$$
\begin{aligned}
& G(t)=R(t)-S \\
& R(t)=a(t) \cdot M E \cdot R_{n}
\end{aligned}
$$


where $\mathrm{R}(\mathrm{t})$ is the actual capacity of the pole at time $\mathrm{t}, \mathrm{S}$ is the actual load based on various intervening variables (e.g. wind speed, pole geometry, wire geometry), $a(t)$ is the timedependent decay function, and ME is the model error, determined from available test data (Vanderbilt et al. 1982). The uncertainty of the resistance is accounted for by including the ME term within the equations, which is relative to the nominal strength (Lupoi et al. 2006, Zhai and Stewart 2010).

As a distribution pole ages, the strength of the pole degrades (Stewart and Goodman 1990, Gustavsen and Rolfseng 2000, Haldar and Tucker 2006). The main contributor to the degradation of strength of distribution poles is in-ground decay due to fungal attacks. In-ground decay occurs because the poles are in direct contact with the soil creating good conditions for fungal attacks (Baraneedaran et al. 2009, Leicester et al. 2003, Wang et al. 2008b). In order to take into account this deterioration of strength with age, the resistance in Eq. (5.5) is modified with a decay function $(\mathrm{a}(\mathrm{t}))$ to represent how the strength deteriorates over time.

The limit state for the performance function (Eq. 5.4) between failure and not failure is defined as $G=0$. If the variables result in $G>0$, then the system has fulfilled its performance criteria, but if $\mathrm{G}<0$, then the system has failed. The $\mathrm{P}(\mathrm{G}>0)$ is defined as the reliability of the system, and the probability of failure is defined as:

$P_{f}=P(G<0)$

Hurricane fragility can be defined as the conditional probability of failure of a structural member as a function of wind speed, and is often modeled as a lognormal cumulative distribution function (CDF) (Li and Ellingwood 2006).

$F_{D}(V)=\Phi\left(\left(\ln \left(V / m_{R}\right) / \xi_{\mathrm{R}}\right)\right.$

where $\mathrm{V}$ is the 3 -sec gust wind speed, $\mathrm{m}_{\mathrm{R}}$ is the median capacity or resistance, $\xi_{\mathrm{R}}$ is the logarithmic standard deviation of the capacity or resistance, and $\Phi(\cdot)$ is the standard normal probability integral.

This paper will consider the service proven reliability of distribution poles, by considering the effects load history may have on their reliability. The minimum 
structural capacity of a distribution pole can be determined from the number of years the distribution pole has survived. The analysis conducted herein will implement an updated annual $\mathrm{p}_{\mathrm{f}}$ of the distribution poles to account for load history. The updated annual $\mathrm{p}_{\mathrm{f}}$ is the probability that a distribution pole will fail in the subsequent year given that the distribution pole has survived g years of service (Stewart 1997, Stewart and Val 1999), and is estimated at each subsequent year by conducting a MCS. Given the load (S) and the resistance $(\mathrm{R})$ of the distribution poles, the MCS estimates the number of poles that fail in a given year. The total number of poles remaining each year is determined by subtracting the number of poles that failed the previous year. The updated annual $\mathrm{p}_{\mathrm{f}}$ is determined for each subsequent year from the total number of poles and the number of failed poles (Bjarnadottir et al. 2012).

The updated annual $\mathrm{p}_{\mathrm{f}}$ is a conditional probability that estimates the likelihood that the distribution poles will fail in year $\mathrm{g}+1$ given that the distribution poles have survived $\mathrm{g}$ years:

$p_{f}(1 \mid g)=\frac{p_{f}(g+1)-p_{f}(g)}{1-p_{f}(g)}$

where $\mathrm{p}_{\mathrm{f}}(\mathrm{t})$ is the cumulative probability of failure up to time $\mathrm{t}$ (Stewart and Val 1999).

The actual load, S, is influenced by the Weibull distribution of the maximum annual 3sec gust wind speed, at a height of $10 \mathrm{~m}$ on open terrain for hurricanes in the U.S. (Li and Ellingwood 2006). The PDF of the Weibull distribution is:

$f_{v}(V)=\frac{k}{u} \cdot\left(\frac{V}{u}\right)^{k-1} \exp \left[-\left(\frac{V}{u}\right)^{k}\right]$

where $\mathrm{V}$ is the 3-sec gust wind speed, and $\mathrm{k}$ and $\mathrm{u}$ are site-specific parameters.

To take into account the effects of exposure on wind speed and, ultimately, on the $\mathrm{p}_{\mathrm{f}}$ of distribution poles, the location of the distribution poles is identified within this study. Bjarnadottir et al. (2011) identified three exposure categories for residential construction: Foreshore (within $1 \mathrm{~km}$ from coast), Locations within $10 \mathrm{~km}$ inland, and Locations further inland. These three exposure categories are assumed to apply to distribution poles, because distribution poles located in foreshore locations will be exposed to higher wind 
speeds than poles located further inland; therefore the poles located foreshore will have a higher $\mathrm{p}_{\mathrm{f}}$ than poles located in the other exposure categories (Bjarnadottir et al. 2011). Once other information becomes available, it can be implemented into the proposed framework.

\subsection{Mitigation Strategies and Their Cost-effectiveness}

After putting forth the framework to assess the damage risk of distribution poles to hurricane hazard, it is possible to evaluate the economic viability of various hazard mitigation strategies. Failure rates of distribution lines can be significantly reduced by replacing the distribution poles with stronger poles (Stewart and Goodman 1990). Therefore, this analysis will investigate mitigation strategies that include replacing distribution poles with stronger poles (i.e. younger and/or larger poles able to withstand higher wind loads). The economic viability of mitigation measures related to replacement is investigated using a life cycle cost (LCC) analysis. The analysis includes modifications of the vulnerability model to help account for the effects of aging (deterioration). For this analysis, the annual growth rate $(\alpha)$, annual rate of additional replacement $(\delta)$, cost of replacement, and discount rate will be considered.

\subsubsection{Four Mitigation Strategies}

As a starting point, four mitigation strategies are explored, considering distribution poles designed according to the ASCE method (ASCE-111 2006). The replacement of an additional percentage of distribution poles (or rate of replacement, $\delta$ ) is considered a proactive measure that could aide in the reduction of existing vulnerability.

\section{Mitigation Strategy 1}

Distribution poles are designed according to ASCE-111 (2006). Using the design standard, the required pole size is determined based on the location of the distribution pole. For Mitigation Strategy 1, it is assumed that the distribution poles that fail annually are replaced with new distribution poles of the required (i.e. same) pole size, and as a proactive measure, it is assumed that annually an additional percentage of distribution poles $(\delta)$ that have reached the threshold criteria for strength are replaced with new 
distribution poles of the required (i.e. same) pole size. The threshold criteria for strength refers to the recommendation within NESC standards (2002) that distribution poles should be replaced if the strength is less than $2 / 3$ of the initial strength of the pole. This mitigation strategy is assumed to be applied to the whole region.

\section{Mitigation Strategy 2}

Mitigation Strategy 2 involves replacing distribution poles that fail annually with distribution poles that are one class stronger than the required pole size. For example, it was determined that the ASCE design method requires a Class 5 pole for Miami-Dade County, Florida; therefore, for this mitigation strategy it is assumed that distribution poles will be replaced by a higher class pole (i.e. a Class 4 pole). The Class 5 pole has a circumference at ground line of $790 \mathrm{~mm}$ and a nominal strength of 99,000 N-m, while the Class 4 pole has a circumference at ground line of $890 \mathrm{~mm}$ and a nominal strength of $123,000 \mathrm{~N}-\mathrm{m}$. This is an increase of $13 \%$ in circumference and $25 \%$ in nominal strength. This mitigation strategy does not assume that there is any additional pole replacement $(\delta=0)$, and it is assumed to apply to the whole region.

\section{Mitigation Strategy 3}

Mitigation Strategy 3 includes replacing distribution poles that fail annually, and an

additional percentage of distribution poles $(\delta)$ that have reached the threshold criteria for strength. The replaced poles are assumed to be replaced with distribution poles that are one class stronger than the required pole size. This mitigation strategy is assumed to be applied to the whole region.

\section{Mitigation Strategy 4}

Mitigation Strategy 4 looks solely at proactive measures for the foreshore locations (i.e. within $1 \mathrm{~km}$ of the shore). It is assumed that within the Foreshore category, distribution poles that fail annually are replaced with stronger distribution poles and an additional percentage of poles that have reached the threshold criteria for strength are replaced annually with stronger poles. However, for this mitigation strategy, it is assumed that for the other two exposure categories the distribution poles that fail annually are replaced with distribution poles of the required (i.e. same) pole size and there is no additional 
replacement in these exposure categories. In other words, this mitigation strategy applies Mitigation Strategy 3 only to areas of highest vulnerability (i.e. foreshore locations).

\subsubsection{Life Cycle Cost Analysis (LCC)}

Based on a survey of utility companies in the U.S., distribution poles are inspected on 8 year intervals (Mankowski et al 2002). The NESC (2002) recommends that poles should be replaced once the strength of the poles has deteriorated to approximately $2 / 3$ of their initial resistance. The threshold of strength is commonly met when the poles are approximately 32 years old, based on the framework proposed herein. For this analysis, it is assumed that poles are only replaced if they (i) fail due to wind exceedance of limit state given by Eq. (5.4) or (ii) the mitigation strategy involves additional pole replacement (i.e. Mitigation Strategies 1, 3, and 4).

A life cycle cost analysis (LCC) is conducted to evaluate the cost-effectiveness of the various mitigation strategies. The replacement case involves combining the reduction in structural vulnerability due to using larger distribution poles and the cost associated with strengthening construction (Stewart et al. 2003). The LCC for this analysis is calculated for the pole replacement by implementing the updated annual $\mathrm{p}_{\mathrm{f}}$ of the distribution poles, and it depends on various factors within the area, such as the pole inventory, the age distribution of the poles, the annual rate of additional replacement $(\delta)$, the annual growth $(\alpha)$, the cost of replacement, and the discount rate. After the LCC has been calculated, the cost-effectiveness of the retrofit scenario can be identified by comparing the LCC to the case of "do nothing" or "business as usual", i.e. existing vulnerability.

The net benefit, $\mathrm{E}_{\mathrm{b}, \mathrm{LCC}}$, for the LCC analysis is estimated as the difference of the cumulative LCC of the "do nothing" scenario and the cumulative LCC after adaption:

$E_{b, L C C}=L C C_{\text {"do nothing" }}(1, T)-L C C(1, T)$

In general, in order to estimate the cumulative replacement costs, the replacement cost for each exposure category needs to be determined first. For each exposure category, the replacement cost is determined with the sum of the number of poles that fail annually within each exposure category and the expected annual growth rate of new distribution poles. Once the replacement cost has been determined for each of the three exposure 
categories, the replacement cost for the region is the sum of the three values. The cumulative replacement cost involves summing up the regional replacement cost for each year within a set time frame (Bjarnadottir et al. 2011). Once more detailed information is available on costs associated with distribution pole failure, it can be incorporated into the proposed framework. Eq. (5.11) and Eq. (5.12) estimate the cumulative replacement cost for the mitigation strategies.

The annual replacement cost due to distribution pole failure is found by multiplying the updated annual $\mathrm{p}_{\mathrm{f}}$ with the cost of pole replacement $\left(\mathrm{C}_{\mathrm{rep}}\right)$, including labor, material, and disposal cost. Costs due to interruption of power supply; death, injury and damage to property caused by falling poles or wires; and other direct or indirect losses are not considered herein, but will be considered in future implementations of the proposed framework. The cumulative replacement cost $(\operatorname{LCC}(1, \mathrm{~T}))$ is found by summing the cost of replacement over a time period, $\mathrm{T}$, for the region. The equation for the "do nothing" case:

$$
\operatorname{LCC}(1, T)=\sum_{t=1}^{50} \sum_{g=1}^{50} \sum_{n=1}^{3} \varphi_{n}\left(N(t, g) p_{f}(1 \mid g)+\alpha N_{t o t}\right) \frac{C_{r e p, b}}{(1+r)^{t}}
$$

where $\mathrm{N}_{\text {tot }}$ is the total number of existing poles at $\mathrm{t}=1$ (2011), $\mathrm{N}$ is the number of poles of each survival age $(\mathrm{g})$ at time $(\mathrm{t}), \mathrm{p}_{\mathrm{f}}(1 \mid \mathrm{g})$ is the updated annual probability of failure of poles with survival age (g) within exposure category $(\mathrm{n}), \alpha$ is the annual growth rate of new poles due to population growth, $\varphi_{n}$ is the proportion of poles located in each exposure category, $\mathrm{r}$ is the discount rate, and $\mathrm{C}_{\mathrm{rep}, \mathrm{b}}$ is the replacement cost. It should be noted that $\mathrm{C}_{\text {rep,b }}$ will vary between the "do nothing" case and the mitigation strategies (this is discussed in the following chapter). For instance, Mitigation Strategy 2 implements this equation modified slightly by incorporating a higher replacement cost due to the use of larger distribution poles after replacement, and therefore the larger poles implement a lower $\mathrm{p}_{\mathrm{f}}$ associated with the larger poles.

In order to assess Mitigation Strategies 1 and 3, Eq. (5.11) must be modified because these strategies involve additional replacement (annual rate of replacement, $\delta$ ). Although Strategies 1 and 3 use the same equation (i.e. Eq. 5.12), the input values will differ because Mitigation Strategy 3 will implement a higher replacement cost associated with 
the larger pole and therefore a lower $\mathrm{p}_{\mathrm{f}}$. Furthermore, Mitigation Strategy 4 involves the use of a combination of Eq. (5.11) and Eq. (5.12), because it involves proactive mitigation measures at high vulnerability locations. The equation for Mitigation Strategies 1 and 3 is given as:

$$
\operatorname{LCC}(1, T)=\sum_{t=1}^{50} \sum_{g=1}^{50} \sum_{n=1}^{3} \varphi_{n}\left(N(t, g) p_{f}(1 \mid g)+(\alpha+\delta) N_{t o t}\right) \frac{C_{r e p, b}}{(1+r)^{t}}
$$

\subsubsection{Cost of Replacement $\left(C_{\text {rep}}\right)$ and Annual Replacement Rate ( $\left.\delta\right)$}

The annual rate of additional replacement $(\delta)$ of distribution poles for the U.S. is estimated at $1.4 \%$ (Roliadi et al. 2000), and it is estimated that $4.6 \%$ of distribution poles were replaced in Texas after Hurricane Ike (Quanta 2009). Therefore, to explore a range of $\delta$, it is assumed to vary from $1 \%$ to $10 \%$. Furthermore, the cost of replacement is assumed to be an additional cost, and the discount rate is investigated for a range of possible rates as discussed below. The cost of labor of removing an existing pole and installing a new distribution pole is approximately $\$ 1115$, including disposal cost (Butera 2000). The material cost is additional; therefore the cost of replacement is the total cost (i.e. $\$ 1115$ plus material cost). Because the mitigation strategies involve either replacing a pole with a new same size pole or a new larger pole, the material costs will differ between the mitigation strategies; therefore two costs of replacement are implemented $\left(\mathrm{C}_{\text {rep }, 1}\right.$ and $\left.\mathrm{C}_{\text {rep }, 2}\right)$. The material cost for a new Class 5 pole is approximately $\$ 180$ and, for a new Class 4 pole, is approximately $\$ 260$ (Butera 2000). Therefore, for Mitigation Strategies 1 and 4 , the cost of replacement $\left(C_{\text {rep }, 1}\right)$ is $\$ 1115+\$ 180$, and for Mitigation Strategies 2, 3, and 4, the cost of replacement $\left(\mathrm{C}_{\text {rep, }, 2}\right)$ is $\$ 1115+\$ 260$.

\subsubsection{Consideration of Discount Rate}

There is some uncertainty about the level of discount rate. For public-sector decisions in the U.S., a discount rate of 3-4\% is reasonable (Wen 2001). The United States Office of Management and Budget (OMB 2003) mandate that discount rates of $3 \%$ and $7 \%$ be used to "assist analysts in the regulatory agencies by defining good regulatory analysis.... and standardizing the way benefits and costs of Federal regulatory actions are measured and reported". The Australian Government Office of Best Practice Regulation (OBPR) 
recommends that the discount rate for regulatory interventions is $7 \%$, and that sensitivity analyses consider discount rates of $3 \%$ and 10\% (OBPR 2010).

Discount rates are generally assumed to be constant with time. Projects with significant effects beyond 30-50 years are considered intergenerational. In this case, a time-declining interest rate may be appropriate because of (i) increasing time aversion resulting in lower discount rates, (ii) ethical dilemmas of costs and benefits having negligible value far into the future if a constant discount rate is used, (iii) time-declining discount rate will place greater weight on future generations, and (iv) lower discount rates should be used to reflect greater inherent uncertainty about the future growth rate of the economy and future market rates the further we look into the future (Boardman et al. 2011). For this reason, the British Treasury recommends that following declining long-term discount rates (HM Treasury 2003): 3.5\% (0-30 years), 3.0\% (31-75 years), 2.5\% (76-125 years), $2.0 \%$ (126-200 years), $1.5 \%$ (201-300 years), and 1.0\% (300+ years).

The U.S. OMB also believes that intergenerational effects are important, and mandates: "If your rule will have important intergenerational benefits or costs you might consider a further sensitivity analysis using a lower but positive discount rate in addition to calculating net benefits using discount rates of 3 and 7 percent." (OMB 2003). The OMB provides no quantitative guidance about the 'lower' time-declining discount rate. There is some controversy about time-declining interest rate (e.g., Viscusi 2007), and the Australian OPBR states that "there is no consensus about how to value impacts on future generations" and "Rather than use an arbitrarily lower discount rate, the OBPR suggests that the effects on future generations be considered explicitly" (OBPR 2010).

In the cost-benefit analysis, the following discount rates will be used to be consistent with U.S. practice and regulations:

- $\mathrm{r}=7 \%$

- $\mathrm{r}=3 \%$

- $\mathrm{r}=3.5 \%(2010-2030), 3.0 \%(2031-2060)$

Since the time period for our analysis is the 50 year period 2011 to 2060, then intergenerational affects may be important and so a time-declining interest rate similar to 
that specified by the U.K. is used herein. Monte Carlo Simulation (MCS) can be used to estimate the mean and $10^{\text {th }}$ and $90^{\text {th }}$ percentiles of LCC.

\subsection{Illustrative Example}

Miami-Dade County, Florida was chosen as the location for the illustrative example of the proposed framework. In Miami-Dade County, there are currently 220,000 distribution poles $\left(\mathrm{N}_{\text {tot }}=220,000\right)$, with an annual growth rate $(\alpha)$ of $1.4 \%$ (FP\&L 2006, Roliadi et al. 2000). It is assumed that these distribution poles are made of Southern pine timber (i.e. $14 \mathrm{~m}$ high with a spacing of $46 \mathrm{~m}$ ), designed using the ASCE method.

Furthermore, the typical timber pole is assumed to support three conductors, one neutral wire, and one communication cable. It was found that the required distribution pole for Miami-Dade County is a Class 5 pole (Bjarnadottir et al. 2012). Table 5.1 shows the design parameters for this distribution pole (ANSI 2002). The table shows the circumference at ground line $\left(\mathrm{C}_{\mathrm{g}}\right)$, the nominal resistance, and the actual resistance. The actual resistance was obtained by adjusting the nominal resistance with the model error (ME). The ME for Southern pine distribution poles is approximately 1.12 (Vanderbilt et al. 1982).

Table 5.1: Design Parameters for Distribution Pole

\begin{tabular}{|c|c|c|c|c|}
\hline Method & $\mathbf{C}_{\mathbf{g}}$ & Class & $\begin{array}{c}\text { Design Resistance } \\
\left(\mathbf{R}_{\mathbf{n}}\right)\end{array}$ & Actual Resistance (R) \\
\hline ASCE & $775 \mathrm{~m}$ & 5 & $99,000 \mathrm{~N}-\mathrm{m}$ & $111,000 \mathrm{~N}-\mathrm{m}$ \\
\hline
\end{tabular}

In order to estimate the updated annual $\mathrm{p}_{\mathrm{f}}$, a MCS is conducted. Therefore, the uncertainty within both the resistance and the applied load must be accounted for. The actual resistance is determined from the nominal resistance and the model error, and both these parameters have uncertainty associated with them. The ASCE-111 (2006) suggests that the resistance can be described with three distributions: normal, lognormal, and Weibull. Bingel et al. (2003), Li et al. (2006), and Wolfe et al. (2001) recommend that the resistance of the pole should be described with a lognormal distribution; therefore, it is chosen as a starting point for this analysis. The ASCE-111 (2006) also recommends a 
COV of $20 \%$ for the resistance. The ME is assumed to be 1.12 and to be normally distributed with a COV of $14 \%$ (Vanderbilt et al. 1982). The uncertainty of both the nominal resistance and the model error can then be accounted for within the MCS. Also, as stated earlier, the distribution poles are assumed to age by incorporating a decay function into the estimation of the resistance (Eq. 5.5). The decay function is obtained from Wang et al. (2008a).

The nominal wind load is determined from Eq. (5.2) and Eq. (5.3). The actual wind load (S) for this analysis is determined using the equations for the nominal wind load, including the uncertainty present within some of the values. Therefore the applied wind load $(\mathrm{S})$ is dependent on various random variables, and the variables must be identified along with their corresponding statistical distributions and COV. The wind load for the poles is determined based on the wind speed $(\mathrm{V})$, the projected wind area (A) (which varies between the components of the pole), the air density factor $(\mathrm{Q})$, the importance factor $\left(\mathrm{I}_{\mathrm{FW}}\right)$, the terrain exposure coefficient $(\mathrm{k})$, the gust response factor $\left(\mathrm{G}_{\mathrm{RF}}\right)$, the force coefficient $\left(\mathrm{C}_{\mathrm{F}}\right)$, and the height of the components from the ground (h) (ASCE-111 2006). These values are presented in Table 5.2 with the corresponding statistical distribution and COV. However, the wind speed is discussed specifically in the next section so it is not included in the table. Also not included in the table are the air density factor $(\mathrm{Q})$ and the importance factor $\left(\mathrm{I}_{\mathrm{FW}}\right)$ as these are constants with values of 0.00256 for U.S. units ( 0.613 for SI Units) and 1.0, respectively. The details of the statistics and development of the fragility curve can be found in (Bjarnadottir et al. 2012). 
Table 5.2: Statistics for Wind Load

\begin{tabular}{|c|c|c|c|c|c|}
\hline $\begin{array}{l}\text { Random } \\
\text { Variable }\end{array}$ & Component & Distribution & Mean Value & $\mathrm{COV}$ & Source \\
\hline \multirow{4}{*}{$\mathrm{A}\left(\mathrm{m}^{2}\right)$} & Pole & Normal & Varies & $6 \%$ & \multirow{4}{*}{$\begin{array}{c}\text { Wolfe and } \\
\text { Moody } \\
1997\end{array}$} \\
\hline & Conductor & Normal & $1.50 \mathrm{~m}^{2}$ & $6 \%$ & \\
\hline & Neutral Wire & Normal & $1.00 \mathrm{~m}^{2}$ & $6 \%$ & \\
\hline & Communication Cable & Normal & $3.20 \mathrm{~m}^{2}$ & $6 \%$ & \\
\hline \multirow{2}{*}{$\mathrm{k}$} & Pole & Normal & 0.98 & $6 \%$ & \multirow{2}{*}{$\begin{array}{c}\text { ASCE-111 } \\
2006\end{array}$} \\
\hline & Wires & Normal & 1.05 & $6 \%$ & \\
\hline \multirow{4}{*}{$\mathrm{h}(\mathrm{m})$} & Pole & Normal & $5.40 \mathrm{~m}$ & $3 \%$ & \multirow{4}{*}{ Assumed } \\
\hline & Conductor & Normal & $11.50 \mathrm{~m}$ & $3 \%$ & \\
\hline & Neutral Wire & Normal & $10.20 \mathrm{~m}$ & $3 \%$ & \\
\hline & Communication Cable & Normal & $8.80 \mathrm{~m}$ & $3 \%$ & \\
\hline \multirow{2}{*}{$\mathrm{G}_{\mathrm{RF}}$} & Pole & Normal & 0.96 & $11 \%$ & \multirow{2}{*}{$\begin{array}{c}\text { Ellingwood } \\
\text { and Tekie } \\
1999\end{array}$} \\
\hline & Wires & Normal & 0.81 & $11 \%$ & \\
\hline \multirow{2}{*}{$\mathrm{C}_{\mathrm{f}}$} & Pole & Normal & 1 & $12 \%$ & \multirow{2}{*}{$\begin{array}{c}\text { Ellingwood } \\
\text { and Tekie } \\
1999\end{array}$} \\
\hline & Wires & Normal & 1 & $12 \%$ & \\
\hline
\end{tabular}

The resistance of a timber distribution pole decreases with age, as the degradation results in a decreased diameter of the pole due to decay. Because available data from MiamiDade County on the age profiles of distribution poles states that the poles vary from 1 years old to 50 years old (FP\&LC 2006), the actual resistance and its corresponding COV are determined for each year over the 50 year time frame. For illustration purposes, Table 5.3 shows the actual resistance estimated for poles that are $\mathrm{g}=1,20$, and 40 years old. The table also includes the COV for the estimated resistance. The values found within the table are estimated based on Wang et al. (2008b), and for the sake of brevity are not included herein, but the interested reader is directed to Bjarnadottir et al. (2012) 
for details on how the equations outlined in Wang et al. (2008b) are implemented in assessing the affects degradation has on the strength of timber distribution poles in the U.S. The table shows that as the poles are assumed to age, the uncertainty within the estimated resistance increases which translates to the increasing $\mathrm{COV}$ with age. Furthermore, deterioration will impact the updated annual $\mathrm{p}_{\mathrm{f}}$; the distribution poles are more vulnerable to damage from wind as the age of the poles increases.

Table 5.3: Mean and COV of Resistance R(t) for Various Ages

\begin{tabular}{|c|c|c|c|c|c|}
\hline \multicolumn{2}{|c|}{1 years } & \multicolumn{2}{c|}{20 years } & \multicolumn{2}{c|}{ 40 years } \\
\hline $\begin{array}{c}\text { Mean } \\
\text { Resistance }\end{array}$ & COV & $\begin{array}{c}\text { Mean } \\
\text { Resistance }\end{array}$ & COV & $\begin{array}{c}\text { Mean } \\
\text { Resistance }\end{array}$ & COV \\
\hline $73,000 \mathrm{lb}-\mathrm{ft}$ & $20.0 \%$ & $58,600 \mathrm{lb}-\mathrm{ft}$ & $28.7 \%$ & $43,700 \mathrm{lb}-\mathrm{ft}$ & $54.4 \%$ \\
\hline
\end{tabular}

Hurricane fragility curves show the probability of failure of a distribution pole conditioned at a specific wind speed, which increases monotonically, and can be developed based on the information in Table 5.2 to examine the differences in vulnerability between distribution poles of varying age, size, or material. The probability of failure for the fragility curves is estimated by a MCS, which involves counting the number of times the load $(\mathrm{S})$ exceeds the resistance $(\mathrm{R})$. The load $(\mathrm{S})$ and resistance $(\mathrm{R})$ are randomly generated with the wind speed being deterministic within the selected range (i.e. from $0 \mathrm{~m} / \mathrm{s}$ to $120 \mathrm{~m} / \mathrm{s}$ ). For illustration purposes, fragility curves are presented for Class 5 distribution poles, of varying age, located foreshore in Figure 5.2. From the figure it is seen that as poles age they become more vulnerable to failure. For example, for a wind speed of $36 \mathrm{~m} / \mathrm{s}$, the 1 year old distribution pole has a 0.005 probability of failure, the probability of failure increases to 0.228 for a 30 year old pole, and to 0.570 for a 50 year old pole. 


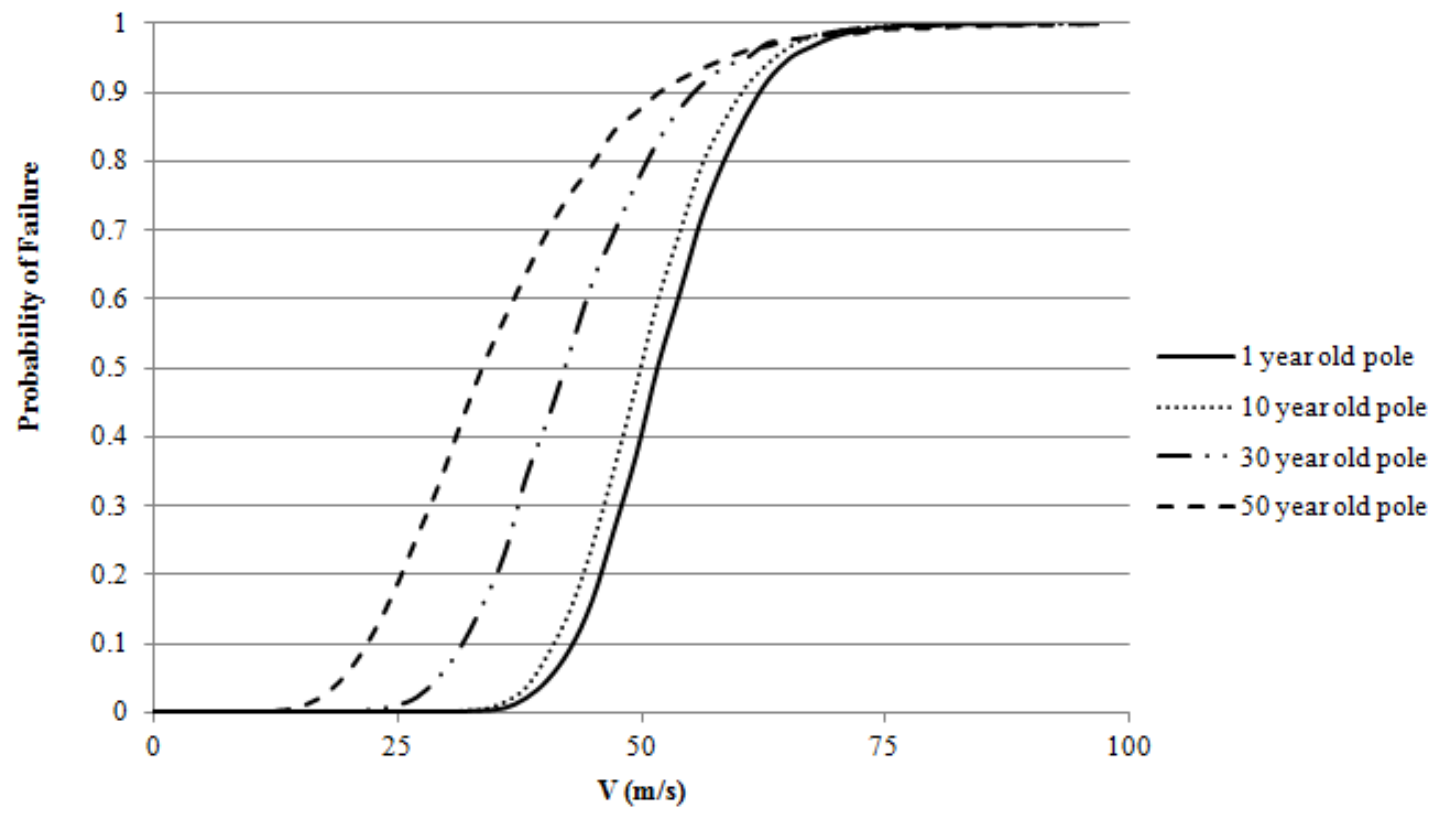

Figure 5.2: Fragility Curves for Class 5 Distribution Pole of Varying Age

\subsubsection{Annual $p_{\mathrm{f}}$ Considering Effects of Deterioration}

The updated annual $\mathrm{p}_{\mathrm{f}}$ is estimated by first determining the Weibull distribution parameters for wind speed in Miami-Dade County. Using wind contour maps, these parameters are estimated to be $\mathrm{u}=27.36$ and $\mathrm{k}=1.77$ (Vickery et al. 2009). Once the Weibull parameters have been estimated, the hurricane fragility parameters are determined. The fragility parameters are estimated at $\ln \mathrm{m}_{\mathrm{R}}=3.95$ and $\xi_{\mathrm{R}}=0.146$ for Class 5 distribution poles.

The updated annual $\mathrm{p}_{\mathrm{f}}$ for new Class 5 distribution poles is estimated to be approximately 0.054 (i.e. no deterioration at Foreshore locations). In comparison, given an extreme wind criterion of $65 \mathrm{~m} / \mathrm{s}$, the annual probability of failure for timber poles located in Southern Florida is estimated to be 0.045 (FP\&LC 2006, Quanta 2009). This estimate by Quanta (2009) is lower than the updated annual $\mathrm{p}_{\mathrm{f}}$ estimated using the proposed framework. This can be attributed to the fact that Class 4 poles are the most common class of distribution poles in the U.S. (Foedingur et al. 2002), while the ASCE design method recommended a Class 5 pole. A lower annual probability of failure is expected for a higher class of pole, because it is larger and able to withstand higher wind speeds. 
The updated annual $\mathrm{p}_{\mathrm{f}}$ is determined for distribution poles ranging from 1 years old to 50 years old.

Figure 5.3 shows the updated annual $\mathrm{p}_{\mathrm{f}}$ for Class 5 distribution poles located foreshore considering both degradation and no degradation over a 100 year period (Bjarnadottir et al. 2012). The updated annual $\mathrm{p}_{\mathrm{f}}$ is quite similar for the first years of the assessment. When degradation is accounted for, the updated annual $\mathrm{p}_{\mathrm{f}}$ increases significantly. However, when degradation is not considered, the updated annual $\mathrm{p}_{\mathrm{f}}$ decreases. This is attributed to the fact that the reliability of service-proven structures should increase if no degradation is accounted for (Stewart 1997, Stewart and Val 1999). The updated annual $\mathrm{p}_{\mathrm{f}}$ considering degradation is used herein.

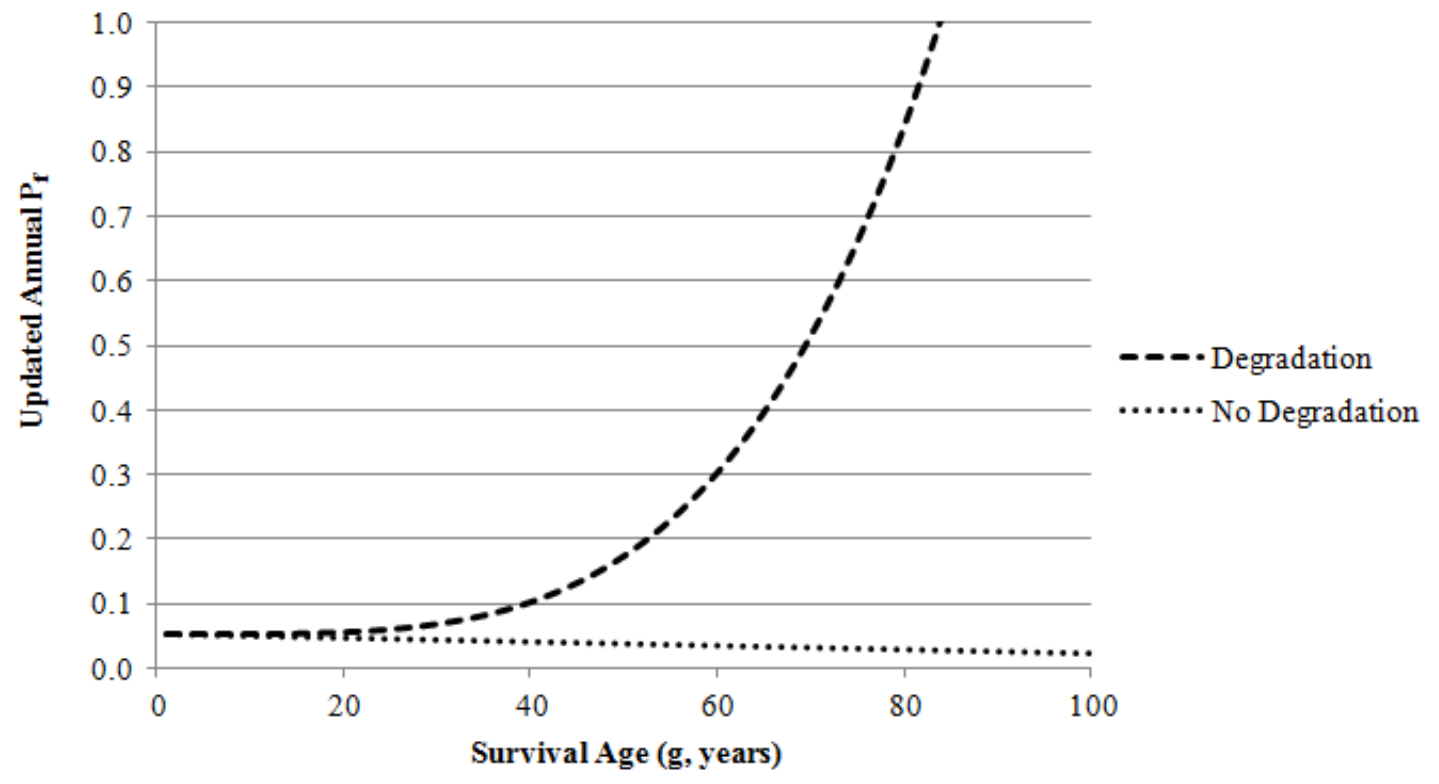

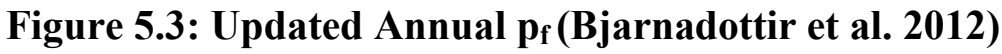

\subsubsection{Cost-effectiveness of Mitigation Strategies}

To assess the cost effectiveness of mitigation by using a LCC analysis, the number of poles that fail annually are determined for the "do nothing" (or "business as usual") case and for the four mitigation strategies. Information is available on the age profiles of distribution poles in Miami-Dade County ranging from $\mathrm{g}=1$ years old to 50 years old (FP\&LC 2006). Therefore, it is assumed that distribution poles in Miami-Dade County are between the ages of 1 and 50 years old. As stated previously, it is assumed that the 
initial strength of Class 5 poles follow a lognormal distribution, with a mean strength and COV found in design standards (ANSI 2002). In order to perform this analysis, a 51 by 220,000 matrix is generated, where 220,000 initial pole strengths are created to represent the actual number of poles in Miami-Dade County (FP\&L 2006) and degraded over 50 years with the degradation function (Eq. 5.5). From information available the percentage of poles of each age are known; therefore, from the 220,000 degraded initial strengths, strengths corresponding to every age are extracted. Each age has a corresponding updated annual $p_{f}$ that is combined with the number of poles of each age to determine the number that fail annually.

In order to conduct a comparative analysis of the cost effectiveness of mitigation strategies, the cost of the "do nothing" case should first be estimated. The "do nothing" case corresponds to current practices without mitigation. Furthermore, the "do nothing" case assumes that the distribution poles that fail annually are replaced with new poles of the required (same) pole class size. However, the "do nothing" case does not assume that there is any additional distribution pole replacement within the region (i.e. distribution poles are only replaced if they fail). The cost of the "do nothing" case at year 2060 (i.e. after 50 years) is presented in Table 5.4. The table also includes the cost per pole which is calculated based on the LCC and the total number of poles, including the effects exposure has on the number of poles potentially exposed to hurricane wind. The results are shown considering various discount rates. From the table it can be seen that the discount rate has a significant effect on the cost, i.e. the higher the rate results in lower future costs. As the affects of the discount rate are consistent throughout this illustrative example, results will be presented for a discount rate of $3 \%$ hereafter. 
Table 5.4: Cost of the "Do Nothing" Case at Year 2060

\begin{tabular}{|c|c|c|}
\hline Discount Rate & $\begin{array}{c}\text { Cumulative } \\
\text { LCC } \\
(\$ \text { millions })\end{array}$ & $\begin{array}{c}\text { Cost per } \\
\text { Pole }\end{array}$ \\
\hline $7 \%$ & $\$ 77$ & $\$ 767$ \\
\hline $3 \%$ & $\$ 152$ & $\$ 1514$ \\
\hline $3.5 \%(2010-2030), 3.0 \%(2031-2060)$ (Varies) & $\$ 145$ & $\$ 1444$ \\
\hline
\end{tabular}

After estimating the "do nothing" case, the cost effectiveness of the various mitigation strategies can be assessed by first determining the cumulative LCC for each strategy. Once the strength and deterioration of the distribution poles has been estimated and accounted for, it is possible to begin replacing the distribution poles. First, the updated annual $p_{f}$ is implemented and each year the distribution poles that are assumed to fail within each age classification are replaced. Furthermore, for Mitigation Strategies 1, 3, and 4 , an annual rate of replacement $(\delta)$ of distribution poles that have reached the threshold criteria for strength are replaced with stronger poles as a proactive measurement. The results for Mitigation Strategies 1, 3, and 4 are determined assuming a replacement rate of $\delta=5 \%$ per year. Essentially, the results of the outlined process estimate approximately the number of distribution poles that are replaced annually. Once the number of poles being replaced has been estimated, the cost of replacement is implemented, accounting for the various discount rate scenarios mentioned above.

The average number of poles replaced, the average time to failure, and the mean loss of resistance for the "do nothing" case and the mitigation strategies are shown in Table 5.5. From the table it can be seen that because Mitigation Strategy 1 involves the proactive measurement of replacing a percentage of old poles with new, but same size, poles, it does not actually decrease the vulnerability of the distribution poles. The other mitigation strategies do decrease the average number of poles being replaced from the "do nothing" case. The reason for this decrease is due to the fact that these mitigation strategies involve replacing poles with stronger distribution poles which results in the 
decreased vulnerability of the poles, so fewer poles are failing annually due to wind. The mean time to failure refers to the mean age distribution poles are replaced for the respective strategy. Mitigation Strategies 2, 3, and 4 involve replacement of distribution poles with larger poles, able to withstand higher wind loads, this, in turn, translates into a longer average service life of the distribution poles. From the table it can also be seen that within this framework, distribution poles are replaced on average earlier than the NESC threshold criteria of strength (i.e. $2 / 3$ of the initial strength), and this attributed to the fact that these values include poles that are assumed to fail annually due to hurricanes.

Table 5.5: Average Number of Poles Replaced

\begin{tabular}{|c|c|c|c|c|c|}
\cline { 2 - 6 } \multicolumn{1}{c|}{} & $\begin{array}{c}\text { Do } \\
\text { Nothing }\end{array}$ & $\begin{array}{c}\text { Mitigation } \\
\text { Strategy 1 }\end{array}$ & $\begin{array}{c}\text { Mitigation } \\
\text { Strategy 2 }\end{array}$ & $\begin{array}{c}\text { Mitigation } \\
\text { Strategy 3 }\end{array}$ & $\begin{array}{c}\text { Mitigation } \\
\text { Strategy 4 }\end{array}$ \\
\hline $\begin{array}{c}\text { Average } \\
\text { Number of } \\
\text { Poles } \\
\text { Replaced } \\
\text { (per year) }\end{array}$ & 9,700 & 10,300 & 6,600 & 6,930 & 9,200 \\
\hline $\begin{array}{c}\text { Mean time to } \\
\text { failure (year) }\end{array}$ & 28 & 28 & 32 & 32 & 30 \\
\hline $\begin{array}{c}\text { Mean loss of } \\
\text { resistance at } \\
\text { replacement or } \\
\text { at time of } \\
\text { failure (\%) }\end{array}$ & $27 \%$ & $27 \%$ & $32 \%$ & $32 \%$ & $29 \%$ \\
\hline
\end{tabular}

Figure 5.4 shows the cumulative LCC at year 2060 associated with the mitigation strategies, and the results for the "do nothing" case are included for comparative purposes. From the figure it can be seen that certain mitigation measures could be cost effective in reducing the vulnerability of the distribution poles to hurricane damage. Mitigation Strategies 2 and 3 are the most effective, resulting in a potential net benefit of up to approximately $\$ 30$ million. Mitigation Strategy 4 requires the fewest number of replacement poles and could be a cost effective and economical measure to reduce replacement costs. From the figure it can be seen that mitigation measures that involve 
replacing poles with stronger ones are the most effective. Mitigation Strategy 1, which involves replacing an additional percentage of poles that have reached the threshold criteria for strength annually with new poles of the same pole size, is not found to be cost effective as the cost of the additional replacement outweighs the benefits of the reduction in vulnerability. Because Mitigation Strategy 2 does not require any additional replacement of distribution poles, this strategy involves the least amount of disruption as it involves replacing only distribution poles that have failed. The additional percentage of distribution poles being replaced (Mitigation Strategy 1, 3, and 4) does not seem to be as cost effective as solely replacing failed poles with stronger poles. This can be attributed to the fact that the cost of the additional distribution poles does not resonate into a large enough reduction in vulnerability of distribution poles.

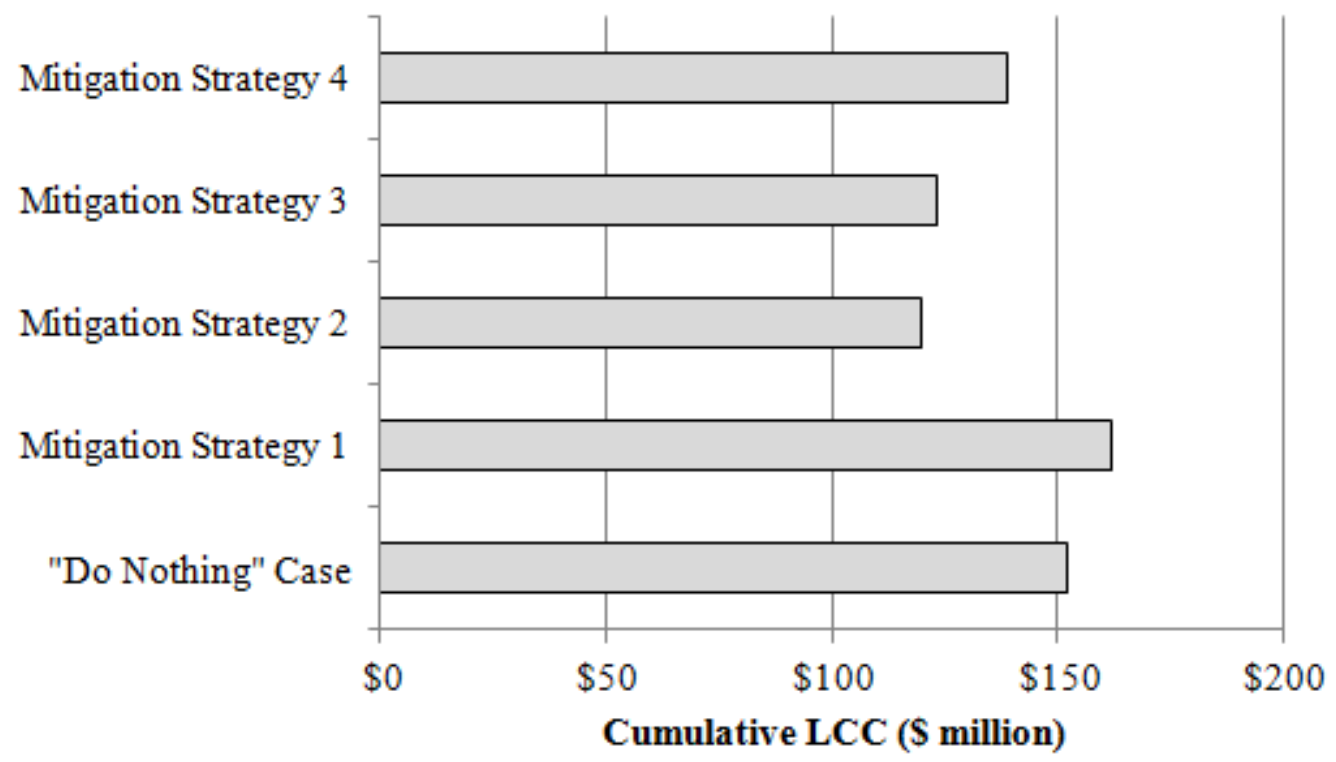

Figure 5.4: Cumulative LCC of the "Do Nothing" Case and the Mitigation Strategies at Year 2060, for $\alpha=5 \%$ per year

The following results (i.e. Figure 5.5) were generated using the $10^{\text {th }}$ and $90^{\text {th }}$ percentile values of the LCC based on 10,000 MCS runs. It was found that the replacement cost of the "do nothing" case is $\$ 102$ million using the $10^{\text {th }}$ percentile values and $\$ 201$ million using the $90^{\text {th }}$ percentile values. Figure 5.5 shows the $10^{\text {th }}, 50^{\text {th }}$, and $90^{\text {th }}$ percentile values of the cumulative LCC for the "do nothing" case and the mitigation strategies at year 
2060. These results confirm the results found previously, as they show that mitigation can be cost effective. Mitigation Strategies 2 and 3 are again the most economical choices.

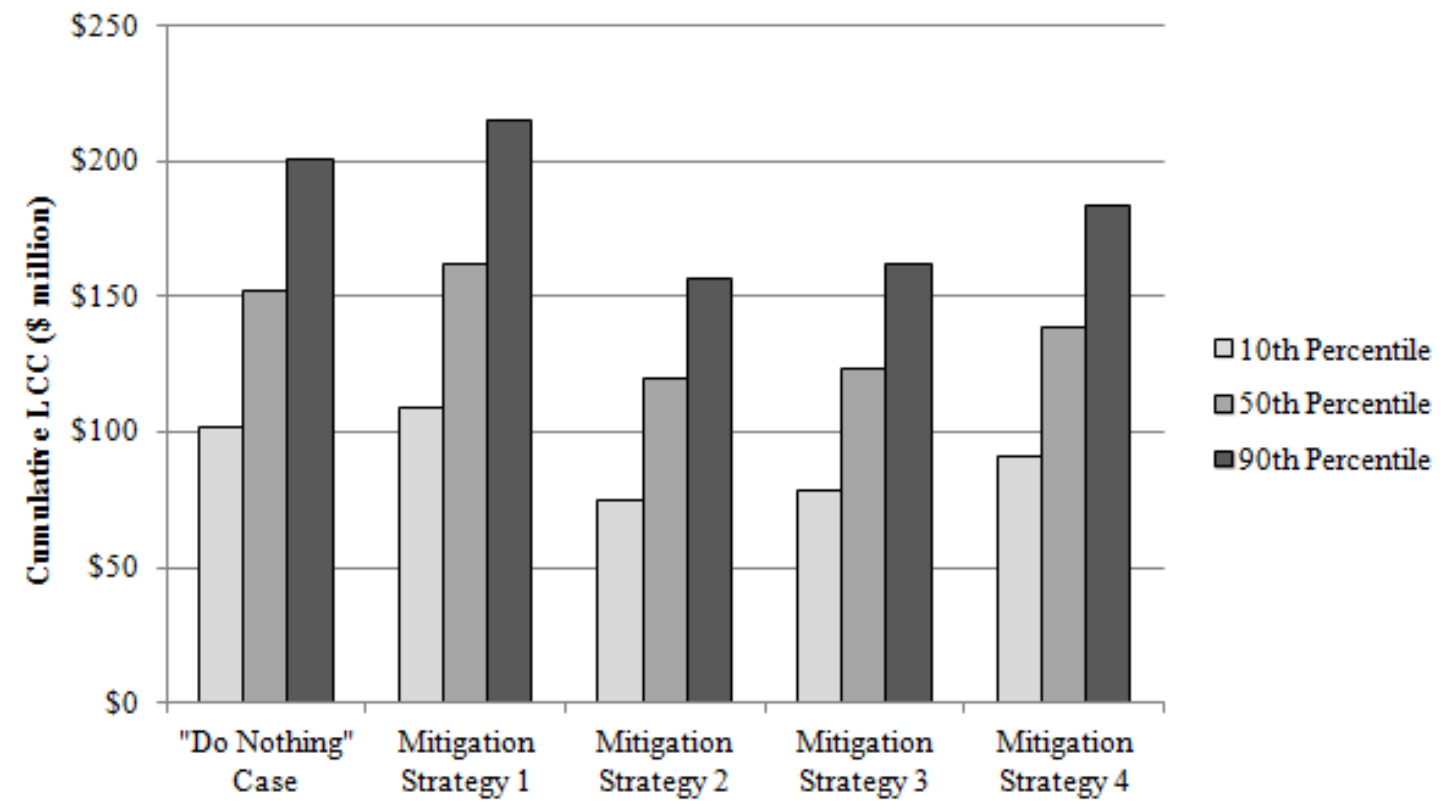

Figure 5.5: $10^{\text {th }}, 5^{\text {th }}$, and $90^{\text {th }}$ Percentile Values of the Cumulative LCC for the "Do Nothing" Case and Mitigation Strategies at Year 2060

The results for Figure 5.6 were generated using the $10^{\text {th }}$ and $90^{\text {th }}$ percentile values of the LCC based on 10,000 MCS runs. Figure 5.6 shows the $10^{\text {th }}, 50^{\text {th }}$, and $90^{\text {th }}$ percentile values of the net benefit at year 2060 for the mitigation strategies in comparison to the "do nothing" case. Mitigation strategies 2 and 3 are the most cost effective, resulting in median net benefits of $\$ 32$ million and \$29 million, while Mitigation Strategy 1 is not cost effective resulting in a net loss of $\$ 10$ million. Mitigation Strategy 4 could be a viable option, with net benefits of up to $\$ 13$ million if implemented, but causes potentially little disruption, because it focuses solely on mitigation in high vulnerability areas. For Mitigation Strategy 2, there is a 90\% chance that the net benefits will exceed $\$ 27$ million in 2060, and there is a 10\% chance that net benefits may exceed $\$ 44$ million in 2060 if the strategy is implemented. On the other hand, if Mitigation Strategy 1 was to be implemented, there is a $90 \%$ chance that the net loss will exceed $\$ 7$ million in 2060, which is not a desirable outcome. 


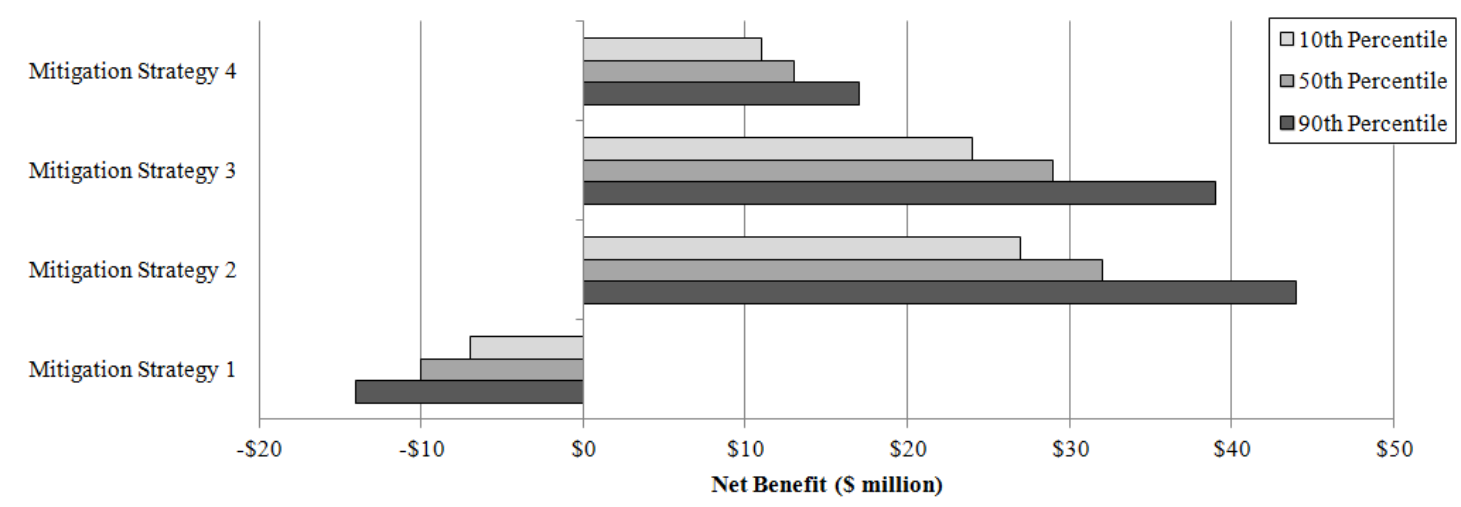

Figure 5.6: 10th, 50th, and $90^{\text {th }}$ Percentile Values of the Net Benefit for the Mitigation Strategies at Year 2060

Exceedance plots (e.g. Figure 5.7) are useful in relating what the probability is of expected replacement costs exceeding a specified value. Figure 5.7 shows the probability that replacement costs at year 2060 will exceed some given value. The exceedance plot for the "do nothing" case and, for comparison purposes, the plot assuming the implementation of Mitigation Strategy 2 are presented. Similar plots can be developed for the other mitigation strategies; but, because, Mitigation Strategy 2 was found to be most economical in the previous analysis it is presented.

Figure 5.7 shows how the vulnerability of the distribution poles can be reduced by implementing Mitigation Strategy 2. For example, the probability of annual replacement costs exceeding $\$ 1,000,000$ is about $93 \%$ but by implementing Mitigation Strategy 2 the probability of exceedance is reduced to $67 \%$ (i.e. there is $67 \%$ chance that replacement costs may exceed $\$ 300,000$ in year 50 ). The probability of exceeding $\$ 2,000,000$ in annual replacement costs is about $34 \%$ for the "do nothing" case and approximately $6 \%$ after the implementation of Mitigation Strategy 2. This is a reduction in exceedance probability of approximately $83 \%$. 


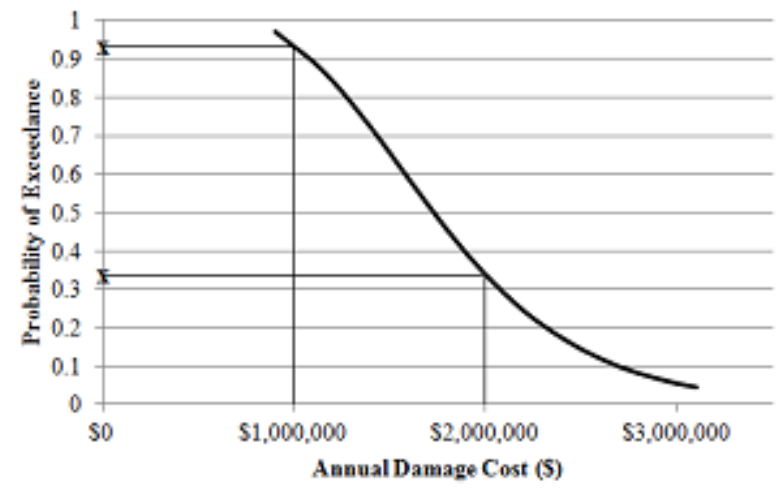

(a)

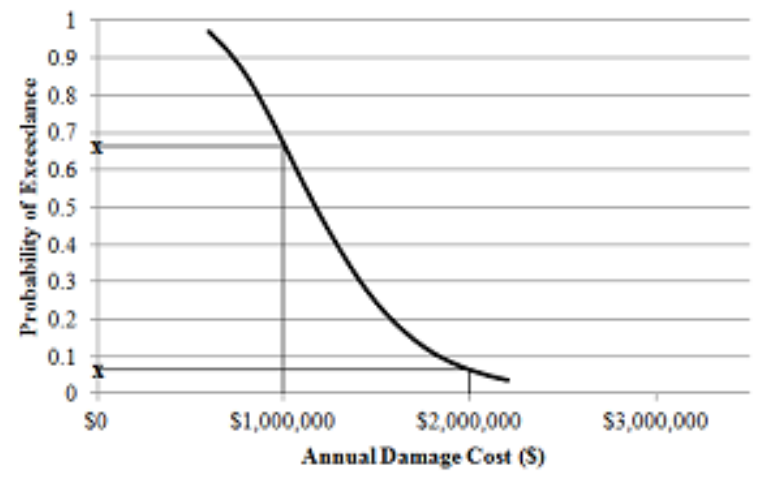

(b)

Figure 5.7: Probability of Exceedance for Distirbution Poles for: a) the "Do Nothing" Case and b) Mitigation Strategy 2

\subsection{Conclusions}

The proposed framework provides a tool to evaluate hurricane vulnerability and damage risk of distribution poles, as well as the economical variability of mitigation strategies. The replacement costs of distribution poles for Miami-Dade County over a 50 year time frame were found to be approximately $\$ 152$ million for the "do nothing" case, i.e. without mitigation. The high replacement costs warrant an investigation into the cost effectiveness of various mitigation strategies that may aid in reducing replacement costs. Through this analysis, it was found that mitigation strategies may significantly reduce replacement costs due to hurricanes. 
Four mitigation measures were explored: Mitigation Strategy 1 included the additional replacement of distribution poles with younger poles (i.e. new of same size), Mitigation Strategy 2 involved replacing failed distribution poles with stronger distribution poles, Mitigation Strategy 3 involves the replacement of failed distribution poles and an additional replacement with stronger distribution poles, and Mitigation Strategy 4 is a combination of Strategies 1 and 3, focusing solely on proactive measures for distribution poles located in foreshore locations. The cost effectiveness of these mitigation strategies was evaluated using a life cycle cost (LCC) analysis. The LCC analysis found that Mitigation Strategy 2 was the most economical, as it involves no additional replacement rather just the replacement of poles failing annually with stronger poles. This mitigation strategy is suitable for implementation because it causes the least amount of disruption as it only involves the replacement of poles that have failed. Mitigation Strategy 2 could result in net benefits of up to $\$ 32$ million. It was also found that Mitigation Strategy 2 could result in a significant reduction in the probability of exceedance from the "do nothing" case over the next 50 years.

\subsection{Acknowledgements}

The research described in this paper was supported, in part, by the National Science Foundation (NSF) Catalyzing New International Collaborations Program and Infrastructure Management and Extreme Events Program under Grant No. NSF1050443. The support is gratefully acknowledged. However, the writers take sole responsibility for the views expressed in this paper, which may not represent the position of the NSF or their respective institutions. Some of the work was undertaken while the first author was supported by the Centre for Infrastructure Performance and Reliability at The University of Newcastle, Australia. The first author appreciates this financial support.

\subsection{References}

American Society of Civil Engineers (ASCE-111) (2006) Reliability-Based Design of Utility Pole Structures (No. 111). ASCE manuals and reports on engineering practices. 
American Society of Civil Engineers (ASCE-113) (2008) Substation structure design guide (No. 113). ASCE manuals and reports on engineering practices.

American National Standards Institute (ANSI) (2002) Wood Poles Specifications and Dimensions, 05.1.

Baraneedaran, S., Gad, E.F., Flatley, I., Kamiran, A., and Wilson, J.L. (2009) Review of In-service Assessment of Timber Poles. Proceedings of the Australian Earthquake Engineering Society, Newcastle 2009.

Bhuyan, G., and Li, H. (2006) Achieved Reliability of the North American Design Approaches for Transmission Overhead Structures. Probabilistic Methods Applied to Power Systems 11-15 June 2006, 1-5.

Bingel, N., Dagher, H., Randle, R., Wolfe, R., Slavin, L., Voda, M., and Wong, J. (2003) Panel session: structural reliability-based design of utility poles and the national electrical safety code. Transmission and Distribution Conference and Exposition, September 2003, 1088- 1093.

Bjarnadottir, S., Li, Y. and Stewart, M.G. (2012) Hurricane Risk Assessment Of Power Distribution Systems Considering Impacts Of A Changing Climate, Journal of Infrastructure Systems, ASCE (In press, http://dx.doi.org/10.1061/(ASCE)IS.1943555X.0000108).

Bjarnadottir, S., Li, Y. and Stewart, M.G. (2011) A Probabilistic-based Framework for Impact and Adaptation Assessment of Climate Change on Hurricane Damage Risks and Costs, Structural Safety, 33, 173-185.

Boardman, A.E., Greenberg, D.H., Vining, A.R. and Weimer, D.L. (2011) Cost-Benefit Analysis: Concepts and Practice. Pearson, Boston.

Brown, R.E. (2008) Electric Power Distribution Reliability. CRC Press: Boca Raton, FL. Butera, R. (2000) Asset management for the distribution pole plant-closing the performance gap between traditional maintenance and asset management, Power Engineering Society Summer Meeting, 2000. IEEE , 1,561-565. 
Columbia Broadcasting System (CBS) (2011) Hurricane Irene [cited 2011 September 14]; Available from: http://www.cbs.com/news/

Dagher, H.J., 2001. Reliability of poles in NESC grade C construction, Rural Electric Power Conference, 2001.

Davidson, R. A., Liu, H. I., Sarpong, K., Sparks, P., and Rosowsky, D. V. (2003) Electric power distribution system performance in Carolina hurricanes. Natural Hazards Review, 4, 36-45.

Ellingwood, B. R.., and Tekie, P.B. (1999) Wind load statistics for probability-based structural design, Journal of Structural Engineering, 125, 453-463.

Florida Power \& Light Company (FP\&LC) (2006) Technical Report: Post Hurricane Wilma Engineering Analysis. KEMA, Inc.

Foedinger, R., Boozer, J.F., Bronstad, M.E., and Davidson, J.W. (2002) Development of an energy composite utility pole, Transportation Research Board Annual Meeting.

Gustavsen, B., and Rolfseng, L. (2000) Simulation of wood pole replacement rate and its application to life cycle economy studies, IEEE Transactions on Power Delivery, 15, 300-306.

Haldar, A., and Tucker, K. (2006) Condition Based Management of Wood Pole Transmission Lines Using Structural Reliability Analysis, ASCE Conf. Proc. 218, 28, 304-316.

HM Treasury (2003) The Green Book: Appraisal and Evaluation in Central Government. HM Treasury, The Stationery Office, London.

Johnson, B. (2005) After the Disaster: Utility Restoration Cost Recovery. Edison Electricity Institute, Washington D.C.

Larsen, T., Porter, K., Zadeh, M., Van Anne, C., and Scawthorn, C. (1996) Impact of Hurricane Andrew on performance, interaction, and recovery of lifelines. EQE International, San Francisco, CA. 
Leicester, R.H., Wang, C.H., Minh, M.N., Thornton, J.D., Johnson, G.C., and Gardner, D. (2003) An engineering model for the decay of timber in ground contact. IRG/WP/03, 34th annual meeting, Brisbane, Australia, 19-23 May 2003.

Li, H., Zhang, J. and Bhuyan, G. (2006) Reliability Assessment of Electrical Overhead Distribution Wood Poles. Probability Methods Applied to Power Systems, International Conference, 11-15 June, 2006, Stockholm.

Li, Y., and Ellingwood, B.R. (2006) Hurricane damage to residential construction in the US: Importance of uncertainty modeling in risk assessment, Engineering Structures, 28, 1009-1017.

Louisiana Public Service Commission (LPSC) (2005) Emergency operations center, daily service outage repots- September 24, 2005 through October 17, 2005. December 9, 2005.

Lupoi, G., Franchin, P., Lupoi, A., and Pinto, P.E. (2006) Seismic Fragility Analysis of Structural Systems, J. Eng. Mech., 132, 385-396.

Mankowski, M., Hansen, E., and Morrell, J. (2002) Wood Pole Purchasing, inspection, and maintaince: Survey of Utility Practices, Forests Products Journal, 52, 43-50.

National Electrical Safety Code (NESC) (2002) IEEE Standard. Piscataway, New Jersey.

Office of Best Practice Regulation (OBPR) (2010) Best Practice Regulation Handbook. Australian Government, Canberra, June 2010.

Office of Management and Budget (OMB) (2003) Circular A-4. United States Office of Management and Budget, Washington, DC, September 172003.

Public Utility Commission of the State of Texas (PUCT) (2006) PUB investigation of methods to improve electric and telecommunications infrastructure to minimize long term outages and restoration costs associated with Gulf Coast hurricanes. Final Report, Project number 32812, Public Utility Commission of Texas, Austin.

Quanta Technology (2009) Cost-Benefit Analysis of the Deployment of Utility Infrastructure Upgrades and Storm Hardening Programs: Final Report. Public Utility Commission of Texas. 
Reed, D.A., Powell, M.D., and Westerman, J.M. (2010) Energy Infrastructure Damage Analysis for Hurricane Rita, Natural Hazards Review, 11, 102-109.

Roliadi, H., Hse, C.Y., Choong, E.T, and Shupe, T.F. (2000) Decay Resistance of out-ofservice utility poles as related to the distribution of residual creosote content, Forest Products Journal, 17, 149-159.

Roth, R.J. (1997) Insurable risks, regulation, and the changing insurance environment, in Hurricanes: Climates and socioeconomic impacts, H.F. Diaz and R.S. Pulwarthy, Editors. Springer: Berlin, Germany; 261-272.

Schwartz, N. (2011) Violent wind storm leaves path of destruction [cited 2011 December 2]; Available from: http://www.businessweek.com/

Stewart, M.G. (1997) Time-Dependent Reliability of Existing RC Structures, Journal of Structural Engineering, ASCE, 123, 896-903.

Stewart, A.H. and Goodman, J.R. (1990) Life cycle economics of wood pole utility structures, Power Delivery, IEEE Transactions, 5, 1040-1046.

Stewart, M.G., Rosowsky, D.V., and Huang, Z. (2003) Hurricane Risks and Economic Viability of Strengthened Construction, Natural hazards review, 4, 12-19.

Stewart, M G., and Val, D.V., 1999. Role of load history in reliability-based decision analysis of aging bridges, Journal of structural engineering, 125, 776-783.

Utility Solid Waste Activities Group (USWAG) (2005) Notice of Availability of the Preliminary Risk Assessment for Wood Preservatives Containing Pentachlorophenol Reregistration Eligibility Decision, 1-13.

Vanderbilt, M D., Criswell, M.E., Folse, M.D., and Landers, P.G. (1982) ProbabilityBased Design of Wood Transmission Line Structures Electric Power Research Institute Project RP-1352-1: A Status Report. IEEE transactions on power apparatus and systems, 2451-2459.

Vickery, P.J., Wadhera, D., Twisdale, L.A.Jr., and Lavelle, F.M. (2009) U.S. Hurricane Wind Speed Risk and Uncertainty, Journal of Structural Engineering, 135, 301-320. 
Viscusi, W.K. (2007) Rational Discounting for Regulatory Analysis, The University of Chicago Law Review, 74, 209-246.

Wang, C.-h., Leicester, R.H., and Nguyen, M. (2008a) Decay in ground. Forest and Wood Products Australia. CSIRO.

Wang, C.-h., Leicester, R.H., and Nguyen, M. (2008b) Probabilistic procedure for design of untreated timber poles in-ground under attack of decay fungi, Reliability Engineering \& System Safety, 93, 476-481.

Wen, Y.K. (2001) Minimum lifecycle cost design under multiple hazards, Reliability Engineering and System Safety, 73, 223-231.

Wolfe, R., Bodig, J., and Lebow, P. (2001) Derivation of Nominal Strength for Wood Utility Poles. Forest Products Laboratory. U.S. Department of Agriculture.

Wolfe, R. and Kluge, R. O. (2005) Designated Fiber Stress of Wood Poles. Forest Products Laboratory. U.S. Department of Agriculture.

Wolfe, R. and Moody, R. (1997) Standard Specifications for Wood Poles. Forest Products Laboratory. U.S. Department of Agriculture.

Zhai, X. and Stewart, M.G. (2010) Structural reliability analysis of reinforced grouted concrete block masonry walls in compression, Engineering Structures, 32, 106-114. 


\title{
Chapter 6
}

\section{Social Vulnerability Index for Coastal Communities at Risk to Hurricane Hazard and a Changing Climate ${ }^{5}$}

\author{
Sigridur Bjarnadottir ${ }^{1}$, Yue $\mathrm{Li}^{2}$, Mark G. Stewart ${ }^{3}$ \\ ${ }^{1}$ Ph.D. Candidate \\ Department of Civil and Environmental Engineering \\ Michigan Technological University, Houghton, Michigan, USA, sobjarna@mtu.edu \\ ${ }^{2}$ Associate Professor \\ Department of Civil and Environmental Engineering \\ Michigan Technological University, Houghton, Michigan, USA, yueli@mtu.edu \\ ${ }^{3}$ Professor and Director \\ Center for Infrastructure Performance and Reliability, \\ School of Engineering, The University of Newcastle, Callaghan, NSW, Australia \\ mark.stewart@newcastle.edu.au
}

5 The material contained in this chapter was previously published in the journal Natural Hazards.
Bjarnadottir, S., Li, Y. and Stewart, M.G. (2011) Social Vulnerability Index for Coastal Communities at
Risk to Hurricane Hazard and a Changing Climate, Natural Hazards 59(2), 1055-1575. See Appendix IV
for documentation of permission to republish this material. 


\subsection{Abstract}

This paper presents the development of the Coastal Community Social Vulnerability Index (CCSVI) in order to quantify the social vulnerability of hurricane-prone areas under various scenarios of climate change. The 2004-2005 Atlantic hurricane season is estimated to have caused $\$ 150$ billion dollars in damages, and, in recent years, the annual hurricane damage in the United States (U.S.) is estimated at around \$6 billion. Hurricane intensity or/and frequency may change due to the increase in sea surface temperature as a result of climate change. Climate change is also predicted to cause a rise in sea levels, potentially resulting in higher storm surges. The CCSVI combines the intensity of hurricanes and hurricane-induced surge to create a comprehensive index that considers the effects of a changing climate. The main contributing factors of social vulnerability (such as race, age, gender, socioeconomic status) in hurricane-prone areas are identified through a principal components analysis. The impact of social characteristics on the potential hurricane damage under various scenarios of climate change is evaluated using Miami-Dade County, Florida as a case study location. This study finds that climate change may have a significant impact on the CCSVI.

Keywords: Climate Change, Social Vulnerability, Hurricane Risk, Uncertainty, Surge

\subsection{Introduction}

The United States Government Accountability Office estimated in a 2007 report that insurers, private and federal, have paid more than $\$ 320$ billion dollars in losses due to weather-related hazards from 1980 to 2005 (GAO 2007). One-third of these losses are attributed to hurricane events in the United States (U.S.) (GAO 2007). The 2004-2005 Atlantic hurricane season alone is estimated to have caused $\$ 150$ billion dollars in damages (Pielke et al. 2008).

Hurricane damages are increasing, principally due to a growing U.S. coastal population. In 2003, approximately $53 \%$ of the U.S. population, or 153 million people, live in coastal counties (Crosset 2008). This is an increase in population of 33 million since 1980, and it is estimated that the U.S. coastal population will increase by another 12 million by 2015 
(W\&PE 2003). Social vulnerability is a combination of a region's capacity to respond and recover from a natural hazard, with minimal damage (Cutter et al. 2003). Therefore, it is important to identify the societal factors that have the greatest effect on hurricane vulnerability and combine them to create an index which describes the hurricane risk for the region (Davidson and Lambert 2001).

Studies have indicated that hurricane activity in the Atlantic Ocean has increased significantly since 1995 (Goldenberg et al. 2001). This increased hurricane activity has been attributed to two factors. First, the increase in hurricane activity is due to the warming global climate (Elsner et al. 2008; Emanuel 2005). Second, the increased hurricane activity is due to the Atlantic Multidecadal Oscillation (i.e. the natural cycle) (Goldenberg et al. 2001; Klotzbach 2006; Landsea et al. 2006). The changing global climate has resulted in both rising sea surface temperatures (SST) and a rising sea level, as indicated by the Intergovernmental Panel on Climate Change (IPCC 2007). Emanuel (2005) found that every increase in SST of $1{ }^{\circ} \mathrm{C}$ could result in an increase of the peak wind speed of a tropical cyclone by 5\%. As hurricane wind speeds increase, it can be assumed that the frequency of hurricanes may increase as well (CCSP 2008). Broccoli and Manabe (1990) concluded that the frequency of hurricanes may increase by $6 \%$ under enhanced greenhouse conditions. The IPCC predicts that by the end of this century the average global sea level may increase by about $40 \mathrm{~cm}$ (IPCC 2007). This projected increase in sea level will result in higher storm surges, because the surge will be riding on a higher sea level, and will bring storm surges further inland (Scavia et al. 2002).

Li and Stewart (2011) proposed a framework for the assessment of damage risks and costs due to tropical cyclones in Queensland, Australia considering the change in wind speeds due to the changing global climate. Bjarnadottir et al. (2011) evaluated the costeffectiveness of adaptation strategies for hurricane damage risks due to climate change in the U.S. The study found that climate change may have a substantial impact on the damage and loss estimation in coastal areas, and that certain adaptation strategies can cost-effectively decrease the damage, even though the wind speed does not change. Bjarnadottir et al. (2010) investigated the effects social characteristics have on potential hurricane damage costs, by using a multivariate regression model, and found that certain 
social characteristics may have an impact on the potential hurricane losses. The social characteristics that were found to have an impact on hurricane losses include Race, Poverty, Age, Gender, Socioeconomic Status, Unemployment, and Poverty (Bjarnadottir et al. 2010b).

Existing metrics of social vulnerability consider only current climate conditions (Davidson and Lambert 2001), but because studies are suggesting that the hurricane intensity/frequency may change as a result of the warming global climate, it is imperative to evaluate the potential effects of climate change on social vulnerability. In order to account for the effects of climate change, existing metrics will be utilized and modified to create an index of vulnerability that accounts for the non-stationary aspects of hurricanes, i.e. hurricane intensity and hurricane-induced surge.

This paper develops a Coastal Community Social Vulnerability Index (CCSVI) that measures the social vulnerability of hurricane-prone areas that accounts for the potential impacts of climate change. This study does not endorse any specific scenario of climate change (or lack thereof), rather investigates the impacts of climate change on the social vulnerability of hurricane-prone regions through the development of a comprehensive social vulnerability index. This is a scenario-based approach. Because climate change has the potential to result in more devastating hurricane events and coastal populations continue to grow, a descriptive index that considers the effects of climate change could be invaluable to assessment of the social vulnerability of hurricane-prone areas.

The CCSVI differs from existing metrics (e.g. Cutter et al. 2003; Davidson and Lambert 2001). The hurricane intensity is measured in wind speed in order to utilize probabilistic wind field models (i.e. the Weibull distribution, which will be discussed in the section titled Hurricane Wind Models and Hurricane-Induced Surge Models) to effectively represent hurricane wind speed under the impacts of climate change after a 50 year time period. Specifically, the Weibull distribution parameters will be used to estimate the maximum annual wind speed a specific location. The hurricane-induced surge is measured as surge height because the height of the surge is directly related to the vulnerability of a region. Surge models will be utilized as a starting point to represent the 
variation in surge height under various parameters of climate change. The social characteristics (i.e. race, gender, age) of the CCSVI are accounted for by conducting a principal components analysis (PCA). The PCA is used to reduce a large number of social factors (such as percentage of female, percentage African American) to a smaller number of dominant social factors (i.e. race, gender) that have the most influence on hurricane vulnerability in a specific region. Because the PCA is conducted with different statistics on social composition for different regions, this results in an index that is based on site-specific social parameters which is more representative of a region than an index which is composed of the same social parameters despite location.

\subsection{Development of the Coastal Community Social Vulnerability Index}

The social characteristics of a community or region have an impact on the vulnerability of a region to hurricanes and other natural disasters. For example, the presence of both the elderly and the poor contribute significantly to the vulnerability of a region to a hurricane event, however the contribution is quite different. The elderly are more vulnerable because of their mobility constraints, while lower income residents are more vulnerable to potential hurricane damage because the poor are often located in inadequate housing that is more susceptible to hurricane damage (Cutter et al. 2003). There are many aspects and factors that contribute to the social makeup of a community, and though they are difficult to quantify, there is some consensus as to what factors influence social vulnerability, such as race, gender, and race (Cutter et al. 2003).

Agencies, worldwide, have tried to quantify the social vulnerability of various hurricaneprone regions (UNDP 2000; World Bank 2001; NRC 2000). Cutter et al. (2003) created the Social Vulnerability Index (SoVI) by using demographic information for the United States. The SoVI involves quantifying the social variables that have the greatest impact on the vulnerability of the region to a natural hazard. Finally, the "place vulnerability" (i.e. the vulnerability of a community to a natural hazard) of each county was found by combining the social variables with the probability of a natural hazard and regional exposure. Davidson and Lambert (2001) established the Hurricane Disaster Risk Index 
(HDRI). The HDRI was calculated by identifying certain characteristics within a region, such as probability of a hurricane hazard, the demographic makeup of the individuals residing within the region (e.g. ethnicity, gender, age), and the exposure of construction within the region.

In this paper, a principal component analysis (PCA) will be used to identify the dominant social factors (SF) within a region (Cutter et al. 2003; Burton 2010). The dominant social factors (SF) may include Wealth, Age, Race, etc. Once the dominant social factors have been identified, the CCSVI is determined by combining the hazard factors $(\mathrm{H})$ comprising of hurricane wind speed and hurricane-induced surge, and the dominant social factors (SF), creating an index that takes into account the changing global climate and is site-specific. The wind speed and the hurricane induced surge will be estimated at year 50 to assess the impacts the changing global climate may have on the social vulnerability of coastal areas. The CCSVI is expressed as:

$\operatorname{CCSVI}(t)=H(t) \prod_{j=1}^{n} Q_{j} S F_{j}(t)$

where $\mathrm{H}(\mathrm{t})$ is the hazard factor at year $\mathrm{t}, \mathrm{SF}_{\mathrm{j}}(\mathrm{t})$ are the dominant social factors at year $\mathrm{t}$, and $\mathrm{Q}_{\mathrm{j}}$ are the social factor weights.

The dominant social factors of the CCSVI can be obtained through Eq. (6.2), once a principal components analysis (PCA) has been conducted.

$S F_{j}(t)=\sum_{k=1}^{m} w_{j k} X_{j k}(t)$

where $\mathrm{SF}_{\mathrm{j}}(\mathrm{t})$ is social factor $\mathrm{j}$ at time $\mathrm{t}, \mathrm{X}_{\mathrm{jk}}(\mathrm{t})$ refer to the dimensionless social indicators that are combined to create the dominant social factor $(j)$ at time $t$, and $w_{j k}$ refer to the relative weights of the social indicators that combine to create dominant social factor $j$ which are found through the analytical hierarchy process (AHP). The number of dominant social factors (n) is determined through the PCA and the number of social indicators (m) used is dependent on the sample data available. In the following, the derivation of Eq. (6.1) and Eq. (6.2) are developed. 


\subsubsection{Hurricane Wind Models and Hurricane-Induced Surge Models}

Various hurricane wind field models have been developed over the years. Georgiou (1985) developed a model based on the gradient level wind field, which has since been improved by Huang (1999), for hurricane winds along the Gulf Coast. Batts' model (1980) used the rise in the central pressure parameter to model the deterioration of a hurricane at landfall. Vickery et al. (1995) also developed a distribution to model hurricane wind speed. This model has been modified with the latest wind contours (Vickery et al. 2009).

The Weibull distribution is an appropriate model of the 3-sec gust wind speed, at a height of $10 \mathrm{~m}$ on open terrain for hurricanes in the U.S. (Li and Ellingwood 2006). When nonstationary wind speed is assumed due to climate change, the probability density function (PDF) of the distribution is:

$f_{v}(v, t)=\frac{\alpha(t)}{u(t)} \cdot\left(\frac{v}{u(t)}\right)^{\alpha(t)-1} \exp \left[-\left(\frac{v}{u(t)}\right)^{\alpha(t)}\right]$

where $\mathrm{v}$ is the 3 -sec gust wind speed, and $\alpha$ and $\mathrm{u}$ are time dependent and site-specific parameters for the Weibull distribution.

Eq. (6.3) includes two parameters of the Weibull distribution; the shape parameter, $\alpha$, and the smallest probable value, $u$. These parameters can be estimated, at year 1 , by using the relationship between wind speed $\left(\mathrm{V}_{\mathrm{T}}\right)$ and return period $(\mathrm{T})$ :

$V_{T}=u \cdot\left[-\ln \frac{1}{T}\right]^{1 / \alpha}$

where $V_{t}$ and $T$ are found using wind contour maps (Vickery et al. 2009). For example, using the wind contour maps, two wind speeds were found for Miami-Dade County, 132 mph corresponding to a 50 year return period and $180 \mathrm{mph}$ corresponding to a 1000 year return period (where $1 \mathrm{mph}=0.447 \mathrm{~m} / \mathrm{s}$ ). Using these values and solving for Eq. (6.4) simultaneously, the Weibull parameters at year 1 were estimated to be $u(1)=27.36$ and $\alpha(1)=1.77$. Once the Weibull parameters at year 1 have been determined, the mean maximum annual wind speed can be estimated for year 1, and for Miami-Dade County, the mean maximum annual wind speed at year 1 was found to be approximately $24.3 \mathrm{~m} / \mathrm{s}$. 
The maximum annual wind speed for Miami-Dade County under the current climate was determined using the Weibull distribution (see Figure 6.1).

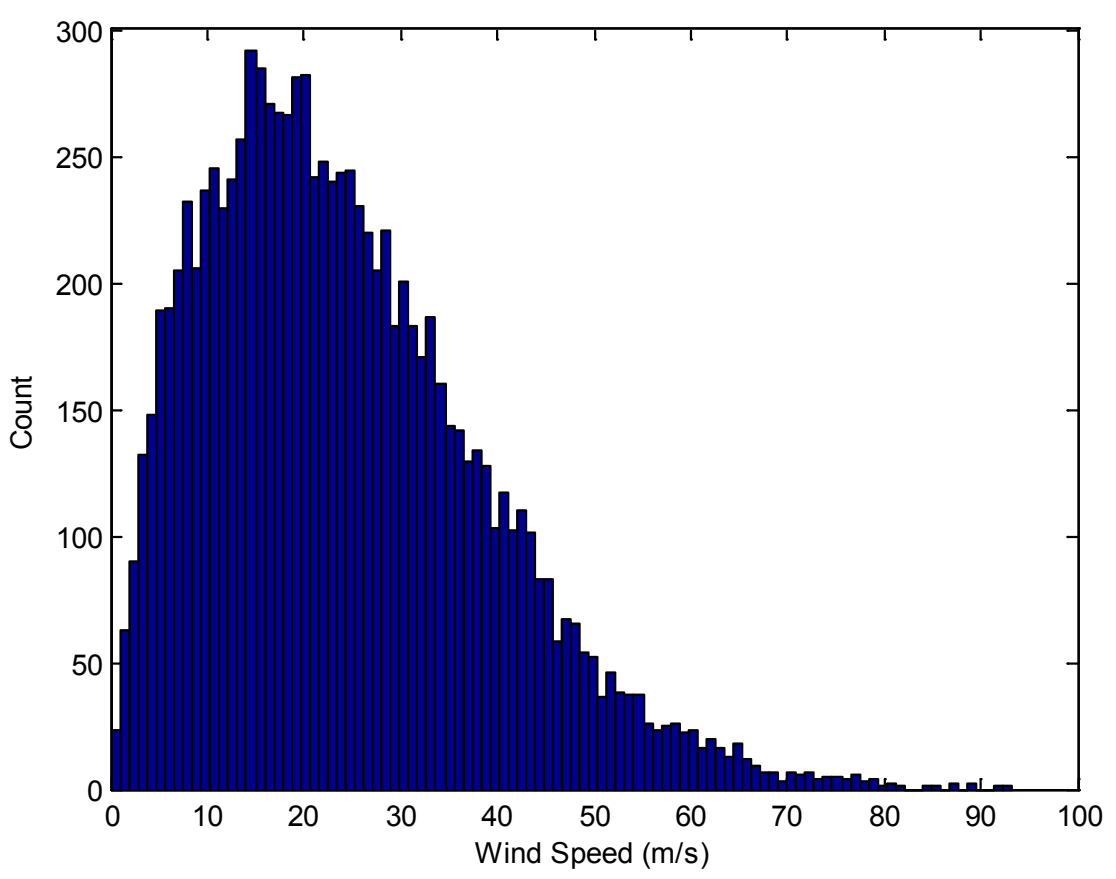

\section{Figure 6.1: Histogram of Wind Speeds}

The Saffir-Simpson Scale (SSS) is used to classify tropical cyclones (i.e. hurricanes) that exceed the intensity of tropical storms. The SSS classifies hurricanes based on the wind intensity and storm surge height of the hurricane on a scale of 1 to 5; however, for the 2011 hurricane season, the SSS was modified classifying hurricanes solely based on the wind intensity, excluding storm surge height in the description of hurricanes. The exclusion of surge height is attributed to the fact that information on surge height can be misleading (NOAA 2009c). For example, Hurricane Katrina (2005) was categorized as a category 3 hurricane and Hurricane Charley (2004) was categorized as a category 4 hurricane. Hurricane Katrina produced a maximum surge height of $8.7 \mathrm{~m}$ (NOAA 2009c), while Hurricane Charley produced a maximum surge height of $2.0 \mathrm{~m}$ (NOAA 2009c).

Throughout the years, various models have been developed to predict the surge height of potential hurricanes. The Sea, Lake, and Overland Surge from Hurricanes (SLOSH) is a 
model that estimates surge height based on historical, hypothetical, or predicted hurricanes by utilizing certain parameters (i.e. storm pressure, size, forward speed, forecast track, wind speeds, and topographical data) (NOAA 2009b). The Advanced Circulation (ADCIRC) model is a finite element method used to simulate the circulation in coastal waters, and for forecasting storm surge height and propagation (Luettich et al. 1992, Westerink et al. 1994). Westerink et al. (1992) used a finite element model to estimate hurricane surge along the coast of Mississippi. Verboom et al. (1992) used a fine grid model to estimate storm surge heights in the North Sea. Hubbert and McInnes (1999) used an inundation algorithm to create a surge model for Australia.

Irish et al. (2008) developed a storm surge model that combines the central pressure deficit, storm size, and storm forward speed to estimate surge height. The following equations are combined to estimate the surge height $(\mathrm{m})$ where the $\wedge$ refers to a dimensionless quantity (Irish et al. 2008):

$$
\begin{aligned}
& \widehat{\Delta p}(t)=\frac{\Delta p(t)}{p_{a t m}} \\
& \widehat{R_{\max }}(t)=\frac{R_{\max }(t) \cdot g}{v_{\max }(t)^{2}} \\
& \sqrt{\hat{\zeta}(t)}=\left[\begin{array}{ll}
\sqrt{R_{\max }(t)} & 1
\end{array}\right]\left\{\begin{array}{c}
- \\
C\left(S_{0}\right) \\
-
\end{array}\left\{\begin{array}{c}
\widehat{\Delta p}(t)^{2} \\
\widehat{\Delta p}(t) \\
1
\end{array}\right)\right\} \\
& \hat{\zeta}(t)=\frac{\zeta(t) \cdot g}{V_{\max }(t)^{2}}
\end{aligned}
$$

where $\Delta \mathrm{p}$ is the central pressure deficit (millibars, or $\mathrm{mb}$ ) at year $\mathrm{t}, \zeta$ is the surge height (m) at year $t, R_{\max }$ is the radius to maximum wind speed $(\mathrm{km})$ at year $t, V_{\max }$ is the maximum wind speed $(\mathrm{m} / \mathrm{s})$ at year $\mathrm{t}, \mathrm{C}\left(\mathrm{S}_{0}\right)$ is the $2 \times 3$ curve fitting coefficient matrix for the ocean slope, $\mathrm{p}_{\mathrm{atm}}$ is the atmospheric pressure $(1013.2 \mathrm{mb}$, standard value), and $\mathrm{g}$ is the gravitational constant $\left(9.813 \mathrm{~m} / \mathrm{s}^{2}\right)$. Eq. (6.5c) involves the multiplication of three matrices that include the parameters estimated with Eq. (6.5a) and (6.5b), with the addition of the $\mathrm{C}\left(\mathrm{S}_{0}\right)$ matrix, which is determined based on the ocean slope of the region in which the surge height is being estimated (Irish et al. 2008). 
Using the Irish model and data from historical hurricanes (NOAA 2009a), a histogram of hurricane-induced surge height was derived, with a mean surge height of $2.3 \mathrm{~m}$ for an ocean bed slope of 1:250 (see Figure 6.2). For illustration purposes, various statistical distributions were examined for goodness-of-fit, using the Kolmogorov-Smirnov test and the Anderson-Darling test (Ang and Tang 2007). Both tests were performed at a 5\% significance level. The tests showed that the lognormal distribution is appropriate for hurricane-induced surge height.

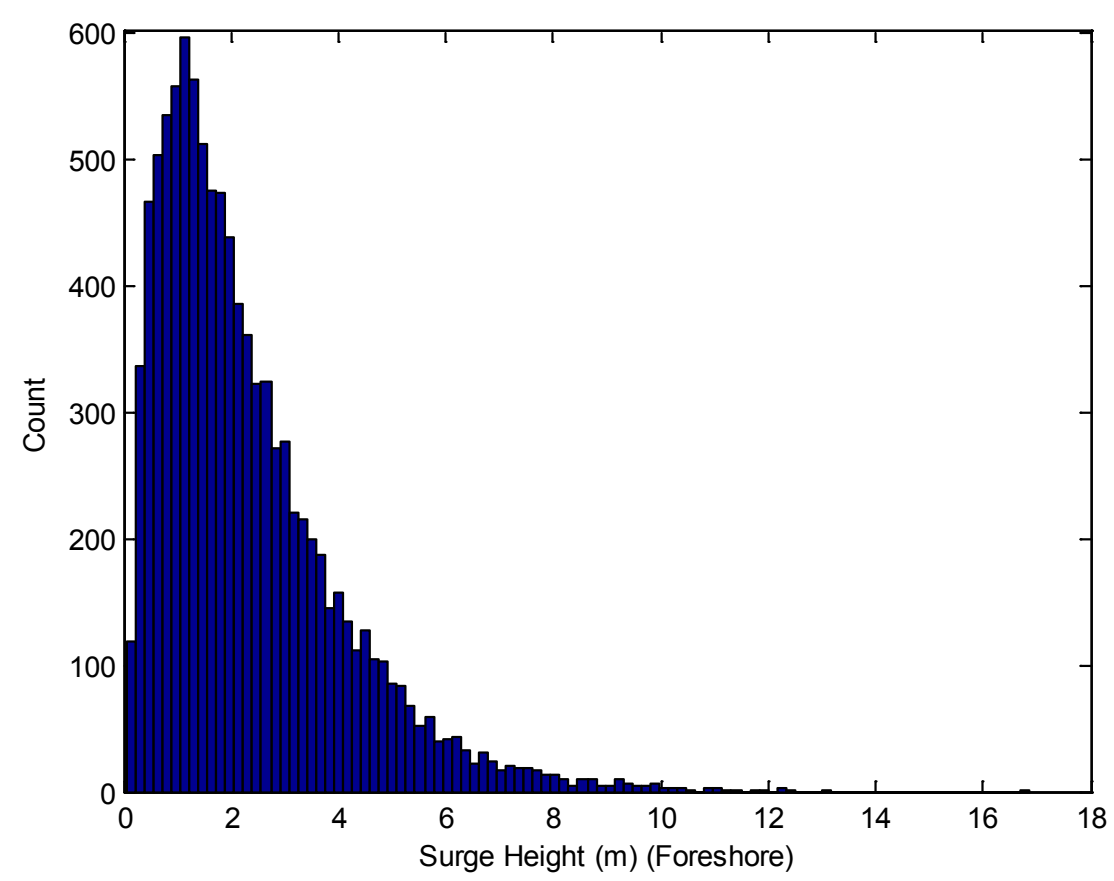

Figure 6.2: Histogram of Surge Heights Assuming a Slope of 1:250

To investigate the impacts climate change may have on the CCSVI, the CCSVI will be estimated at year 50 (or 50 years from now) for various scenarios of climate change. For the determination of the CCSVI at year 50 (CCSVI(50)), the Weibull distribution parameters will be used to determine the mean maximum annual wind speed for a specific exposure category at year 50 for scenarios of climate change, where the mean maximum annual wind speed at year 50 is referred to as $\mathrm{X}^{\prime}{ }_{\mathrm{H} 1, \mathrm{c}}$. However, the Irish et al. (2008) model of surge height is based on historic hurricane data, because the parameters for the Irish surge model are scenario-based parameters (Eq. 6.5). The Irish et al. (2008) 
model will be used to determine the maximum surge height at year 50 for scenarios of climate change. The maximum surge height at year 50 is assumed to be the mean value generated with Eq. (6.5) and is referred to as $\mathrm{X}^{\prime}{ }_{\mathrm{H} 2}$. This is a starting point for this analysis, and when new surge models and wind speed models become available, they can be incorporated into the framework herein.

To take into account the effects of exposure on hurricane intensity and surge, the various exposure categories were identified. Huang et al. (2001) identified three exposure categories (c), which will be used herein:

$\mathrm{c}=1$ ) Foreshore (within $1 \mathrm{~km}$ from coast)

$\mathrm{c}=2$ ) Locations within $10 \mathrm{~km}$ inland

$\mathrm{c}=3$ ) All other locations further inland

\subsubsection{Principal Components Analysis (PCA)}

Burton (2010) assessed the effects that social characteristics had on the damage caused by Hurricane Katrina in three counties in Mississippi, by using the SoVI (Cutter et al. 2003). The dominant social factors (SF) of the counties were found by using a principal components analysis (PCA). PCA transforms a number of correlated variables into a smaller number of uncorrelated variables (i.e. principal components or PCs), or reduces the dimensionality of a dataset by performing covariance analyses between the variables within the dataset. Within a set of PCs, the first PC accounts for as much of the variability in the data as possible, and the subsequent PCs account for as much of the remaining variability as possible (Jackson 1991; Jolliffe 2002). Geometrically the objective of PCA is to identify a new set of orthogonal axes, such that the each principle component is a linear combination of the original variables (Jackson 1991). For example, Cutter et al. (2003) reduced 42 social variables (i.e. percentage African American, percentage female, etc.) for all U.S. counties to 11 dominant factors using a PCA. Through the PCA, the SF will be determined for a region, and the combination original factors (referred to hereafter as social indicators) within the SF will be identified. 


\subsubsection{Coastal Community Social Vulnerability Index (CCSVI)}

The CCSVI is capable of examining the impact of climate change by considering hurricane intensity and hurricane-induced surge height at year 50, and comparing the results to the no climate change case (i.e. existing/current climate conditions). The dominant social factors (SF) are comprised of social indicators, and these social indicators were the original input factors for the PCA (e.g. percentage of African Americans, percentage of females). The hazard factors $(\mathrm{H})$ is comprised of hazard indicators (e.g. wind speed, surge height). The CCSVI is a descriptive index, with a scale of 1 to 10,1 being low risk and 10 being high risk; similarly, the hazard factor $(\mathrm{H})$ and the dominant social factors (SF) also have a scale of 1 to 10 .

In order to create the CCSVI, both the social and hazard indicators must be scaled to dimensionless values, because the social and hazard indicators have different units (i.e. percentages, $\mathrm{m} / \mathrm{s}$, dollars); thus, the indicators can be combined to create the CCSVI. The scaling method includes identifying the minimum and maximum possible values for each social and hazard indicator (Davidson and Lambert 2001). This scaling method was chosen because it is not sample-specific and is, therefore, easily interpretable. For example, the dimensionless value $\mathrm{X}_{\mathrm{jk}}$, for dominant social factor $\mathrm{j}$, is given by:

$X_{j k}=\frac{\left(X_{j k}^{\prime}-M I N_{j k}\right) \times 10}{\left(M A X_{j k}-M I N_{j k}\right)}$

where $X^{\prime}{ }_{j k}$ refers to the unscaled value for social indicator within dominant social factor $j$, $\mathrm{MIN}_{\mathrm{jk}}$ is the minimum possible value of the social indicator, and $\mathrm{MAX}_{\mathrm{jk}}$ is the maximum possible value of the social indicator. The maximum and minimum possible values were determined by making best guess estimates through studying U.S. Census Bureau projections (Davidson 1997). The dimensionless value for the hazard indicators $\left(\mathrm{X}_{\mathrm{H} 1, \mathrm{c}}\right.$ and $\mathrm{X}_{\mathrm{H} 2}$ ) is determined in the same manner, using the unscaled hazard indicator values $\left(\mathrm{X}_{\mathrm{H} 1, \mathrm{c}}\right.$ and $\mathrm{X}_{\mathrm{H} 2}$ ) found with the Weibull distribution for wind speed and the Irish model for surge height, and the minimum and maximum values were estimated using available hurricane data (NOAA 2009a). 
Next, the weights for the dimensionless social indicators (i.e. relative weight, w) and the weights for the dominant social factors (i.e. factor weight, Q) are determined through the use of the analytical hierarchy process (AHP) (Saaty 1990). The AHP assesses the importance of a set of factors through a pairwise comparison. First, the AHP is used in determining the relative weight $(\mathrm{w})$ for an individual social indicator within a dominant social factor. For instance, the percentage of labor participation may have more importance than the average number of persons within a household to the social vulnerability, which will be reflected in the determination of the weights of the social indicators.

The factor weights $(\mathrm{Q})$ of the dominant social factors are also determined through the AHP, because the dominant social factors will influence a region's vulnerability in different magnitudes. For example, the number of retirees (over 65 years old) and the number of Hispanics will have the greatest impact on the social vulnerability of MiamiDade County, Florida (Burton 2010); therefore, these factors will have the greatest weight when determining the CCSVI for Miami-Dade County.

Once the social and hazard indicators, their minimum and maximum values, and their respective weights have been established, the CCSVI can be calculated. The hazard factor $(\mathrm{H})$ has two components, the wind hazard and the surge hazard, and each component has its hazard indicator. The CCSVI defines the wind hazard indicator as the wind intensity at a specific location or exposure determined with the parameters of the Weibull distribution, and the surge hazard indicator is defined the annual average surge height, which is affected by the continental slope at the site, determined through Eq. (6.5). Fritz et al. (2007) found that Hurricane Katrina caused a surge that carried as far as $10 \mathrm{~km}$ inland in some parts of Mississippi, while Rodríguez et al. (1994) found that the surge caused by Hurricane Hugo penetrated several hundred meters inland in Puerto Rico. As a starting point, this analysis will assume that the hurricane-induced surge will only effect high vulnerability locations (i.e. foreshore), and that the hurricane intensity will affect all three exposure categories; however, this can be modified.

$H_{w i n d, c}(t)=X_{H 1, c}(t)$ 
$H_{\text {surge }}(t)=X_{H 2}(t)$

where $H_{\text {wind,c }}$ refers to the wind hazard [1-10] at time $t$ for exposure category $\mathrm{c}, \mathrm{X}_{\mathrm{H} 1, \mathrm{c}}$ refers to the mean maximum annual wind speed at site at time $t$ (dimensionless hazard indicator) for exposure category c (determined from the Weibull parameters), $\mathrm{H}_{\text {surge }}$ refers to the surge hazard [1-10] at time $t$, and $\mathrm{X}_{\mathrm{H} 2}$ refers to the surge height at site at time $\mathrm{t}$ (dimensionless hazard indicator) (Eq. 6.5). $\mathrm{X}_{\mathrm{H} 1, \mathrm{c}}$ and $\mathrm{X}_{\mathrm{H} 2}$ have been scaled to dimensionless values using Eq. (6.6).

The $\mathrm{H}_{\text {wind }}$ and $\mathrm{H}_{\text {surge }}$ are then combined to find the Hazard Factor for each exposure category. The National Weather Service (2009) estimates that $60 \%$ of Hurricane Katrina damage costs can be attributed to hurricane-induced surge. The combination of damage due to hurricane intensity and hurricane induced surge may vary due to specific geographical information (e.g. elevation), different hazard measures (i.e. the wind intensity is an annual value while the surge height is based on historical data), and epistemic (knowledge-based) uncertainties within the study. Therefore, the ratio between $\mathrm{H}_{\text {wind }}$ and $\mathrm{H}_{\text {surge }}$ can be modified by varying $\mathrm{a}_{1}$ and $\mathrm{a}_{2}$.

$$
\begin{aligned}
& H_{1}(t)=a_{1} H_{\text {wind }, 1}(t)+a_{2} H_{\text {surge }}(t) \quad a_{1}+a_{2}=100 \% \\
& H_{2}(t)=H_{\text {wind }, 2}(t) \\
& H_{3}(t)=H_{\text {wind }, 3}(t)
\end{aligned}
$$

where $a_{1}$ and $a_{2}$ are constants that can be varied to represent different weightings of $H_{\text {wind }}$ and $H_{\text {surge, }}, H_{1}(t)$ is the hazard factor for foreshore locations (i.e. category 1$), H_{2}(t)$ is the hazard factor for locations within $10 \mathrm{~km}$ of the coast (i.e. category 2), and $\mathrm{H}_{3}(\mathrm{t})$ is the hazard factor for locations further than $10 \mathrm{~km}$ inland (i.e. category 3 ).

The hazard factors for the three exposure categories are combined to create the Hazard Factor $(\mathrm{H})$ for the region. The population density within each exposure category is identified to determine the ratio of the hazard factors within the Hazard Factor $(\mathrm{H})$, in order to represent the how the impact of each hazard factor varies.

$$
H(t)=\zeta_{1} H_{1}(t)+\zeta_{2} H_{2}(t)+\zeta_{3} H_{3}(t)
$$


where $\zeta_{1}$ refers to the proportion of the population located within exposure category $1, \zeta_{2}$ refers to the proportion of the population located within exposure category 2 , and $\zeta_{3}$ refers to the proportion of the population located within exposure category 3 .

The dominant social factors (SF) of the CCSVI are calculated by weighting the indicator values together, and are obtained through Eq. (6.2). The CCSVI is includes the Hazard Factor $(\mathrm{H})$ and the dominant social factors (SF) and can be expressed as Eq. (6.1).

\subsection{Illustrative Example}

Miami-Dade County is used as a case study to illustrate the development of the CCSVI and to explore the possible effect climate change may have on social vulnerability. The county has a population of 2.4 million, making it the eighth largest county in the U.S. and the most populous county in Florida. The CCSVI will be determined by combining the dominant social factors (SF) found through the PCA with hurricane intensity and

hurricane induced surge. The CCSVI will be estimated after a 50 year time frame. This time frame was chosen to illustrate the potential effects (or lack thereof) of climate change on the CCSVI; this framework can be expanded to include other time frames. In 2006, the Climate Change Advisory Task Force was established in Miami-Dade County. The purpose of the Task Force is to identify the potential effects climate change may have and to provide recommendations for adaptation to mitigate these potential changes. The Task Force stated in the 2008 report (Climate Change Advisory Task Force 2008) that an increase in the sea level of 90 to $150 \mathrm{~cm}$ is to be expected during this century for Miami-Dade County. The report also found that increases in severe weather events could be a result of the warming climate of Miami-Dade County (Climate Change Advisory Task Force 2008). If the projections of the Task Force become a reality, it is necessary to identify the social vulnerability of Miami-Dade County and to examine the effects climate change may have on the social vulnerability.

\subsubsection{Hurricane Wind Intensity and Hurricane-Induced Surge}

There is large uncertainty on the possible change of wind speeds in the U.S.; however information is available from other locations. The Australian Greenhouse Office (AGO) (2007) suggests that there will be an increase in wind speed of $5 \%$ to $10 \%$ by 2050 in 
Queensland, Australia. A recent study by Vickery et al. (2009) indicates that 5\% to $10 \%$ increase in wind speed in the U.S. may be possible. While, Pryor et al. (2009) suggested that decrease in annual mean wind speeds is possible. For this paper, changes of $-5 \%$ to $15 \%$ in mean maximum annual wind speed over 50 years is considered to account for the uncertainty in investigating the potential impact of climate change. The mean maximum annual wind speed was obtained through the parameters of the Weibull distribution, and was found to b $24.3 \mathrm{~m} / \mathrm{s}$ for Miami-Dade County under current climate conditions. As there is no projection on how the change of wind speed will occur over time, it is assumed that the wind speed over a 50 year time period changes linearly regardless of climate change scenario (Bjarnadottir et al. 2010a). Therefore, the wind speed in year 50 is estimated to be $23.1 \mathrm{~m} / \mathrm{s}, 25.5 \mathrm{~m} / \mathrm{s}, 26.7 \mathrm{~m} / \mathrm{s}$, and $28.0 \mathrm{~m} / \mathrm{s}$ for changes in wind speed of $-5 \%, 5 \%, 10 \%$, and $15 \%$, respectively.

There is also uncertainty with regards to the potential changes in storm surge height. The IPCC (2007) indicated that an increase in surge height of $40 \mathrm{~cm}$ is possible by the end of the century. While the Climate Change Advisory Task Force (2008) of Miami-Dade County estimates that surge heights may increase by 90 to $150 \mathrm{~cm}$ for Miami-Dade County. For example, in 1992, Hurricane Andrew devastated South Florida causing around $\$ 25.5$ billion in damages (NOAA 2009a). Hurricane Andrew had a maximum surge height of $5.2 \mathrm{~m}$. Using the predictions made by the Climate Change Advisory Task Force, which reports increases of 90 to $150 \mathrm{~cm}$ over 100 years, or 45 to $75 \mathrm{~cm}$ over 50 years, the surge height of Hurricane Andrew would increase by $9 \%$ to $15 \%$ over 50 years. On the other hand, using IPCC predictions (i.e. increase of $20 \mathrm{~cm}$ over 50 years), the surge height of Hurricane Andrew would increase by $4 \%$ over 50 years. To account for the uncertainty present, changes in surge height of $-5 \%$ to $15 \%$ over the next 50 years will be investigated. The surge height under existing climate is found by using Eq. (6.5), using historical hurricane data (NOAA 2009a). Florida has a regional continental slope of $4^{\circ}$ (Pratson and Haxby 1996), corresponding to a slope of 1:250. The surge height was estimated to be $2.3 \mathrm{~m}$ for Miami-Dade County under current climate conditions, using the Irish model. It is assumed that over a 50 year time period surge height will change linearly regardless of climate change scenario; therefore, the surge height is determined 
to be $2.2 \mathrm{~m}, 2.5 \mathrm{~m}, 2.6 \mathrm{~m}$, and $2.7 \mathrm{~m}$ for changes in surge height of $-5 \%, 5 \%, 10 \%$, and $15 \%$, respectively.

Table 6.1 presents the wind speed and surge height for Miami-Dade County at year 50 assuming various scenarios of climate change. The values for the wind speed have been adjusted to account for the affects exposure have on wind speed (Bjarnadottir et al. 2010a). These values are referred to as the hazard indicators, and will be scaled to dimensionless values (Eq. 6.6), before the Hazard Factor (Eq. 6.7) is estimated.

Table 6.1: Wind speed and surge height at year 50 for various scenarios of climate change

\begin{tabular}{|c|c|cccccc|}
\cline { 3 - 6 } \multicolumn{2}{c|}{} & \multicolumn{5}{|c|}{ Change } \\
\cline { 3 - 7 } & Foreshore & $-5 \%$ & $0 \%$ & $5 \%$ & $10 \%$ & $15 \%$ \\
\hline $\begin{array}{c}\text { Wind Speed } \\
(\mathbf{m} / \mathbf{s})\end{array}$ & $\begin{array}{c}\text { Within } 10 \mathrm{~km} \text { from } \\
\text { shore }\end{array}$ & 18.5 & 19.4 & 20.4 & 21.4 & 22.4 \\
& Further than $10 \mathrm{~km}$ & 16.6 & 17.5 & 18.4 & 19.2 & 20.2 \\
\hline $\begin{array}{c}\text { Surge Height } \\
(\mathbf{m})\end{array}$ & Foreshore & 2.2 & 2.3 & 2.50 & 2.60 & 2.70 \\
\hline
\end{tabular}

\subsubsection{Principal Components Analysis (PCA)}

There are 35 municipalities in Miami-Dade County, and demographic information for these municipalities was obtained from the U.S. Census Bureau (2009) for sixteen different social factors (Cutter et al. 2003). By using the PCA, five dominant social factors (SF) were identified by extracting the factors with eigenvalues greater than 1 (Burton 2010). These five social factors (SF) collectively account for $84 \%$ of the variance: $\mathrm{j}=1$ ) Race (African American) and Poverty, $\mathrm{j}=2$ ) Age and Gender, $\mathrm{j}=3$ ) Socioeconomic Status, $\mathrm{j}=4$ ) Race (Native American and Asian) and Unemployment, and $\mathrm{j}=5$ ) Hispanic. Table 6.2 displays the results of the PCA, which include the five social factors, eiginvalues, percentage of explained variance, and percentage of cumulative explained variance. 
Table 6.2: Results of PCA, including the Social Factors, Eigenvalues, percentage of explained variance, and percentage of cumulative explained variance

\begin{tabular}{|c|c|c|c|}
\hline Social Factor & Eigenvalue & $\begin{array}{c}\text { \% of } \\
\text { Explained } \\
\text { Variance }\end{array}$ & $\begin{array}{c}\text { \% of Cumulative } \\
\text { Explained } \\
\text { Variance }\end{array}$ \\
\hline $\begin{array}{c}\text { Race (African American) and } \\
\text { Poverty }\end{array}$ & 5.36 & $34 \%$ & $34 \%$ \\
\hline Age and Gender & 3.46 & $22 \%$ & $55 \%$ \\
\hline $\begin{array}{c}\text { Socioeconomic Status } \\
\text { Asian) and Unemployment }\end{array}$ & 1.73 & $11 \%$ & $66 \%$ \\
\hline Hispanic & 1.34 & $8 \%$ & $76 \%$ \\
\hline
\end{tabular}

\subsubsection{The Coastal Community Social Vulnerability Index (CCSVI)}

To investigate the possible effects climate change may have on the social vulnerability of a region; the CCSVI is calculated under both current hurricane projections (i.e. no change) and an assumed change in hurricane intensity and changes in the hurricaneinduced surge after 50 years. The 50 year time frame is chosen as a starting point, other time frames can be investigated using the methodology herein. The CCSVI will be calculated based on hurricane intensity and hurricane-induced surge.

The first step of calculating the CCSVI involves gathering demographic data for the social indicators at year 50 . Table 6.3 shows the dominant social factors (SF), their social indicators, $X^{\prime}{ }_{j k}$, and the dimensionless social indicator, $X_{j k}$. The table also includes the social factor weights, $\mathrm{Q}_{\mathrm{j}}$, and the relative weights, $\mathrm{w}_{\mathrm{jk}}$.

The value of each social indicator $\left(\mathrm{X}_{\mathrm{jk}}\right)$ is found through actual demographic projections. Specifically, the values for the social indicators were determined using U.S. Census Bureau (2009) projections on how demographic data may change over 50 years; therefore, the values for the social indicators $\left(\mathrm{X}_{\mathrm{jk}}\right)$ is given at year 50 . For example, the U.S. Census Bureau (2009) predicts that the population of retirees (i.e. age of 65 years 
and older) will increase significantly for Miami-Dade, from $14 \%$ to $33 \%$, and the percentage of Hispanics will increase from $62 \%$ to approximately $80 \%$.

Once the values for the social indicators have been determined, the dimensionless social indicator $\left(\mathrm{X}_{\mathrm{jk}}\right)$ can be estimated using Eq. (6.6). Eq. (6.6) involves identifying the maximum and minimum values for each social indicator (e.g. the maximum percentage of Hispanics, minimum percentage of retirees), which are found using demographic projections on probable minimum and maximum values for the social indicator.

Finally the weights ( $\mathrm{w}$ and $\mathrm{Q}$ ) are determined using the analytical hierarchy process (AHP). 
Table 6.3: Social Indicators for the CCSVI

\begin{tabular}{|c|c|c|c|c|c|c|}
\hline $\begin{array}{l}\text { Dominant Factor } \\
\text { SF }\end{array}$ & $\begin{array}{c}\text { Factor } \\
\text { Weight } \\
\mathbf{Q}_{j}\end{array}$ & & Indicator Description & $\begin{array}{c}\text { Unscaled } \\
\text { indicator } \\
\mathbf{X}_{\mathbf{j k}}^{\prime}\end{array}$ & $\begin{array}{c}\text { Scaled } \\
\text { Indicator } \\
\mathbf{X}_{\mathbf{j k}}\end{array}$ & $\begin{array}{c}\text { Relative } \\
\text { Weight } \\
\mathbf{w}_{\mathbf{j k}}\end{array}$ \\
\hline \multirow{6}{*}{$\begin{array}{c}\text { Social Factor (SF) } \\
\mathrm{j}=1 \\
\text { Race (African } \\
\text { American) and } \\
\text { Poverty }\end{array}$} & \multirow{6}{*}{0.10} & $X_{11}$ & $\begin{array}{c}\text { Percent of African } \\
\text { American populations }\end{array}$ & 23.0 & 2.30 & 0.18 \\
\hline & & $\mathrm{X}_{12}$ & $\begin{array}{l}\text { Average number of people } \\
\text { per household }\end{array}$ & 2.8 & 2.00 & 0.07 \\
\hline & & $X_{13}$ & $\begin{array}{c}\text { Percent of persons living } \\
\text { in poverty }\end{array}$ & 15.5 & 6.21 & 0.24 \\
\hline & & $\mathrm{X}_{14}$ & $\begin{array}{c}\text { Percent of civilian } \\
\text { unemployment }\end{array}$ & 6.8 & 1.35 & 0.24 \\
\hline & & $\mathrm{X}_{15}$ & $\begin{array}{l}\text { Percent of aged over } 25 \\
\text { with less than } 12 \text { years } \\
\text { education }\end{array}$ & 22.7 & 2.53 & 0.12 \\
\hline & & $X_{16}$ & $\begin{array}{l}\text { Percent of civilian labor } \\
\text { force participation }\end{array}$ & 62.2 & 3.78 & 0.15 \\
\hline \multirow{4}{*}{$\begin{array}{c}\text { Social Factor } \\
\quad(\mathrm{SF}) \mathrm{j}=2 \\
\text { Age and Gender }\end{array}$} & \multirow{4}{*}{0.35} & $X_{21}$ & $\begin{array}{c}\text { Percent of population } \\
\text { under } 5 \text { years old }\end{array}$ & 5.3 & 7.88 & 0.35 \\
\hline & & $\mathrm{X}_{22}$ & $\begin{array}{c}\text { Percent of population } 65 \\
\text { years or older }\end{array}$ & 33.0 & 8.25 & 0.45 \\
\hline & & $\mathrm{X}_{23}$ & Percent of female & 52.0 & 6.84 & 0.10 \\
\hline & & $\mathrm{X}_{24}$ & $\begin{array}{c}\text { Percent of female headed } \\
\text { households }\end{array}$ & 17.0 & 4.25 & 0.10 \\
\hline \multirow{4}{*}{$\begin{array}{l}\text { Social Factor (SF) } \\
\mathrm{j}=3 \text { : } \\
\text { Socioeconomic } \\
\text { Status }\end{array}$} & \multirow{4}{*}{0.10} & $\mathrm{X}_{31}$ & $\begin{array}{c}\text { Percent of renter occupied } \\
\text { housing units }\end{array}$ & 40.0 & 4.00 & 0.47 \\
\hline & & $X_{32}$ & $\begin{array}{l}\text { Average number of people } \\
\text { per household }\end{array}$ & 2.8 & 8.00 & 0.09 \\
\hline & & $\mathrm{X}_{33}$ & Per capita income $(\$)$ & 25,985 & 6.86 & 0.20 \\
\hline & & $\mathrm{X}_{34}$ & $\begin{array}{l}\text { Percent of families earning } \\
\text { more than } \$ 100,000\end{array}$ & 20.5 & 7.95 & 0.24 \\
\hline \multirow{3}{*}{$\begin{array}{c}\text { Social Factor (SF) } \\
\mathrm{j}=4 \text { : } \\
\text { Race (Native } \\
\text { American and } \\
\text { Asian) and } \\
\text { Unemployment }\end{array}$} & \multirow{3}{*}{0.10} & $\mathrm{X}_{41}$ & $\begin{array}{c}\text { Percent of Native } \\
\text { American populations }\end{array}$ & 0.2 & 0.08 & 0.33 \\
\hline & & $\mathrm{X}_{42}$ & Percent of Asian & 1.5 & 0.60 & 0.20 \\
\hline & & $\mathrm{X}_{43}$ & $\begin{array}{c}\text { Percent of civilian } \\
\text { unemployment }\end{array}$ & 6.9 & 1.39 & 0.47 \\
\hline $\begin{array}{c}\text { Social Factor (SF) } \\
\mathrm{j}=5: \\
\text { Hispanic }\end{array}$ & 0.35 & $\mathrm{X}_{51}$ & $\begin{array}{l}\text { Percent of Hispanic } \\
\text { populations }\end{array}$ & 80.0 & 8.00 & 1.00 \\
\hline
\end{tabular}

Once the dimensionless social indicators and their relative weights have been established for year 50 using actual demographic projections, each dominant social factor can be determined using Eq. (6.2). Then, the Hazard Factor is determined using Table 6.1. The hazard indicators are scaled to dimensionless values using Eq. (6.5), where the minimum 
and maximum values are determined using hurricane data. Once the dimensionless hazard indicators have been determined, the Hazard Factor is determined using Eq. (6.7).

The CCSVI is estimated using the Hazard Factor (H), the dominant social factors (SF), and the factor weights $(\mathrm{Q})$ :

$\operatorname{CCSVI}(50)=H(50) \cdot Q_{1} S F_{1} 1(50) \cdot Q_{2} S F_{2}(50) \cdot Q_{3} S F_{3}(50) \cdot Q_{4} S F_{4}(50) \cdot Q_{5} S F_{5}(50)$

To investigate the potential effects of climate change on social vulnerability, the CCSVI is determined for Miami-Dade County using demographic information currently available, under current projections of hurricane intensity and hurricane-induced surge, and under changes in hurricane frequency ranging from $-5 \%$ to $15 \%$ and changes in hurricane-induced surge ranging from $-5 \%$ to $15 \%$. These changes are assumed to represent the variable nature of changes in the wind climate as a result of climate change. Demographic data may change in 50 years. Therefore, the CCSVI is calculated with projections on demographics. These changes are reflected within the estimation of the CCSVI for Miami-Dade County. The results herein are for Miami-Dade County at year 50 under various scenarios of climate change.

\subsubsection{Results and Discussions}

The CCSVI was determined for Miami-Dade County under various scenarios of climate change. The Hazard Factor was based on the mean maximum annual wind speed and the mean maximum surge height, and was determined through Eq. (6.7f), by combining the hazard factor for the three exposure categories. For this preliminary study, it was assumed that surge effects solely the foreshore locations; therefore, the hazard factor for foreshore locations was found by combining the wind hazard $\left(\mathrm{H}_{\text {wind }}\right)$ and the surge hazard $\left(\mathrm{H}_{\text {surge }}\right)$. There is some uncertainty as to how wind speed and surge combine when determining damage costs and vulnerability, so various combinations of the weights of $\mathrm{H}_{\text {wind }}$ and $\mathrm{H}_{\text {surge }}$ can be explored within Eq. (6.7c).

As a starting point, three different ratios of wind hazard and surge hazard were explored. The first ratio of $a_{1}-a_{2}(50-50)$ was explored because it averages out vulnerability due to wind speed and surge height, as assumed in the preliminary results for Davidson and 
Lambert (2001). The second ratio (40-60) was chosen because the hurricane surge of Hurricane Katrina is estimated to have caused $60 \%$ of the total loss (NWS 2009). The third ratio (65-35) was chosen to cover a wide range of different combinations of the weights.

The CCSVI for Miami-Dade County was established using Eq. (6.8). The CCSVI(1) was determined under current climate projections and current demographics for the three ratios, see Table 6.4. These values are used in evaluating how the CCSVI will change under a changing climate and projected changes in demographics.

Table 6.4: CCSVI(1) for the three ratios of weight of $H_{\text {wind }}$ and $\mathbf{H}_{\text {surge }}$

\begin{tabular}{|c|c|c|c|}
\hline $\mathbf{a}_{1}-\mathbf{a}_{2}$ & $50 \%-50 \%$ & $40 \%-60 \%$ & $65 \%-35 \%$ \\
\hline CCSVI(1) & 6.57 & 6.55 & 6.62 \\
\hline
\end{tabular}

The wind speed and surge height were assumed to vary by $-5 \%$ to $15 \%$ over 50 years. The CCSVI was determined for various scenarios of climate change and for projected demographic changes for Miami-Dade County. The three various combinations of the weight of $\mathrm{H}_{\text {wind }}$ and $\mathrm{H}_{\text {surge }}$ (i.e. ratios) were explored, and it was found that the percentage changes from CCSVI(1) for the three ratios were similar, subsequently for the sake of brevity, the results are presented for the ratio of $50 \%-50 \%$. Table 6.5 shows the CCSVI(50), and Table 6.6 shows how much the CCSVI could potentially change over a 50-year timeframe from CCSVI(1). If climate conditions remain constant after a 50 year timeframe, the CCSVI(50) is estimated at 7.27, which is an increase of $11 \%$ from the CCVSI(1). The worst case climate change scenario explored (i.e. increases in wind speed and surge height of $15 \%$ ) could result in a CCSVI(50) of 7.92, which is an increase of $20 \%$ from CCSVI(1). The CCSVI(50) for other climate change scenarios were explored and the results are presented in Tables 6.5 and 6.6. 
Table 6.5: CCSVI(50) for the weight of $H_{\text {wind }}: H_{\text {surge }}=50 \%: 50 \%$

\begin{tabular}{|c|c|c|c|c|c|c|}
\hline & & \multicolumn{5}{|c|}{ Change in Surge Height } \\
\hline & & $-5 \%$ & $0 \%$ & $5 \%$ & $10 \%$ & $15 \%$ \\
\hline \multirow{5}{*}{ 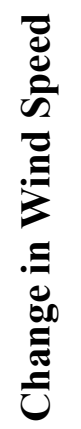 } & $-5 \%$ & 7.06 & 7.26 & 7.45 & 7.66 & 7.85 \\
\hline & $\mathbf{0 \%}$ & 7.08 & 7.27 & 7.47 & 7.67 & 7.87 \\
\hline & $5 \%$ & 7.09 & 7.29 & 7.49 & 7.69 & 7.89 \\
\hline & $10 \%$ & 7.11 & 7.31 & 7.50 & 7.70 & 7.90 \\
\hline & $15 \%$ & 7.12 & 7.32 & 7.52 & 7.72 & 7.92 \\
\hline
\end{tabular}

Table 6.6: The percentage change in CCSVI in year 50 from year 1 for weight of $\mathrm{H}_{\text {wind }}: \mathrm{H}_{\text {surge }}=\mathbf{5 0 \% : 5 0 \%}$

\begin{tabular}{|c|c|c|c|c|c|c|}
\hline & & \multicolumn{5}{|c|}{ Change in Surge Height } \\
\hline & & $-5 \%$ & $\mathbf{0 \%}$ & $5 \%$ & $10 \%$ & $15 \%$ \\
\hline \multirow{5}{*}{ 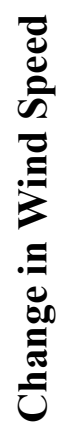 } & $-5 \%$ & $7.4 \%$ & $10.4 \%$ & $13.4 \%$ & $16.4 \%$ & $19.5 \%$ \\
\hline & $0 \%$ & $7.6 \%$ & $10.7 \%$ & $13.6 \%$ & $16.7 \%$ & $19.7 \%$ \\
\hline & $5 \%$ & $7.9 \%$ & $10.9 \%$ & $13.9 \%$ & $16.9 \%$ & $19.9 \%$ \\
\hline & $10 \%$ & $8.1 \%$ & $11.1 \%$ & $14.1 \%$ & $17.2 \%$ & $20.2 \%$ \\
\hline & $15 \%$ & $8.4 \%$ & $11.4 \%$ & $14.4 \%$ & $17.4 \%$ & $20.4 \%$ \\
\hline
\end{tabular}

For comparison purposes, the CCSVI is determined for a 25 year time frame, assuming variations in wind speed and surge height of $-5 \%$ to $15 \%$ at year 25 and demographic projections at year 25. Table 6.7 shows the CCSVI(25), and Table 6.8 shows how much the CCSVI could potentially change over a 25-year timeframe from CCSVI(1). If climate conditions remain constant after a 25 year timeframe, the CCSVI(25) is estimated at 6.86 , which is an increase of $4 \%$ from the CCVSI(1). The CCSVI(25), assuming increases in wind speed and surge height of $15 \%$, is estimated at approximately 7.50 , and this value corresponds to the CCSVI(50) value under increases in wind speed and surge 
height of 5\%. From this comparison, it can be inferred that the dominant social factors have a significant impact on the CCSVI, because the social factors increase over time for Miami-Dade County, which result in higher CCSVI values for the 50 year time frame.

Table 6.7: CCSVI(25) for the weight of $H_{\text {wind }}: H_{\text {surge }}=50 \%: 50 \%$

\begin{tabular}{|c|c|c|c|c|c|c|}
\hline & & \multicolumn{5}{|c|}{ Change in Surge Height } \\
\hline & & $-5 \%$ & $0 \%$ & $5 \%$ & $10 \%$ & $15 \%$ \\
\hline \multirow{5}{*}{ 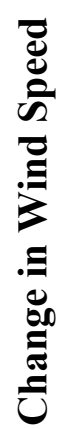 } & $-5 \%$ & 6.64 & 6.84 & 7.04 & 7.24 & 7.44 \\
\hline & $0 \%$ & 6.66 & 6.86 & 7.05 & 7.25 & 7.45 \\
\hline & $5 \%$ & 6.68 & 6.87 & 7.07 & 7.27 & 7.47 \\
\hline & $10 \%$ & 6.69 & 6.89 & 7.09 & 7.29 & 7.48 \\
\hline & $15 \%$ & 6.71 & 6.91 & 7.10 & 7.30 & 7.50 \\
\hline
\end{tabular}

Table 6.8: The percentage change in CCSVI in year 25 from year 1 for weight of $\mathbf{H}_{\text {wind }}: \mathbf{H}_{\text {surge }}=\mathbf{5 0 \%}: \mathbf{5 0 \%}$

\begin{tabular}{|c|c|c|c|c|c|c|}
\hline & \multicolumn{5}{|c|}{ Change in Surge Height } \\
\hline & & $-5 \%$ & $0 \%$ & $5 \%$ & $10 \%$ & $15 \%$ \\
\hline \multirow{5}{*}{ 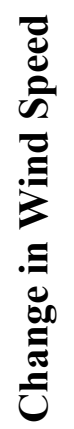 } & $-5 \%$ & $1.1 \%$ & $4.1 \%$ & $7.1 \%$ & $10.1 \%$ & $13.1 \%$ \\
\hline & $0 \%$ & $1.3 \%$ & $4.3 \%$ & $7.3 \%$ & $10.3 \%$ & $13.4 \%$ \\
\hline & $5 \%$ & $1.5 \%$ & $4.6 \%$ & $7.5 \%$ & $10.6 \%$ & $13.6 \%$ \\
\hline & $10 \%$ & $1.8 \%$ & $4.8 \%$ & $7.8 \%$ & $10.8 \%$ & $13.8 \%$ \\
\hline & $15 \%$ & $2.0 \%$ & $5.0 \%$ & $8.0 \%$ & $11.1 \%$ & $14.1 \%$ \\
\hline
\end{tabular}

In order to assess the impacts natural hazards may have on the CCVSI, the CCSVI was determined for different levels of storm systems. First, the CCSVI was determined for Miami-Dade County using the data from the devastating Hurricane Katrina. The maximum wind speed and surge height were input into Eq. (6.8) along with current demographics to determine the CCSVI for such an extreme case. The CCSVI was 
estimated to be 7.60; therefore, the CCSVI(50) for Miami-Dade County could reach a similar magnitude under a $10 \%$ increase in wind speed and surge height in 50 years and with demographic projections (see Table 6.4). Tropical Storm (TS) Bonnie made landfall in Florida during the 2010 Atlantic hurricane season, and was reported to have caused strong gusts of wind and minimal disruption (NOOA 2009a). The CCSVI was estimated in the same manner as for Hurricane Katrina, by inputting the maximum wind speed and surge height of TS Bonnie into Eq. (6.8) along with current demographics. The CCSVI was estimated to be 6.70 , which is about $4 \%$ higher than the CCSVI for Miami-Dade County at year 1 (see Table 6.4). Furthermore, the CCSVI was determined for tsunami conditions. The 2004 Asian Tsunami produced waves of approximately $30 \mathrm{~m}$ high (NOAA 2009d). The CCSVI was estimated to be approximately 8.40 for tsunami conditions. This would result in an increase from the CCSVI(1) for Miami-Dade County (see Table 6.4 ) of approximately $30 \%$.

From these values it can be observed that the CCSVI can be a useful tool in assessing the social vulnerability of community to a hurricane hazard. The CCSVI increases as the intensity of the hurricane or storm hazard increases. The CCSVI increases as the intensity of the hurricane or storm hazard increases. TS Bonnie was found to increase the CCSVI(1) by about $4 \%$ and Hurricane Katrina was found to increase the CCSVI(1) by about $16 \%$. A $4 \%$ increase in CCSVI, as for TS Bonnie, may not translate into a significant impact on the social vulnerability of a community, but increases in CCSVI of $16 \%$, as for Hurricane Katrina, could given an indication as to how much damage a community could sustain_ (directly and indirectly). If these estimated increases in social vulnerability are possible, it is vital that decision makers explore strategies that could mitigate the vulnerability of a region to the impacts of increased hurricane activity as a result of climate change.

As defined previously, social vulnerability is a combination of a region's capacity to respond and recover from a natural hazard, with minimal damage (Cutter et al. 2003). Mitigating the social vulnerability of hurricane-prone areas would, therefore, include enhancing the regions capacity to respond and, ultimately, recover from a hurricane event. There are numerous ways decision makers can mitigate the social vulnerability of 
their respective region to hurricane events, such as land-use planning and creating comprehensive hazard/vulnerability maps. The CCSVI is a descriptive index, based on site-specific social factors and localized hurricane data. The proposed framework herein can be applied to communities that are susceptible to hurricanes, creating a ranking system for hurricane-prone communities. This ranking system could be an effective tool in aiding government authorities in making decisions on land-use planning and resource allotment.

Furthermore, by conducting a PCA, as in this study, regions are able to identify the dominant social factors (SF) that have the greatest impact on the vulnerability for a given community. Once these dominant social factors have been identified and quantified, the locations of these groups should be mapped and, therefore, specific measures can be taken to address the special needs of each dominant social factor. For example, ethnic communities are often hindered by a language barrier that affects their ability to respond (Cutter et al. 2003). Areas where there the elderly are prominent, for instance, may need special consideration because of mobility restrictions.

Although they are not directly based on the analysis conducted herein, there are other strategies available that can aid in reducing the social vulnerability of a region. Strategies can involve enhancing the region's response time by increasing public awareness and knowledge of potential events through media, such as television, radio, and the internet. Enhancing the response time could also include reducing the evacuation time of regions by creating shorter and more effective evacuation routes. An increase in the number of available emergency shelters will accommodate a greater number of residents. All these strategies could mitigate the social vulnerability of regions to hurricane events.

\subsection{Uncertainty in CCSVI}

In order to address some of the uncertainty present in key variables within the study, the CCSVI is determined considering the random variability of wind speed and surge height using Eq. (6.3) and Eq. (6.5). For these preliminary results, a ratio $\mathrm{a}_{1}: \mathrm{a}_{2}$ of $50 \%: 50 \%$ between wind speed and surge height is assumed in the determination of the Hazard Factor. 
The CCSVI can be established for various combinations of changes in wind speed and surge height at year 50; however, for the sake of brevity four combinations of changes in wind speed and surge height are presented (i.e., $0 \%$ to $15 \%$ ). The simulation histograms of CCSVI(50) for Miami-Dade County for various scenarios of climate change are presented in Figure 6.3. The mean was determined for each scenario of climate change, and was found to be 6.81, 7.01, 7.19, and 7.37, for increases in wind speed and surge height of $0 \%, 5 \%, 10 \%$, and $15 \%$, respectively. These values are lower than the values found in Table 6.4, which can be explained because of the wide range the wind speeds and surge heights used in the calculations (see Figure 6.1 and 6.2).

Several distributions were fitted to the CCSVI(50) for no increase in wind speed or surge. Various statistical distributions were examined for goodness-of-fit, using the Kolmogorov-Smirnov test and the Anderson-Darling test (Ang and Tang 2007). Both tests were performed at a 5\% significance level. The tests showed that the Weibull distribution is appropriate for CCSVI at year 50. Similar analyses were run on the CCSVI at year 25, and it was found that the Weibull distribution the best fit for 25 years, at a $10 \%$ significance level.

The means and $5^{\text {th }}$ and the $95^{\text {th }}$ percentiles of the CCSVI are presented in Table 6.9. The means of the CCSVI vary as the wind speed and surge height are assumed to change, increasing with time if the wind speed and surge height are assumed to increase, and decreasing otherwise; however, the $\mathrm{COV}$ is constant regardless of climate change scenario $(\mathrm{COV}=8 \%)$. It is clear that there is variability within the CCSVI values which is expected given the high uncertainty associated with the random variability of the Weibull distribution and surge hazard model ( see Figure 6.1 and 6.2). This suggests that even under a 5\% increase scenario there is more than 5\% likelihood of CCSVI values exceeding that experienced by Hurricane Katrina, and that the probability of exceeding this benchmark set by Hurricane Katrina increases with more severe climate scenarios. 


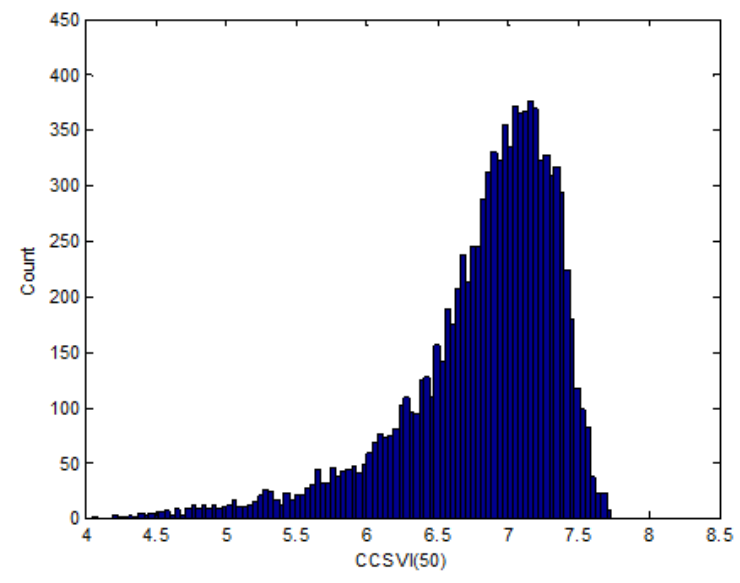

(a)

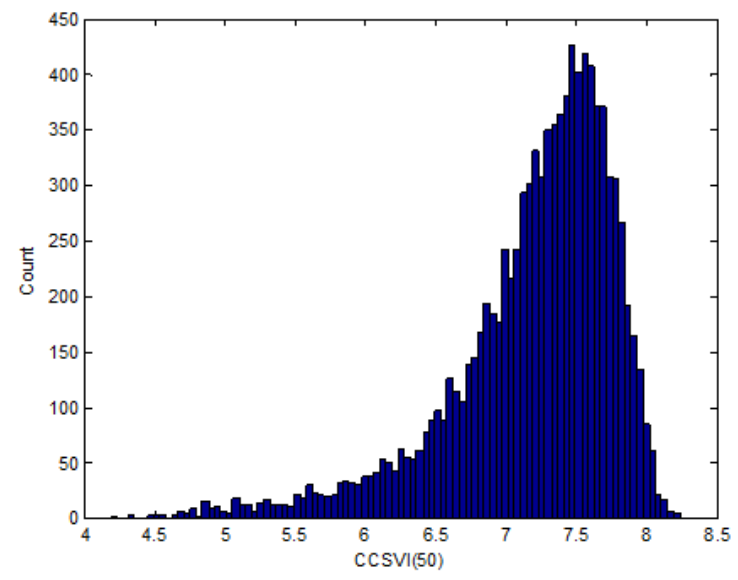

(c)

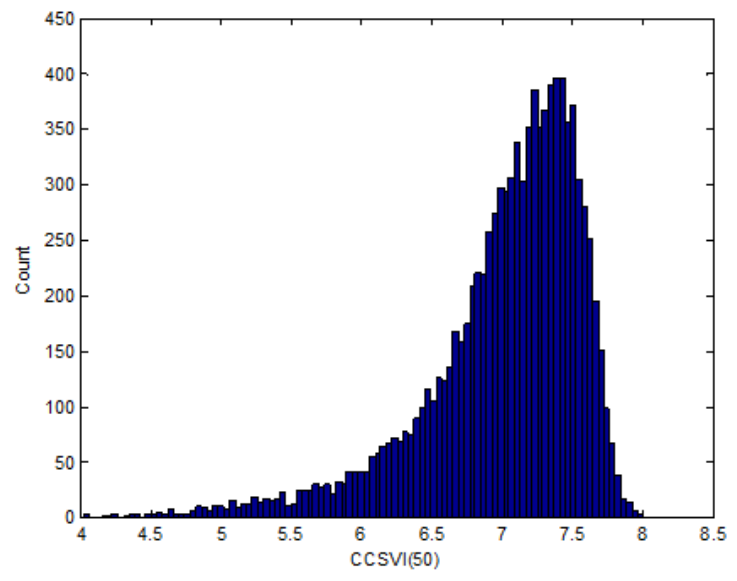

(b)

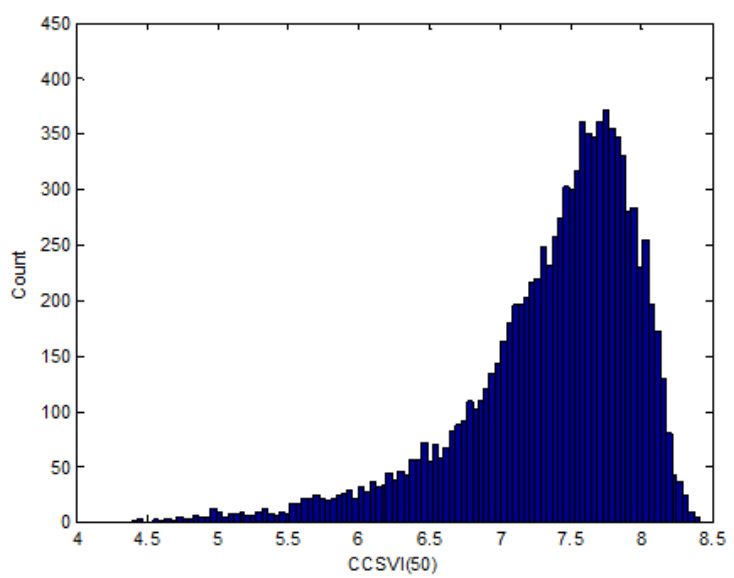

(d)

Figure 6.3: Distributions of CCSVI(50) for various scenarios of climate change. (a) No increase in wind speed and surge height (b) $5 \%$ increase in wind speed and surge height (c) $10 \%$ increase in wind speed and surge height (d) $15 \%$ increase in wind speed and surge height.

Table 6.9: The mean, the $5^{\text {th }}$ and $95^{\text {th }}$ percentiles of the CCSVI(50)

\begin{tabular}{|l|c|c|c|c|}
\cline { 2 - 5 } \multicolumn{1}{c|}{} & \multicolumn{4}{c|}{ Change in wind speed and surge height } \\
\cline { 2 - 5 } & $\mathbf{0 \%}$ & $\mathbf{5 \%}$ & $\mathbf{1 0 \%}$ & $\mathbf{1 5 \%}$ \\
\hline $5^{\text {th }}$ percentile & 5.69 & 5.88 & 5.99 & 6.12 \\
\hline Mean & 6.81 & 7.01 & 7.19 & 7.37 \\
\hline $\mathbf{9 5}^{\text {th }}$ percentile & 7.45 & 7.66 & 7.88 & 8.09 \\
\hline
\end{tabular}




\subsection{Conclusions and Future Work}

It is possible that hurricane hazard patterns may change as a result of climate while coastal populations continue to grow. Therefore, this study proposes the Coastal Community Social Vulnerability Index (CCSVI) that considers the potential impact of climate change on the social vulnerability of hurricane-prone areas. The potential impact of climate change on social vulnerability was determined using a principal components analysis (PCA). The 5 dominant social factors (SF) in the county were found to be: $j=1$ ) Race (African American) and Poverty, $\mathrm{j}=2$ ) Age and Gender, $\mathrm{j}=3$ ) Socioeconomic Status, $\mathrm{j}=4$ ) Race (Native American and Asian) and Unemployment, $\mathrm{j}=5$ ) Hispanic. These dominant social factors (SF) were combined with hurricane intensity and hurricaneinduced surge to create the CCSVI, which describes the social vulnerability of the region to hurricane events. The CCSVI was calculated under current climate conditions and various scenarios of climate change. The study found that the CCSVI could increase significantly under various scenarios of climate change and for demographic projections; therefore, it is necessary for decision-makers to develop strategies that could mitigate the social vulnerability of a community to hurricane events.

Social characteristics are difficult to quantify, but there is some consensus on which factors influence social vulnerability, as stated within this study; however, the effects of these dominant social factors vary between regions, which is why the PCA is utilized, as it identifies the dominant social factors within a specific community. Therefore, the CCSVI should be determined for a number of hurricane-prone communities to investigate how different social characteristics and hurricane hazards affect the CCSVI, and to create a ranking system for communities susceptible to hurricanes. This would also allow for additional insights on how to mitigate social vulnerability through use of the CCSVI. The CCSVI used, herein, could be refined to adequately represent conditions of the future so that a more accurate portrayal of the effects of climate change can be made.

The CCSVI could be connected to direct loss by using a regression analysis, because a regression model can be used to find the relationship between the dominant social factors, wind speed, and surge height and the potential hurricane damage. Other direct losses 
including injury and death can be considered when estimating the hurricane risk of a region. Furthermore, the proposed framework could be expanded to investigate the effects of climate change after different time frames (i.e. 10 years, 30 years). As hurricanes are expected to become more frequent and/or have higher intensities, it can be expect that they will result in more injury and deaths. But frequency and intensity are not the only contributing factor to hurricane related death and injury, the social composition has an effect, as does the quality of the construction within a community.

\subsection{References}

AGO (2007) An Assessment of the Need to Adopt Buildings for the Unavoidable Consequences of Climate Change. Final Report, Australian Greenhouse Office, Commonwealth of Australia.

Ang, A.H-S., and Tang, W.H. (2007) Probability Concepts in Engineering. Wiley: New York.

Batts, M., Cordes, M., Russell, C., Shaver, J., and Simiu, E. (1980) Hurricane wind speeds in the United States. National Bureau of Standards Report no. BSS-124, U.S. Department of Commerce, Washington, D.C.

Bjarnadottir, S., Li, Y. and Stewart, M.G., 2011. A Probabilistic-based Framework for Impact and Adaptation Assessment of Climate Change on Hurricane Damage Risks and Costs, Structural Safety, 33, 173-185.

Bjarnadottir, S., Li, Y. and Stewart, M.G. (2010) Assessing Impacts of Climate Change and Social Dynamics on Hurricane Damage Risks and Adaptation Strategies. Journal of Climatic Change (submitted in June 2010).

Broccoli, A.J., and Manabe, S. (1990) Can existing Climate Models be used to study Anthropogenic Changes in Tropical Cyclone Climate? Geophys. Res. Letters, 17, 19171920.

Burton, C.G. (2010) Social Vulnerability and Hurricane Impact Modeling. Natural Hazards Review, 11, 58-68. 
CCSP (2008) Impacts of Climate Change and Variability on Transportation Systems and Infrastructure: Gulf Coast Study, Phase I. A Report by the U.S. Climate Change Science Program and the Subcommittee on Global Change Research [Savonis, M. J., V.R. Burkett, and J.R. Potter, Eds. Department of Transportation, Washington, DC, USA.

Climate Change Advisory Task Force. (2008) Second Report and Initial Recommendations. [cited 2010 August 04]; Available from: http://www.miamidade.gov/derm/library/08-10-04_CCATF_BCC_Package.pdf

Crosset, K.M., Culliton, T. J., Wiley, P. C., and Goodspeed, T. R. (2008) Population Trends along the Coastal United States: 1980-2008. National Oceanic and Atmospheric Administration: Silver Spring, MD.

Cutter, S.L., Bornuff, B.J., and Shirley, W.L. (2003) Social Vulnerability to Environmental Hazards. Social Science Quarterly, 84, 242-261.

Davidson, R. (1997) An urban earthquake disaster risk index. PhD Dissertation, Earthquake Engineering Research Institute, Berkeley, California.

Davidson, R., and Lambert, K. (2001) Comparing the Hurricane Disaster Risk of U.S. Coastal Counties. Natural Hazards Review, 2, 132-142.

Elsner, J.B., Kossin, J.P., and Jagger, T.H. (2008) The increasing intensity of the strongest tropical cyclones. Nature, 455, 92-95.

Emanuel, K. (2005) Increasing destructiveness of tropical cyclones over the past 30 years. Nature, 436, 686-688.

Fritz, H.M., Blount, C., Sokoloski, R., Singleton, J., Fuggle, A., McAdoo, B.G., Moore, A., Chad Grass, C., and Tate, B. (2007) Hurricane Katrina storm surge distribution and field observations on the Mississippi Barrier Islands. Estuarine, Coastal and Shelf Science, $74,12-20$.

Georgiou, P.N. (1985) Design wind speeds in tropical cyclone-prone regions. PhD dissertation, University of Western Ontario. 
GAO (2007) Climate Change: Financial Risks to Federal and Private Insurers in Coming Decades are Potentially Significant. Unites States Accountability Office: Washington, D.C.

Goldenberg, S. B., Landsea, C. W., Mestas-Nunez, A. M. \& Gray, W. M. The recent increase in Atlantic hurricane activity: causes and implications. Science 293, 474-479 (2001).

Huang, Z. (1999) Stochastic models for hurricane hazard analysis. PhD dissertation, Clemson University.

Huang, Z., Rosowsky, D. V., and Sparks, P. R. (2001) Long-term hurricane risk assessment and expected damage to residential structures. Reliability engineering \& system safety, 74, 239-249.

Hubbert, G.D., and McInnes, K. (1999) A Storm Surge Inundation Model for Coastal Planning and Impact Studies. Journal of Coastal Research, 15, 168-185.

IPCC (2007) Climate Change 2007: The Physical Science Basis. Contribution of Working Group I to the Fourth Assessment Report of the Intergovernmental Panel on Climate Change. Solomon, S., Qin, D., Manning, M., Chen, Z., Marquis, M., Averyt, K.B., Tignor, M., and Miller, H.L. (eds.). Cambridge: Cambridge University Press.

Irish, J.L., Resio, D.T., and Ratcliff, J.J. (2008) The Influence of Storm Size on Hurricane Surge. Journal of Physical Oceanography, 38,2003-2013.

Jackson, J.E. (1991) A User's Guide to Principal Components Analysis. John Wiley \& Sons: New York City.

Jolliffe, I.T. (2002) Principal Components Analysis. Springer: New York City.

Klotzbach, P.J. (2006) Trends in global tropical cyclone activity over the past twenty years (1986-2005). Geophys. Res. Letters, 33.

Landsea, C.W., Harper, B.A., Hoarau, K., and Knaff, J.A. (2006) Can we detect trends in extreme tropical cyclones? Science, 313, 452-454. 
Li, Y., and Ellingwood, B.R. (2006) Hurricane damage to residential construction in the US: Importance of uncertainty modeling in risk assessment. Engineering Structures, 28, 1009-1017.

Li, Y.and Stewart, M.G. (2011) Cyclone Damage Risks Caused by Enhanced Greenhouse Conditions and Economic Viability of Strengthened Residential Construction, Natural Hazards Review, ASCE, 12, 9-18.

Luettich, R. A.J., Westerink, J. J., and Scheffner, N. W. (1992) ADCIRC: An advanced three-dimensional circulation model for shelves, coasts and estuaries, Report 1: Theory and methodology of ADCIRC-2DDI and ADCIRC-3DL. Dredging Research Program Technical Report DRP-92-6, Department of Army, United States Army Corport of Engineers, Waterways Experiment Station, Vicksburg, Mississippi.

NOAA (2009a) Historical Hurricane Data [cited 2010 September 10]; Available from: http://www.noaa.gov/

NOAA (2009b) SLOSH Model [cited 2010 August 04]; Available from: http://slosh.nws.noaa.gov/

NOAA.(2009c) The Saffir Simpson Hurricane Wind Scale [cited 2010 September 06]; Available from: http://www.nhc.noaa.gov/aboutsshws.shtml National Research Council. (2000). Ecological Indicators for the Nation. National Academy Press: Washington D.C.

NOAA (2009d) Tsunami [cited 2011 April 2]; Available from: http://www.tsunami.noaa.gov/National Weather Service (NWS) (2009) Flood Losses: Compilation of Flood Loss Statistics. [cited 2010 August 04]; Available from: http://www.weather.gov/oh/hic/flood_stats/Flood_loss_time_series.shtml

Pielke, R.A.J., Gratz, J., Landsea, C.W., Collins, D., Saunders, M.A., and Musulin, R. (2008) Normalized Hurricane Damage in the United States: 1900--2005. Natural Hazards Review, 9, 29-42.

Pratson, L.F., and Haxby, W.F. (1996) What is the slope of the U.S. continental slope? Geology, 24, 3-6. 
Pryor, S.C., Barthelmie, R.J., and Takle, G.S. (2009) Wind speed trends over the contiguous USA, IOP Conference Series: Earth and Environmental Science.

Rodríguez, R. W., Webb, R. M. T., and Bush, D. M. (1994) Another Look at the Impact of Hurricane Hugo on the Shelf and Coastal Resources of Puerto Rico, U.S.A. Journal of Coastal Research, 10, 278-296.

Saaty, T.L. (1990) The Analytical Hierarchy Process. PWS Publications: Pittsburg, Pennsylvania.

Scavia, D., Field, J.C., Boesch, D.F., Buddemeier, R., Burkett, V., Canyan, D., Fogarty, M., Harwell, M.A., Howarth, R.W., Mason, C., Reed, D.J., Royer, T.C., Sallenger, A.H. and Titus, J.G. (2002) Climate change impacts on U.S. coastal and marine ecosystems. Estuaries, 25, 149-164.

Stewart, M.G., and Li, Y. (2010) Methodologies for Economic Impact and Adaptation Assessment of Cyclone Damage Risks Due to Climate Change, Australian Journal of Structural Engineering, 10, 121-136.

Stewart, M.G., Rosowsky, D.V., and Huang, Z. (2003) Hurricane Risks and Economic Viability of Strengthened Construction. Natural hazards review, 4, 12-19.

United Nations Development Program (UNDP) (2000). Human Development Report 2000. Oxford Press: New York.

US Census Bureau (2009) State and County Quick Facts [cited 2009 April 14]; Available from: http://quickfacts.census.gov/qfd/states/12/12086.html.

Verboom, G.K., de Ronde, J.G., and van Dijk, R.P. (1992) A fine grid tidal flow and storm surge model of the North Sea. Continental Shelf Research. 12, 213-233.

Vickery, P.J. and Twisdale (1995) Wind-Field and Filling Models for Hurricane WindSpeed Predictions. Journal of Structural Engineering, 121, 1700-1709.

Vickery, P.J., Skerlj, P.F., and Twisdale (2000) Simulation of Hurricane Risk in the U.S. Using Empirical Track Model. Journal of structural engineering, 126, 1222-1237. 
Vickery, P.J., Wadhera, D., Twisdale, L.A.Jr., and Lavelle, F.M. (2009) U.S. Hurricane Wind Speed Risk and Uncertainty. Journal of Structural Engineering, 135, 301-320.

Westerink, J.J., Luettich, R.A., Baptista, A.M., Scheffner, N.W., and Farrar, P. (1992) Tide and Storm Surge Predictions using the Finite Element Model. J. Hydraul. Eng., 118, 373-1390.

Westerink, J. J., Luettich, R.A.J., and Scheffner, N. W. (1994) ADCIRC: An advanced three-dimensional circulation model for shelves, coasts and estuaries, Report 2: Users manual for ADCIRC-2DDI, Dredging Research Program Technical Report DRP-94-6 Department of Army, United States Army Corps of Engineers, Waterways Experiment Station, Vicksburg, Mississippi.

Woods and Poole Economics, Inc. (W\&PE) (2003) 2003 Desktop Data Files. W\&PE, Washington, DC.

World Bank. (2001) World Development Indicators. <www.worldbank.org/wdi2001/enviornment.htm> 


\section{Chapter 7}

\section{Future Work}

This research covers a wide range of subjects; therefore there is much capacity for future work. Within this chapter the main avenues for potential future work as seen by the author are outlined. This research could be split into four sections: Hurricane Risk Assessment of Residential Construction considering Climate Change, Hurricane Risk Assessment of Timber Distribution Poles considering Climate Change, Adaptation/Mitigation for Reduced Hurricane Damage Costs, and Social Vulnerability of Hurricane-Prone Regions considering Climate Change. Therefore the future work proposed herein will be split into four sections, however it can be noted that in some cases the future work proposed in one section could be applied to another (this especially applies to some proposed avenues with the first section (Hurricane Risk Assessment of Residential Construction) which can be applied to other sections). It is for the sake of brevity that some ideas are not duplicated between the four sections.

\subsection{Hurricane Risk Assessment of Residential Construction Considering Climate Change}

The hurricane risk assessment of residential construction includes hurricane wind field models, hurricane surge height models, and hurricane vulnerability models. There is much uncertainty associated with these models; therefore future work would involve the reduction of these uncertainties. First off, a more accurate probabilistic wind field model could be incorporated to eliminate some of the uncertainty present. The ideal wind field model would consider local topographic factors, shielding effects present within the region, and terrain roughness. In order to include these parameters, more detailed information is needed from historical hurricanes, and the uncertainty associated with the 
parameters should be assessed through a best-fit analysis of comprehensive historical hurricane records. Furthermore, the comprehensive hurricane records can be used to create a centralized database that can be useful in validating current and future wind field models. In addition, other parameters of hurricanes could also be included in this hurricane risk assessment, such as average translation speed (i.e. wind speed duration on structures), radius to maximum winds (i.e. size of the wind field and impact zone), trajectory, probability of impacting land, rate of inland decay, rainfall rates, etc.

In order to create a comprehensive hurricane risk assessment, that is capable of combining hurricane wind speed, hurricane frequency, and hurricane-induced storm surge, a more sophisticated hurricane surge height model could be developed. The hurricane surge height model should have the capabilities to estimate an annual surge height in a similar manner that wind field models estimate an annual peak wind speed. Hurricane-induced surge height is affected by many intertwining factors (e.g. storm size, hurricane wind speed, central pressure deficit); therefore the surge height model should account for these parameters in its estimation of surge height. More comprehensive records on historical and future hurricanes would greatly aid in the future development of surge height models. A surge height model of this nature would enable users of the framework proposed herein to more accurately estimate damage costs and evaluate the potential impacts of climate change in a more complete manner.

Hurricane damage risks due to wind speed are estimated by convolving the hurricane wind field model with the hurricane damage model. Within this convolution a boundary layer model is implemented, because wind speeds generated with the wind field model need to be modified to account for surface conditions. Typically, the boundary layer model is simply in the form of a multiplication factor. For example, within this study, a conversion factor of 0.70 is used to adjust the 3 -sec gust stipulated in wind speed maps to surface wind speed. The accuracy of this value could be refined through improved observations of the entire wind field.

To account for the uncertainties present even further, building vulnerability models could be developed for specific construction types, construction materials, age profiles, code 
specifications, etc. Aging effects on existing building that will be retrofitted over a period of time need to be considered. In addition, to evaluate the indirect losses and social disruption by hurricanes, it would be beneficial to develop a more thorough economic decision analysis, which would consider the effect of various factors (e.g. insurance premiums, discount rates, exposure periods, life safety, social issues, incentives, and hurricane mitigation).

Since some (if not the majority of) vulnerability damage models for both hurricane wind and surge are developed based on regressive curve fitting, all post-disaster damage data needs to be readily available in the public domain. The proprietary issues of ownership has restricted the availability of insurance claims information, but it is necessary that policies are developed that allow public access to this information. Issues of inconsistency of the claims information may arise following allowing public access, because adjusters' assessments of damage may vary between insurance companies and even within the same insurance company. But this could result in standardized methods of damage assessments, which could in turn result in more consistent post-disaster damage information; although it is not possible to completely eliminate human error due to individual interpretation and judgment.

Access to all historical and future post-disaster damage data would aid in the development of more accurate vulnerability curves. In addition, expert opinion could be incorporated in the form of comprehensive damage surveys post-disaster. The combination of claims data and expert opinion could aid in the consistency and, potentially, in the accuracy of damage estimates. Furthermore, extensive damage testing (e.g. wind tunnel or flood simulation) could be performed to gain more insights into how damage progresses due to a simulated hurricane. Testing of this nature is vital in developing mitigation/adaptation measures to reduce potential damage.

\subsection{Hurricane Risk Assessment of Timber Poles Considering Climate Change}

Determining the replacement cost to distribution infrastructure, as presented in Chapter 4 and Chapter 5, is only one step in determining the hurricanes replacement costs to power 
systems. Because of infrastructure failure (i.e. timber distribution pole failure), the power system may experience a power outage. As a result of the power outage it can be expected that customers experience lost production, equipment damage, utility costs, idle resources, etc (Billinton and Allan 1996). Each hour of outage or interruption can lead to significant losses for customers. Sullivan et al. (1997) estimated the cost of interruption for individual customers. The study conducted a survey of power system outages within the last ten years, and developed a statistical model for the determination of interruption costs. When determining the cost of interruption, first the type of customer (i.e. commercial, industrial, or residential) affected by the power outage must be identified. For example, a one hour outage occurring during business hours could result in a mean cost for a commercial or industrial customer that is 2000 times higher than that of a residential customer. Not only is the cost to residential customers significantly less, but the cost to commercial and industrial customers varies significantly ( $\$ 0$ to $\$ 1,000,000$ ) (Sullivan et al. 1997). When a distribution pole fails, customers in the area will experience a power outage; therefore, the future work of the proposed framework is to model the costs of the outage (i.e. interruption).

However, before the interruption costs can be estimated, the duration of interruption due to a potential hurricane event must be estimated. In the past few decades, estimating the duration of power outages due to hurricanes has been widely explored. Isumi and Shibuya (1985) modeled the restoration procedure after a hurricane event ignoring all uncertainty, where the restoration time is equivalent to the outage duration. Then an optimization model is used to minimize the time a customer is without power, using decision variables (e.g. repair times). The effect of these variables on the restoration times is then evaluated through a sensitivity analysis. Nojima and Sugito (2002) developed restoration curves from past data from earthquakes that show the percentage of customers for whom service has been restored. These curves represent utility performance during an extreme event; however, its application to estimating outage costs for future events is untested.

Balijepalli et al. (2005) implemented a bootstrap method to estimate the parameters of a lightning storm. The parameters and fault rates were then combined in a MCS to 
estimate system reliability indices. The network approach involves simplifying the power system by using supply and demand nodes that are connected by functional/nonfunctional links. The mean time for restoration is then minimized through graph theory and optimization techniques. Xu et al. (2007) optimized the order substations were repaired after a major disaster.

The regression approach accounts for the many variables that interact to affect the duration of a power outage. The past dataset must be large enough to describe the response of the power system to an approaching hurricane. Liu et al. (2005) implements a negative binomial regression to estimate power outages in North Carolina. The study recommends the implementation of a zip code regression model to estimate the duration of power outages. The zip code regression model has 5 input parameters. These input parameters are derived from data available using a similar technique as a PCA (principal components analysis), i.e. the input parameters are estimated by using a SAS statistical analysis package. The SAS takes variables based on the hurricane-outage rates, electrical power system inventory, hurricane wind speed, hurricane rainfall rates, soil drainage level, tree type, and land cover. From these variables the 5 input parameters are estimated for North Carolina, and are then input into the regression model. Unfortunately, the authors state that this model can only be used for North Carolina because the parameters are based on historical data for North Carolina.

The author proposes using the Liu et al. (2005) binomial regression model to the duration of interruption due to a potential hurricane event in New Hanover County, North Carolina, as a starting point. Within the binomial regression, hurricane parameters consistent with the parameters used to estimate annual damage costs due to timber pole failure in New Hanover County (Chapter 4) will be used to estimate annual interruption times. Once the duration of interruption has been estimated, the customers within the region will be assigned a customer group (i.e. residential, commercial, industrial) and the proportion of customers within each customer group will be identified. LaCommare and Eto (2006) estimated the cost of interruption per hour for the three classes of customers, in 2001 U.S. dollars, is: Residential \$8, Commercial \$2,558, and Industrial \$9,373. Finally, the duration of interruption, the proportion of customers, and cost of interruption 
per hour are combined to estimate the total cost of interruption for the area. The total cost of interruption is then added to the structural damage estimates found in Chapter 4. As hurricane intensity and/or frequency may change due to climate change, it can be expected that the frequency of intense hurricanes may increase; indicating that interruption costs may increase.

Furthermore, the hurricane risk assessment of timber poles can be enhanced to account for hurricane frequency. This can be achieved by incorporating the GPD model for hurricane wind speed in a similar manner as for the hurricane risk assessment for residential construction (Chapter 3). In some cases it may be practical to include hurricane-induced storm surge in damage estimates for timber distribution poles, even though research strongly suggests that the primary cause of damage to timber distribution poles during hurricane events is hurricane wind speed (Reed et al. 2010). However, in such applications where damage estimates due to hurricane-induced surge height are preferred, the damage to timber distribution poles due to hurricane-induced surge height can be determined in a similar manner as outlined for residential surge damage in Chapter 3.

In addition, studies have shown that windborne debris (includes anything that has been broken or destroyed) and windborne trees due to intense hurricane wind can account for a considerable amount of damage to the power system (Winkler et al. 2010). Windborne debris during a hurricane can cause excessive damage to the environment; therefore to further enhance the accuracy of this hurricane risk assessment, the framework should be extended to include windborne debris in the damage estimates. Models have been developed (e.g. Willis et al. 2002) that estimate the damage that buildings may sustain as the result of windborne debris during hurricane events, and these models could be modified to be incorporated into the hurricane risk assessment framework developed herein.

\subsection{Adaptation/Mitigation for Reduced Hurricane Damage Costs}

The research herein developed a framework for hurricane risk assessment considering the impacts of a changing global climate. The framework was developed originally for 
residential construction and then adapted to timber distribution poles. In addition to the hurricane risk assessment framework, this research developed adaptation/mitigation strategies that could aid in reducing hurricane damage costs to both forms of infrastructure. A more detailed prediction of localized change in hurricane hazard patterns and sea levels change is desirable for regional adaptation.

First, the research developed and evaluated five adaptation strategies for residential construction. These adaptation measures were developed to mitigate damages due to hurricane wind speed considering the impacts of a changing climate. As the hurricane risk assessment framework was extended to include hurricane-induced storm surge, a reasonable next step would be to develop adaptation strategies that would have the capacity to mitigate damage costs to residential construction from both hurricane wind speed and hurricane-induced storm surge. These measures would be potentially more costly and more disruptive, but could also significantly reduce damage costs, if the current work on adaptation for hurricane wind damage is any indication.

Second, the work proposed four mitigation strategies for timber distribution poles to reduce damage costs due to hurricane winds. The mitigation strategies were developed for current climate conditions (i.e. no climate change); therefore, it is proposed that strategies for climate change adaptation be developed to mitigate the potential increase in hurricane damage costs due to climate change. The proposed mitigation strategies included replacing failed distribution poles with poles that are stronger (i.e. larger) than the failed poles and the pro-active measure of replacing old distribution poles. Future work could include looking at replacing failed timber poles with distribution poles that are constructed from different materials, e.g. steel poles and concrete. Using different materials could be a cost-effective measure in reducing pole failure rates in high risk areas.

\subsection{Social Vulnerability of Hurricane-Prone Regions Considering Climate Change}

It is possible that hurricane hazard patterns may change as a result of climate while coastal populations continue to grow. Therefore, this study proposes the Coastal 
Community Social Vulnerability Index (CCSVI) that considers the potential impact of climate change on the social vulnerability of hurricane-prone areas. The work herein looked solely at time-dependant changes in demographics and hurricane patterns (i.e. hurricane wind speed and hurricane-induced storm surge). The current work did not look into changes in the relative weights of each of the social indicators within the CCSVI. For example, from Table 6.3, if Social Factor 1 (Race) is selected, it includes six indicators: Percent of African American Population, Average Number of People per Household, Percent of Persons Living in Poverty, Percent of Civilian Unemployment, Percent of Aged over 25 with Less than 12 years Education, and Percent of Civilian Labor Force Participation. Each of the six indicators has a relative weight, which indicates its importance within Social Factor 1. For instance, Percent of Persons Living in Poverty has a relative weight of 0.24 and Percent of African American Population has a relative weight of 0.18 within the current work. It is possible that in a set time frame the relative importance of each indicator has changed within its social factor, e.g. perhaps in 50 years the Percent of African American Population has a much smaller effect on the social vulnerability of a region to a hurricane hazard than stated in Table 6.3.

In addition, the Social Factors were assigned a factor weight that indicates their respective importance within the CCSVI. It is quite possible that these factor weights may change with time. Currently, Social Factor 2 (Age and Gender) and Social Factor 5 (Hispanic) have the greatest influence on the CCSVI. Potentially, with time, Social Factor 2 could continue to be a driving force between the CCSVI in Miami-Dade County, but Social Factor 5 could become less dominant with the other social factors (i.e. 1, 3, and 4) becoming more influential in contrast. With changing social views characteristics, it is quite challenging to forecast the social dynamics that are driving forces behind social vulnerability of the future. Therefore, it would be interesting to look at possible changes within both the relative weights of the indicators and the factor weights of the dominant social factors.

As previously stated, social characteristics are difficult to quantify; however, this research has presented a potential method in an attempt to quantify social vulnerability to hurricane hazards. The CCSVI is a compilation of social characteristics and hurricane 
parameters, and the social characteristics are grouped into dominant social factors through a PCA. Social characteristics vary between locations; furthermore, the relative importance of the social characteristics varies between locations. Therefore, the CCSVI should be determined for a number of hurricane-prone regions and to create a ranking system for communities susceptible to hurricanes. This would also allow for additional insights on how to mitigate social vulnerability through use of the CCSVI.

\subsection{References}

Balijepalli, N., Venkatta, S., Richter, C. Jr., Christie, R., and Longo, V. (2005) Distribution system reliability assessment due to lightning storms. IEEE Transactions on Power Delivery, 20, 2153-2159.

Billinton R., and Allan, R. N. (1996) Reliability Evaluation of Power Systems, 2nd Edition, Plenum Press, New York, 1996.

Isumi, M. and Shibuya, T. (1985) Simulation of post earthquake restoration for lifeline systems. International Journal of Mass Emerging Disasters, 3,87-105.

LaCommare, K.H., and Eto, J.H. (2006) Cost of power interruptions to electricity consumers in the United States (US). Energy, 31,1845-1855.

Liu, H., Davidson, R.A, Rosowsky, D.V, and Stedinger, J.R. (2005) Negative Binomial Regression of Electric Power Outages in Hurricanes, Journal of Infrastruct. Systems, 11, 258-267.

Nojima, N. and Sugito, M. (2002) Empirical Estimation of Outage and Duration of Lifeline Disruption Due to Earthquake Disaster. Proceedings of the US-China-Japan Workshop on Lifeline Systems, October.

Reed, D.A., Powell, M.D., and Westerman, J.M., 2010. Energy Infrastructure Damage Analysis for Hurricane Rita, Natural Hazards Review, 11, 102-109.

Sullivan, M.J., Vardell, T., and Johnson, M. (1997) Power interruption costs to industrial and commercial consumers of electricity. Industry Applications, IEEE Transactions, 33, 1448-1458. 
Willis, J.A.B., Lee, B.E., and Wyatt, T.A. (2002) Journal of Wind Engineering and Industrial Aerodynamics, 90, 555-565.

Winkler, J., Dueñas-Osorio, L, Stein, R, and Subramanian, D. (2010) Performance assessment of topologically diverse power systems subjected to hurricane events, Reliability Engineering and System Safety, 95, 323- 336.

Xu, N., Guikema, S.D., Davidson, R.A., Nozick, L.K., Cagnan, Z., and Vaziri, K. (2007) Optimizing scheduling of post-earthquake electric power restoration tasks, Earthquake Engineering and Structural Dynamics, 36, 265-284. 


\section{Chapter 8}

\section{Conclusions}

It is possible that hurricane patterns and resulting damage losses may change as a result of climate change. The proposed framework provides a tool to evaluate the potential impact of such change on hurricane damage risks assessment. Furthermore, this research develops a hurricane risk assessment that is capable of accounting for the time-dependent aspects of hurricanes, such as hurricane intensity, hurricane frequency, and hurricaneinduced storm surge. This framework is adapted to various types of infrastructure (such as residential construction and power distribution poles), with the capability of being applied to other vital infrastructure. In addition, cost-effective measures of mitigation/adaptation are evaluated and provided in an attempt to reduce expected damage costs due to hurricane hazards. Finally, in an effort to provide a comprehensive hurricane risk assessment tool, the research includes the social vulnerability of regions to hurricane hazards with the development of the Coastal Community Social Vulnerability Index. Notwithstanding the relatively simple wind field and vulnerability models, mainly due to the proprietary nature of such models, the framework is appropriate for comparative studies to explore the potential impact of climate change on hurricane risk assessment.

In essence, three different forms of analysis were implemented for the hurricane risk assessment of residential construction. First, hurricane damage costs were estimated from solely looking at hurricane wind speeds on an annual base, and summing up damage costs over a specified time frame. As hurricane wind speeds contribute to only a portion of damage costs this research strove to find ways to combine other dominant parameters of hurricanes (i.e. hurricane frequency and hurricane-induced storm surge). Due to limitations of the surge height model, it was found that combining all three parameters is 
not possible at this time; however, when more sophisticated surge height models are available they can be easily incorporated into the proposed framework herein. Therefore, two other analyses are included; one that combines hurricane wind speed and hurricane frequency and one that combines hurricane wind speed and hurricane induced storm surge. This research finds that climate change could have a significant impact on hurricane damage costs to residential construction.

If these increases in damage costs due to climate change are believed likely then, it is necessary to assess the economic viability of mitigation (adaptation) strategies to strengthen or retrofit construction in hurricane-prone zones. Five adaptation strategies were developed to mitigate damage costs to residential construction. An adaptation strategy involving strengthening new construction at foreshore locations also proved to be very cost effective and to cause the least disruption because it did not require the retrofit of older buildings. These adaptation strategies were found to be cost effective even if there is no change in wind speed, which implies that the strategies could result in a "win-win" situation. In comparison, similar adaptation strategies may not be economical for building in Queensland, Australia, mainly due to the relatively low hurricane intensity in the area.

The research adapted the hurricane risk assessment framework to include timber power distribution poles, and assessed the potential impacts of climate change on the annual failure probability of the distribution poles. A fragility analysis was used to evaluate the damage risk of timber distribution poles. The annual failure probability of timber distribution poles was found to change significantly when they are subjected to changing patterns of hurricane hazard. Under the assumptions of the proposed framework for the hurricane risk assessment of distribution poles, the replacement costs of distribution poles for the "do nothing" case, i.e. without mitigation was found to be approximately $\$ 152$ million for Miami-Dade County over a 50 year time frame. The high replacement costs warrant an investigation into the cost effectiveness of various mitigation strategies that may aid in reducing replacement costs. Four mitigation measures were developed for distribution poles in an attempt to reduce replacement costs, and through an evaluation of 
the mitigation strategies, it was found that mitigation strategies may significantly reduce replacement costs due to hurricanes.

This research proposes the Coastal Community Social Vulnerability Index (CCSVI) that considers the potential impact of climate change on the social vulnerability of hurricaneprone areas. The study found that the CCSVI could increase significantly under various scenarios of climate change and for demographic projections; therefore, it is necessary for decision-makers to develop strategies that could mitigate the social vulnerability of a community to hurricane events. As hurricanes are expected to become more frequent and/or have higher intensities, it can be expect that they will result in more injury and deaths. But frequency and intensity are not the only contributing factor to hurricane related death and injury, the social composition has an effect, as does the quality of the construction within a community. 


\section{References}

Adachi, T. and Ellingwood, B. R. (2010) Comparative assessment of civil infrastructure network performance under probabilistic and scenario earthquakes, J. Infrastructure Systems ASCE, 16, 1-10.

AGO (2007) An Assessment of the Need to Adopt Buildings for the Unavoidable Consequences of Climate Change. Final Report, Australian Greenhouse Office, Commonwealth of Australia.

American Society of Civil Engineers (ASCE) (1996) Minimum design loads for buildings and other structures. ASCE, 97-5, New York.

American Society of Civil Engineers (ASCE-111) (2006) Reliability-Based Design of Utility Pole Structures (No. 111). ASCE manuals and reports on engineering practices.

American Society of Civil Engineers (ASCE-113) (2008) Substation structure design guide (No. 113). ASCE manuals and reports on engineering practices.

American National Standards Institute (ANSI) (2002) Wood Poles Specifications and Dimensions, 05.1.

Ang, A.H-S., and Tang, W.H. (2007) Probability Concepts in Engineering. Wiley: New York.

ANSI (2002) Wood Poles Specifications and Dimensions, 05.1.

AS 5604 (2005) Timber-Natural Durability Ratings, Australia. Standards Australia: 2005.

ASCE-7 (2007) Minimum Design Loads for Buildings and Other Structures. (ASCE Standard 7-05), Am. Soc. of Civil. Engineers, Reston.

Australian Greenhouse Office (AGO) (2007) An Assessment of the Need to Adopt Buildings for the Unavoidable Consequences of Climate Change. Final Report, Australian Greenhouse Office, Commonwealth of Australia. 
Baraneedaran, S., Gad, E.F., Flatley, I., Kamiran, A., and Wilson, J.L. (2009) Review of In-service Assessment of Timber Poles. Proceedings of the Australian Earthquake Engineering Society, Newcastle, 2009.

Batts, M., Cordes, M., Russell, C., Shaver, J., and Simiu, E. (1980) Hurricane wind speeds in the United States. National Bureau of Standards Report no. BSS-124, U.S. Department of Commerce, Washington, D.C.

Bender, M. A., Knuston, T.R., Tuleya, R.E., Sirutis, J.J., Vecchi, G.A., Garner, S.T., and Held, I.M. (2010) Modeled impact of anthropogenic warming of the frequency of intense Atlantic hurricanes, Science 327, 454-458.

Bhunderwala, S. (1995) "Insurance loss of single family dwellings damages in Hurricane Andrew", M.S., Clemson University.

Bhuyan, G., and Li, H. (2006) Achieved Reliability of the North American Design Approaches for Transmission Overhead Structures. Probabilistic Methods Applied to Power Systems 11-15 June 2006, 1-5.

Billinton R., and Allan, R. N. (1996) Reliability Evaluation of Power Systems, 2nd Edition, Plenum Press, New York, 1996.

Bingel, N., Dagher, H., Randle, R., Wolfe, R., Slavin, L., Voda, M., and Wong, J. (2003) Panel session: structural reliability-based design of utility poles and the national electrical safety code. Transmission and Distribution Conference and Exposition, Sept.2003 IEEE PES, 3, 1088- 1093

Bjarnadottir, S., Li, Y. and Stewart, M.G, (2012) Hurricane Risk Assessment Of Power Distribution Systems Considering Impacts Of A Changing Climate, Journal of Infrastructure Systems, ASCE (In press).

Bjarnadottir, S., Li, Y. and Stewart, M.G., (2011) A Probabilistic-based Framework for Impact and Adaptation Assessment of Climate Change on Hurricane Damage Risks and Costs, Structural Safety, 33, 173-185. 
Bjarnadottir, S., Li, Y. and Stewart, M.G. (2010) Assessing Impacts of Climate Change and Social Dynamics on Hurricane Damage Risks and Adaptation Strategies. Journal of Climatic Change, (submitted in June 2010).

Boardman, A.E., Greenberg, D.H., Vining, A.R. and Weimer, D.L. (2011) Cost-Benefit Analysis: Concepts and Practice. Pearson, Boston.

Boesch, D.F., Field, J.C., Scavia, D. (2000) The Potential Consequences of Climate Variability and Change on Coastal Areas and Marine Resources. Report of the coastal areas and marine resources sector team, U.S. National Assessment of the Potential Consequences of the Climate Variability and Change. U.S. Global Change Research Program. National Oceanic and Atmospheric Administration Coastal Ocean Program Decision Analysis Series No. 21. Silver Spring, Maryland.

Broccoli, A.J., and Manabe, S. (1990) Can existing Climate Models be used to study Anthropogenic Changes in Tropical Cyclone Climate? Geophys. Res. Letters, 17, 19171920.

Brown, R.E. (2008) Electric Power Distribution Reliability. CRC Press: Boca Raton, FL. Burton, C.G. (2010) Social Vulnerability and Hurricane Impact Modeling. Natural Hazards Review, 11, 58-68.

Butera, R. (2000) Asset management for the distribution pole plant-closing the performance gap between traditional maintenance and asset management, Power Engineering Society Summer Meeting, 2000. IEEE , 1, 561-565.

CCSP (2008) Impacts of Climate Change and Variability on Transportation Systems and Infrastructure: Gulf Coast Study, Phase I. A Report by the U.S. Climate Change Science Program and the Subcommittee on Global Change Research, eds: Savonis, M. J., V.R. Burkett, and J.R. Potter, Eds. Department of Transportation, Washington, DC, USA.

Chen, S.-C., Chen, M., Zhao, N., Hamid, S., Chatterjee, K., and Armella, M. (2009) Florida public hurricane loss model: Research in multi-disciplinary system integration assisting government policy making. Government Information Quarterly, 26, 285-294. 
Climate Change Advisory Task Force. (2008) Second Report and Initial Recommendations. [cited 2010 August 04]; Available from: http://www.miamidade.gov/derm/library/08-10-04_CCATF_BCC_Package.pdf

Climate Change Science Program (CCSP) (2008) Impacts of Climate Change and Variability on Transportation Systems and Infrastructure: Gulf Coast Study, Phase I. A Report by the U.S. Climate Change Science Program and the Subcommittee on Global Change Research. Savonis, M. J., V.R. Burkett, and J.R. Potter, Eds. Department of Transportation, Washington, DC, USA.

Columbia Broadcasting System (CBS) (2011) Hurricane Irene [cited 2011 September 14]; Available from: http://www.cbs.com/news/

Crosset, K.M., Culliton, T. J., Wiley, P. C., and Goodspeed, T. R. (2004) Population Trends along the Coastal United States: 1980-2008. National Oceanic and Atmospheric Administration: Silver Spring, MD.

Culliton, T.J. (1998) Population: distribution, density and growth. National Oceanic and Atmospheric Administration State of the Coast Report. Silver Spring, Maryland. Available: http://state-of-coast.noaa.gov/topics/html/pressure.html

Cutter, S.L., Bornuff, B.J., and Shirley, W.L. (2003) Social Vulnerability to Environmental Hazards. Social Science Quarterly, 84, 242-261.

Dagher, H.J. (2001) Reliability of poles in NESC grade C construction, Rural Electric Power Conference, 2001.

Dagher, H.J., Lu, Q., and Peyrot, A.H. (1998) Reliability of Transmission Structures Including Nonlinear Effects, Journal of Structural Engineering, 124, 966-973.

Dao, T.N. (2010) "The Development of Performance-Based Wind Engineering for Residential Structures: From Concept to Application", Ph.D. Dissertation, Colorado State University, Fort Collins, CO, USA.

Dao, T.N., and van de Lindt, J.W. (2010) Methodology for Wind-Driven Rainwater Intrusion Fragilities for Light-Frame Wood Roof Systems, Journal of Structural Engineering, 136, 700-706. 
Das, P.K., Sinha, M.C., and Balasubramanyam, V. (1974) Storm surges in the Bay of Bengal, Quarterly Journal of the Royal Meteorological Society, 100, 437-449.

Davidson, R. (1997) An urban earthquake disaster risk index. $\mathrm{PhD}$ Dissertation, Earthquake Engineering Research Institute, Berkeley, California.

Davidson, R. A., Liu, H. I., Sarpong, K., Sparks, P., and Rosowsky, D. V. (2003a) Electric power distribution system performance in Carolina hurricanes, Natural Hazards Review, 4, 36-45.

Davidson, R., and Lambert, K. (2001) Comparing the Hurricane Disaster Risk of U.S. Coastal Counties, Natural Hazards Review, 2, 132-142.

Davidson, R., Zhao, H., Jain, V.K. (2003b) Quantitative Model to Forecast Changes in Hurricane Vulnerability of Regional Building Inventory, Journal of Infrastructure Systems, 9, 55-64.

Dube, A. T., Rao, A.D., Sinha, P.C., Murty, T.S., and Bahulayan, N. (1997) Storm surge in the Bay of Bengal and Arabian Sea: The problem and its prediction, Mausam, 48, 283290.

Ellingwood, B.R., and Kinali, K. (2008) Quantifying and communicating uncertainty in seismic risk assessment, Structural Safety, 31, 179-187.

Ellingwood, B. R., and Tekie, P.B. (1999) Wind load statistics for probability-based structural design, Journal of Structural Engineering 125, 453-463.

Elsner, J.B. (2006) Evidence in support of the climate change-Atlantic hurricane hypothesis, Geophysical Research Letters, 33.

Elsner, J.B., Kossin, J.P., and Jagger, T.H. (2008) The increasing intensity of the strongest tropical cyclones, Nature, 455, 92-95.

Emanuel, K. (2005) Increasing destructiveness of tropical cyclones over the past 30 years, Nature, 436, 686-688.

Emanuel, K., Ravela, S., Vivant, E., and Risi, C. (2006) A statistical-deterministic approach to hurricane risk assessment, Bull. Am. Meteorol. Soc., 19, 299-314. 
FEMA (1999). HAZUS-MH Hurricane Model. [cited 2009 April 7]; Available from: http://www.fema.gov/plan/prevent/hazus/hz_wind.shtm.

FEMA (2003) RSDE field workbook: preparing structure inventories using Residential Substantial Damage Estimator Software Program RSDE 2.0. Federal Emergency Management Agency: Washington, D.C.

FEMA (2006) Multi-hazard loss estimation methodology-flood model. Federal Emergency Management Agency: Washington, D.C.

FEMA (2009) Midwest Floods of 2008 in Iowa and Wisconsin, Federal Emergency Management Agency (FEMA).

Flather, R., and Heaps, N.S. (1975) Tidal computations for Morecambe Bay, Geophysical Journal of the Royal Astronomical Society, 42, 489-517.

Flierl, G. R., and Robinson, A.R. (1972) Deadly Surges in the Bay of Bengal: Dynamics and Storm-tide Tables, Nature, 239, 213-215.

Florida Power \& Light Company (FP\&LC) (2006) Technical Report: Post Hurricane Wilma Engineering Analysis, KEMA, Inc.

Foedinger, R., Boozer, J.F., Bronstad, M.E., and Davidson, J.W. (2002) Development of an energy composite utility pole, Transportation Research Board Annual Meeting.

Fritz, H.M., Blount, C., Sokoloski, R., Singleton, J., Fuggle, A., McAdoo, B.G., Moore, A., Chad Grass, C., and Tate, B. (2007) Hurricane Katrina storm surge distribution and field observations on the Mississippi Barrier Islands. Estuarine, Coastal and Shelf Science, $74,12-20$.

GAO (2007) Climate Change: Financial Risks to Federal and Private Insurers in Coming Decades are Potentially Significant. Unites States Accountability Office: Washington, D.C.

Georgiou, P.N. (1985) Design wind speeds in tropical cyclone-prone regions. PhD dissertation, University of Western Ontario. 
Georgiou, P.N., Davenport, A.G., and Vickery, B.J. (1983) Design Wind Speeds in Regions Dominated by Tropical Cyclones, Journal of Engineering and Industrial Aerodynamics, 13, 139-152.

Gere, J., and Carter, W. (1962) Critical Buckling loads for tapered columns, Journal of Structural Engineering, 88, 1-11.

Goldenberg, S. B., Landsea, C. W., Mestas-Nunez, A. M., and Gray, W. M. (2001) The recent increase in Atlantic hurricane activity: causes and implications, Science, 293, 474479.

Government Accountability Office (GAO) (2007) Climate Change: Financial Risks to Federal and Private Insurers in Coming Decades are Potentially Significant, Unites States Accountability Office: Washington, D.C.

Goldenberg, S. B., Landsea, C. W., Mestas-Nunez, A. M. \& Gray, W. M. (2001) The recent increase in Atlantic hurricane activity: causes and implications, Science, 293, 474479.

Green, C. (2003) Handbook of Water Economics: Principles and Practice, Wiley: Chicester.

Grigg, N.S, and Helweg, O.J. (1975) State-of-the-Art of Estimating Flood Damage in Urban Areas, Water Resources Bulletin, 11, 379-390.

Grigoriu, M. (2006) Probabilistic Models for Directionless Wind Speeds in Hurricanes. National Institute of Standards and Technology, U.S. Department of Commerce: NIST GCR 06-906.

Guikema, S.D., Quiring, S.M., and Han, S-R. (2010) Prestorms Estimation of Hurricane Damage to Electric Power Distribution Systems, Natural Hazards, 30, 1744-1752.

Gustavsen, B., and Rolfseng, L. (2000) Simulation of wood pole replacement rate and its application to life cycle economy studies. IEEE Transactions on Power Delivery, 15, 300-306. 
Gustavsen, B., and Rolfseng, L. (2005) Asset management of wood pole utility structures. International Journal of Electrical Power \& Energy Systems, 27, 641-646.

Haldar, A., and Tucker, K. (2006)Condition Based Management of Wood Pole Transmission Lines Using Structural Reliability Analysis, ASCE Conf. Proc. 218, 28, 304-316.

Hatcher, M. (2009) The Price is Right for Many First-time Home Buyers. The Miami Herald. [cited 2009 April 21]; Available from: http://www.miamiherald.com/251/story/964599.html.

HM Treasury (2003) The Green Book: Appraisal and Evaluation in Central Government. HM Treasury, The Stationery Office, London.

Holmes, J. (1996) Vulnerability curves for buildings in tropical cyclone regions, Probabilistic Mechanics and Structural Reliability: Proceedings of the 7th Specialty Conference, $78-81$.

Huang, Z. (1999) Stochastic models for hurricane hazard analysis. PhD dissertation, Clemson University.

Huang, Z., Rosowsky, D. V., and Sparks, P. R. (2001). Long-term hurricane risk assessment and expected damage to residential structures. Reliability engineering \& system safety, 74, 239-249.

Hubbert, G.D., and McInnes, K. (1999) A Storm Surge Inundation Model for Coastal Planning and Impact Studies. Journal of Coastal Research, 15, 168-185.

Intergovernmental Panel on Climate Change (IPCC) (2007) Climate Change 2007: The Physical Science Basis. Contribution of Working Group I to the Fourth Assessment Report of the Intergovernmental Panel on Climate Change. Solomon, S., Qin, D., Manning, M., Chen, Z., Marquis, M., Averyt, K.B., Tignor, M., and Miller, H.L. (eds.). Cambridge: Cambridge University Press.

Irish, J.L., Resio, D.T., and Ratcliff, J.J. (2008) The Influence of Storm Size on Hurricane Surge. Journal of Physical Oceanography, 38, 2003-2013. 
Jagger, T., and J. Elsner, (2006) Climatology models for extreme hurricane winds in the United States. J. Climate, 19, 3220-3236.

Jackson, J.E. (1991) A User's Guide to Principal Components Analysis. John Wiley \& Sons: New York City.

Jain, V.K., and Davidson, R. (2007) Forecasting Changes in the Hurricane Wind Vulnerability of Regional Inventory of Wood-Frame Houses. Journal of Infrastructure Systems, 13, 31-42.

Jain, V.K., Davidson,R., and Rosowsky, D. (2005) Modeling changes in hurricane risk over time, Natural Hazards Review, 6, 88-96.

Jelesnianski, C. P., Chen, J., and Shaffter, W.A. (1994) SLOSH: Sea, Lake, and Overland Surges from Hurricanes, NOAA Technical Report NWS, 48, U.S. Department of Commerce, Sliver Springs, MD.

Jelesnianski, C.P. (1972) SPLASH: Special Program to List Amplitudes of Surges from Hurricanes I: Landfall storms. NOAA Technical Memo NWS-TDL-46, U.S. Department of Commerce, Sliver Springs, MD.

Jelesnianski, C.P. (1974) SPLASH: Special Program to List Amplitudes of Surges from Hurricanes I: Landfall General track and variant storm conditions. NOAA Technical Memo NWS-TDL-52, U.S. Department of Commerce, Sliver Springs, MD.

Johnson, B. (2005) After the Disaster: Utility Restoration Cost Recovery. Edison Electricity Institute, Washington D.C.

Jolliffe, I.T. (2002) Principal Components Analysis. Springer: New York City.

Kelman I. (2002). Physical Flood Vulnerability of Residential Properties in Coastal, Eastern England. Thèse, Université de Cambridge.

Khanduri, A.C., and Morrow, G.C. (2003) Vulnerability of buildings to windstorms and insurance loss estimation, Journal of wind engineering and industrial aerodynamics, 91, 455-467. 
Klima, K., Lin, N., Emanuel, K., Morgan, M.G., and Grossmann, I. (2012) Hurricane Modification and adaptation in Miami-Dade County, Florida, Environ. sci. Technol, 46, 636-642.

Klotzbach, P.J. (2006) Trends in global tropical cyclone activity over the past twenty years (1986-2005), Geophys. Res. Letters, 33.

Knuston, T.R., McBride, J.L., Chan, J., Emanuel, K., Holland, G., Landsea, C., Held, I., Kossin, J.P., Srivastava, A.K., and Sugi, M. (2010) Tropical Cyclones and Climate Change, Nature Geoscience, 3, 157-163.

Knutson, T. R., Sirutis, J. J., Garner, S. T., Vecchi, G. A., and Held, I. (2008) Simulated reduction in Atlantic hurricane frequency under twenty-first-century warming conditions, Nature Geosci., 1, 359-364.

Knutson, T.R., and Tuleya, R.E. (1999) Increased hurricane intensities with CO2 induced warming as simulated using the GFDL hurricane prediction system, Climate Dynamics, $15,503-519$.

Knutson, T.R., Tuleya, R.E., and Kurihara, Y. (1998) Simulated Increase of Hurricane Intensities in a CO2 Warmed Climate, Science, 279, 1018-1021.

Kwasinski, A., Weaver, W.W., Chapman, P.L., and Krein, P.T. (2009) Telecommunications Power Plant Damage Assessment for Hurricane Katrina- Site Survey and Follow-Up Results, Systems Journal, 3, 277-287.

Landsea, C.W. (2007) Counting Atlantic tropical cyclones back to 1990. EOS Trans. Am. Geophysical Union, 88, 197-208.

Landsea, C.W., Harper, B.A., Hoarau, K., and Knaff, .JA. (2006) Can we detect trends in extreme tropical cyclones? Science, 313, 452-454.

Larsen, P., Goldsmith, S., Smith, O., Wilson, M., Strzepek, K., Chinowsky, P., and Saylor, B. (2007) Estimating Future Costs for Alaska Public Infrastructure at Risk from Climate Change. Institute of Social and Economic Research, University of Alaska Anchorage. 
Larsen, T., Porter, K., Zadeh, M., Van Anne, C., and Scawthorn, C. (1996) Impact of Hurricane Andrew on performance, interaction, and recovery of lifelines, EQE International, San Francisco, CA.

Lavelle, F., Vickery, P. J., Schauer, B., Twisdale, L. A., and Laatsch, E. (2003) HAZUSMH Hurricane Model, Proc., 11th ICWE, Texas Tech, Lubbock, TX.

Lee, K., and Rosowsky, D. (2007) Synthetic hurricane wind speed records: development of a database for hazard analyses and risk studies, Nat. Hazard. Rev., 8, 23-34.

Leicester, R.H. (1981) A risk model for cyclone damage to dwellings, in Proc. 3rd Int. Conf. on Structural Safety and Reliability, 761-771.

Leicester, R.H., Bubb, C.T.J., Dorman, C., and Beresford, F.D. (1979) An assessment of potential cyclone damage to Dwellings in Australia, in Proc. 5th Int. Conf. on Wind Engineering, J.E. Cermak, Editor. Pergamon: New York, United States, 23-36.

Leicester, R.H., Wang, C.H., Minh, M.N., Thornton, J.D., Johnson, G.C., and Gardner, D. (2003) An engineering model for the decay of timber in ground contact. IRG/WP/03, 34th annual meeting, Brisbane, Australia, 19-23 May 2003.

Li, H., and Bhuyan, G. (2000) Reliability-Based Design of Transmission Line Structures, Structural Design, Analysis, and Testing, 357-366.

Li, H., Zhang, J. and Bhuyan, G. (2006) Reliability Assessment of Electrical Overhead Distribution Wood Poles, Probability Methods Applied to Power Systems, International Conference, 11-15 June, 2006, Stockholm.

Li, Y., and Ellingwood, B.R. (2006) Hurricane damage to residential construction in the US: Importance of uncertainty modeling in risk assessment. Engineering Structures, 28, 1009-1017.

Li, Y., and Ellingwood, B.R. (2009) Risk-based Decision Making for Multi-hazard Mitigation for Wood-frame Residential Construction. Australian Journal of Structural Engineering, 9, 17-26. 
Li, Y. and Stewart, M.G. (2011) Cyclone Damage Risks Caused by Enhanced Greenhouse Conditions and Economic Viability of Strengthened Residential Construction, Natural Hazards Review, ASCE, 12, 9-18.

Li, Y., van de Lindt, J.W., Dao, T., Bjarnadottir, S., and Ahuja, A. (2012) Loss Analysis for Combined Wind and Surge in Hurricanes, Natural Hazards Review, ASCE, 13, 1-10.

Louisiana Public Service Commission (LPSC) (2005) Emergency operations center, daily service outage repots- September 24, 2005 through October 17, 2005, December 9, 2005. Luettich Jr., R., Westerink, J., and Scheffner, N. (1992) ADCIRC: an advanced threedimensional circulation model for shelves coasts and estuaries, Report 1: Theory and methodology of ADCIRC-2DDI and ADCIRC-3DL, Dredging Research Program Tech. Rep. DRP-92-6, U.S. Army Engineers Waterways Experiment Station, Vicksburg, MS.

Lupoi, G., Franchin, P., Lupoi, A., and Pinto, P.E. (2006) Seismic Fragility Analysis of Structural Systems, J. Eng. Mech. 132, 385-396.

Malmedal, K., and Sen, P.K. (2003) Structural loading calculations of wood transmission structures. Rural Electric Power Conference, May 2003, 4-6.

Malmstadt, J.C., Elsner, J.B., and Jagger, T.J., (2010). Risk of Strong Hurricane Winds to Florida Cities. J. Appl. Meteor. Climatol., 49, 2121-2132.

Mankowski, M., Hansen, E., and Morrell, J. (2002) Wood Pole Purchasing, inspection, and maintaince: Survey of Utility Practices, Forests Products Journal, 52, 43-50.

Mann, M., and Emanuel, K. (2006) Atlantic hurricane trends linked to climate change, Eos 87, 233-241.

Mastenbroek, G., Burger, and Jansson, P. (1993) The dynamical coupling of wave model and a storm surge model through the atmospheric boundary layer, Journal of Physical Oceanography, 23, 1856-1866.

McCormac, J.C. (2008) Structural Steel Design. Pearson: New Jersey.

Miami-Dade County Department of Planning and Zoning (2003). Housing in MiamiDade County 2000. Planning Research Section: Miami. 
Mitsuta, Y., Fujii, T., and Nagashima, I. (1996) A Predicting method of typhoon wind damages, Probabilistic Mechanics and Structural Reliability: Proceedings of the 7th Specialty Conference, 970-973.

Moreno, D., Murray, N., Lerma, V., Gorski, A., Kerr, O., Gonzalez, D., Hurtado, C., and Smith, S. (2008) Miami-Dade County Workforce Housing Needs Assessment. Greater Miami Chamber of Commerce: Miami.

Morrell, J. (2005) Estimated Service Life of Wood Poles. Technical Bulletin for the NAWPC (North American Wood Pole Council).

Multi-hazard Mitigation Council (2005) Natural hazard mitigation saves: An independent study to assess the future savings from mitigation activities. National Institute of Building Sciences, Washington, D. C.

NAHB (1993) Assessment of Damage to Single-Family Homes Caused By Hurricane Andrew and Iniki, NAHB Research Center Report: Upper Marlboro, MD.

National Association of Home Builders (NAHB) (1993) Assessment of Damage to Single-Family Homes Caused By Hurricane Andrew and Iniki, NAHB Research Center Report, Upper Marlboro, MD.

National Atlas of the United States [cited 2009 August 24]; Available from: http://nationalatlas.gov

National Cooperative Highway Research Program (NCHRP) (2009) NCHRP \#20-83(5): Synthesis of Information on Projections of Change in Regional Climates and Recommendation of Analysis Regions. [cited 2012 February 12]; Available from: http://onlinepubs.trb.org/onlinepubs/nchrp/docs/NCHRP20-83\%2805\%29_Task24TechnicalReport.pdf

National Institute of Standards and Technology (NIST) (2009) Hurricane wind speeds. [cited 2011 August 30]; Available from: http://www.nist.gov/wind National Electrical Safety Code (NESC) (2002) IEEE Standard. Piscataway, New Jersey. 
National Research Council (NRC) (2000). Ecological Indicators for the Nation. National Academy Press: Washington D.C.

National Weather Service (NWS) (2009) Flood Losses: Compilation of Flood Loss Statistics. [cited 2010 August 04]; Available from: http://www.weather.gov/oh/hic/flood_stats/Flood_loss_time_series.shtml

Neumann, C.J. (1991) The National Hurricane Center Risk Analysis Program (HURISK), NOAA Technical Memo, HWS-NHC-22, U.S. Department of Commerce, Washington D.C.

New York City Panel on Climate Change (2009) Climate Change Adaptation in New York City: Building a Risk Management Response. New York Academy of Sceinces, 1196, May 2010.

National Oceanic and Atmospheric Administration (NOAA) (2009) Historical Hurricane Data. [cited 2010 September 10]; Available from: http://www.noaa.gov/

NOAA (2009a) Historical Hurricane Data [cited 2010 September 10]; Available from: http://www.noaa.gov/

NOAA (2009b) SLOSH Model [cited 2010 August 04]; Available from: http://slosh.nws.noaa.gov/

NOAA.(2009c) The Saffir Simpson Hurricane Wind Scale [cited 2010 September 06]; Available from: http://www.nhc.noaa.gov/aboutsshws.shtml National Research Council. (2000). Ecological Indicators for the Nation. National Academy Press: Washington D.C.

NOAA (2009d) Tsunami [cited 2011 April 2]; Available from: http://www.tsunami.noaa.gov/National Weather Service (NWS) (2009) Flood Losses: Compilation of Flood Loss Statistics. [cited 2010 August 04]; Available from: http://www.weather.gov/oh/hic/flood_stats/Flood_loss_time_series.shtml

NOAA (2009) Storm Surge Overview, The National Oceanic and Atmospheric Administration (NOAA), National Weather Service. [cited 2009 March 18]; Available from: http://www.nhc.noaa.gov/ssurge/ssurge_overview.shtml 
Office of Best Practice Regulation (OBPR) (2010) Best Practice Regulation Handbook. Australian Government, Canberra, June 2010.

Office of Management and Budget (OMB) (2003) Circular A-4. United States Office of Management and Budget, Washington, DC, September 172003.

Palutikof, J.P., Brabson, B.B., Lister, D.H., and Adcock, S.T. (1999) A reveiw of methods to calculate extreme winds, Meteorological Applications, 6, 119-132.

Parisi, F., and Lund, R. (2008): Return periods of continental U.S. hurricanes. J. Climate, $21,403-410$.

Peel, M. C., Finlayson, B. L., and McMahon, T. A. (2007) Updated world map of the Köppen-Geiger climate classification, Hydrol. Earth Syst. Sci. 11, 1633-1644.

Peters, G., DiGioia, A.M.J., Hendrickson, C., and Apt, J. (2006) Transmission Line Reliability: Climate Change and Extreme Weather, Electrical Transmission Line and Substation Structures, Proceedings of 2006 Electrical Transmission Conference, 12-26.

Pielke, R.A.J., and Pielke, R.A.S. (1997) Hurricanes: Their nature and impacts on society. Wiley, U.K.: Chichester.

Pielke, R.A.J., Gratz, J., Landsea, C.W., Collins, D., Saunders, M.A., and Musulin, R. (2008) Normalized Hurricane Damage in the United States: 1900--2005. Natural Hazards Review, 9, 29-42.

Pielke, R.A.J., Landsea, C., Mayeld, M., Laver, J., and Pasch, R. (2005) Hurricanes and global warming. Bulletin of the American Meteorological Society; 86, 1571-1575.

Pinelli, J.P., Simiu, E., Gurley, K., Subramanian, C., Zhang, L., Cope, A., Filliben, J.J., and Hamid, S. (2004) Hurricane Damage Prediction Model for Residential Structures, Journal of Structural Engineering, 130, 1685-1691.

Pinelli, J.P., Torkian, B.B., Gurley, K., Subramanian, C., and Hamid, S. (2009) Cost Effectiveness of Hurricane Mitigation Measures for Residential Buildings, The 11th Americas Conference on Wind Engineering (ACWE), San Juan, Puerto Rico. 
Pistrika A. and Jonkman S. (2010). Damage to residential buildings due to flooding of New Orleans after hurricane Katrina. Nat Hazards, 54, 413-434.

Porter, K.A. (2000) Assembly-based vulnerability of buildings and its uses in seismic performance evaluation and risk-management decision-making, Doctoral dissertation, Stanford University, Stanford CA.

Powell, M., Soukup, G., Cocke, S., Gulati, S., Morisseau-Leroy, N., Hamid, S., Dorst, N., and Axe, L. (2005) State of Florida hurricane loss projection model: atmospheric science component, J. Wind Eng. Ind. Aerodyn., 93, 651-674.

Powell, M.D., and Reinhold, T.A. (2007) Tropical cyclone destructive potential by integrated kinetic energy. Bulletin of the American Meteorological Society, 88, 513-526

Pratson, L.F., and Haxby, W.F. (1996) What is the slope of the U.S. continental slope? Geology, 24, 3-6.

Pryor, S.C., Barthelmie, R.J., and Takle, G.S. (2009) Wind speed trends over the contiguous USA, IOP Conference Series: Earth and Environmental Science.

Public Utility Commission of the State of Texas (PUCT) (2006) PUB investigation of methods to improve electric and telecommunications infrastructure to minimize long term outages and restoration costs associated with Gulf Coast hurricanes, Final Report, Project number 32812, Public Utility Commission of Texas, Austin.

Quanta Technology (2009) Cost-Benefit Analysis of the Deployment of Utility Infrastructure Upgrades and Storm Hardening Programs: Final Report, Public Utility Commission of Texas.

RealtyTrac Inc. (2008) Miami Beach. [cited 2009 June 11]; Available from: http://www.realtytrac.com/states/Florida/Miami-Dade-County/Miami-Beach.html

Reardon, G.F., and Henderson, D. (1988) Cyclone risk assessment of houses in North Queensland. J. Butterworth (Ed.), Australasian Structural Engineering Conference, Vol. 2, Structural Engineering Society of New Zealand, Auckland, 1007-1014. 
Reed, D.A. (2008) Electric utility distribution analysis for extreme winds, Journal of Wind Engineering and Industrial Aerodynamics, 96, 123-140.

Reed, D.A., Powell, M.D., and Westerman, J.M. (2010) Energy Infrastructure Damage Analysis for Hurricane Rita, Natural Hazards Review, 11, 102-109.

Rodríguez, R. W., Webb, R. M. T., and Bush, D. M. (1994) Another Look at the Impact of Hurricane Hugo on the Shelf and Coastal Resources of Puerto Rico, U.S.A. Journal of Coastal Research, 10, 278-296.

Roliadi, H., Hse, C.Y., Choong, E.T, and Shupe, T.F. (2000) Decay Resistance of out-ofservice utility poles as related to the distribution of residual creosote content, Forest Products Journal, 17, 149-159.

Roth, R.J. (1997) Insurable risks, regulation, and the changing insurance environment, in Hurricanes: Climates and socioeconomic impacts, H.F. Diaz and R.S. Pulwarthy, Editors. Springer: Berlin, Germany; 261-272.

Rumpf, J., Weindl, H., Hoppe, P., Rauch, E., and Schmidt, V. (2007) Stochastic modeling of tropical cyclone tracks, Math. Meth. Oper. Res., 66, 475-490.

Russell, L.R. (1968) "Probability distribution for Texas Gulf Coast hurricane efforts of engineering interest", Ph.D. thesis, Stanford University.

Saadat, H. (2002) Power System Analysis. McGraw Hill: New York City

Saaty, T.L. (1990) The Analytical Hierarchy Process. PWS Publications: Pittsburg, Pennsylvania.

Sanders, C. H., and Phillipson, M. C. (2003). UK adaptation strategy and technical measures: the impacts of climate change on buildings, Building Research \& Information. Building Research \& Information, 31, $210-221$.

Scavia, D., Field, J.C., Boesch, D.F., Buddemeier, R., Burkett, V., Canyan, D., Fogarty, M., Harwell, M.A., Howarth, R.W., Mason, C., Reed, D.J., Royer, T.C., Sallenger, A.H. and Titus, J.G. (2002) Climate change impacts on U.S. coastal and marine ecosystems, Estuaries, 25, 149-164. 
Scawthorn, C., Blais, N., Seligson, H., Tate, E., Mifflin, E., Thomas, W., Murphy, J., and Jones, J. (2006) HAZUS-MH Flood Loss Estimation Methodology 1: Overview and Flood Hazard Consideration, Natural Hazards Review, 60-71.

Schwartz, N. (2011) Violent wind storm leaves path of destruction [cited 2011 December 2]; Available from: http://www.businessweek.com/

Sill, B.L., and Kozlowski, R.T. (1997) Analysis of storm damage factors for low-rise structures, Journal of Performance of Constructed Facilities, 11, 168-176.

Skinner, R.L. (2006) Review of Hurricane Katrina Activities, Department of Homeland Security: Washington, D.C.

Sparks, P.R., Schiff, S.D., and Reinhold, T.A. (1994) Wind damage to envelopes of houses and consequent insurance losses, Journal of wind engineering and industrial aerodynamics, 53, 145-155.

Stainforth, D. A. (2005) Uncertainty in predictions of the climate response to rising levels of greenhouse gases, Nature, 433, 403-406.

Steenbergen, R.D.J.M., Koster, T., and Geurts, C.P.W. (2012) The effect of climate change and natural variability on wind loading values for buildings. Building and Environment, 55, 178-188.

Stewart, M.G. (1997) Time-Dependent Reliability of Existing RC Structures, Journal of Structural Engineering, ASCE, 123,896-903.

Stewart, A.H. and Goodman, J.R. (1990) Life cycle economics of wood pole utility structures, Power Delivery, IEEE Transactions, 5,1040-1046.

Stewart, M G., and Val, D.V. (1999) Role of load history in reliability-based decision analysis of aging bridges, Journal of structural engineering, 125, 776-783.

Stewart, M. G. and Wang, X. (2011b) Risk Assessment of Climate Adaptation Strategies for Extreme Wind Events in Queensland, CSIRO Climate Adaptation Flagship, Canberra, May 2011b [cited 2012 February 30]; Available from: 
http://www.csiro.au/resources/ /media/CSIROau/Flagships/Climate\%20Adaptation/Extre meWind_CAF_pdf\%20Standard.pdf

Stewart, M.G. and Wang, X. (2011a), Risk assessment and economic viability of climate adaptation measures for Australian housing subject to extreme wind events, MODSIM, 19th International Congress on Modelling and Simulation, Perth, 2852-2858.

Stewart, M.G., and Li, Y. (2010) Methodologies for Economic Impact and Adaptation Assessment of Cyclone Damage Risks Due to Climate Change, Australian Journal of Structural Engineering, 10, 121-136.

Stewart, M.G., Rosowsky, D.V., and Huang, Z. (2003) Hurricane Risks and Economic Viability of Strengthened Construction, Natural hazards review, 4, 12-19.

Stewart, M.G. and Wang, X. (2011a), Risk assessment and economic viability of climate adaptation measures for Australian housing subject to extreme wind events, MODSIM, 19th International Congress on Modelling and Simulation, Perth, 2852-2858.

Stewart, M. G. and Wang, X. (2011b) Risk Assessment of Climate Adaptation Strategies for Extreme Wind Events in Queensland, CSIRO Climate Adaptation Flagship, Canberra, May 2011b [cited 2012 February 30]; Available from: http://www.csiro.au/resources/ /media/CSIROau/Flagships/Climate\%20Adaptation/Extre meWind_CAF_pdf\%20Standard.pdf

Stubbs, N., and Perry, D.C. (1996) A damage simulation model for buildings and contents in a hurricane environment, in Building an International Community of Structural Engineers- Proc. Structures Congress S.K. Ghosh and J. Mohammadi, Editors., ASCE: New York, United States, 989-996.

Taggart, M. and van de Lindt, J.W. (2009) Performance-Based Design of Residential Wood-Frame Buildings for Flood Based on Manageable Loss, Journal of Perfor-mance of Constructed Facilities, ASCE, 23, 2, 56-64.

Taggart, M. (2007) Performance-Based Design of Woodframe Structures for Flooding. M.Sc. Thesis, Colorodo State University, Fort Collins, CO. 
Unanwa, C.O., and McDonald, J.R. (2000) Building wind damage prediction and mitigation using damage bands, Natural Hazards Review, 4, 197-203.

United Nations Development Program (UNDP) (2000) Human Development Report 2000, Oxford Press: New York.

US Census Bureau (2009): State and County Quick Facts. [cited 2009 April 14]; Available from: http://quickfacts.census.gov/qfd/states/12/12086.html.

US Federal Insurance Administration (FIA) (1970) Flood Hazard Factors, Depth-Damage Curves, Elevation Frequency Curves, Standard Tables.

U.S. Geological Survey (USGS) (2007) U.S. EEZ Atlantic Continental Margin GLORIA. [cited 2012 May 25]; Available from: http://coastalmap.marine.usgs.gov/gloria/eastcst/geology.html

US Census Bureau (2009): State and County Quick Facts. [cited 2009 April 14]; Available from: http://quickfacts.census.gov/qfd/states/12/12086.html.

USACE (1970) Guidelines for Flood Insurance Studies. U.S. Army Corps of Engineers: Washington, D.C.

USACE (2000) Generic depth-damage relationships. U.S. Army Corps of Engineers: Washington, D.C.

USACE (2003) Generic depth-damage relationships for residential structure with basements. U.S. Army Corps of Engineers: Washington, D.C.

Utility Solid Waste Activities Group (USWAG). (2005) Notice of Availability of the Preliminary Risk Assessment for Wood Preservatives Containing Pentachlorophenol Reregistration Eligibility Decision, 1-13.

Vanderbilt, M D., Criswell, M.E., Folse, M.D., and Landers, P.G. (1982) ProbabilityBased Design of Wood Transmission Line Structures Electric Power Research Institute Project RP-1352-1: A Status Report, IEEE transactions on power apparatus and systems, 2451-2459. 
Van der Sande, C.J., de Jong, S.M., and de Roo, A.P.J. (2003) A segmentation and classification approach of IKONOS-2 imagery for land cover mapping to assist flood risk and flood damage assessment, International Journal of Applied Earth Observation and Geoinformation, 217-229.

Verboom, G.K., de Ronde, J.G., and van Dijk, R.P. (1992) A fine grid tidal flow and storm surge model of the North Sea. Continental Shelf Research. 12, 213-233.

Vickery, P.J. and Twisdale, L.A.Jr (1995) Wind-Field and Filling Models for Hurricane Wind-Speed Predictions. Journal of Structural Engineering, 121, 1700-1709.

Vickery, P.J., Adhere, D., Teasdale, L.A.Jr., and Lavelle, F.M. (2009) U.S. Hurricane Wind Speed Risk and Uncertainty. Journal of Structural Engineering, 135, 301-320.

Vickery, P.J., Skerlj, P.F., and Twisdale, L.A.Jr (2000) Simulation of Hurricane Risk in the U.S. Using Empirical Track Model. Journal of structural engineering, 126, 12221237.

Vickery, P.J., Skerlj, P.F., Lin, J., Twisdale, L.A.Jr., Young, M.A., and Lavelle, F.M. (2006) HAZUS-MH Hurricane Model Methodology. II: Damage and Loss Estimation. Natural Hazards Review, 7, 94-103.

Vickery, P.J., Wadhera, D., Twisdale, L.A.Jr., and Lavelle, F.M. (2009) U.S. Hurricane Wind Speed Risk and Uncertainty, Journal of Structural Engineering, 135, 301-320.

Viscusi, W.K. (2007) Rational Discounting for Regulatory Analysis, The University of Chicago Law Review, 74, 209-246.

Walsh, K., Cai, W.J., Hennessy, K., Jones, R., McInnes, K., Nguyen, K., Page, C., and Whetton, P. (2002) Climate change in Queensland under enhanced greenhouse conditions: Final Report, 1997-2002., ed. A.R. Australian Commonwealth Scientific and Research Organization (CSIRO), Australia.

Wang, C.-h., Leicester, R.H., and Nguyen, M. (2008a) Decay in ground. Forest and Wood Products Austrailia. CSIRO. 
Wang, C.-h., Leicester, R.H., and Nguyen, M. (2008b) Probabilistic procedure for design of untreated timber poles in-ground under attack of decay fungi, Reliability Engineering \& System Safety, 93, 476-481.

Webersik, C., Esteban, M. and Shibayama, T. (2010) The economic impact of future increase in tropical cyclones in Japan, Natural Hazards, 55, 233-250.

Webster, P.J., Holland, G.J., Curry, J.A., and Chang, H.R. (2000) Changes in Tropical Cyclone Number, Duration, and Intensity in a Warming Environment. Science, 309, 1844-1846.

Wen, Y.K. (2001) Minimum lifecycle cost design under multiple hazards. Reliability and System Safety, 73, 223-231.

Westerink, J., Luettich Jr., R., Feyen, J., Atkinson, J., Dawson, C., Powell, M., Dunion, J., Roberts, H., Kubatko, E., and Pourtaheri, H. (2008) A basin-to-channel-scale unstructured grid hurricane storm surge model as implemented for Southern Louisiana, Mon. Weather Rev., 136, 833-864.

Westerink, J.J., Luettich, R.A., Baptista, A.M., Scheffner, N.W., and Farrar, P. (1994) Tide and Storm Surge Predictions using the Finite Element Model. J. Hydraul. Eng., 118, 373-1390.

Westerink, J. J., Luettich, R.A.J., and Scheffner, N. W. (1994) ADCIRC: An advanced three-dimensional circulation model for shelves, coasts and estuaries, Report 2: Users manual for ADCIRC-2DDI, Dredging Research Program Technical Report DRP-94-6 Department of Army, United States Army Corps of Engineers, Waterways Experiment Station, Vicksburg, Mississippi.

White House (2009) Global Climate Change Impacts in the United States, U.S. Global Change Research Program. Washington, D.C. http://downloads.globalchange.gov/usimpacts/pdfs/climate-impacts-report.pdf.

Winkler, J., Dueñas-Osorio, L, Stein, R, and Subramanian, D. (2010) Performance assessment of topologically diverse power systems subjected to hurricane events, Reliability Engineering and System Safety, 95, 323- 336. 
Wolfe, R., Bodig, J., and Lebow, P. (2001) Derivation of Nominal Strength for Wood Utility Poles, Forest Products Laboratory. U.S. Department of Agriculture.

Wolfe, R. and Kluge, R. O. (2005) Designated Fiber Stress of Wood Poles, Forest Products Laboratory. U.S. Department of Agriculture.

Wolfe, R. and Moody, R. (1997) Standard Specifications for Wood Poles, Forest Products Laboratory. U.S. Department of Agriculture.

Woods and Poole Economics, Inc. (W\&PE) (2003) 2003 Desktop Data Files. W\&PE, Washington, DC.

World Bank. (2001). World Development Indicators. $<$ www.worldbank.org/wdi2001/enviornment.htm>

Wu, S-Y., Yarnal, B., and Fisher, A. (2002) Vulnerability of coastal communities to sealevel rise: a case study of Cape May County, New Jersey, USA, Climate Research, 22, 255-270.

Wurtele, M., Paegle, J., and Sielecki, A. (1971) The use of open boundary conditions with the storm-surge equations, Monthly Weather Review, 99, 537-544.

Zhai, X., and Stewart, M.G. (2010) Structural reliability analysis of reinforced grouted concrete block masonry walls in compression, Engineering Structures, 32, 106-114.

Zigomanis, A. (2007) Land Prices Still Challenge for New Housing Market. Property Council of Australia. [cited 2009 April 21]; Available from: http://www.propertyoz.com.au/Article/NewsDetail.aspx?id=15. 


\section{Appendix I}

\section{Supplement to 'A Probabilistic-based Framework for Impact and Adaptation Assessment of Climate Change on Hurricane Damage Risks and Costs'}

Although not published, hurricane damage risks and costs were determined for three separate counties (Miami-Dade County, Florida, New Hanover County, North Carolina, and Galveston County, Texas). A regional analysis of this nature is used to confirm the possible effects of climate change on hurricane damage costs across the United States. The procedures used to estimate the damage risks are the same as for the published work 'A Probabilistic-based Framework for Impact and Adaptation Assessment of Climate Change on Hurricane Damage Risks and Costs' (Chapter 2); and are, therefore, not included in this supplement. In addition, the adaptation measures outlined in Chapter 2 were implemented within each county and the cost-effectiveness of each was evaluated. For comparison purposes the results for Miami-Dade County are included with the following results.

\section{Al.1 Hurricane Damage Risks and Cost}

The demographic information from the U.S. Census Bureau (2009) was compiled to estimate the hurricane damage risk in each of the three counties. The demographic information and how it influences wind field and economic characteristics are summarized in Table AI.1. The site-specific Weibull parameters at year 1, $\mathrm{u}(1)$ and $\alpha(1)$, the mean maximum wind speed at year 1, the number of single-family housing units, the housing distribution (i.e. \% of houses located foreshore-\% of houses located within 10 
$\mathrm{km}-\%$ of houses located further than $10 \mathrm{~km}$ ), and the median insured house value are included in the table for each county.

Table AI.1: Demographic information for each county used to estimate the hurricane damage

\begin{tabular}{|c|c|c|c|}
\hline Parameter & $\begin{array}{c}\text { Miami-Dade } \\
\text { County }\end{array}$ & $\begin{array}{c}\text { New Hanover } \\
\text { County }\end{array}$ & $\begin{array}{c}\text { Galveston } \\
\text { County }\end{array}$ \\
\hline $\mathrm{u}(1)$ & 27.4 & 19.9 & 23.4 \\
$\alpha(1)$ & 1.8 & 1.6 & 1.8 \\
Mean Wind Speed (year 1) & $24.3 \mathrm{~m} / \mathrm{s}$ & $18.0 \mathrm{~m} / \mathrm{s}$ & $21.0 \mathrm{~m} / \mathrm{s}$ \\
Single-family Housing & 452,000 & 58,200 & 56,300 \\
Units & $20-60-20$ & $20-70-10$ & $20-30-50$ \\
Housing Distribution & $\$ 147,000$ & $\$ 191,100$ & $\$ 82,000$ \\
Insured House Value & & & \\
\hline
\end{tabular}

A comparison of the expected cumulative damage after 50 years under various climate change scenarios for each of the exposure sites, at each case study location, is shown on Table AI.2. For example, the expected cumulative damage for Miami-Dade County at foreshore locations is about $300 \%$ higher than the expected cumulative damage in New Hanover County and 200\% higher than Galveston County for all scenarios of climate change. 
Table AI.2: The expected cumulative damage after 50 years under various climate change scenarios $(-5 \%, 0 \%, 5 \%, 10 \%)$

\begin{tabular}{|c|c|c|c|c|}
\hline \multicolumn{5}{|c|}{ Foreshore } \\
\hline & $-5 \%$ & $0 \%$ & $5 \%$ & $10 \%$ \\
\hline Miami-Dade County & $134 \%$ & $116 \%$ & $155 \%$ & $177 \%$ \\
\hline New Hanover County & $334 \%$ & $29 \%$ & $40 \%$ & $47 \%$ \\
\hline Galveston County & $44 \%$ & $37 \%$ & $51 \%$ & $61 \%$ \\
\hline \multicolumn{5}{|c|}{10 km inland } \\
\hline Miami-Dade County & $57 \%$ & $67 \%$ & $78 \%$ & $91 \%$ \\
\hline New Hanover County & $14 \%$ & $16 \%$ & $19 \%$ & $22 \%$ \\
\hline Galveston County & $17 \%$ & $20 \%$ & $24 \%$ & $28 \%$ \\
\hline \multicolumn{5}{|c|}{ Other locations } \\
\hline Mew Hanover County & $7 \%$ & $8 \%$ & $10 \%$ & $11 \%$ \\
\hline Galveston County & $9 \%$ & $10 \%$ & $12 \%$ & $14 \%$ \\
\hline
\end{tabular}

To normalize the damage risk, Figure AI.1 shows the cumulative damage cost after 50 years per 100,000 residents for all three counties under various scenarios of climate change. From this figure it can be seen that Miami-Dade County has considerably higher expected cumulative damage cost per 100,000 residents than the other two counties. If no climate change is assumed, the cumulative damage costs is $\$ 1,600$ million per 100,000 residents in Miami-Dade County, $\$ 620$ million per 100,000 residents in New Hanover County, and \$240 million per 100,000 residents in Galveston County. These figures increase to $\$ 1,840$ million, $\$ 720$ million, and $\$ 280$ million for Miami-Dade County, New 
Hanover County, and Galveston County, respectively, under an assumed increase in wind speed of $5 \%$.

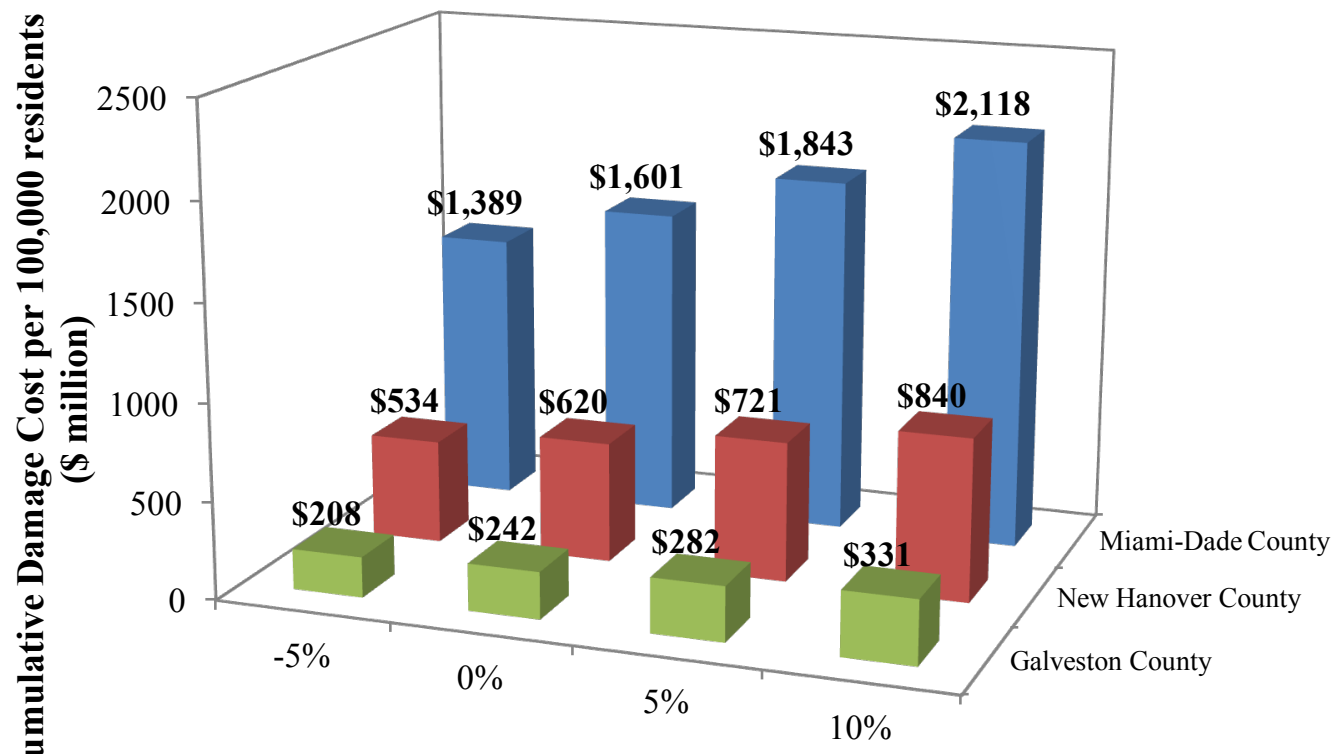

Wind Speed Change after 50 years

Figure AI.1: Cumulative damage cost per 100,000 residents to single-family units under different changes in wind speeds

Figure AI.2 shows the percentage increase in cumulative damage costs from the no climate change scenario to various changes in wind speeds. From this figure it can be seen that despite the considerable differences in potential damage costs, the percentage change from no climate change to various changes in wind speed is similar for all the counties. Therefore, wind speed changes may have a considerable effect on the cumulative damage cost to an individual county even though the damage cost seems insignificant in comparison to other more high risk counties, such as Miami-Dade County. 


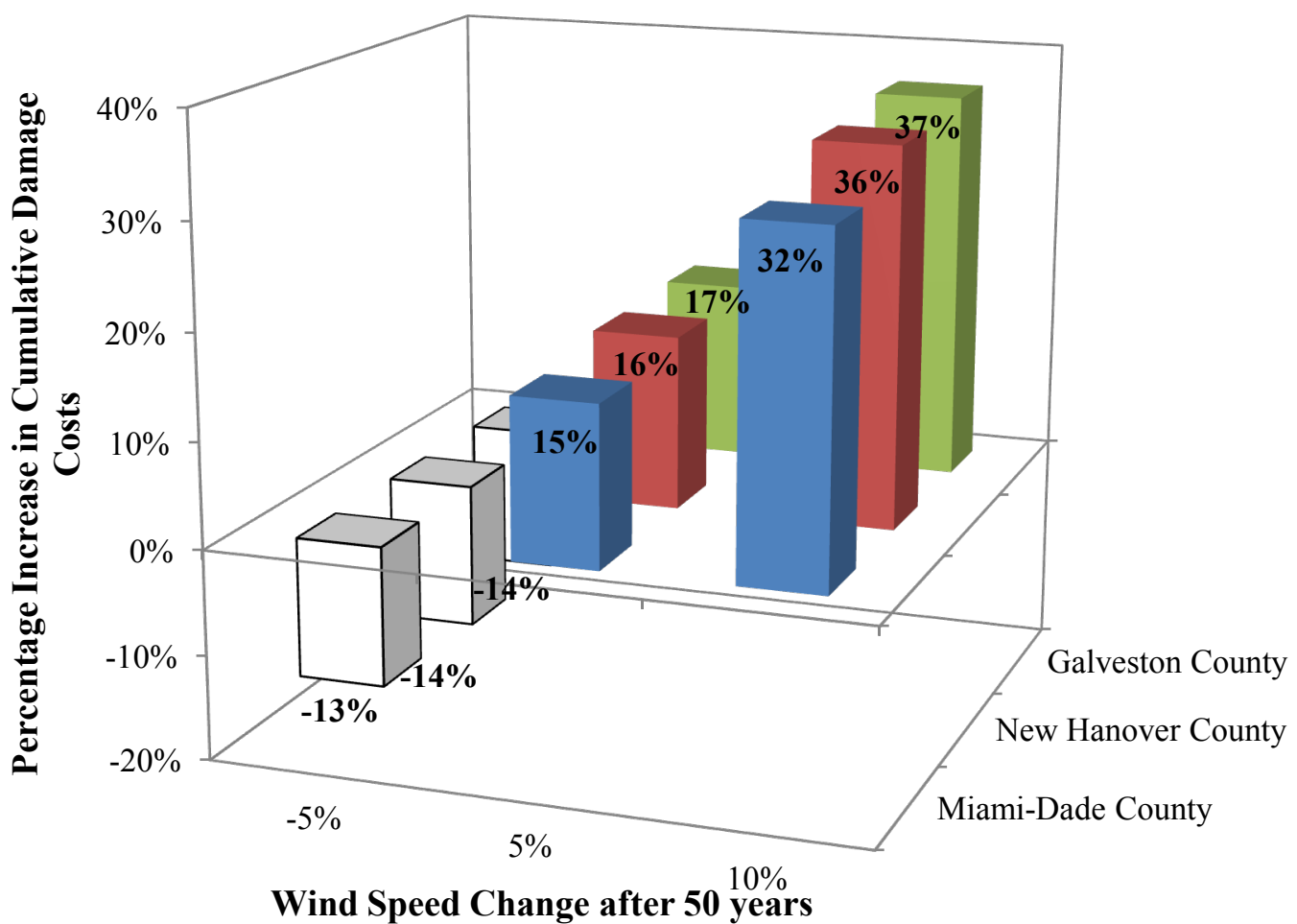

Figure AI.2: Percentage change in cumulative regional damage under different changes in wind speeds

\section{Al.2 Cost-Benefit Analysis of Adaptation Strategies}

The cost-effectiveness of the adaptation strategies varies significantly among the three counties, mainly due to the fact that the expected annual damage in Miami-Dade County is considerably higher than that of the two other case study locations. All adaptation strategies were found to be cost-effective for Miami-Dade County if the cost of retrofit is not greater than $10 \%$. In comparison, for New Hanover and Galveston Counties, the cost of retrofit would have to be as low as $3 \%$ for all strategies to be cost-effective.

Table AI.3 shows the net benefit for adaptation strategies 1 through 4 for Miami-Dade County, New Hanover County, and Galveston Counties, respectively, under an increase in wind speed of 5\% and for no change in wind speed. The net benefit, seen on Table AI.3, is calculated for a fixed rate of retrofit of $n=3 \%$ (i.e. all houses retrofitted within 34 years), as it is assumed that this is a reasonable annual rate of retrofit for the region. The cost of retrofit varies from $1 \%$ to $25 \%$. 
From Table AI.3, it can be seen that under an increase in wind speed of $5 \%$, adaptation strategy 2 could result in a net benefit of $\$ 1.06$ billion for Miami-Dade County over 50 years, if the cost of retrofit is $10 \%$ and the annual rate of retrofit is $3 \%$. Even if there is no change in wind speed, and rate and cost of retrofit were unchanged, adaptation strategy 2 could result in a net benefit of $\$ 780$ million over 50 years. This implies that certain adaptation strategies could result in a "win-win" situation for society irrespective of climate change predictions. Similarly to the results for Miami-Dade County, adaptation strategies for New Hanover and Galveston Counties were often found to be cost-effective even if there is no change in wind speed, see Table AI.3. 
Table AI.3: Comparing the net benefit (\$ million) for adaptation strategies with increase in wind speed of $5 \%$ and $0 \%$ for Miami-Dade County, New Hanover County, and Galveston County (annual retrofit rate $\mathbf{n}=\mathbf{3 \%}$ )

\begin{tabular}{|c|c|c|c|c|c|c|c|c|c|c|}
\hline & & & \multicolumn{2}{|c|}{ Strategy 1} & \multicolumn{2}{|c|}{ Strategy 2} & \multicolumn{2}{|c|}{ Strategy 3} & \multicolumn{2}{|c|}{ Strategy 4} \\
\hline & & & $0 \%$ & $5 \%$ & $0 \%$ & $5 \%$ & $0 \%$ & $5 \%$ & $0 \%$ & $5 \%$ \\
\hline \multirow{5}{*}{ 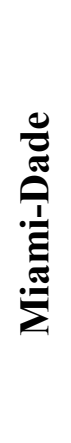 } & \multirow{5}{*}{$\begin{array}{c}\text { Cost of } \\
\text { Retrofit } \\
\left(C_{s t}\right)\end{array}$} & $1 \%$ & 610 & 690 & 1820 & 2100 & 910 & 1030 & 2690 & 3100 \\
\hline & & $2.5 \%$ & 580 & 660 & 1650 & 1930 & 850 & 970 & 2390 & 2810 \\
\hline & & $5 \%$ & 520 & 600 & 1360 & 1640 & 750 & 870 & 1900 & 2310 \\
\hline & & $10 \%$ & 400 & 480 & 780 & 1060 & 550 & 670 & 900 & 1320 \\
\hline & & $25 \%$ & 60 & 140 & -950 & -670 & -40 & 70 & -2070 & -1650 \\
\hline \multirow{5}{*}{ 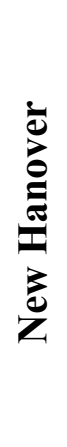 } & \multirow{5}{*}{$\begin{array}{l}\text { Cost of } \\
\text { Retrofit } \\
\quad\left(\mathrm{C}_{\mathrm{st}}\right)\end{array}$} & $1 \%$ & 18.1 & 21.2 & 50 & 59.9 & 24.9 & 29.4 & 67.1 & 81.3 \\
\hline & & $2.5 \%$ & 15.3 & 18.5 & 36.4 & 46.3 & 20.4 & 24.5 & 42.5 & 56.7 \\
\hline & & $5 \%$ & 10.8 & 13.9 & 13.7 & 23.6 & 11.8 & 16.3 & 1.5 & 15.7 \\
\hline & & $10 \%$ & 1.7 & 4.9 & -31.6 & -21.7 & -4.6 & -0.1 & -80.5 & -66.3 \\
\hline & & $25 \%$ & -25.5 & -22.3 & -167.7 & -157.8 & -53.8 & -49.3 & -326.5 & -312.3 \\
\hline \multirow{5}{*}{$\frac{5}{0}$} & \multirow{5}{*}{$\begin{array}{l}\text { Cost of } \\
\text { Retrofit } \\
\quad\left(C_{s t}\right)\end{array}$} & $1 \%$ & 11.7 & 13.8 & 31 & 37.6 & 15.9 & 18.9 & 40.9 & 50.3 \\
\hline & & $2.5 \%$ & 9.7 & 11.8 & 21.2 & 27.8 & 12.4 & 15.4 & 23.3 & 32.7 \\
\hline & & $5 \%$ & 6.4 & 8.6 & 4.9 & 11.5 & 6.5 & 9.5 & -6 & 3.3 \\
\hline & & $10 \%$ & -0.1 & 2 & -27.8 & -21.2 & -5.2 & -2.2 & -64.7 & -55.3 \\
\hline & & $25 \%$ & -19.7 & -17.6 & -125.9 & -119.3 & -40.4 & -37.4 & -240.7 & -231.3 \\
\hline
\end{tabular}

Adaptation strategy 5 involved strengthening only new construction built at foreshore locations. Table AI.4 summarizes the net benefit for all three counties, under increases in wind speed of 5\% and $0 \%$, for Strengthened Construction Type I and Type II. From the table it can be seen that reducing the vulnerability of new construction by $80 \%$ is more cost-effective than reducing the vulnerability of new housing by $50 \%$, if the cost of 
strengthening stays the same. From Table AI.4, it is evident that adaptation strategy 5 could be cost-effective if wind speeds in the three counties remain constant over a 50 year time frame. This implies that this adaptation strategy could result in a "win-win" situation for society.

Table AI. 4: The net benefit (\$ million) for adaptation strategy 5 with increase in wind speed of $5 \%$ and of $0 \%$ for Strengthened Construction Type I and Type II for three counties

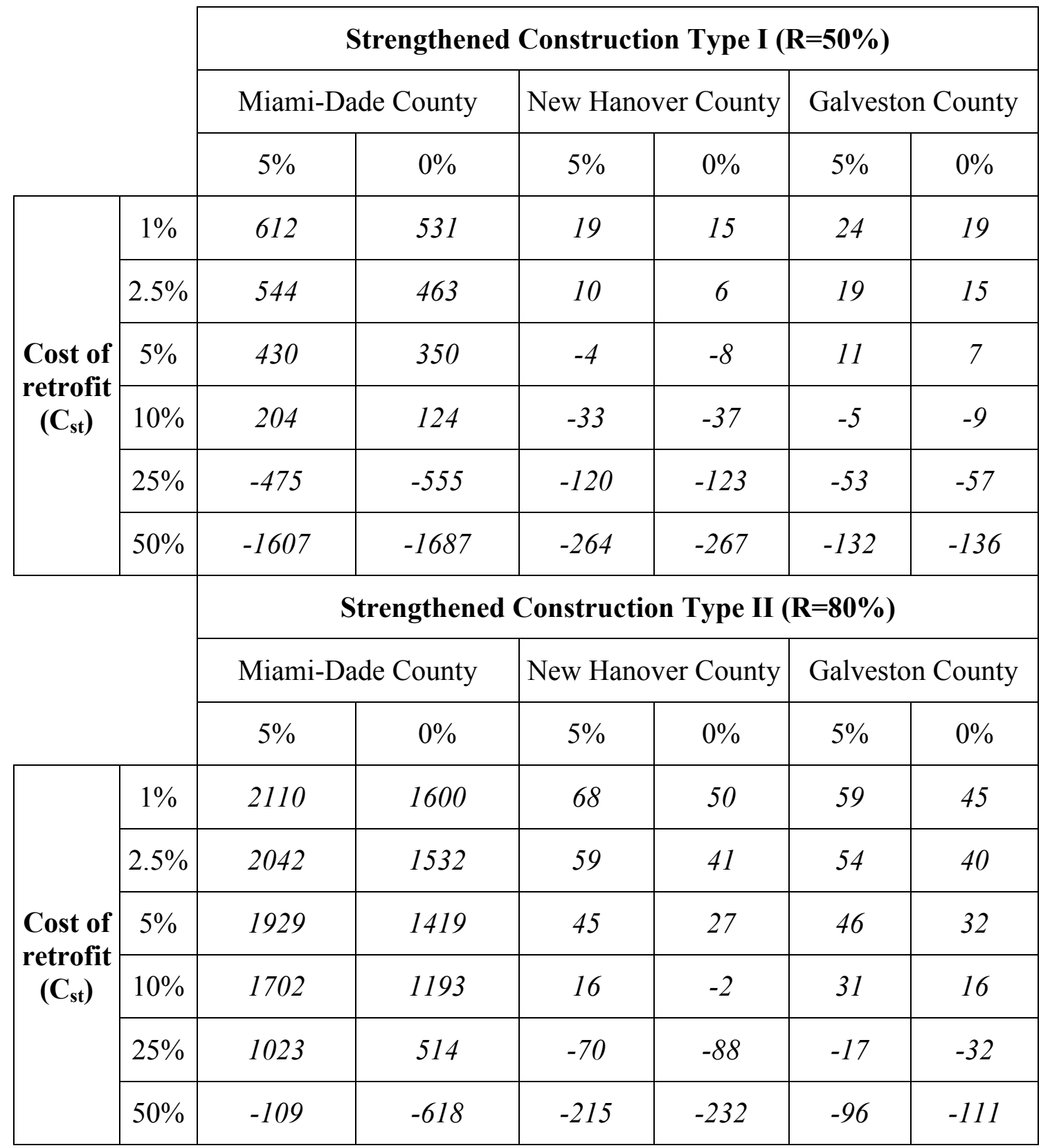


Figure AI.3 shows the various combinations of reduced vulnerability (R) and cost of retrofit $\left(\mathrm{C}_{\mathrm{st}}\right)$ for adaptation strategy 5 that result in a net benefit of zero, i.e. breakeven point, for a time period of 50 years, under an assumed increase in wind speed of $5 \%$. The area above each line shows for what combinations the strategy is not cost effective, while the area below represents the cost effective combinations. From this figure it can be seen that adaptation strategy 5 is not cost effective for reduction in vulnerability that is less than $40 \%$. Reducing the vulnerability of new construction at foreshore locations by $40 \%$ could is cost effective if the cost of retrofit is not greater than $8 \%$. In contrast, reducing the vulnerability of new construction by $70 \%$ could be cost effective at a cost of retrofit as high as $32 \%$.

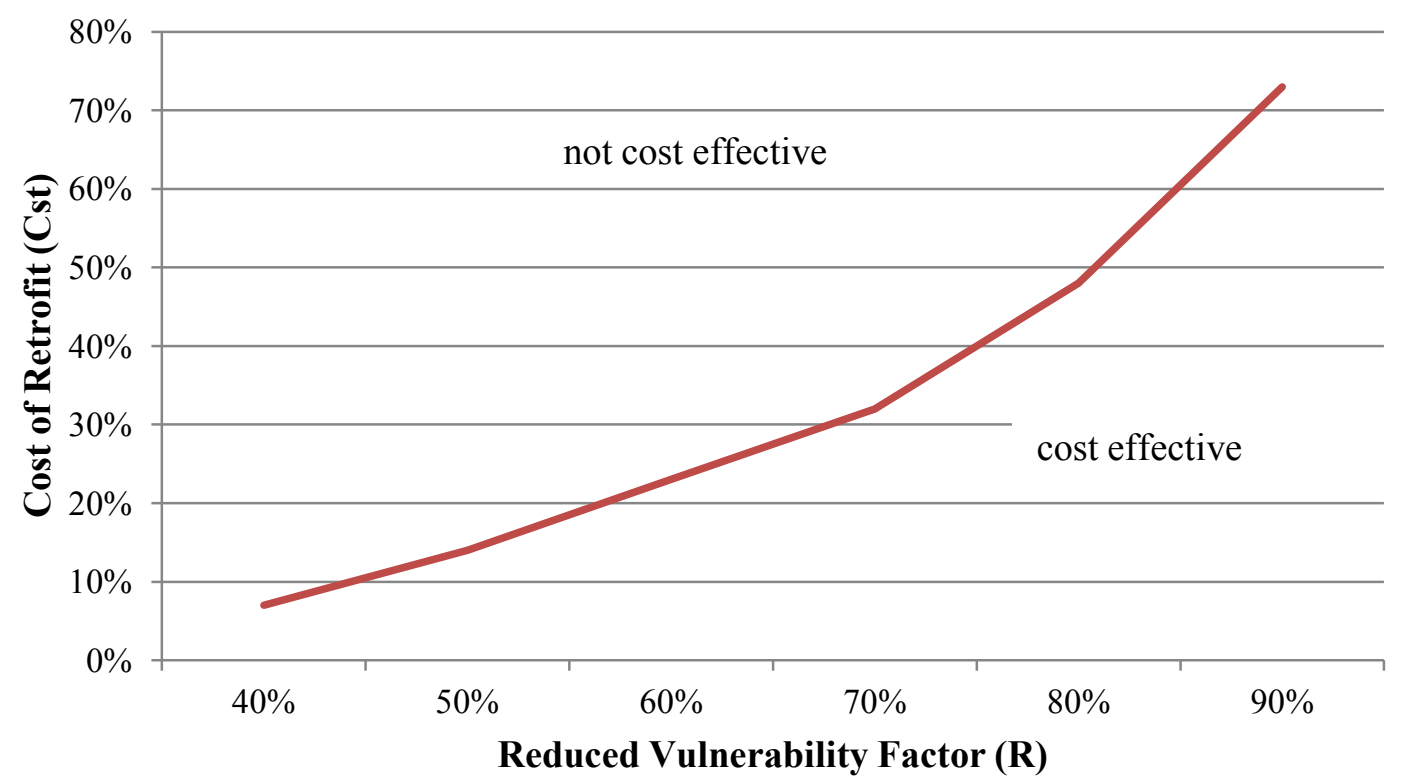

Figure AI.3: Combinations of $\mathrm{C}_{\mathrm{st}}$ and $\mathrm{R}$ in which the net benefit is zero over 50 years for adaptation strategy 5 for Miami-Dade County (5\% increase in wind speed)

The adaptation strategies were ranked individually for the three counties, summarized in Table AI.5. The rankings are based on how cost-effective the strategies are for each county and also how probable they are in implementation for each county. Adaptation strategy 2 was found to be the most economically viable for Miami-Dade County, despite being an unlikely option for New Hanover and Galveston Counties, because of the large 
number of houses needed to be retrofitted for its implementation. Strategy 2 is most economic for Miami-Dade County because of the high expected annual damage for foreshore locations there. As mentioned before, the annual expected damage at foreshore locations in Miami-Dade County is $2.7 \%$, compared to $0.7 \%$ for New Hanover County and $0.9 \%$ for Galveston County, so reducing vulnerability provides a higher net benefit for Miami-Dade County.

Adaptation strategy 1 was the most likely option for both New Hanover and Galveston Counties, because it can be undertaken at the highest cost of retrofit. Adaptation strategy 4 was the least likely option for all three counties, because of the sheer number of houses the strategy requires to be implemented. Adaptation strategy 5 is recommended in all counties, because it causes the least disruption while being cost-effective. Adaptation strategy 5 was found to be cost-effective for the three counties under current climate conditions, i.e. no climate change, which could result in a "win-win" situation for the regions.

Table AI.5: The ranking for the adaptation strategies in each of the counties

\begin{tabular}{|c|c|c|c|}
\hline & Miami-Dade County & New Hanover County & Galveston County \\
\hline $\mathbf{1}^{\text {st }}$ place & 2 and 5 & 1 and 5 & 1 and 5 \\
\hline $\mathbf{2}^{\text {nd }}$ place & 3 & 3 & 3 \\
\hline $\mathbf{3}^{\text {rd }}$ place & 1 & 2 & 2 \\
\hline $\mathbf{4}^{\text {th }}$ place & 4 & 4 & 4 \\
\hline
\end{tabular}

\section{Al.3 References}

US Census Bureau (2009): State and County Quick Facts. [cited 2009 April 14]; Available from: http://quickfacts.census.gov/qfd/states/12/12086.html. 


\section{Appendix II}

\section{Supplement to 'Risk-Based Economic Assessment of Mitigation Strategies for Power Distribution Poles Subjected to Hurricanes'}

In addition to the LCC analysis presented in the published work 'Risk-Based Economic Assessment of Mitigation Strategies for Power Distribution Poles Subjected to Hurricanes' (Chapter 5), a scenario-based analysis of the cost effectiveness of the mitigation strategies presented was conducted. A scenario-based analysis involves conducting an assessment of the cost effectiveness of a mitigation strategy considering a specific event (e.g. Saffir-Simpson Hurricane Category 4 or a hurricane with a wind speed of $130 \mathrm{mph}(58 \mathrm{~m} / \mathrm{s}))$.

\section{All.1 Mitigation of Timber Distribution Poles considering a Scenario- Based Analysis}

To assess the cost effectiveness of the mitigation strategies for the scenario-based analysis, the replacement cost will be estimated in a similar manner as for the LCC analysis. For the scenario-case analysis, it is assumed that a specific extreme wind speed occurs at a specific year that is determined based on the return period of the extreme wind speed (Vickery et al. 2009). Therefore, the replacement cost must be determined before the hazard occurs, and this follows the procedure outlined for the LCC analysis. However, the year the extreme wind event is assumed to occur, the replacement cost is for that year is determined by estimating the ages of the distribution poles within the inventory at that year. The updated annual $\mathrm{p}_{\mathrm{f}}$ for each age is then determined based on extreme hurricane winds (not an annualized value as for the LCC analysis) to determine 
the number of distribution poles that fail due to the extreme wind event. The total cost is then estimated by summing the cost of distribution pole replacement before the event and as a result of the extreme wind event. The replacement cost is estimated without mitigation (i.e. "do nothing") and considering various mitigation measures. The difference between these estimates is the net benefit, and will be utilized in the assessment of the cost-effectiveness of the strategies considering extreme events.

\section{All.2 Results}

For the scenario-based analysis, the cost effectiveness of the mitigation strategies is assessed considering extreme wind speeds. First, the fragility curves of the distribution poles are established to estimate the conditional probability considering a specific wind speed. Figure AII.1 shows a fragility curve for Class 5 distribution poles considering no deterioration (i.e. new distribution poles). For this example, two wind speeds were examined $36 \mathrm{~m} / \mathrm{s}$ and $56 \mathrm{~m} / \mathrm{s}$, and their return periods were determined to be 5 years and 35 years, respectively, for Miami-Dade County. The wind speeds and the corresponding $\mathrm{P}_{\mathrm{f}}$ are indicated on Figure AII.1. Fragility curves such as this can be developed for all ages of poles and for the stronger pole class (i.e. Class 4). 


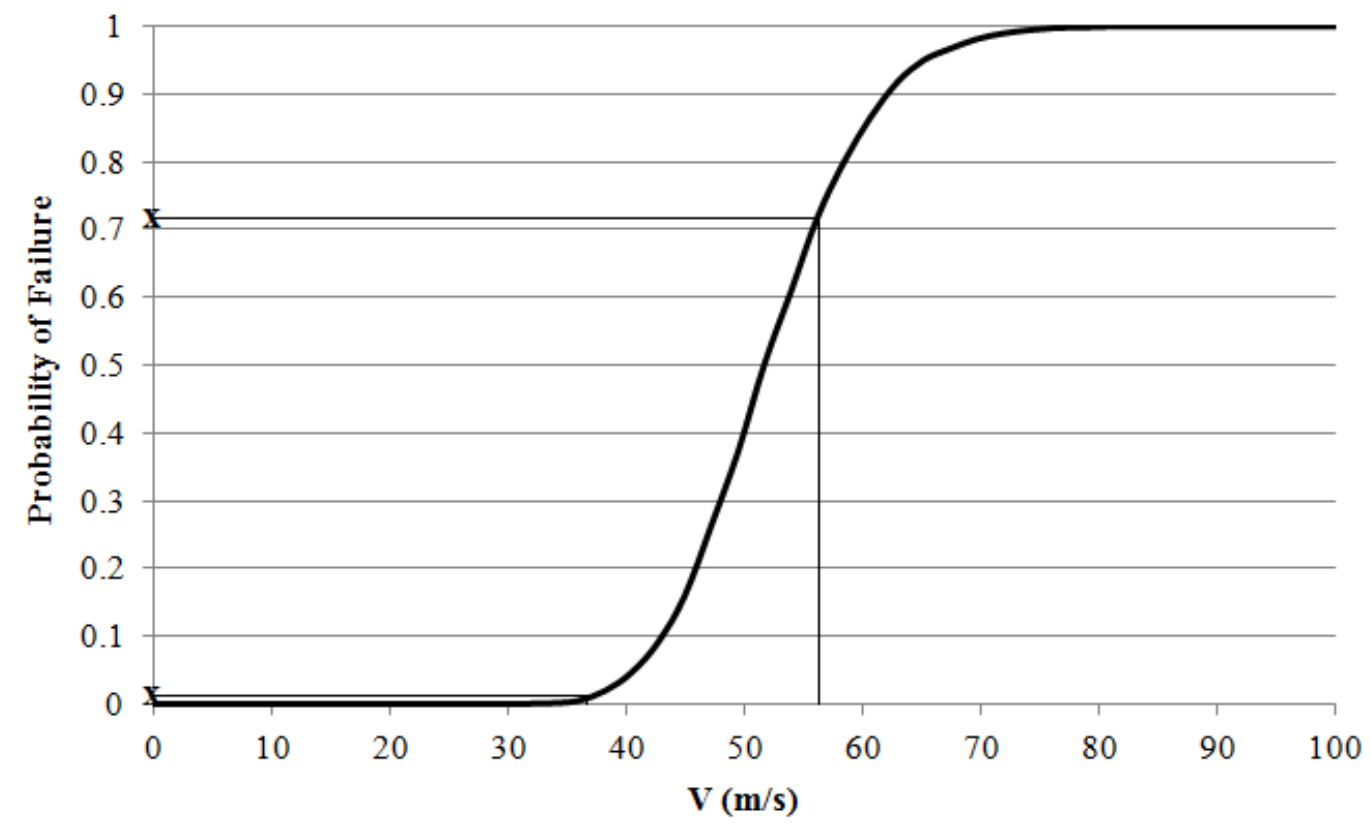

Figure AII.1: Fragility Curve for Class 5 Distribution Poles, no deterioration

The $36 \mathrm{~m} / \mathrm{s}$ wind speed was determined to have a return period of 5 years and, the $56 \mathrm{~m} / \mathrm{s}$ wind speed was found to have a return period of 35 years. In order to conduct the scenario-based analysis, a snapshot of the pole inventory is taken at the year in which a specific wind speed is assumed to occur, i.e. the $36 \mathrm{~m} / \mathrm{s}$ may occur in year 5 and the 56 $\mathrm{m} / \mathrm{s}$ may occur in year 35 . Using the inventory and the cost of replacement modified with a discount rate of $3 \%$, the replacement cost due to an extreme wind speed can be determined.

Figure AII.2 presents the net benefit of these mitigation strategies considering both an extreme wind speed of $36 \mathrm{~m} / \mathrm{s}$ and $56 \mathrm{~m} / \mathrm{s}$. From Figure AII.2a it can be seen that no mitigation strategy is cost effective for the $36 \mathrm{~m} / \mathrm{s}$ wind. However, Figure AII.2b indicates that Mitigation Strategies 2, 3, and 4 could be cost effective if a $56 \mathrm{~m} / \mathrm{s}$ wind event is assumed to occur in year 35 year. Mitigation Strategy 2 could result in net benefits of up to $\$ 20$ million if a $56 \mathrm{~m} / \mathrm{s}$ wind event occurs in 35 years. This is a significant decrease in damage costs, which indicates that mitigation could have a considerable impact on the reduction of the vulnerability of poles to an extreme wind event. Furthermore, from this example, the mitigation measures result in higher net 
benefits for the $56 \mathrm{~m} / \mathrm{s}$ which is assumed to occur after a longer time period, and this is indicates that the mitigation strategies result to a higher reduction in vulnerability after longer time frames. These figures also confirm previous results that found that Mitigation Strategies 2 and 3 are the most cost effective in reducing the vulnerability of distribution poles.

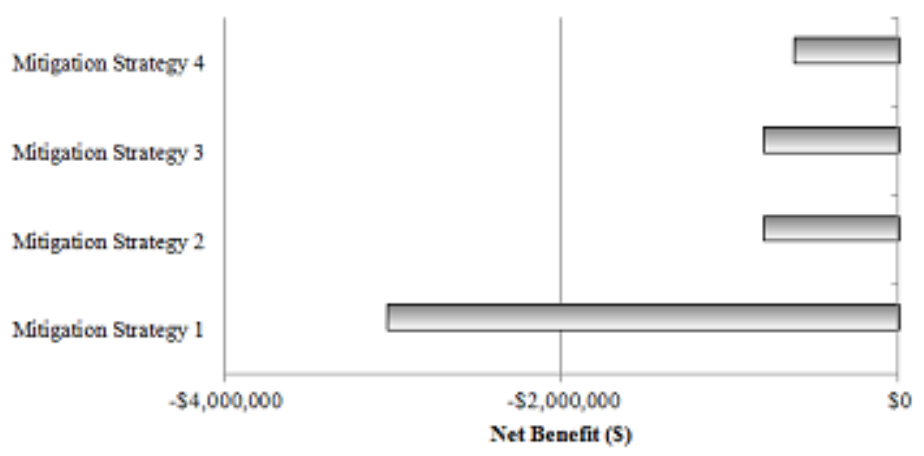

(a) $36 \mathrm{~m} / \mathrm{s}$

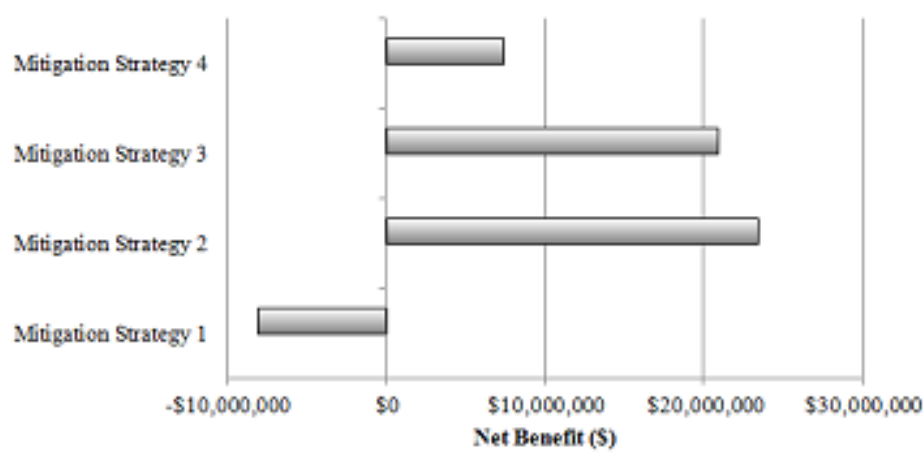

(b) $56 \mathrm{~m} / \mathrm{s}$

Figure AII.2: Net Benefit for the Mitigation Strategies Extreme Wind Speeds of 36 $\mathrm{m} / \mathrm{s}$ and $56 \mathrm{~m} / \mathrm{s}$

\section{All.3 References}

Vickery, P.J., Wadhera, D., Twisdale, L.A.Jr., and Lavelle, F.M. (2009) U.S. Hurricane Wind Speed Risk and Uncertainty. Journal of Structural Engineering, 135, 301-320. 


\section{Appendix III}

\section{Supplement To 'Social Vulnerability Index for Coastal Communities at risk to Hurricane Hazard and a Changing Climate'}

In addition to the published work 'Social Vulnerability Index for Coastal Communities at risk to Hurricane Hazard and a Changing Climate' (Chapter 6) presented, a preliminary study was conducted in attempt to verify whether or not social dynamics have an impact on hurricane damage costs within a region. In the following a brief background, overview, and results of the preliminary study are presented. Not all the details associated with the principal components analysis (PCA) is included in the following, because the information is located in detail in Chapter 6.

\section{All.1 The Impacts of Social Dynamics in Hurricane Damage Costs}

There are numerous societal factors that contribute to the hurricane vulnerability of a region. These social aspects are difficult to quantify, but there is some consensus on which factors have the greatest influence (Cutter et al. 2003).

Burton (2010) proposed a methodology to assess the impacts various social factors had on the damage caused by Hurricane Katrina in three counties in Mississippi, by using the SoVI (an index of Social Vulnerability developed based on demographic and socioeconomic data available) (Cutter et al. 2003). The evaluation was conducted by identifying the most dominant social factors of the counties, through a principal components analysis (PCA). The PCA, in this case, involves using the Kaiser Criterion and a Varimax rotation to find the loadings of the original factors within the dominant factors. Once the dominant factors and the loadings of their respective sub-factors have 
been identified, a multivariate regression model is used to evaluate the relationship between the factors and the hurricane damage. A multivariate regression model to evaluate the connection between the 8 dominant social factors of three counties in Mississippi and the damage Hurricane Katrina caused.

To investigate the impacts of social dynamics on hurricane damage under scenarios of climate change, a similar procedure will be utilized. The dominant factors will be found using a PCA. Then the regression model will be used to establish the relationship between these dominant, composite social factors and the potential damage costs that could be expected as a result of climate change made previously within this study.

The maximum annual wind speed is found with the Weibull distribution and wind contour maps (Vickery et al. 2000), and the expected cumulative damage costs are found by convolving the hurricane wind model and the hurricane vulnerability model using the maximum annual wind speed. Therefore, these factors will be used within the regression model along with the dominant social factors found with the PCA. The regression model will be used to find the relationship between these factors and the expected cumulative damage costs, under various scenarios of climate change. The affects of climate change will be modeled by changing the maximum annual wind speed $(-5 \%$ to $10 \%)$ and as the expected cumulative damage cost is directly related, it will change accordingly.

The regression model is used to solve for $\mathrm{x}_{0}-\mathrm{x}_{\mathrm{n}}$, regression factors, as these variables indicate the relationship between their respective factor and the expected cumulative damage costs $\mathrm{L}_{\mathrm{c}}(1, \mathrm{~T})$.

$y_{i}=x_{0}+x_{1}$ WINDSP $+x_{2} F a c(1)+x_{3} F a c(2)+x_{4} F a c(3)+\cdots x_{w} F a c(k)+e_{i}$

(AIII.1)

where y refers to the cumulative damage costs, $\mathrm{L}_{\mathrm{c}}(1, \mathrm{~T})$, in region $\mathrm{i}$ after a scenario of climate change, after 50 years, WINSP refers to the annual maximum wind speed for region $i$ at year $50, \operatorname{Fac}(1)-\operatorname{Fac}(\mathrm{k})$ refer to the dominant social factors, $\mathrm{x}_{0}-\mathrm{x}_{\mathrm{w}}$ are the variables being solved for (regression factors), and e is the error term. 


\section{All.2 Results}

A principal components analysis (PCA) was conducted by using U.S. Census data for the 35 municipalities of Miami-Dade County. Sixteen social factors were identified in accordance with Cutter et al. (2003). Through the PCA, these 16 factors were reduced to 5 dominant social factors: Race (African American) and Poverty, Age and Gender, Socioeconomic Status, Race (Native American and Asian) and Unemployment, Hispanic.

Once the dominant social factors and the loadings have been identified for Miami-Dade County, a multivariate regression model is used to evaluate the impacts the social factors have on the potential hurricane damage costs considering various scenarios of climate change. Since the 35 municipalities of Miami-Dade County were used in the PCA, they will be used for the multivariate regression analysis. Therefore, it was necessary to identify the maximum annual wind speed of each municipality and the expected cumulative damage costs associated with the maximum annual wind speed. The maximum annual wind speed was found by applying the gradient-to-surface factor, according to the exposure category of the municipality, to the maximum annual wind speed found for Miami-Dade County. Then, the cumulative damage costs after 50 years were calculated for that municipality based on the wind speed found. Because each municipality has a specific social make-up, the expected cumulative damage costs were calculated for each municipality separately, taking into account the number of singlefamily housing units present and the median insured house value, for each individual municipality. Hence, relating the damage cost to the social dynamics of each respective municipality.

Eq. (AIII.1) was used to find the relationship between the annual loss (y), the maximum annual wind speed (WINDSP) and the 5 dominant social factors (Fac1-Fac5). The regression model was then run assuming various scenarios of climate change, in which both the maximum annual wind speed and the expected cumulative damage costs change accordingly, and the changes in the $\mathrm{x}$ factors was assessed. The $\mathrm{x}$ factors (regression factors) in Eq. (AIII.1) indicate how much their respective factors influence the output, or the expected damage cost, $y$. 
Table AIII.1 shows the results of the regression analysis for various scenarios of climate change. From these results we are able see the effects certain social characteristics have on the potential hurricane damage of a region under climate change. The values of the regression factors indicate if and how strongly the social factors contribute to hurricane damage under a specific scenario of climate change. Social Factor 2 (i.e. Age and Gender) has the greatest impact on the potential hurricane damage, and Social Factors 1(i.e. Race and Poverty) and 3 (i.e. Socioeconomic Status) also a have a noticeable impact on the potential damage costs. The table shows the impacts of social dynamics on potential hurricane damage costs increase as wind speeds are assumed to increase.

Table AIII.1: Results from regression analysis under various scenarios of climate change (-5\%-10\%) for Miami-Dade County after 50 years

\begin{tabular}{|c|c|c|cccc|}
\hline \multirow{2}{*}{ Social Factor } & \multirow{2}{*}{ Description } & \multirow{2}{*}{$\begin{array}{c}\text { Regression } \\
\end{array}$} & Factors & \multicolumn{4}{|c|}{ Increase in Wind Speed } \\
\cline { 5 - 7 } & & $\mathbf{- 5 \%}$ & $\mathbf{0 \%}$ & $\mathbf{5 \%}$ & $\mathbf{1 0 \%}$ \\
\hline Factor 1 & Race and Poverty & $\mathrm{x}_{2}$ & 0.89 & 1.02 & 1.17 & 1.34 \\
Factor 2 & Age and Gender & $\mathrm{x}_{3}$ & 1.54 & 1.77 & 2.03 & 2.32 \\
Factor 3 & Socioeconomic Status & $\mathrm{x}_{4}$ & 0.69 & 0.79 & 0.91 & 1.03 \\
Factor 4 & Race and Unemployment & $\mathrm{x}_{5}$ & 0.33 & 0.38 & 0.43 & 0.49 \\
Factor 5 & Hispanics & $\mathrm{x}_{6}$ & 0.04 & 0.04 & 0.05 & 0.06 \\
\hline
\end{tabular}

\section{Alll.3 References}

Burton, C.G. (2010) Social Vulnerability and Hurricane Impact Modeling. Natural Hazards Review, 11, 58-68.

Cutter, S.L., Bornuff, B.J., and Shirley, W.L. (2003) Social Vulnerability to Environmental Hazards. Social Science Quarterly, 84, 242-261.

Vickery, P.J., Wadhera, D., Twisdale, L.A.Jr., and Lavelle, F.M. (2009) U.S. Hurricane Wind Speed Risk and Uncertainty. Journal of Structural Engineering, 135, 301-320. 


\section{Appendix IV}

\section{Permission to Republish}

This appendix includes electronic permissions obtained by the author to republish previously published material. 


\section{This is documentation for Chapter 2:}

8/22/12 Rights link: Printable License

\section{ELSEVIER LICENSE TERMS AND CONDIDITIONS}

Aug 22, 2012

This is a License Agreetrent between Sigridur 0 Bjarnadottir ("You") and Elsevier ("Elsevier") provided by Copyright Clearance Center ("CCC'). The license consists of your order details, the terms and conditions provided by Elsevier, and the payment terms and conditions.

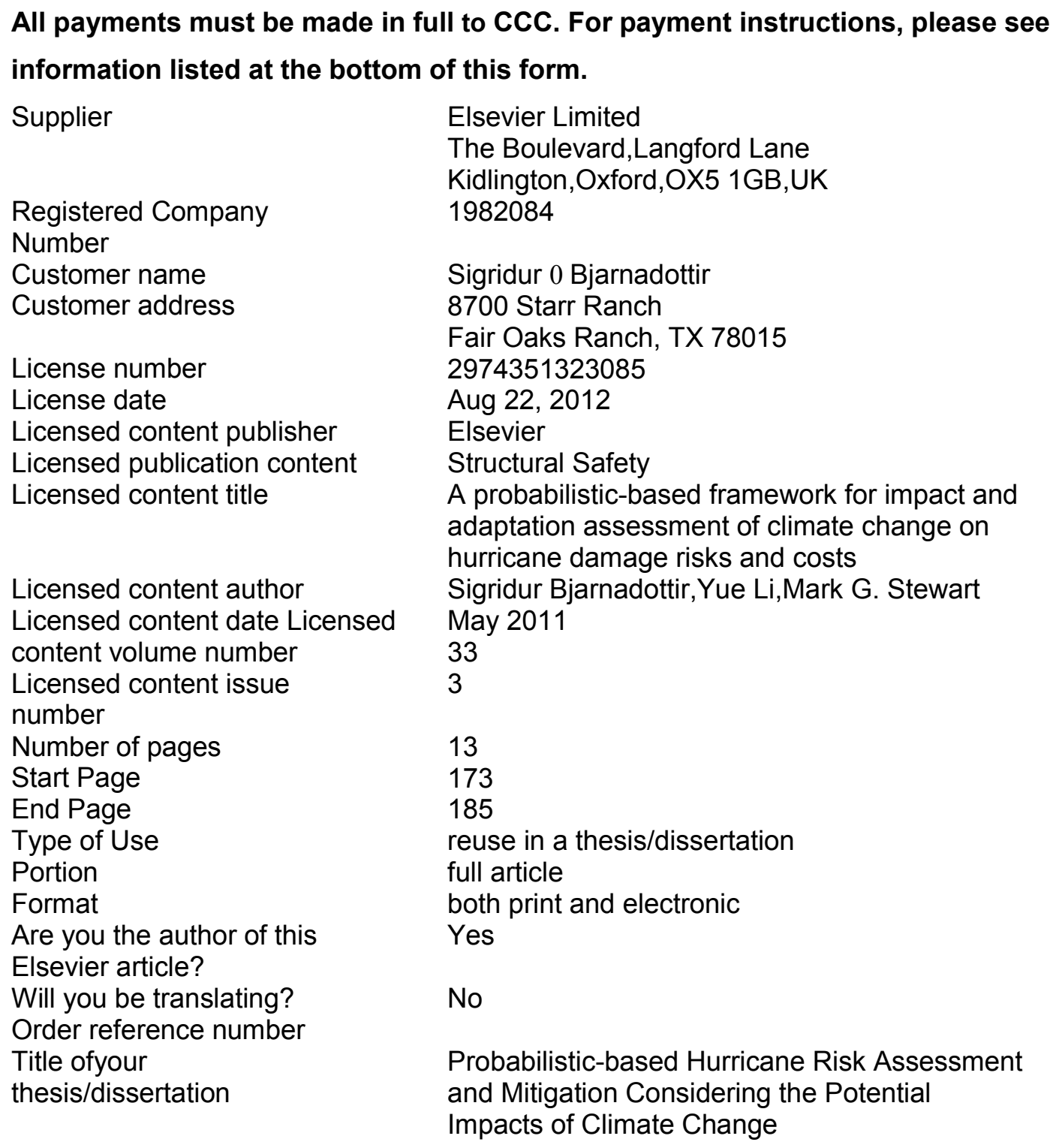


Expected completion date

Estimated size (number of

pages)

Elsevier VAT number

Permissions price

VAT/Local Sales Tax

Total

Terms and Conditions
Sep 2012

250

GB 494627212

0.00 USD

0.0 USD / 0.0 GBP

0.00 USD 
This is documentation for Chapter 4:

Copyright Clearance Center

\section{RightsLink ${ }^{2}$}

ASCE

AMERICAN SOCIETY OF CIVIL ENGINEERS

TITLE: HURRICANE RISK ASSESSMENT OF POWER DISTTRIBUTION POLES

CONSIDERING IMPACTS OF A CHANGING CLIMATE

\section{PERMISSION REQUEST}

PUBLICATION: JOURNAL OF INFRASTRUCTURRE SYSTEMS

PUBLISHER: AMERICAN SOCIETY OF CIVIL ENGINEERS

DATE: pap-00

Copyright $@ 1969$, ASCE, All rights reserved

As an ASCE author, you are permitted to reuse your own content for another ASCE or non-ASCE publication.

Please add the full credit line "With permission from ASCE" to your source citation, Please pring this page for your records.

Type of use: Dissertation/Thesis

Portion: full article

Format: print and electronic

Use of this content will make up more than $25 \%$ of the new work: no

Author of this ASCE work or ASCE will publish the new work: yes 


\section{This is documentation for Chapters 3 and 5:}

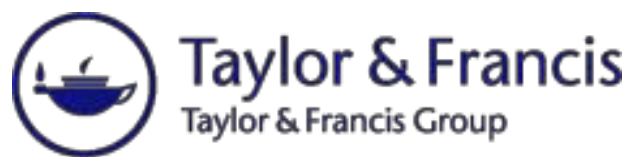

\section{SCEDULE OF AUTHOR RIGHTS}

\section{The rights that you personally retain as Author}

1. the right to be identified as the Author of an article whenever and wherever the Article is published;

2. patent rights, trademark rights, or rights to any process, product or procedure described in an article;

3. the right to share (but not on a commercial or systematic basis) with colleagues print or electronic 'preprints' (i.e., versions of the article created prior to peer review) of an unpublished Article, perhaps in the form and content as submitted for publication;

4. always providing that the editorial policy of the journal concerned allows this within its policies on prior publication, the right to post such a 'preprint' on your own website, or on your institution's intranet, but only with the following acknowledgement or such other acknowledgement as we or Taylor \& Francis may notify to you:

This is a preprint of an article submitted for consideration in the [JOURNAL TITLE] [year of publication] [copyright Taylor \& Francis]; [JOURNAL TITLE] is available online at: http://www.informaworld.com/smpp/ with the open URL of your article;

5. the right to retain a preprint version of the Article as specified above following publication in a Taylor \& Francis journal, on the following condition, and with the following acknowledgement or such other acknowledgement as Taylor \& Francis may notify to you:

This is a preprint of an article whose final and definitive form has been published in the [JOURNAL TITLE] [year of publication] [copyright Taylor \& Francis]; [JOURNAL TITLE] is available online at: http://www.informaworld.com/smpp/ with the open URL of your article; 
6. the right to post your revised text version of the 'postprint' of the Article (i.e., the Article in the form accepted for publication in a Taylor \& Francis journal following the process of peer review), as an electronic file on your own website for personal or professional use, or on your institution's network or intranet or website, but not for commercial sale or for any systematic external distribution by a third party (for example a listserv or database connected to a public access server) provided that you do not use the PDF version of the Article prepared by us and you include any amendments or deletions or warnings relating to the Article issued or published by us or Taylor \& Francis and only with the following acknowledgement or such other acknowledgement as Taylor \& Francis may notify to you:

'This is an electronic version of an article published in [include the complete citation information for the final version of the article as published in the print edition of the journal]. [JOURNAL TITLE] is available online at: http://www.informaworld.com/smpp/ with the open URL of your article.

The right in this paragraph 6 is subject always to an embargo of 12 months after first Publication (be it online or in print) in STM (science,technology and medicine) subjects and the behavioural sciences and of 18 months after first publication for SSH (social science, arts and humanities) journals. You must not post manuscripts directly to PubMed Central (PMC) or other third party sites for any systematic external distribution by a thirdparty (for example to a listserv or database connected to a public access server). Individual modifications to this general policy may apply to some Taylor \& Francis, Routledge and Psychology Press journals and society publishing partners;

7. the right to share with colleagues (but not on a commercial or systematic basis) copies of an article in its published form as supplied by Taylor \& Francis as an electronic or printed offprint or reprint;

8. the right to make printed copies of all or part of an article for use by you for lecture or classroom purposes provided that such copies are not offered for sale or distributed in any systematic way, and provided that acknowledgement to prior publication in the relevant Taylor \& Francis journal is made explicit. For the avoidance of doubt, authors 
may use the publisher-supplied PDF version in teaching and for coursepacks, within their own institution, so long as they are distributed free of charge and not sold to students, in which case we would require permission to be sought. In addition, authors may also use the publisher-supplied PDF for posting in e-reserves, so long as it is also only within the author's institution. We allow this on the basis of the AAP/Cornell agreement:

http://www.pressoffice.cornell.edu/releases/release.cfm?r=15899\&y=2006\&m=9

9. the right to facilitate the distribution of the Article if the Article has been produced within the scope of an Author's employment, so that the Author's employer may use all or part of the Article internally within the institution or company provided that acknowledgement to prior publication in the relevant Taylor \& Francis journal is made explicit;

10. the right to include an article in a thesis or dissertation that is not to be published commercially, provided that acknowledgement to prior publication in the relevant Taylor $\&$ Francis journal is made explicit;

11. the right to present an article at a meeting or conference and to distribute printed copies of the Article to the delegates attending the meeting provided that this is not for commercial purposes and provided that acknowledgement to prior publication in the relevant Taylor \& Francis journal is made explicit;

12. the right to use the Article in its published form in whole or in part without revision or modification in personal compilations [in print or electronic form] or other publications of an Author's own articles, provided that acknowledgement to prior publication in the relevant Taylor \& Francis journal is made explicit;

13. the right to expand an article into book-length form for publication, provided that acknowledgement to prior publication in the relevant Taylor \& Francis journal is made explicit.

14. As part of our author services program, Taylor \& Francis will deposit to PubMed Central (PMC) author manuscripts on behalf of Taylor \& Francis, Routledge and 
Psychology Press authors reporting NIH funded research. This service is offered as part of Taylor \& Francis'

2008 deposit agreement with the NIH. This service will help authors to comply with the National Institutes of Health (NIH) revised 'Public Access Policy', which came into force on April 7, 2008. The NIH's revised policy mandates NIH-funded authors to submit to PubMed Central (PMC), or have submitted on their behalf, at the point of acceptance, their peer- reviewed author manuscripts, to appear on PMC no later than 12 months after final publication. Taylor \& Francis will deliver to PMC the final peer-reviewed manuscript, which was accepted for publication and that reflects any author-agreed changes made in response to the peer review. Taylor \& Francis will also authorize the author manuscript's public access posting 12 months after final publication in print or electronic form (whichever is the sooner). Following the deposit by Taylor \& Francis, authors will receive further communications from the NIH with respect to the submission. 


\section{This is documentation for Chapter 6:}

\section{8/22/12 RightsLink: Printable License}

\section{SPRINGER LICENSE TERMS AND CONDITIONS}

Aug 22, 2012

This is a License Agreement between Sigridur O Bjarnadottir ("You") and Springer ("Springer") provided by Copyright Clearance Center (CCR). The license consists of your order details, the terms and conditions provided by Springer, and the payment terms and conditions.

\begin{tabular}{|c|c|}
\hline License Number & 2963390567310 \\
\hline License date & Aug 06,2012 \\
\hline Licensed content publisher & Springer \\
\hline Licensed content publication & Natural Hazards \\
\hline Licensed content title & $\begin{array}{l}\text { Social wlnerabilityindexfor coastal communities } \\
\text { at risk to hurricane hazard and a } \\
\text { changing climate }\end{array}$ \\
\hline Licensed content author & Sigridur Bjamadottir \\
\hline Licensed content date & Jan 1, 2011 \\
\hline Volume number & 59 \\
\hline Issue number & 2 \\
\hline Type of Use & Thesis/Dissertation \\
\hline Portion & Full text \\
\hline Number of copies & 1 \\
\hline Author of this Springer article & Yes and you are the sole author of the new work \\
\hline Order reference number & None \\
\hline Title of your thesis/dissertation & $\begin{array}{l}\text { Probabilistic-based Hurricane Risk Assessment } \\
\text { and Mitigation Considering the Potential } \\
\text { Impacts of Climate Change }\end{array}$ \\
\hline Expected completion date & Sep 2012 \\
\hline Estimated size(pages) & 250 \\
\hline Total & 0.00 USD \\
\hline
\end{tabular}




\section{This is documentation for Figure 3.1:}

From the FAQ section on the National Atlas of the United States (http://www.nationalatlas.gov/help/faq.html\#tweleve):

Nearly all information collected by the Federal Government is in the public domain and use of National Atlas Data produced under this project is not restricted in any way. Both "National Atlas of the United States ${ }^{\circledR}$ " and "The National Atlas of the United States of America ${ }^{\circledR} "$ are registered trademarks of the United States Department of the Interior. The USGS has been publishing National Atlas products since 1970 and has simply taken action to trademark this term to incorporate all new graphic and electronic products of The National Atlas of the United States of America ${ }^{\circledR}$.

Although the content of most National Atlas Web pages is in the public domain, some pages may contain material that is copyrighted by others and used by the National Atlas with permission. You may need to obtain permission from the copyright owner for other uses. Furthermore, some non-National Atlas data, products, and information linked, or referred to, from this site may be protected under U.S. and foreign copyright laws. You may need to obtain permission from the copyright owner to acquire, use, reproduce, or distribute these materials. 